\title{
THE LOG IN MY EYE: AWARENESS, ACCEPTANCE, AND CORRECTION OF PARTISAN POLITICAL BIAS
}

A Dissertation
presented to
the Faculty of the Graduate School
at the University of Missouri-Columbia
In Partial Fulfillment
of the Requirements for the Degree
Doctor of Philosophy
By
S. GLENN BAKER
Dr. Laura Scherer, Dissertation Supervisor
JULY 2019


The undersigned, appointed by the dean of the Graduate School, have examined the dissertation entitled

THE LOG IN MY EYE: AWARENESS, ACCEPTANCE, AND CORRECTION OF

\section{PARTISAN POLITICAL BIAS}

presented by S. Glenn Baker, a candidate for the degree of doctor of philosophy, and hereby certify that, in their opinion, is worthy of acceptance.

Professor Laura D. Scherer

Professor Laura King

Professor Jamie Arndt

Professor Victoria Shaffer

Professor Laron K. Williams 


\section{ACKNOWLEDGMENTS}

Special thanks to Zeke F. Elkins and Niraj B. Patel for figure consultation, as well as Dr. Sarah Ward for comments on early drafts. Thank you to Dr. Laura D. Scherer and Dr. Laura King for feedback and help developing this dissertation. 


\section{TABLE OF CONTENTS}

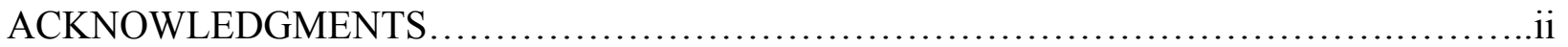

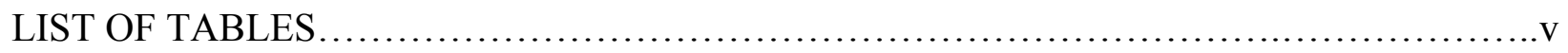

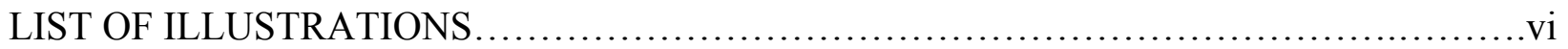

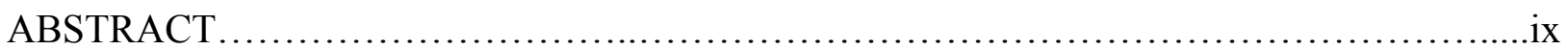

\section{CHAPTERS}

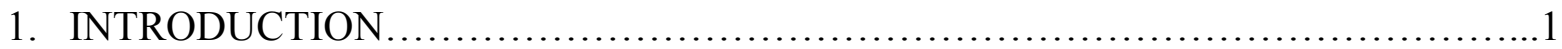

How Political Judgments Are Influenced.................................................................6

The Judgment Correction Process ..................................................................

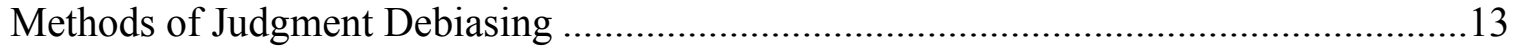

Models of Judgment Correction...................................................................... 14

Judgment Correction: Remaining Questions ......................................................18

2. PRESENT RESEARCH...................................................... 22

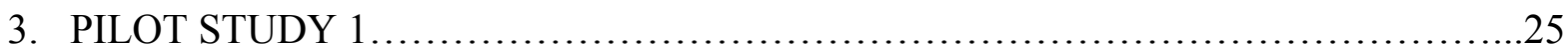

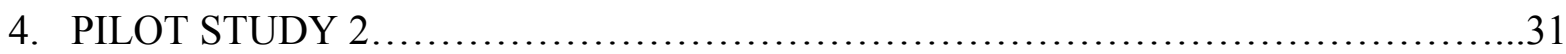

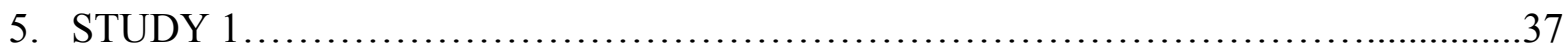

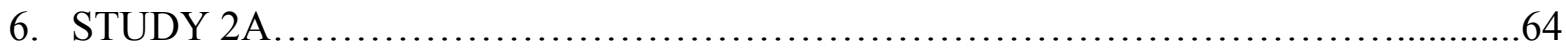

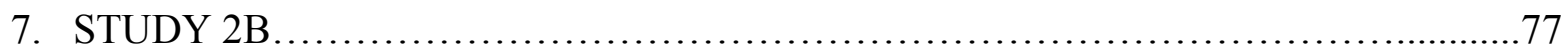

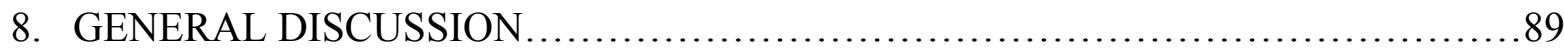


Judgment Correction: An Updated View

Correction Instructions Do Not Influence Information Seeking ………...........................98

Updating Models of Judgment Correction ......................................................................99

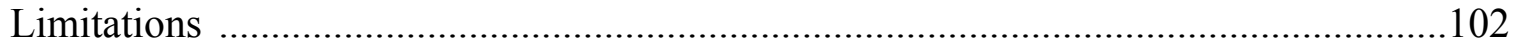

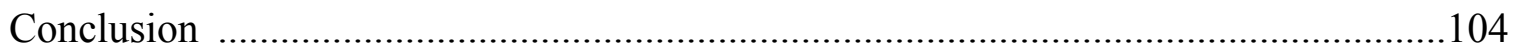

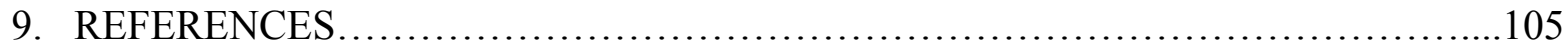

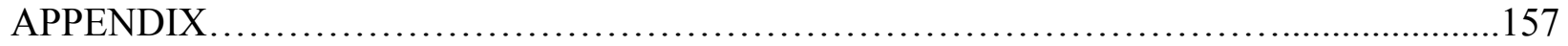

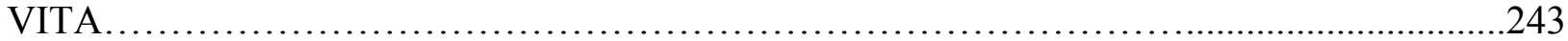




\section{LIST OF TABLES}

Tables

Page

Table 1: Means (SDs) of narrative ratings in Study 1 (Pilot) 116

Table 2: Means (SDs) of flu belief and attitude outcomes at each time point in Study 1 (Pilot) 117

Table 3: Study 2 demographic characteristics for each sample and tests of differences among the samples 118 


\section{LIST OF ILLUSTRATIONS}

$\begin{array}{lll}\text { Figures } & \text { Page }\end{array}$

Figure 1: Lay theories (absolute value measure) by political affiliation.

Figure 2: Lay theories (absolute value measure) of quotes between in-group and out-group president, and presentation order. 120

Figure 3: Lay theories of guilt judgments between in-group and out-group defendant, and presentation order 121

Figure 4: Acceptability (quotes) between in-group and out-group president, and presentation order.

Figure 5: Acceptability (guilt) between in-group and out-group defendant, and presentation order. .123

Figure 6a: Study 1: Lay theories (absolute value measure) by partisanship strength

Figure 6b: Study 1: Lay theories (absolute value measure) by political affiliation .125

Figure 7: Study 1: Judgments of acceptability between conditions, partisanship strength, and judgment type 126

Figure 8a: Study 1: Evaluation of quotes between conditions. X-axis: Lay theories (absolute value measure). 127

Figure 8b: Study 1: Evaluating of quote evaluations between conditions. X-axis: Judgments of acceptability. 128

Figure 9: Study 1: Evaluation of quote evaluations across lay theories, between partisanship strength and condition. X-axis: Lay theories (absolute value measure).

Figure 10: Study 1: Quote ratings across motivation, between condition and categorized level of lay theories. Lay theories "no influence": Lowest quartile of lay theories. "Strong influence": Highest quartile of lay theories. 130

Figure 11: Study 1: Judgments of assault by condition and partisanship strength...131

Figure 12: Study 1: Perceived guilt: Assault across views of acceptability and between conditions 132 
Figure 13: Study 1: Judgments of assault across motivation, between condition and grouped lay theories 133

Figure 14: Study 1: Perceived guilt of attempted murder across views of acceptability and between conditions. .134

Figure 15: Study 1: Judgments of attempted murder across motivation, between conditions and grouped lay theories 135

Figure 16: Study 1: Bias perception on quote judgments, between condition and partisanship strength 136

Figure 17: Study 1: Percentage of participants electing to view irrelevant political information about defendant between conditions .137

Figure 18: Study 1: Judgments of guilt in second jury scenario, across lay theories and between those who chose to view irrelevant partisan information and those who chose to avoid it 138

Figure 19a: Study 2a: Lay theories between levels of partisanship strength 139

Figure 19b: Study 2a: Lay theories across political affiliation. .140

Figure 20: Study 2a: Acceptability by partisanship strength .141

Figure 21: Study 2a: Bias prevention measures between conditions and political affiliation 142

Figure 22: Study 2a: Quote ratings (In-group vs. Out-group) between condition and political affiliation 143

Figure 23: Study 2a: Quote judgments (difference score) across lay theories and between condition 144

Figure 24: Study 2a: Quote judgments (difference score) across political knowledge, between conditions and grouped lay theories 145

Figure 25: Study 2a: Bias perception (In-group vs. Out-group) between conditions 146

Figure 26: Study 2a: Bias perception (In-group vs. Out-group) between conditions and political affiliation .147

Figure 27a: Study 2b: Lay theories by partisanship strength .148

Figure 27b: Study 2b: Lay theories across political affiliation 149 
Figure 28: Study 2b: Ratings of acceptability between condition and partisanship strength. 150

Figure 29: Study 2b: Judgments of guilt between condition and level of partisanship151

Figure 30: Study 2b: Judgments of guilt across lay theories and between conditions 152

Figure 31: Study 2b: Judgments of guilt across political loyalty and between condition 153

Figure 32. Study 2b: Selection of irrelevant political information between condition. Y-axis represents percentage of sample within each condition 154

Figure 33: Study 2b: Guilt ratings across lay theories and between informational choice 155

Figure 34: Study 2b: Bias perception between condition and level of partisanship strength. 156 


\begin{abstract}
People are often unaware of or under-estimate their own cognitive biases, suggesting that political bias - measured by the influence of irrelevant political information on otherwise non-political judgments - may be difficult to change. However, when it comes to political bias, peoples' expectation of bias (i.e., lay theories), have rarely been directly measured, despite their purported importance for judgment debiasing (Wegener \& Petty, 1995). Furthermore, extant research has never directly asked people how acceptable they believe it is to make a judgment influenced by irrelevant political information. Study 1 asked participants to make a series of judgments, some more subjective (evaluating quotes) and others more objective (assessing guilt of defendant on trial). Some participants were presented with noninfluential irrelevant political information (control), while others were presented with influential irrelevant political information (e.g., Trump or Obama) for the judgments they were making. Some participants who were exposed to influential irrelevant political information were explicitly asked to not allow their judgments to be influenced by the information they were exposed to. As expected by the Flexible Correction Model (FCM), participant's lay theories (but not judgments of acceptability) guided their (mostly) successful attempt to correct for the influence of irrelevant political information, though only when evaluating quotes. When judging the guilt of a defendant on trial, participants asked to correct their judgments did so, with only an indirect influence from lay theories and judgments of acceptability. Secondary measures indicated correction instructions did not temper the desire to seek out irrelevant political information on subsequent judgments. People possess self-awareness into their own capacity to make biased judgments and often choose not to correct their judgments, despite having the ability to do so. Studies $2 \mathrm{a}$ and $2 \mathrm{~b}$ replicated primary findings using online samples.
\end{abstract}

Keywords: Lay Theories, Bias, Politics, Bias Perception, Judgments, Jury Verdicts 
Beware of my partisanship, my mistakes of fact and the distortion inevitably caused by

my having seen only one corner of events.

\section{— George Orwell, Homage to Catalonia}

\section{Introduction}

In the modern world of heated political rhetoric, partisan polarization, and overt misinformation campaigns (Doherty, Kiley, \& Johnson, 2017), the United States is in the midst of strong political convulsions. Domestically, the political stakes and potential for widespread politically-motivated violence have not been this high since at least the late 1960's (Doherty, Kiley, \& Johnson, 2017), largely driven by an increasingly politically-tribal populace frustrated by partisan gridlock. For many, supporting either the Democratic or the Republican political party has become an integral part of American identity. Republicans and Democrats alike have undergone both social-based sorting and issue-based sorting, such that partisan lines have shifted to more closely reflect racial and religious lines (Mason, 2018). This shift has resulted in increased favoritism towards political in-groups and intense distain for political out-group members, so much so that people often view out-group political actors as failed moral agents (Bruchman, Koopman-Holm, \& Scherer, 2018), rendering the political arena both socially toxic and inhibitive towards normative governance. Regrettably, such partisan divides are arguably predictable, given classic research on group identity and in-group favoritism (Brewer, 1999; Crocker \& Schwartz, 1985; Mason, 2018; Sherif, Harvey, White, Hood, \& Sherif, 1988).

Given the realities of political polarization, the need for people to make informed political judgments and update their political views based on facts and well-reasoned argumentation is more imperative than ever. For many, this is easier said than done. Judgment 
and decision making research over the past four decades has revealed a host of insights into how political judgments are unduly influenced by irrelevant or misleading information (Entman, 2007; Iyengar, 1990; Redlawsk, 2002; Lord, Ross, \& Lepper, 1979; Sears, 1994), as well as the stumbling blocks that exist towards updating and changing these attitudes (Nam, Jost, \& Van Bavel, 2013; Wegener \& Petty, 1995; Wilson \& Brekke, 1994) in light of new information. Furthermore, many of the heuristics and biases that inevitably play a role in political judgments and decision making are not attenuated by expertise or cognitive ability (Stanovich \& West, 2008; West, Meserve, \& Stanovich, 2012), suggesting that the biased reasoning emerging from political partisanship is not reserved for the politically uninformed or the cognitively disadvantaged. If anything, recent evidence has suggested that individuals with strong cognitive abilities may display more motivated reasoning than their less astute peers (Kahan, Peters, Dawson, \& Slovic, 2017), though research extending this noteworthy study have suggested that people display political bias regardless of their numerical ability (Baker, Patel, \& Scherer, under revision). The tendency (or, arguably, temptation) to interpret politically relevant information in a worldview-confirming fashion is so strong, it has been suggested that people should be viewed not as intuitive psychologists or self-interested economists, but as intuitive politicians (Tetlock, 1991; Tetlock, 2002).

Because there may be serious consequences for unduly biased political judgments and decisions, such as biased jury deliberations, voting behavior (e.g., voting against one's own interests), and social consequences (e.g., alienation, exclusion, or hostile work environments due to one's political values), it is crucial to understand not only when and how people make biased political judgments and decisions, but also when and why a person might view their own 
judgments (e.g., jury deliberations) as susceptible to being unduly influenced by politicallycharged information (e.g., a defendant with disagreeable political views). This anticipation of influence — or lay theory— is vital to understand as it informs people how they should adjust their judgments for a given, unwanted influence (Wegener \& Petty, 1995; Wegener \& Petty, 1997).

However, research has yet to explore in detail precisely how people do (or do not) anticipate making biased political judgments and decisions. Understanding whether lay theories guide people's efforts to make unbiased (or less biased) judgments requires attention to how people view the biasing (or potentially biasing) information. First, it is vital to understand whether people anticipate that political information might influence their judgments/decisions even when this information is technically irrelevant to the judgment at hand (e.g., judging a work of art by an artist known to be a staunch Republican or Democrat). Second, if people believe it is acceptable (or unacceptable) to incorporate irrelevant political information into judgments and decisions, they are not likely to try and make an unbiased judgment, precisely because they do not view incorporating that information as bias. Although researchers have, to some extent, examined how people anticipate their political judgments being influenced (Isbell \& Wyer, 1999; Isbell, Ottari, \& Burns, 2006; Petty, Brinol, Tormala, \& Wegener, 2007), to date no research has examined the perceived acceptability of incorporating irrelevant information into judgments in conjunction with lay theories.

Notably, how acceptable someone finds incorporating an objectively irrelevant source of influence on their judgments and decisions is not identical with their internal motivation to correct their judgments. It is possible for a person to find incorporating a source of political 
information (e.g., the political affiliation of the speaker) into a judgment as unacceptable but unmotivated to adjust for it. Similarly, an individual might view incorporating political information into a judgment (e.g., art evaluation) as acceptable but be motivated to adjust their judgments for the influence anyway. Bias acceptability can (and should) be viewed as a separate construct that can influence the process of judgment correction alongside lay theories, bias perception, motivation to correct, and effort for judgment correction. Each of these factors has been identified as necessary for judgment correction to occur (Wegener \& Petty, 1995; Wilson \& Brekke, 1994).

When it comes to bias perception, a significant amount of research has chronicled the extent to which people are often unaware of their biases (Amodio \& Mendoza, 2010; Dovidio \& Gaertner, 2000; Holroyd, 2015; Larrick, 2004), severely underestimate their biases (Larrick, Morgan, \& Nisbett, 1990; Pronin, 2007; Wilson \& Brekke, 1994), or assume that their judgments and decisions are comparatively less biased than most others (Pronin, Lin, \& Ross, 2002; Pronin, Gilovich, \& Ross, 2004). Put simply, people often view their own judgments and decisions as minimally biased, and certainly less bias than most others. As a result, people may view their political attitudes and beliefs as pertinent, non-biasing, and diagnostic sources of information that should be considered in their evaluations, even if they don't necessarily extend that consideration to others (Pronin \& Kugler, 2007; Pronin, 2009). People may also be overconfident in their ability to prevent or control bias (Hansen et al., 2014), leading them to conclude that their judgments are reasonable, fair, and worthy of respectful consideration. If people believe that their judgments and decisions not being influenced by a given source of irrelevant information, then they are unlikely to engage in the mental effort necessary to try to prevent an unwanted 
influence on their judgments (Wegener \& Petty, 1995).

On the other hand, the ubiquity, transparency, and ferocity of bias in the modern political arena might prove too obvious for anyone to effectively engage in the self-deception necessary to think that one's political perspective is free from bias. As a result, counter to some of the literature on heuristics, biases, and bias awareness (Kahneman \& Tversky, 1974; Pronin et al., 2002; Pronin, 2007; Pronin, Gilovich, \& Ross, 2004), people might view themselves as capable of making biased political judgments and decisions. If this latter perspective is correct, then people may be capable of making, and may even desire to make, unbiased political judgments and decisions in some circumstances.

Because having a well-informed public is vital to the health of a Republic (Kuklinski, Quirk, Jerit, Schwieder, \& Rich, 2000; Lewandowsky et al., 2012), and a component of being well-informed is to have an accurate appraisal of one's own tendency to see the world through rose-tinted glasses, these studies will extend previous work by exploring three things together that have hitherto not been addressed within the same study: (1) how people think about bias in their own judgments (lay theories) (2) how acceptable people believe it is to incorporate objectively irrelevant information into their judgments and decisions and (3) whether participants are aware of how biased their judgments are (or are not) after making them. This is vital to explore as both lay people and researchers alike often describe awareness that one may be biased as an antidote (or potential antidote) to making biased judgments and decision in the first place. Indeed, even researchers who are somewhat skeptical about peoples' abilities to counteract the forces of social polarization and in-group favoritism in the political arena suggest that understanding these internal processes are Americans' responsibility (Mason, 2018), strongly 
implying that doing so would confer positive outcomes.

Thus, Study 1 and 2 will observe whether or not people can correct their judgments for an irrelevant source of information in line with the Flexible Correction Model (Wegener \& Petty, 1995; 1997), as well as peoples' awareness of bias (or lack thereof) in their own judgments. A prosocial possibility is that individuals who perceive bias in their own judgments will also possess greater motivation and ability to correct their judgments for the biasing information in question. A sobering alternative is that awareness or admission of one's capacity for bias may, ironically, produce greater bias on subsequent judgments as might be expected given research on the perverse outcomes of disclosing conflicts of interest (Cain, Lowenstein, \& Moore, 2010; Lowenstein, Cain, \& Sah, 2011) and moral licensing (Blanken, Van de Ven, \& Zeelenberg, 2015).

As an exploratory goal, Study 1 will also examine what factors are (and are not) associated with lay theories. Understanding what factors are most relevant to understanding why an individual might anticipate (or not anticipate) their judgments being influenced may allow for more precise predictions for who is likely to successfully adjust their judgments for an unwanted influence and under what circumstances. A thorough discussion of the relevant literature will highlight the need for these studies and discuss implications of the various results that could be observed.

\section{How Political Judgments Are Influenced}

People make biased political judgments and decisions, arriving at conclusions favoring their political in-group, supporting their worldview, and reject information that threatens or disconfirms their deeply held convictions (Bartels, 2002; Baron \& Jost, 2018; Crawford, 2012; 
Ditto et al., 2019). Despite the fact that this is plainly apparent, accusing a person of making a biased political judgment or decision may cause social friction, so much so that many Americans consider it rude to even discuss politics outside of designated social arenas dedicated to debate or inter-group political competition (Eliasoph, 1988).

The attentive reader might reasonably ask whether or not "bias", in the various ways researchers have evaluated it, is equivalent across the political spectrum. This question turns out to be challenging to give a concise or clear answer to. A recent meta-analysis argued that liberals and conservatives, across 51 studies, demonstrated bias (e.g., were more likely to make judgments and decisions that bolstered their political views) in their political judgments at roughly equivalent rates (Ditto, et al., 2019). However, this conclusion has been challenged, suggesting that such a position was premature and that conservatives, overall, actually display greater bias in their judgments and decisions than liberals (Baron \& Jost, 2018). For the purposes of the present research, it is sufficient to state that both liberals and conservatives reliably display bias in their political judgments and decisions, such that they are likely to render judgments and make decisions that support and/or bolster their pre-existing political views, and minimize perceived threats to these views. Any unequal display of bias between these two groups is secondary to the question of whether or not individuals are aware of their own propensity for bias, and endorse/denounce this bias.

The plethora of ways in which people make biased political judgments has been extensively documented. For example, race and SES are highly relevant to the formation and maintenance of political views (Sigelman, Sigelman, Walkosz, and Nitz, 1995; Mason, 2018) and are often a lens through which worldviews are formed and maintained, resulting in the political 
views of racial and class out-group members being especially easy to identify and dismiss (Crawford, 2012; Mason, 2018). Additionally, people are likely to selectively expose themselves to worldview-confirming information (Stroud, 2010), engage in motivated skepticism and confirmation bias when examining politically aversive information (Taber \& Lodge, 2006), and are often more willing to accept the frame of an argument from a political ally than a political opponent (Slothuus \& De Vreese, 2009).

This evidence demonstrates that one's political identity does not only influence political judgments but also the terms on which information is considered legitimate to consider in the first place. In addition, one's political leanings also make it easier to dismiss the views of politics opponents and rivals. Partisans often view members of the opposing party as failed moral actors (Bruchman, Koopman-Holm, \& Scherer, 2018), which not only de-legitimizes their perspective but also makes their errors and reasoning biases easy to notice (Kunda, 1990). Compounding this, people generally view others as more biased them themselves (Pronin et al., 2002; Pronin et al., 2004), and information that supports one's worldview is likely more available and accessible when making a judgment (Kahneman \& Tversky, 1974) as available information is less likely to be information that challenges or disconfirms strongly held views. It is noteworthy that this observation about the blindness people hold with regard to their own biases and information seeking behavior is far from a new discovery. As noted in the title of this manuscript, the observation that we may even notice a speck of sawdust in the eyes of others (e.g., small biases) while missing the plank within our own eyes (e.g., larger biases) is a famous biblical parable warning of this bias blindness and the hypocrisy it engenders (Mathew 7:3-5; NIV). Thus, noting the gap between the biases we foster and our awareness of those biases has been noted for 
millennia. The political world people cannot help but be immersed in is one in which motivated reasoning, working to preserve and bolster one's worldview, influences every step of the judgment-making process from information seeking to the final judgment rendered.

\section{The Judgment Correction Process}

Although it is clear that the judgments and decisions people make are biased by their political views, it is not clear how to correct for these influences, if one desired to do so. To be sure, just as heuristics often lead people to make quick, typically accurate judgments (Jussim, 1991; Kahneman, Slovic, \& Tversky, 1982; Plessner, Betsch, \& Betsch, 2011), so too can one's political biases help to make reasonably accurate predictions in many cases. For example, without being able to collect more information it would be warranted to assume any given selfidentified liberal takes a pro-choice stance on abortion while a conservative takes a pro-life stance, even though this would never be correct in every case. However, political biases become consequential in cases in which a viewpoint is rejected not based the facts of the position but because of the person proposing it. Real life examples include Republican opposition to the Affordable Care Act despite the fact the specific policies contained within often have bipartisan appeal, especially when political identities are not primed (James \& Van Ryzin, 2016), and Democratic rejection of the proposed space force, despite the fact that such a program might support space-oriented initiatives with bipartisan appeal (Funk \& Caiazza, 2018).

Given that lay people, journalists, and researchers are all likely to hold that there are some instances in which certain information must be disregarded in order to make optimal judgments and decisions, it is important to examine common ways in which this is handled. Often, the first step taken is to counteract the influence of a given piece of information by 
providing additional, clarifying information (Johnson \& Seifert, 1998). For example, an author might correct a piece of work not only for factual errors but potentially misleading statements by re-distributing the article along with a statement of correction.

Despite how intuitive and reasonable this approach seems, there is ample evidence to suggest that informational correction is ineffective (Lewandowsky et al., 2013). Not only does providing people with corrected information fail to change attitudes and beliefs, it often causes people to double-down on their prior attitudes and beliefs in what is known as "the backfire effect" (Nyhan \& Reifler, 2010). Although the backfire effect, as tested by Nyhan and Reifler, may not replicate (Haglin, 2017; Wood \& Porter, 2016), subsequent research has nonetheless found sobering evidence with regard to the limited ability of people to update their beliefs in the face of new information (Wood \& Porter, 2016). That is, even if people do not exhibit the backfire effect, they may still fail to correct their judgments for a suspected and unwanted influence. This is due in large part due to cognitive limitations, such as memory retrieval, familiarity with prior information, and an inability to make sense of the world (or a concept) without incorrect or misleading information (Lewandowsky, 2012).

Although judgment corrections often fail due to cognitive limitations, people sometimes resist adjusting their judgments and decisions due to reactance (see Miron \& Brehm, 2006). If people feel that a judgment or decision put before them threatens their worldview, they may reject this information in a bid to defend their beliefs from challenge. More recent research has identified that people are likeliest to experience reactance in situations in which their autonomy is threatened in a non-absolute way. That is, when participants are told that their government would likely vote to reduce municipal speed limits, but whether or not this actually happened 
would depend on an internal vote made by government officials (i.e., the outcome is uncertain), people displayed reactance against the measure (Laurin, Kay, \& Fitzsimons, 2012). Thus, judgmental bias sometimes occurs because people feel their beliefs or viewpoints are threatened; when feeling threatened, people may intentionally refuse to correct their judgments.

In addition, seminal research has identified the rebound effects that may occur when people are instructed to suppress their thoughts (Wegner, Schneider, Carter, \& White, 1987). The most classic example being the instructions to "not think about a white bear" and finding that participants given such instructions actually thought of the white bear more, revealing the difficulty people have in suppressing thoughts and, more generally, knowledge. Furthermore, research has long identified that people are unduly (and often unknowingly) influence by information that they know (Birch \& Bloom, 2007; Camerer, Lowenstein, \& Weber. 1989; Heath $\&$ Heath, 2016). This effect, known as the curse of knowledge, suggests that people struggle to both recognize and adjust for the influence of influential information which is often relevant, but may not always be. Finally, beliefs have been shown to persevere over time after being exposed to evidence that one's beliefs are predicated on faulty information, even on topics that are not identity threatening (Anderson, Lepper, \& Ross, 1980).

It is important to note that the difficulty people have in suppressing irrelevant knowledge from influencing their judgments is not merely a quirk of cognitive architecture but a reality that presents major real world challenges. One arena is which this is abundantly clear is in the court of law. Research has noted that people (acting as jurors) often fail to disregard irrelevant information that has been stricken by a judge and are influenced by the information anyway (Daftary-Kapur, Dumas \& Penrod, 2010; Fein, McCloskey, \& Tomlinson, 1997; Steblay et al., 
2006). In fact, even judges have been shown to be influenced by irrelevant information in a court of law-sometimes even information that they themselves struck (Wistrich, Guthrie, \& Rachlinski, 2004). Despite this, some factors has been identified that reduce this distressing tendency, such as making jurors suspicious of the irrelevant information (Kassim \& Sommers, 1997), explaining the reason for striking the information, or striking information in a fashion that is more accepted by jurors (Steblay et al., 2006).

It is surprising to note that, despite the serious consequences that legal situations often present (e.g., people being unjustly convinced of a crime) researchers, legal experts, and even the supreme court have acknowledged that little progress has been made towards identifying who is most likely to render biased jury verdicts and why people find it so challenging (Daftary-Kapur, Dumas \& Penrod, 2010). More recent research cites older research predicting that the (internal) motivation and sufficient cognitive ability (i.e., jurors not being too distracted or overwhelmed) are keys to successful judgment correction (Daftary-Kapur, Dumas \& Penrod, 2010). However, little to no evidence exists linking motivation (internal or external) to successful judgment correction, nor does extant research on judgment and decision making in the legal realm cite predictors other than motivation and cognitive ability for why people often fail to adjust their judgments for the influence of irrelevant information when asked to do so. Certainty, extant research has not addressed the possibility that people actively view irrelevant but persuasive information as acceptable to incorporate into one's judgments.

Collectively, this convergent evidence indicates that correcting judgments is a taxing mental effort facing cognitive limitations (i.e., trying to suppress thoughts; making sense of novel information, staying focused) that often makes the task perversely challenging, even for 
those who sincerely wish to prevent a given piece of information from influencing their judgments. Although extant research in the domain of legal decision making has made headway into identifying when people are more (or less) likely to make judgments influenced by irrelevant information, it is not clear who is most likely to succeed (or fail) to correct their judgments or why people succeed (or fail) to so do. Also unclear is the issue of whether or not people failing to correct their judgments for the influence of irrelevant information reflect a cognitive failure (e.g., people are unable to not be influenced by information that they know) or a deliberate choice (e.g., people know they are not supposed to consider some information, but choose to do so anyway).

\section{Methods of Judgment Debiasing}

Given that simply presenting corrective information is often woefully inadequate to changing perseverant attitudes and beliefs (Anderson \& Kellam, 1992), it is relevant to review other possible means of debiasing judgments and decisions in an effort to understand what might be effective. Early work on judgment debiasing found that simply asking people to try harder (to reduce hindsight bias and overconfidence in judgments) did not reduced these biases nor did offering higher rewards for more accurate judgments or increasing negative consequences for making biased judgments (Fischoff, 1981; Larrick, 2004).

Although these early studies did not involve political judgments, it nonetheless set a precedent that correcting cognitive biases was not something that could be simply fixed by what Fischoff (1981) dubbed "mechanical" means. Similarly, clarifying subsequent true information (Seifert, 2002) and providing retractions immediately after viewing false information (Johnson \& Seifert, 1998) have proven ineffective at debiasing the influence of misleading information. 
However, warning people before exposure to certain information, coupled with a clear explanation of the long-term impact of that information (Ecker, Lewandowsky, \& Tang, 2010; Lewandowski et al., 2012) may be effective.

Additionally, repetition of retraction (Ecker, Lewandowsky, Swire, \& Chang, 2011) and providing an alternative narrative can update attitudes and beliefs previously based on false, misleading, or irrelevant information. Collectively, these studies suggest that information that is not attached to explicit warning before it is seen is likely to influence judgments and decisions; removing the salt from the water after it is dissolved into the solution seems to be, at best, very challenging for people to do. Only by convincing people that the "salt" should not be taken into account before it is added appears to be effective.

\section{Models of Judgment Correction}

Researchers have developed models to predict how, when, and to what extent individuals are (or are not) likely to correct their judgments from suspected biasing influences (Wegener \& Petty, 1995; Wilson \& Brekke, 1994; Schwarz \& Clore, 2003). The first well-articulated models of judgment correction emerged in the 1990's, such as the "Mental Contamination Model" (MCM), which specifies that irrelevant "contaminant" information influences judgments and decisions unless a list of cognitive requirements to prevent this influence is met. This list includes awareness of the biasing influence, motivation to correct one's judgment, accurate perceptions of the unwanted influence, and sufficient mental ability for correction (e.g., is not distracted; Arkes, 1991; Wilson \& Brekke, 1994). Importantly, this model implies that any and all information is potentially able to "contaminate" judgments; the default setting is, for example, to have irrelevant information incorporated into a judgment unless sufficient self-awareness and 
strenuous mental effort is exerted to adjust for the unwanted influence.

Furthermore, the MCM presupposes that there is no way to prevent a particular influence from influencing one's judgment(s) before the judgment process has become initiated, largely because many aspects of the judgment-making process are beyond conscious awareness; once the "salt" is in the water, so to speak, it cannot easily be removed. This is crucial both because this suggests judgment "contamination" is something people may not be able to help and that correction processes are post-hoc. Thus, biased judgments occur not only because of the effort required to correct them but also for the sheer amount of accurate knowledge (e.g., anticipating unwanted influence, detecting unwanted influence, understanding unconscious processes) and self-perception (e.g., I am capable of making biased judgments) required to successfully navigate correction process. Given the weak introspective abilities people often display (Nisbett \& Wilson, 1977), it is thus no surprise that judgment correction often fails; indeed, Wilson \& Brekke note this when suggesting that the most reliable way to eliminate judgmental biases is to not expose oneself to biasing (or otherwise unwanted) influences in the first place.

To the best of my knowledge, no research has yet addressed (a) which point of the proposed "decontamination process" is most likely to determine success or failure (b) how each of the necessary cognitive elements relate to each other (e.g., are people who are motivated to correct more likely to anticipate that their judgments are biased?), (c) whether each of these “decontamination" steps occur in the sequence outlined (Wilson \& Brekke, 1994, p. 119), or if they operate in a parallel fashion, (d) whether other potentially relevant factors should be added to the model (e.g., time between exposure to biasing information and making the judgment), and (e) whether "mental contamination" is as unconscious and uncontrollable as stated by Wilson 
and Brekke (1994). As a result, the utility of this model is limited, despite breaking crucial ground on this topic and providing a useful theoretical framework.

Emerging at approximately the same time (Wegener \& Pretty, 1993; Wegener \& Petty, 1995), the Flexible Correction Model (FCM) argued that people do not merely correct their judgments by "canceling out" a given, unwanted influence (sometimes called "subtraction"; Martin, Seta, \& Crelia, 1990; Schwarz \& Bless, 1992) but rather that judgments are corrected in line with the predicted direction and magnitude of a given influence (i.e., a lay theory). Thus, the FCM allows for predictions to be made regarding when judgment correction was likely to succeed (i.e., when expectations of influence were accurate) and when they were not likely to succeed (i.e., when expectations of influence were inaccurate; Wegener \& Petty, 1997). The FCM thus builds upon the MCM framework by expanding on the critical role that the accuracy (or inaccuracy) of lay theories play in the judgment correction process.

Bolstering the FCM, research has found evidence of theory-guided correction for numerical estimation tasks (Wegener \& Petty, 1993), assimilation and contrast effects (Wegener \& Petty, 1995), affective influences (Isbell \& Wyer, 1999), and stereotype use (Lepore \& Brown, 2002), among others (see Chien et al., 2014 for review). Importantly, research on the FCM has suggested that this model can be applied to judgments made in a courtroom setting. However, no direct measures of lay theories in these contexts have been made, leaving open the question of whether or not people utilize their lay theories to correct for irrelevant information for either mock or real-life courtroom judgments (Fleming, Wegener, \& Petty, 1999; Wegener, Kerr, Fleming, \& Petty, 2000). More recently, research has suggested that judgment correction may be motivated by self-esteem concerns (McCaslin et al., 2010). Research has also found that theory- 
guided correction can occur even in the absence of a biasing influence (Petty, Wegener, \& White, 1998), suggesting that earlier "subtraction-based" theories were less predictive, as these models were not able to account for findings of over-correction or under-correction. Such findings also highlight the importance of lay theories: people do not necessarily correct their judgments for an unwanted influence, they correct their judgments for an imagined unwanted influence.

Successful judgment correct thus depends on the accuracy of one's lay theories.

Researchers investigating bias correction have also examined the degree to which instructions to correct judgments - blatant (i.e., "do not allow this to influence your judgments"), suggestive (i.e., "if you think there is any undue influence on your judgment, then you may correct them"), or subtle (i.e., "it is important for you to make accurate judgments/decisions")—are important for determining whether people utilize their own naïve theories of influence to engage in the corrective process (Stapel, Martin \& Schwarz, 1998; DeSteno, Petty, Wegener, \& Rucker, 2001). Due to the reputation of the first author of this citation (Stapel), a careful search was made to ensure that the results from this publication were not retracted. As there is no evidence that the results of this study have been found to be fraudulent, they are included in this manuscript. If instructions are blatant, it is possible that participants will incorporate social norms of bias into their judgment processes in order to correct (Stapel et al., 1998). Despite this, it is not clear that these additional expectations could not also be considered naïve lay theories, as described by Wegener \& Petty (1995), so long as the direction and magnitude of correction were not provided to participants. 


\section{Judgment Correction: Remaining Questions}

Although evidence has supported models of judgment correction discussed above, many unanswered questions remain that are highly relevant to how an individual might (or might not) correct their judgments and decisions for a suspected, unwanted influence. First, a crucial absence from extant research on judgment correction is, oddly enough, a lack of explicitly measured lay theories. Lay theories have been conceptually defined as the subjective, unscientific beliefs people generate through experience, intuition, or culture values (Wegener \& Petty, 1995), though they have also been described as both naïve and part of a "common sense" psychology that people possess (Heider, 1958). Despite their importance for models of judgment correction, lay theories regarding influences on judgments have only been explicitly measured in the context of contrast and assimilation effects (Wegener \& Petty, 1993; Wegener \& Petty, 1995) and negative state emotions (albeit in a non-experimental sample; DeSteno et al., 2000). For most reported judgment correction effects, lay theories have been inferred from the presence of apparent over-correction (Berkowitz, 2000; Isbell \& Wyer, 1999; McFarland, White, \& Newth, 2003) and not directly measured. Thus, an important component of any future research on judgment correction should include explicit measurement of how people anticipate their judgments to be influenced.

Second, based on the best available current knowledge, no research has measured how acceptable people believe it is to allow their political views to color judgments in situations in which their political views provide irrelevant information to the judgment at hand. This is likely highly relevant in the context of political judgments, in which a person might fervently believe that a piece of irrelevant information (e.g., disdain for Congressional bill's author) might be 
informative to a given judgment (e.g., evaluating financial impact of Congressional bill) and intentionally incorporate personal information about the author into the judgment of financial impact. Alternatively, an individual might believe that a given influence (e.g., personal information about a bill's author) is irrelevant to making a judgment but might intentionally incorporate it anyway for instrumental purposes.

Moreover, measuring the perceived acceptability of incorporating irrelevant information into judgments would expand theoretical models of judgment correction in two ways. First, measuring acceptability would potentially add to the known criteria necessary (or at least sufficient) to engage in successful judgment correction. Both the MCM and FCM note the importance of motivation to make an unbiased judgment as important, but believing that it is acceptable to allow a given piece of information to influence your judgments and being motivated to adjust for that influence are two separate constructs. Thus, both models may need to update and incorporate perceived acceptability as a predictive factor of successful judgment correction. Second, measuring views of acceptability might require models of judgment correction to update assumptions about the judgment correction process itself with regard to cognitive opacity. Currently, both the MCM and the FCM either explicate or assume that making judgments that are unduly influenced is a default outcome- people happen to be exposed to biasing information and are influenced unless they can meet all the requirements to adjust their judgments successfully; generally speaking, people lack awareness about their own judgment making process that hinders efforts to make unbiased judgments. But if people find it acceptable to allow a given piece of information (relevant or otherwise) to influence their judgments (e.g., allowing how much you like the speaker of a quote to influence how you felt about the speech), 
then models of judgment correction need to update to include situations in which people intentionally "contaminate" themselves by seeking out and incorporating irrelevant (but persuasive) information that would unduly influence their judgments.

Third, lay theories are not almost certainly not monolithic; it is not clear from available evidence why some people may believe that their political views will not influence their judgments (when irrelevant) and others might anticipate a strong influence on their judgments (also when irrelevant). One possibility is that individuals with greater cognitively abilities (e.g., problem solving skills, perspective taking) are more likely to anticipate bias in their judgments. However, this may be unlikely, as cognitive abilities have not been found to attenuate the commission of a host of cognitive biases (Stanovich \& West, 2007; Stanovich, West, \& Toplak, 2013; West, Meserve, \& Stanovich, 2012). Individual may also predict stronger influence on their own judgments if they are prone to categorical thinking (Stanovich \& West, 1997), are strongly partisan, loyal to their political party, strongly motivated to make unbiased judgments, or (as previously discussed) view incorporating worldview-bolstering (but irrelevant) information into their judgments as acceptable. Given the importance of lay theories to models of judgment correction, understanding what lay theories are associated with is a vital first step towards predicting what lay theories an individual is likely to hold.

Finally, to date the potential downstream consequences of attempted bias correction have not yet been examined. Because attempted judgment debiasing is often unsuccessful (Wilson \& Brekke, 1994), it would be multiplicatively consequential if merely engaging in an ineffectual judgment debiasing procedure perversely increases confidence that one's judgments are unbiased; effort justification. Conversely, it might be the case that asking people to adjust their 
judgments for the influence of irrelevant information would encourage people to voluntarily engage in self-examination and become appropriately confident in one's ability (or inability) to make unbiased judgments; a practice effect. Whether explicitly attempting to correct one's judgments leads to increased or decreased awareness in unclear, however, as it has never been examined. 


\section{Present Research}

Although misinformation can be a strong biasing influence on judgments and decisions (De Neys, Cromheeke, and Osman, 2011) and is a large component of modern day political rhetoric and biased decision making (Berinsky, 2017; Chan, Jones, Hall, \& Albarracin, 2017) the present research will not focus on false or misleading information, but the incorporation of true, but irrelevant, biasing information for a given judgment. To be clear, in this manuscript the term "bias" is used to denote an influence on a judgment or decision from an irrelevant factor (e.g., information that is not pertinent to making a given judgment or decision). For example, if one was grading a writing assignment from a student with disagreeable political views, evaluating their writing less favorably because of their political views would be to make a biased judgment, as their political views have no bearing on the quality of their writing. "Bias", when discussed, is not meant as a synonym for "wrong" or "illegitimate".

Expanding on early findings that suggest political partisans both anticipate a stronger influence on their judgments and are more likely to endorse that influence (Baker \& Scherer, under revision), Study 1 first measured lay theories and judgments of acceptability prior to the main portion of the experiment. These items were carefully designed to ensure that participants understand that the political information they were considering (e.g., name of a well-known politician) was inherently irrelevant to the judgment at hand (e.g., positivity towards a quote). Next, Study 1 examined both lay theories and acceptability with respect to judgment correction. In line with predictions made by the FCM, lay theories were predicted to guide judgment correction (Wegener \& Petty, 1997). In addition, the present study predicted that views on the acceptability of incorporating irrelevant political information would also predict who would (and 
would not) correct their judgments. By also collecting information such as acceptability, Study 1 sought to enrich existing judgment correction frameworks, such as the FCM (Wegener \& Petty, 1997) and MCM (Wilson \& Brekke, 1994) by including bias acceptability as an additionally relevant factor necessary for successful judgment correction.

The final goal of Study 1 was to explore the downstream consequences of judgment correction efforts. Following the presentation of the main dependent variables, participants were presented with a final judgment (i.e., guilt of defendant in a jury trial) and given the option to either view or not view the political views of the defendant who was on trial for crimes unrelated to politics. Individual differences measures and measures of comparative bias perception (e.g., are Democrats or Republicans better able to avoid the influence of irrelevant information on their judgments?) were included to get an initial glimpse into understanding what factors are most relevant for understanding the lay theories people hold with regard to their own propensity to make biased political judgments.

Studies $2 \mathrm{a}$ and $2 \mathrm{~b}$ replicated Study 1 in online samples. Study $2 \mathrm{a}$ examined only the quote judgments used in Study 1 and presented participants with quotes from both in-group and outgroup politicians (i.e., Trump and Obama) in order to see if the political bias observed in Study 1 could be replicated in a within-subjects fashion. Study 2 a also sought to replicate findings with regard to both lay theories and judgments of acceptability.

Study $2 \mathrm{~b}$ examined only the judgments of guilt in order to examine if either lay theories or judgments of acceptability guided judgment correction when other measures (i.e., quotes, policy judgments) were not included. Additionally, Study $2 \mathrm{~b}$ sought to replicate the findings from Study 1 with regard to the optional selection of irrelevant political information on in a 
second jury scenario. A measure of political knowledge (adapted from Carpini \& Keeler, 1993) was added to Studies $2 \mathrm{a}$ and $2 \mathrm{~b}$ in order to examine if politically informed participants made different judgments than their less informed peers. 


\section{Pilot Study 1}

In preparation for the present research, pilot data was collected in lab during the fall of 2017. This pilot data focused on two main topics: First, it identified how people believe their political views would influence their evaluations of hypothetical Congressional bills after it is

made clear to them that their personal political views are irrelevant to the judgment at hand (lay theories). Second, this study identified how acceptable people believe that it is to allow their personal political views to influence their evaluations, even after attempting to make it clear to them that such information is, in fact, irrelevant (acceptability). This is crucial to measure, both theoretically, as the FCM predicts that people will only attempt to correct their judgments if they believe that the influence is unwanted (Wegener \& Petty, 1995) and because it would shed light on whether, in everyday life, making political judgments (e.g., policy considerations) free from the influence of one's own political preferences is reasonable to expect. Thus, if someone believes that their personal political views are a relevant source of information, not only would they likely not try and correct for this influence, they would likely treat it as pertinent information and intentionally consider it (Schwarz \& Clore, 2003; Wegener \& Petty, 1995). Furthermore, they might even defend and advocate for the use of this information. These data were instrumental in designing Studies 1 and 2 as they helped refine subsequent research questions.

\section{Methods}

Participants. 218 participants from the psychology 1000 subject pool at the University of Missouri completed this pilot study after completing another in-lab study on anger and political judgments. 
Procedure/Design. Participants were presented with 18 items ( 9 scenarios, each with a Democratic and a Republican version) regarding overtly political evaluations ranging from judging a hypothetical new neighbor, evaluating how positively they regarded a quote said by either President Obama or President Trump, and evaluating the contents of a Congressional bill. Democratic and Republican versions of scenarios only differed in the political affiliation of the target (e.g., author of the bill; President who made a statement). Immediately following each of these 18 questions, participants were asked how they expected their judgments to be influenced by their personal political views if they knew the political leanings of the individual in the scenario on a scale from 1 (would make my evaluation much more negative) to 9 (would make my evaluation much more positive). A 5 on this scale indicated, "Would NOT influence my evaluation". Participants were also asked how acceptable they thought it was for their judgments to be influenced by their political attitudes on a scale from 1 (Strongly unacceptable) to 9 (Strongly acceptable). Finally, participants were presented with measures of numerical ability, science literacy, actively open-minded thinking, categorical thinking, and questions regarding their ability to prevent bias when making judgments. Following these measures, participants were thanked and debriefed.

\section{Results}

Lay theories. High reliability $(\alpha=0.94)$ was found among the 18 items asking participants to indicate how they anticipated their personal political views would influence them on a variety of judgments ranging from evaluating Congressional bills to the athletic ability of their neighbors, and were thus combined into a single measure of lay theories. Importantly, in order to aggregate all 18 items, all versions involving a Democratically attitude objects were 
reverse coded, such that the items became meaningfully aligned with Republican affiliated attitude objects. It is important to note that personal political views were only irrelevant for some of the scenarios presented, (e.g., evaluating the athletic ability of a new neighbor), for other scenarios (e.g., judging the healthcare platform of a Republican Presidential candidate) political attitudes were arguably relevant, as an individual might reasonably bring additional information to the judgment based on their partisan leanings (e.g., I am a Democrat, Republicans hate public healthcare, therefore this political platform is suspicious and insincere).

Approximately $33.4 \%$ of participants anticipated that they would not be influenced at all; $50.5 \%$ anticipated knowing political information would cause them to evaluate various things (e.g., President Trump, a new neighbor) as less desirable. The remaining 16.1\% of participants anticipated that political information would cause them to evaluate various things as more desirable. This aggregate measure of lay theories correlated very highly with political affiliation $(r=0.72)$, so much so that it suggests lay theories may have been a reiteration of political identity; when judgments involved a political out-group (in-group) member, people anticipate evaluating whatever they are judging less (more) favorably. Lay theories were not significantly correlated with partisanship strength, a recoded measure of political affiliation in which strong liberals (Democrats) and strong conservatives (Republicans) were both coded as "strong partisans" (3) and weak political moderates were recoded as "weak partisans" (0). Such a scale is important to the hypotheses of each the following studies, as predictions were such that people with strong ties to a political party (not a specific political party) would be more likely to anticipate a strong influence on their judgments from irrelevant political information. Thus, this measure is used and discussed in the results sections of Studies 1 and 2. Finally, bias 
acceptability was not correlated with lay theories, $r=-0.09$ ).

However, a strong argument can be made that the best way to examine lay theories is with an absolute scale, such that low scores indicate that an individual does not anticipate their judgments will be influenced and a high score would indicate that an individual predicts a very strong influence. Examining lay theories in this manner focuses on the core principle that how a person anticipates some amount of influence, regardless of which direction (i.e., positive or negative) is the most important metric to focus on. Thus, an absolute scale of lay theories was created; lay theories were recoded into a scale of absolute value, such that $0=$ no predicted influence and $4=$ very strong predicted influence. Doing so revealed that lay theories were significantly correlated with bias acceptability $(r=.42)$, Additionally, a key observation was made after examining lay theories across the spectrum of political orientation (Figure 1): Partisans, regardless of political party, were the most likely to anticipate at least a moderate, and sometimes a strong influence on their judgments from the political information presented. A correlation between lay theories and a recoded measure of partisan strength $(0=$ moderate, $4=$ 3trong partisan) indicated a robust correlation between the two variables, $r=.43$ (Figure 1).

Correlates with lay theories. Perceived ability to prevent political bias in one's judgments was strongly negatively correlated with lay theories $(r=-.37)$, indicating that those who anticipate the strongest influence on their judgments are less likely to think that they will be able to prevent political bias in their judgments. Although Actively open-minded thinking (AOT), numerical ability, and science literacy are each significantly correlated with perceived acceptability ( $r=-.24, r=-.25, r=-.25$, respectively), none of these cognitive measures are significant correlated with lay theories ( $r=.05, r=.06, r=-.01$, respectively). Similarly, need 
for cognition (NFC) and faith in intuition (FI) were not correlated with lay theories $(r=.12, r$ $=.05$, respectively).

Additionally, strength of religiosity, just world beliefs, and views of cultural agreement were not significantly correlated with lay theories $(r=-.01, r=-.07, r=.06$, respectively). However, right-wing authoritarianism was significantly correlated, albeit modestly $(r=-.14)$. Finally, cultural political views of individualism were not correlated with lay theories $(r=-.06)$, though hierarchy views were $(r=-.19)$. These results provide an early indication that lay theories are either not related or weakly related to measures of cognitive sophistication and ability. However, strength of partisan political affiliation, predicted ability to prevent bias in one's judgments, and endorsing views of social hierarchy and authoritarianism are predictive of lay theories.

\section{Discussion}

These initial data provided crucial feedback for the subsequent, planned studies. First, results indicated that strongly partisan individuals clearly expected their political views to influence their political judgments, despite the fact that efforts (sometimes insufficient) were taken to explain that political charted information was, in those cases, irrelevant. It is likely that many participants believed that the political information they were exposed to as a relevant source of information for the judgments in these scenarios, despite our attempt to make it clear that this was not the case. Thus, it is possible that participants who believe their personal political views should inform their judgments either did not believe the instructions that were given, disagreed with the instructions and refused to comply, or reacted to double-down on their prior convictions; the last possibility would suggest that some people might intentionally incorporate 
political values into their evaluations if they feel their autonomy is being threatened. Because of the relationship between lay theories and partisanship strength, partisanship strength was identified as a possible predictor of judgments in subsequent studies.

Although awareness of influence from political values on judgments may not seem surprising (i.e., partisan political bias is often very obvious), both the acknowledgment of this bias and acceptance of it is surprising given the robust literature documenting how unaware people often are about the information that is influencing their judgments, as well as how people may strive (or claim to strive) to make unbiased judgments and decisions (Pronin et al, 2002; Hansen et al., 2014). Thus, the willingness of political partisans to acknowledge the presence of partisan influences on their own political judgments and decisions in noteworthy and carries critical implications. Because lay theories in this pilot study were likely a reflection of partisan affiliation (as the $r=0.80$ correlation suggests) it is critical that Studies 1 and 2 use judgment scenarios in which is it unmistakably clear that participants understand their personal political views are inherently irrelevant to the scenarios and judgments presented to them. It is also crucial that key items in Studies 1 and 2 are constructed in such a way that personal political views are objectively irrelevant to the judgments presented. 


\section{Overview}

\section{Pilot Study 2}

Given the findings from the pilot data, the second pilot study addressed two main questions arising from the first pilot study. First, this pilot study examined lay theories, this time ensuring that an accurate representation of lay theories is being measured. For example, it was possible that participants misread the questions presented in Pilot Study 1; when reporting how they anticipated to be influenced by their political views, participants may have instead reported the extent to which they saw their political views as diagnostic information on the judgment at hand. Thus, Pilot Study 2 crafted dependent variables such that personal political views were objectively irrelevant sources of information for the judgments at hand, and that participants fully understand that their personal political views are supposed to be non-diagnostic for the judgment at hand. Judgments selected were also key items later used in Studies 1 and 2.

Second, Pilot Study 2 systematically investigated the relationship between lay theories (anticipated influence of one's own political views) and acceptability of this influence on judgments of hypothetical Congressional bills. It is possible that the order in which these questions are presented is consequential. That is, participants might indicate that bias in one's judgments is more acceptable after admitting that their own judgments would be biased as a post-hoc justification. Therefore, Pilot Study 2 counter-balanced the order of presentation between lay theories and bias acceptability in a between-subjects fashion, with the expectation that strong partisans will only view the influence of irrelevant political information on judgments (e.g., presidential quotes; judging the guilt of a defendant) are more acceptable only after they have indicated they anticipate such an influence. 


\section{Methods}

Participants. 245 participants from the Psychology 1000 pool at the University of Missouri were collected during the Spring 2019 semester. Most participants $(n=173)$ completed these materials online, though some participated in lab $(n=72)$. Online and in-lab groups were not significantly different with regard to political orientation $(M=4.57, M=4.68$, respectively)

Design and procedure. After reading a digital informed consent document prior to the beginning of the study, participants were asked about their partisan affiliation before being randomly assigned to first report a) how acceptable they believe it is to allow irrelevant political information to influence their judgments (e.g., presidential quotes, policy positions, judgments of guilt for a defendant on trial), or b) the degree to which they anticipate irrelevant political information to influence their judgments (i.e., lay theories). Regarding measures of lay theories, participants were randomly assigned to either the quote version —in which they were asked to indicate how knowing the speaker (i.e., Trump or Obama) of a given quote would influence their judgments, or the jury version — in which they were asked to indicate how knowing the political views of a defendant on trial would influence how guilty they thought they were.

Materials and measures. Participants first indicated their political orientation using a scale ranging from 1 (Very liberal) to 9 (Very conservative), with the midpoint (5) indicating "Moderate/Centrist".

Lay theories. Participants randomly assigned to the quote version of this pilot were presented with five quotes and asked how they anticipated knowing that President Donald Trump said them would influence their evaluation of each of those quotes. Similarly, five quotes were presented in which Obama was the orator who had said them. 
Participants randomly assigned to the jury version were asked how knowing the strong Republican (Democratic) political views of a defendant would influence the degree to which they found the defendant a) guilty of assault and b) guilty of attempted murder. Each participant was presented with one jury scenario in which the defendant held extreme right-wing views and one in which the defendant held extreme left-wing views. All items were presented on a scale ranging from 1 (would make my evaluation much more negative) to 9 (would make my evaluation much more positive) with the midpoint (5) indicating "this would not influence my evaluation”.

Bias acceptability. Participants were presented with three acceptability items in total, each on a scale ranging from 1 (Completely unacceptable to 6 (Completely acceptable). Participants were asked how acceptable it would be to allow the knowledge that Donald Trump (Barack Obama) uttered a quote to influence their evaluation of the quote in question. Participants were also asked how acceptable it would be to allow the extreme right-wing (leftwing) views of a defendant to influence how guilty they thought they were of a) assault and b) attempted murder.

\section{Results}

Lay theories: Quotes. A 2 (Lay theories: Out-group pres. vs. In-group pres.) $\times 2$ (Order: Lay theories first vs. Lay theories second) $\times 3$ (Political orientation: Liberal, Moderate, Conservative) mixed-model ANOVA was conducted to examine whether order and/or political orientation influenced lay theories. Neither order nor political orientation influenced lay theories; likewise, these factors did not significantly interact (all $p s>.12$ ). Participants did, however, anticipate a greater influence of an in-group president on their judgments $(M=1.47)$ compared to 
the influence of an out-group president $\left(M=1.12 ; F(1,112)=7.57, p=.007, \eta_{p}{ }^{2}=.06\right)$.

Lay theories: Guilt judgments. A 2 (Lay theories: In-group pres. vs. Out-group pres.) $\times$ 2 (Order: Lay theories first vs. Lay theories second) $\times 3$ (Liberal, Moderate, Conservative) mixed-model ANOVA indicated that participants anticipated greater influence when judging a defendant whose political views they disagreed with $(M=0.58)$, compared with a defendant who's political views they agreed with $(M=0.35 ; F(1,118)=8.32, p=.005)$. A main effect of political orientation was also observed $(F(1,118)=4.97, p=.009)$, though political orientation significantly interacted with lay theories (In-group pres. vs. Out-group pres.). Liberals anticipated greater influence than moderates $\left(M_{\text {diff }}=0.52, p=.005\right)$, though not conservatives $\left(M_{\text {diff }}=0.17, p=.55\right)$; Moderates and conservatives also did not hold significantly different lay theories $\left(M_{\text {diff }}=0.36, p=.12\right)$. There was no effect of order, nor did order interact with either variable $(p s>.77)$.

Acceptability: Quotes. A 2 (Acceptability: Obama influence. vs. Trump influence.) $\times 2$ (Order: Acceptability first vs. Acceptability second) $\times 3$ (Political affiliation: Liberal, Centrist, Conservative) mixed-model ANOVA indicated significant main effects of political orientation $\left.F(1,111)=3.09, p=.050, \eta_{p}{ }^{2}=.05\right)$ and acceptability (In-group vs. Out-group defendant), though not Order $(p=.68)$. These main effects were qualified by a significant 2 -way interaction between acceptability and political orientation $\left.F(2,111)=7.13, p=.001, \eta_{p}{ }^{2}=.05\right)$ and a significant 3-way interaction between acceptability, political orientation, and $\operatorname{Order}(F(2,111)$ $\left.=5.29, p=.006, \eta_{p}^{2}=.09\right)$.

Simple effects tests revealed that, what Obama acceptability was presented first, participants did not make different ratings based on their political orientation $(p=.11)$. However, 
when presented second, Liberal participants judged incorporating irrelevant information about Obama into quote judgments as more acceptable than conservatives $\left(M_{\text {diff }}=1.36, p<.001\right)$ but not moderates $\left(M_{\text {diff }}=0.96, p=.092\right)$. Conversely, Trump acceptability did not vary by political affiliation when presented first or second $(p s>.08)$. Neither political moderates nor conservatives judged incorporating information about Obama and Trump as significant different (ps>.17).

Acceptability: Guilt judgments. A 2 (Acceptability: Republican defendant. vs. Democratic defendant $) \times 2($ Order: Acceptability first vs. Acceptability second $) \times 3$ (Political orientation: Liberal, Moderate, Conservative) mixed-model ANOVA revealed a significant 2-way interaction between acceptability (Republican defendant vs. Democratic defendant) and political affiliation $\left(F(2,113)=5.78, p=.004, \eta_{p}{ }^{2}=.09\right)$, though the rest of the model was nonsignificant $(p s>.14)$. Simple effects tests indicated that this interaction was driven by conservative participants who judged being influenced by a defendant's conservative views was more acceptable $(M=2.83)$ than a defendant's liberal views $(M=2.37)$. Neither liberals nor moderates displayed a difference in judgment acceptability ( $p s>.46)$.

\section{Discussion}

Results of pilot Study 2 confirmed that lay theories regarding the influence of irrelevant political information for both quotes and judgments of guilt were, overall, similar to lay theories observed in Pilot Study 1; a strong minority ( 25-35\%) of participants anticipate that their judgments will not be influenced by irrelevant political information when making subjective judgments, though many more anticipated that their judgments would not be influenced (68$82 \%$ ) when making judgments of guilt in the context of a jury. When liberals were asked to 
imagine if their judgments of guilt would be influenced by knowledge that a defendant was a strong Republican, they anticipated a stronger influence than moderate (but not conservative) participants. Outside of this, however, political affiliation had little influence on lay theories. Moreover, the order of presentation (i.e., before or after judgments of acceptability) did not influence lay theories. The similarity in lay theories between Pilot Studies 1 and 2 are crucial as they reduce the chance that lay theories from Pilot study 1 reflected peoples' views that political information was actually relevant information, and therefore were not identical to a lay theory regarding an irrelevant source of information.

When asking participants about how acceptable it would be to allow irrelevant political information to influence their judgments (e.g., name of President Trump/Obama), the order of presentation mattered, at least for the acceptability for quote judgments. When asked how acceptable such an influence would be when evaluating quotes after being asked to indicate one's lay theories, liberal participants to view doing so as more acceptable. Order did not influence judgments of acceptability for judging the guilt of a defendant on trial. These results make it more likely that judgments of acceptability from Pilot Study 1 were influenced, at least in part, by first acknowledging that one would be biased by political information in the first place. However, this effect is largely context dependent and does not suggest that the order in which items are asked (i.e., lay theories and views of acceptability) is significant enough to influence the design of subsequent studies. 


\section{Overview}

\section{Study 1}

The main purpose of Study 1 was to examine whether lay theories regarding the influence of partisan political information guide judgment correction, as predicted by the FCM (Wegener \& Petty, 1997). The FCM predicts that if a person thinks that they will evaluate a quote more negatively/positively if it was said by Donald Trump (for example) as opposed to different President (e.g., Obama), then they will correct their judgment for this influence by rating the quote more positively, so long as they also possess sufficient motivation and cognitive ability to engage in judgment correction. In Study 1, participants were asked to correct their judgments (or not) for the influence of irrelevant political information on a variety of distinct judgments (i.e., quote evaluations, policy evaluations, judgments of guilt). For each type of judgment, partisan information that might influence participants' judgments (e.g. the political affiliation of a defendant) was either presented or not. Study 1 also examined whether ratings of bias acceptability interact with lay theories to uniquely predict judgment correction, as well as the degree to which participants perceive bias (or not) in the judgments that they made.

Study 1 also addressed how attempts at judgment correction influence future information seeking behavior. In particular, participants who are instructed to correct their judgments may subsequently feel overly confident in their ability to prevent irrelevant information from influencing their judgments. As a result, they may be more likely to expose themselves to further biasing information on subsequent judgments. Such behavior would be problematic, because the optimal strategy for anyone aiming to stave off an unwanted influence on their judgments is to avoid the biasing information in the first place (Wilson \& Brekke, 1994). Conversely, it is also possible that downstream consequences of judgment correction are positive: participants who 
have previously attempted to correct their judgments may instead exhibit a practice effect, such that they become more aware of potential biasing information and try harder to avoid it in subsequent judgments.

\section{Participants}

A power analysis indicated that a minimum sample of $\sim 400$ would be required in order to have adequate statistical power $(\alpha=.05,1-\beta=.2)$ to test regression model predicting quote evaluating involving three between-subjects conditions, one continuous predictor, and interactions between these two variables. A higher than anticipated sample was acquired due to high sign-ups during the Fall 2018 semester. There were 584 participants from Psychology 1000 at the University of Missouri-Columbia who took part this experiment in exchange for partial course credit. Due to a labeling error on the Likert scale of the primary dependent measure (quote judgments), the first eight participants were removed from analyses, leaving a total sample size of 575 . Of the 575 participants, 526 completed the necessary lay theory pre-measure items from a mass pre-test. Thus, for analyses involving lay theories the sample size was 526 . For analyses not involving lay theories (e.g., bias perception), the analytic sample size was 575 .

\section{Design/Procedure}

Participants first reported their political orientation and their lay theories (i.e., subjective expectations) about how those political views would influence a variety of judgments in a mass pretest survey conducted at the beginning of the academic semester (Fall 2018). Importantly, for all of these judgments the participants' own political views, as well as the political views of the person they were evaluating, were objectively irrelevant, but nonetheless might exert a biasing influence. For example, one type of judgment was evaluating the guilt of a defendant, where the 
defendant's political ideology was irrelevant to the crime but nonetheless might color the participants' judgment of guilt. Participants were also asked about how acceptable they thought it was for political information (e.g. about the defendant's politics) to influence their judgments. Lay theories were assessed in advance of the main in-lab experiment due to the possibility that the measurement of lay theories near in time to the study may prompt all participants to spontaneously correct their judgments.

During the in-lab portion of the experiment, participants first responded to a series of questions to determine their political affiliation ranging from strong Democrat to strong Republican. Participants were then randomly assigned to one of three conditions: Control, Partisan induction, or Correction. Participants in the Control condition were told the quotes were said by former U.S. President Warren Harding (a President who students were anticipated to know little about and do not typically associate with strong partisan views) and were not given any information about the author of the policy positions or the political views of the defendant on trial. Participants in the Partisan condition were presented with partisan information (e.g., the quotes were said by Trump or Obama). Correction participants were presented with partisan information and were additionally explicitly told to not allow this information to influence their evaluations. In the Control and Partisan conditions, participants did not receive any instructions with respect to how they should make their judgments.

The main dependent variables included 1) quote evaluations, 2) policy judgments, and 3) judgments of guilt of a defendant on trial (presented in that order), which are described in greater detail below. Following this, participants completed several individual difference measures (listed below) before being thanked and debriefed. 


\section{Materials/measures}

Mass pre-test. Participants responded to eight key items to measure lay theories, four regarding anticipated influence from left-wing politicians and four from right-wing politicians. These items were related to judgments of policy items and one involved quote judgments. For example:

Imagine that you are reading a quote and evaluating the extent to which you agree or disagree with the statement. You learn that the quote you are reading was said by President Donald Trump (Barack Obama).

To what extent would knowing that Donald Trump (Barack Obama) said this quote influence the extent to which you feel positively or negatively towards the quote, relative to not knowing who the quote was from?

Participants were also presented with four questions regarding the acceptability of incorporating irrelevant partisan information into their judgments, such as:

How acceptable is it for your positive or negative views of a presidential quote to be influenced by the knowledge that it was said by President Donald Trump (former President

\section{Barack Obama)?}

Based on findings from Pilot Study 1, lay theory items and acceptability items, respectively, were anticipated to have high internal reliability $(\alpha>0.70)$.

Quotes. Participants were presented with a total of 10 quotes and asked to evaluate how positively/negatively they felt towards each quote $(1=$ very negatively, $6=$ very positively $)$ and the extent to which they agreed/disagreed with the quote $(1=$ Strongly disagree, $6=$ Strongly agree). Nine of the 10 quotes were stated by actual U.S. Presidents, and the remaining quote was 
inspired by a Presidential quote but created for this study ("Bravery demands sacrifice. Sacrifice demands suffering"). Each of the quotes was selected for being vaguely inspiring and generally agreeable. Most importantly, to reinforce the irrelevance of the political affiliation of the speaker when evaluating these quotes, none were overtly political, and instead dealt with topics such as leadership, passion, and morality. Participants in the Partisan and Correction conditions were told that the President from their out-group political party (Trump or Obama) had said each of them. Participants in the Control condition were told that President Warren Harding had said each quote. The internal reliability of all 10 quote evaluations was high $(\alpha=.86)$, and an aggregate measure (mean of all quote ratings) was used in analyses.

Policy judgments. Following quote judgments, participants were presented with two policy judgments: one regarding spending tax dollars on public infrastructure and the second on the creation of National Election Day. These topics were selected based on broad appeal across the political spectrum (Doherty, Kiley, \& Johnson, 2018; Doherty, Kiley, \& Johnson, 2019). Control participants were not given any political information about the sponsor of the proposal, while Partisan induction and Correction participants were told that the proposal's sponsor was either president Trump or president Obama (president was also a member of the participant's political out-group). For each policy judgment, participants were asked to rate the extent to which they supported the proposal $(1=$ Do not support at all, $6=$ Strongly support $)$ and the degree to which they trusted that the proposal would be good for the American people ( 1 = Do not trust at all, $6=$ Strongly trust).

Judgments of guilt. Following policy judgment, participants were asked to rate the extent to which a defendant on trial was guilty of serious crimes (assault and attempted murder). 
The scenario itself involved a fictitious bar fight in which there was only relatively weak evidence of the defendant's guilt. The scenario was intentionally constructed to be ambiguous with respect to the defendant's guilt and participants were never provided with a definitive answer one way or another. While reading the scenario, Control participants were not given any information about the defendant's political views, while Partisan induction and Correction participants were presented with one sentence describing the political affiliation of the defendant who was always an extreme right wing or left wing political actor. Participants in these two conditions were always presented with a defendant who disagreed with their political views (i.e., Democrats always judged an extreme right-wing defendant, Republicans always judged an extreme left-wing defendant). Participants were asked to indicate how certain they were of the defendant's guilt on a scale ranging from $(1=$ Very certain he was not guilty) to 6 (Very certain he was guilty). These specific crimes were selected because they provided a context in which it is explicitly and legally relevant for people to prevent irrelevant information from influencing judgments.

Following the first jury scenario (bar fight) participants were given the opportunity to either view or avoid viewing the political views of the defendant on trial in a second jury scenario regarding an attempted vehicular homicide. Before choosing to see (or not) the political views of the defendant, participants were explicitly (and truthfully) told that the trial they were about to see was completely unrelated to politics. In addition to the binary choice to view or not view this information, participants were also asked the extent to which they were in favor of viewing this information ( 1 = Strongly opposed, $6=$ Strongly in favor $)$ before being shown the actual scenario. As with the first jury scenario, participants were asked how certain they were 
that the defendant was guilty of assault and attempted murder, as well as how serious they viewed these crimes.

Political affiliation and political partisanship. Partisan political affiliation was measured using three funneled questions that resulted in a 6-point scale; there was no "moderate/centrist" mid-point for this scale. Participants were first asked which party they identified with: Democratic, Republican, or Independent. Participants who self-identified as Independents were funneled to a subsequent question which asked them to select whether they identified more closely with Democrats or Republicans. If participants first identified as Democrats (Republicans), then were then asked whether they identified as a "Strong Democrat (Republican) or "Not so strong Democrat (Republican). Responses to these questions were recoded into a 6 -item scale of political affiliation $(1=$ Strong Democrat, $6=$ Strong Republican $)$.

Because partisanship strength predicted lay theories in Pilot Study 1, a measure of partisanship strength was created by collapsing the political affiliation measure across party. Thus, the partisanship strength scale included three groups: Weak partisans (i.e., Independents who leaned either towards Democrats or Republicans), moderate partisans (i.e., "Not so strong" Democrats and Republicans), and strong partisans (i.e., "Strong” Democrats and Republicans).

Bias perception. Participants were asked to indicate whether knowing the President who said the quotes had influenced their judgments $(1$ = caused me to judge much more negatively, 5 $=$ did not influence my judgments, $9=$ caused me to judge much more positively). Next, participants in the Partisan and Correction conditions were asked the extent to which knowing the President who proposed the policy positions and the views of the defendant had influenced their judgments (identical scale). Control participants were not presented with bias perception 
questions for policy judgments or judgments of guilt as they were not exposed to any partisan information for these questions.

Bias Prevention. As a manipulation check, participants were asked on a scale from 1 (No, not at all) to 6 (Yes, definitely) whether they had prevented the political information they were exposed to from influencing their judgments on each of the three main dependent measures (quotes, policy judgments, jury judgments). Reliability of these items was high $(\alpha=.80)$, and an aggregate measure was used in analyses.

In an exploratory measure, participants were asked to indicate their agreement, from 1 (Strongly disagree) to 6 (Strongly agree), with the assertion that they can prevent political information that is irrelevant from influencing their judgments if they want to. Participants were also asked whether they agree or disagree that the average Republican and average Democrat could do the same ${ }^{1}$.

Bias Acceptability. Participants were asked on a scale from 1 (Completely unacceptable) to 6 (Completely acceptable) how acceptable it was for political information (e.g., name of a President, political affiliation of defendant) to influence their evaluation of presidential quotes, evaluation of policy proposals, and judgments of guilt regarding a defendant on trial. Reliability for the former two acceptability judgments was on the low side of acceptable $(\alpha=.71)$ and even lower when all three were included $(\alpha=.66)$. As a result, an aggregate measure was not used in analyses; individual bias acceptability items were used in their respective analyses (i.e., models of quote judgments included judgments of acceptability for quote judgments, and no other acceptability items).

\footnotetext{
${ }^{1}$ Because these exploratory items were tangential to the primary research goals, they will not be discussed further in this manuscript. Results and figures for these items can be found in supplementary materials.
} 
Motivation. Four items (created for this study) pertaining to general motivation to make unbiased judgments were presented on a scale ranging from 1 (Strongly disagree) to 6 (Strongly agree). For example, the items included "I believe it is very important to make unbiased judgments" and "I am highly motivated to make unbiased judgments". Reliability for these four items was low $(\alpha=.56)$; as a result, only the most face valid item ("I am highly motivated to make unbiased judgments") was used in analyses.

Perspective taking. Three items (created for this study) assessed self-rated ability to engage in perspective taking on a scale from 1 (Strongly disagree) to 6 (Strongly agree). Items included "when I confront an argument, I like to do a mental exercise where I look at the issue from both sides", "before making an important judgment, it is very important that I take other peoples' perspectives" and "I am skilled at perspective-taking". Reliability for these three items was low $(\alpha=.67)$, though eliminating any one of the items was insufficient to raise reliability. As a result, an aggregate measure was not created and this construct was not examined further in analyses.

Additional individual difference measures. Participants completed the Cognitive Reflection Task, a 3-item measure that assess numerical ability and insight problem solving skills (Patel, Baker, \& Scherer, 2019) alongside four items used to assess insight problem solving skills independently of numerical ability. Participants were then presented with the Moral Rationality scale, which consisted of a 9-item subscale assessing how moral people believe it is to engage in rational thinking and a 6-item subscale assessing how important people believe it is to make rational judgments. This was followed by a 3-item scale of categorical thinking (Epstein, 1996), a 7-items scale for actively open-minded thinking (Epstein, 1996), an 8-item measure of group 
loyalty (Beer \& Watson, 2009), and a 7-item exploratory scale created for the purposes of this study to assess political loyalty. Although a robust association between partisanship and political loyalty is anticipated, it is not hypothesized that they will assess the same construct. Participants were then asked three items in order to assess the degree to which they rejected the notion that political information was irrelevant to the judgments they had made earlier (e.g., "Is it always relevant to know the political views of a person who you are making a judgment about?"). Finally, participants were given an 11-item scale to measure socially desirable responding (Reynolds, 1982). This was presented in the event that participants did not honestly report their susceptibility to make biased judgments.

\section{Results}

Lay Theories. An absolute value scale was constructed such that 0 indicated a belief that there would be no influence on one's judgments, and a score of 4 indicated a very strong predicted influence (either negative or positive). The absolute value score was created because the FCM predicts that judgment correction will occur based on the strength of anticipated influence, not the predicted direction of influence per se. The 526 participants who completed the lay theories measure on the mass pre-test indicated, on average, a relatively low influence ( $M$ $=0.69$, Median $=0.38, S D=.72$ ), and $29.3 \%$ believed they would not be influenced. Approximately $41.4 \%$ of the sample believed they would be influenced weakly and $29.3 \%$ to a moderate, strong, or very strong degree. This indicates that although most people predicted no influence or a small influence, the variance in beliefs was considerable.

Replicating results from Pilot Study 1, lay theories varied significantly influenced by participants' partisanship strength $\left(F(2,523)=68.83, p<.001, \eta_{p}{ }^{2}=.21\right)$. Weak partisans (Lean 
Democrat/Republican) believed that they would experience little to no influence on average ( $M=$ 0.29). Partisans believed they would be weakly influenced $(M=0.55)$, and strong partisans predicted the strongest influence on their judgments $(M=1.15)$. However, some participants who viewed their judgments as immune to influence were also strong partisans (Figure 6b). A sizable minority of strong Democrats (16\%) and strong Republicans (18\%) predicted that their judgments would not be influenced at all. Because partisanship was highly relevant to lay theories $(r=.44)$, this factor was included in regression models discussed below.

Correlates of lay theories. A number of individual differences were included in this study in order to examine what is (and is not) associated with lay theories of these measures. Correlations indicated that political loyalty $(r=0.30, p<.001)$, perceived acceptability $(r=0.19$, $p<.001)$, and having stronger Democratic affiliation $(r=-0.19, p<.001)$ were all associated with anticipating an influence on one's judgments from irrelevant political affiliation. Additionally, having less motivation to prevent bias $(r=-0.24, p<0.001)$ and worse performance on the CRT $(r=-0.12, p<0.001)$ were likewise associated. NFC, FI, general loyalty, actively open-minded thinking (AOT), categorical thinking, and attitudes on rationality were not associated with lay theories $(p \mathrm{~s}>0.07)$. Collectively, these results indicate that measures of identity are more closely related to lay theories than cognitive measures or measures that assess thinking styles. As such, no further analyses were conducted for NFC, FI, AOT, categorical thinking, and attitudes of rationality and these measures will not be discussed further.

Judgments of Acceptability. Because judgments of acceptability had poor interreliability, each of the three acceptability items (i.e., acceptability of quote evaluations, policy judgments, and guilt judgments) were analyzed separately. First, a 3 (Condition: Control, 
Partisan induction, Correction) $\times 3$ (Partisanship strength: Weak, moderate, strong) x 3 (Withinsubjects: Acceptability of influence on quotes, policy, guilt) mixed-model ANOVA was conducted to examine perception of acceptability for allowing the influence of irrelevant political information to influence quote judgments. A main effect of partisanship strength $(F(2,569)$ $=.57, p=.001, \eta_{p}{ }^{2}=.03$ ) revealed that strong partisans viewed it incorporating irrelevant political information into all of these types of judgments as more acceptable than weak partisans $\left(M_{\text {diff }}=0.48, p<.001\right)$, but not moderate partisans $\left(M_{\text {diff }}=0.22, p=.064\right)$.

Additionally, a main effect of acceptability $\left(F(2,569)=200.27, p<.001, \eta_{p}{ }^{2}=.27\right)$, such that the perceived acceptability of incorporating irrelevant political information into quote evaluations $(M=3.18)$ is perceived as more acceptability than incorporating irrelevant political information into jury evaluations $(M=1.96)$, but not policy evaluations $(M=3.07)$. This main effect is qualified by a significant interaction between acceptability type and condition, $F(2,569)$ $=3.15, p=.044, \eta_{p}{ }^{2}=.01$. Simple effect tests indicated that this interaction was driven by views of acceptability for policy judgments, $F(2,572)=3.25, p=.039, \eta_{p}{ }^{2}=.01$. However, post-hoc Tukey tests indicated that effects between conditions were not significant; Control participants did not give lower ratings than either the Partisan induction condition $\left(M_{\text {diff }}=0.34, p=.063\right)$ or the Correction condition $\left(M_{\text {diff }}=0.33, p=.080\right.$ ). No significant differences between condition were observed for either quote acceptability or jury acceptability $(p s>.24)$.

Manipulation Check. When asked if they had tried to prevent partisan information from influencing their judgments, a 3 (Condition: Control, Partisan, Correction) x 3 (Partisanship: Weak partisan, Partisan, Strong partisan) mixed model ANOVA was conducted. A main effect of condition $\left(F(2,566)=4.97, p=.01, \eta_{p}{ }^{2}=0.02\right)$ indicated that, as expected, participants in the 
Correction condition $(M=4.97)$ reported that they had tried harder to correct their judgments than those in the Partisan $(M=4.50, p=.001)$ and Control conditions $(M=4.62, p=.02)$. A main effect of partisanship strength $\left(F(2,566)=8.05, p<.001, \eta_{p}{ }^{2}=0.03\right)$ indicated that weak partisans viewed themselves as the most successful at judgment correction $(M=5.09)$ relative to partisans $(M=4.64, p=.003)$ and strong partisans $(\mathrm{M}=4.53, p<.001)$. The interaction between condition and partisanship strength $\left(F(2,566)=2.23, p=.06, \eta_{p}{ }^{2}=0.02\right)$ was non-significant.

To check for prior knowledge of President Warren Harding, participants were asked if they knew which political party (Democrat or Republican) Warren Harding was a member of, as well as how confident they were in their response $(1=$ not at all confident, $7=$ extremely confident), which was asked to account for participants correctly guessing. Of the 575 participants, 70 correctly identified that Warren Harding was a member of the Republican Party (12\%), though only $44(8 \%)$ of these participants reported confidence in their response as a "4" or higher.

Quote judgments. To determine the effect of the experimental conditions and participants' partisan strength on the quote judgments, a 3 (Condition: Control, Partisan, Correction) x 3 (Partisanship strength: Weak partisans, Partisan, Strong partisans) betweensubjects ANOVA was conducted on the aggregate quote judgment measure. Results indicated a main effect of condition $\left(F(2,566)=5.85, p=.003, \eta_{p}{ }^{2}=0.02\right)$, indicating that, as predicted, participants in the Partisan condition approved of the quotes less than Control participants $\left(M_{\text {diff }}\right.$ $=.20, p=.005)$, but not Correction participants $\left(M_{d i f f}=-.09, p=.36\right)$. There was no effect involving partisanship or the interaction between partisanship and condition ( $p s>.13)$. 
Second, to test whether the effect of Condition interacted with participants' lay theories (following theoretical predictions derived from the FCM; Wegener \& Petty, 1997), a regression analysis including dummy-coded condition variables (with the control condition as the reference group), lay theories, and interactions as predictors showed that participants in the Control condition evaluated the quotes more positively than participants in the Partisan induction condition $(t=-3.37, \beta=-.17, p=.001)$ and Correction condition $(t=-2.20, \beta=-.11, p=.03)$. These main effects of condition were qualified by a significant interaction between lay theories and Control vs. Partisan conditions $(t=-2.24, \beta=-.14, p=.03)$. Participants who anticipated an influence on their judgments and who were exposed to the partisan speaker gave lower evaluations relative to control participants. Crucially, the interaction between lay theories and Control vs. Correction participants $(t=-0.89, \beta=-.05, p=.38)$ was non-significant, indicating that participants who anticipated an influence on their judgments and were asked to correct their judgments did so in line with their lay theories (Figure 8a).

It was hypothesized that judgments of acceptability might also predict judgment correction, and therefore an additional model was constructed that included lay theories, judgments of acceptability, dummy-coded condition variables, and interactions between these variables (2-way and 3-way). The 3-way interactions were non-significant $(p s>.87)$ and were dropped from the model. Significant interactions were observed between acceptability and Control vs. Correction conditions $(t=-2.88, \beta=-.13, p=.004)$, as well as acceptability and Control vs. Partisan conditions $(t=-2.45, \beta=-.10, p=.03)$. Main effects involving condition (previously reported) were qualified by a significant interaction between lay theories and Control vs. Partisan conditions $(t=-2.06, \beta=-.13, p=.04)$, indicating that both acceptability and lay 
theories interacted with condition, though not with each other $(p=.65)$. The relationship between acceptability and condition can be illustrated by noting the significant correlation between acceptability and quote approval in both the Partisan induction condition $(r=-.17, p=.017)$ and Correction condition $(r=-.19, p=.009)$ compared with the non-significant correlation between acceptability and quote approval in the Control condition $(\mathrm{r}=.03, p=.71)$. Correction and Partisan induction participants who viewed incorporating partisan information into their judgments as acceptable gave lower quote ratings relative to control participants with similar views of acceptability.

Individual differences: Additional analyses. Because of the strong correlation between lay theories and several other factors (partisanship strength, political loyalty, and motivation) a series of alternative models were created in order to further examine what, if any, other variables can account for the interactive effect between condition and lay theories on quote judgments. First, an alternative model including participants' partisanship was included in this model, along with lay theories, dummy-coded condition variables, and interactions between variables (2-way and 3-way). Results indicated a significant 2-way interaction between lay theories and partisanship strength $(t=2.01, \beta=.17, p=.045)$ qualified by a 3-way interaction between lay theories, partisanship strength, and Control vs. Partisan conditions $(t=-2.73, \beta=-.21, p=.01)$. This 3-way interaction indicates that the relationship between lay theories and condition noted earlier is driven in large part by strong partisans. Among strong partisans with stronger lay theories, those in the Control condition gave much higher quote ratings than those in the Partisan induction condition, and somewhat higher than those in the Correction condition (Figure 9). Although moderate partisans who anticipated a strong influence from political information 
approved of the quotes less overall, there was no interaction between lay theories and condition. The range of lay theories for weak partisans was too restricted to interpret clearly.

A final model replacing political partisanship with the item assessing motivation to make unbiased judgments was conducted. This model was tested because both the FCM and MCM predict that motivation to correct one's judgments is necessary for the judgment correction process. Thus, these models would predict participants who both anticipate being influence and who possess the motivation to correct their judgments will do so.

Results from this model indicated a main effect of motivation $(t=2.79, \beta=.23, p=.005)$, as well as a significant 2-way interaction between lay theories and Control vs. Correction conditions $(t=-2.53, \beta=-.16, p=.01)$, which was qualified by a significant 3 -way interaction between motivation, lay theories, and Control vs. Partisan conditions $(t=2.96, \beta=.19, p=.003)$. Among participants who anticipated a strong influence on their judgments, those who had lower motivation to correct their judgments gave lower ratings when evaluating quotes in the Partisan condition relative to participants with equally low motivation in the Control condition.

Conversely, participants with weak lay theories (i.e., did not believe they would be influenced) who had low motivation to correct their judgments gave higher quote ratings in the Partisan condition relative to their peers with similar views in the Control condition (Figure 10).

Policy judgments: Infrastructure. Following the quote evaluations, participants were asked to indicate how much they supported two policy initiatives (i.e., infrastructure spending and creation of National Election Day). Due to low inter-reliability $(\boldsymbol{\alpha}=.39)$, these two policy initiatives were analyzed separately. An initial 3 (Condition: Control, Partisan, Correction) x 3 (Partisanship strength: Weak partisans, Partisan, Strong partisans) between-subjects ANOVA on 
the infrastructure judgment indicated a main effect of partisanship $\left(\mathrm{F}(2,564)=3.02, \mathrm{p}=.049, \eta_{p}{ }^{2}\right.$ $=0.01)$, though not condition $(p=.11)$. Strong partisans were less in favor of the infrastructure plan than weak partisans $\left(M_{\text {diff }}=.27, p=.049\right)$. A regression model including lay theories, dummy-coded condition variables, and interactions indicated that neither condition nor lay theories influenced the endorsement of this policy proposal, and there were no significant interactions (all $p s>.14)$.

An alternative model including lay theories, dummy-coded condition variables, and acceptability (of policy judgments) revealed non-significant 3-way interactions ( $p s>.40$ ); these terms were dropped from the model. No significant interactions between lay theories, acceptability, and condition were observed (ps $>.06)$.

Policy judgments: National Election Day. All three models conducted for the infrastructure policy judgment were conducted for endorsement of National Election Day. None of these models produced a significant result $(p s>.08)$. Experimental condition, lay theories, and judgments of acceptability did not influence the degree to which participants endorsed this policy.

Judgments of guilt. Following policy judgments, participants were presented with a scenario in which they were asked to imagine being a jury member determining the guilt or innocence of a man on trial for assault and attempted murder. Because the internal reliability of judgments of assault and attempted murder was low $(\alpha=.15)$, regression analyses for these two dependent measures were conducted separately.

First, a 3 (Condition: Control, Partisan, Correction) x 3 (Partisanship strength: Weak partisans, Partisan, Strong partisans) x 2 (Within-subjects: Assault, Attempted murder) mixed- 
model ANOVA on judgments of guilt indicated a significant effect of condition $(F(2,566)=$ $\left.5.85, p=.003, \eta_{p}{ }^{2}=0.02\right)$, partisanship strength $\left(F(2,566)=4.01, p=.019, \eta_{p}{ }^{2}=0.01\right)$, and judgment type, $F(1,570)=690.59, p<.001, \eta_{p}{ }^{2}=0.55$. None of these factors significantly interacted $(p s>37)$. Overall, participants were more certain that the defendant was guilty of assault $(M=4.16)$ than attempted murder $(M=2.86)$. Strong partisans viewed the defendant as guiltier than weak partisans $\left(M_{\text {diff }}=0.28, p=.020\right)$ but not moderate partisans $\left(M_{\text {diff }}=0.17, p\right.$ $=.10)$. Additionally, participants in the Partisan induction condition viewed the defendant as guiltier than Control participants $\left(M_{\text {diff }}=0.30, p=.002\right.$; Figure 11), though not Correction participants $\left(M_{\text {diff }}=0.13, p=.034\right)$.

Assault. Next, a regression analyses including lay theories, dummy-coded condition variables, and interactions on judgments of assault revealed that participants in the Partisan induction condition gave higher overall ratings of guilt certainty than control participants $(t=$ $3.02, \beta=.15, p=.003)$. Additionally, the stronger participants' lay theories, the guiltier they viewed the defendant $(t=2.32, \beta=.17, p=.02)$. Interactions between lay theories and were nonsignificant $(p s>.18)$.

A second model including lay theories, dummy-coded condition variables, and acceptability (of guilt judgments) revealed that 3-way interactions were non-significant and were dropped from the model $(p s>.14)$. A main effect of lay theories $(t=2.18, \beta=.17, p=.03)$ and a significant 2-way interaction between views of acceptability and Control vs. Partisan conditions $(t=2.21, \beta=.10, p=.02)$. This interaction indicated that participants in the Partisan induction condition who viewed incorporating partisan information into their judgment as highly acceptable were more certain that the defendant was guilty of assault compared with Control 
participants with similar views of acceptability. Conversely, the interaction between acceptability and Control vs. Correction condition was non-significant $(t=-0.87, \beta=.00, p=.93)$, indicating that Correction participants gave roughly equivalent ratings as their peers in the Control condition; Correction participants with high views of acceptability nonetheless corrected their judgments when asked to do so (Figure 12).

Individual differences: Additional Analyses. Models including partisanship strength likewise indicated a main effect of lay theories $(t=2.38, \beta=.14, p=.04)$, and no significant 3 -way interactions between partisanship, lay theories and condition ( $\mathrm{p} s>.30)$. When dropped from the model, neither lay theories nor partisanship strength interaction with condition ( $p s>.07)$. In order to test the possibility that participants' motivation to correct their judgments could account for the relationship between lay theories can condition, a regression model analogous to those reported above was conducted. Motivation appears to qualify the relationship between lay theories and condition concerning ratings of guilt for assault: Lay theories are again significant as a main effect $(t=-1.82, \beta=-.15, p=.03)$, though this is qualified by both a significant 2 -way interaction between motivation and lay theories $(t=2.36, \beta=.19, p=.02)$, and a significant 3way interaction between motivation, lay theories, and Control vs. Partisan conditions $(t=-3.27$, $\beta=-.21, p=.001)$. Among participants in the Control condition, those with low motivation and expectation of a strong influence on their judgments gave lower ratings of guilt compared with low motivation participants with comparatively weak lay theories. Conversely, in the Partisan condition, those with low motivation who anticipated a strong influence on their judgments gave higher ratings of assault guilt compared to those with low motivation who anticipated a weaker influence on their judgments (Figure 13). 
Attempted murder. Regression analyses including lay theories, dummy-coded condition variables, and interactions indicated that lay theories did not influence judgments of guilt $p$ $=.27)$, nor did lay theories interaction with condition $(p s>.29)$. However, a second regression model including lay theories, acceptability, dummy-coded condition variables, and all interactions (2-way and 3-way) revealed no significant 3-way interactions (ps $>.74)$; these terms were dropped from the model. A significant 2-way interaction between views of acceptability and Control vs. Partisan induction conditions ( $t=4.56, \beta=.20, p<.001)$, while the 2-way interaction between acceptability and Control vs. Correction conditions was non-significant $(t$ $=0.02, \beta=.40, p=.69$ ). These analyses indicated that lay theories did not predict judgment correction for judgments of guilt. These results indicated participants in the Partisan induction condition who viewed incorporating partisan information into their judgments as highly acceptable were more certain that the defendant was guilty of attempted murder than Control participants with similar views. As with the assault judgment, Correction participants with views of high acceptability gave ratings that were not significantly higher than Control participants with similar views, thus indicating that they had corrected their judgments when instructed to do so (Figure 14).

Individual differences: Additional Analyses. As with judgments of assault, an additional regression model (analogous to those described earlier) including partisanship found no influence of either factor or significant interactions with condition or lay theories $(p s>.07)$. However, an exploratory model including motivation indicated significant 2-way interactions between lay theories and Control vs. Partisan conditions $(t=2.09, \beta=.09, p=.04)$ and lay theories and Control vs. Correction conditions $(t=1.94, \beta=.09, p=.05)$. These were qualified by a 
significant 3-way interaction between lay theories, motivation, and Control vs. Partisan conditions $(t=2.37, \beta=-.15, p=.02)$. For participants in the Control condition, judgments of guilt were not influenced by either motivation or lay theories. However, participants in the Partisan condition who were had low in motivation and anticipated a strong influence on their judgments gave significantly higher ratings of guilt compared to people low in motivation with weak lay theories (i.e., predicted little or no influence; Figure 15).

Bias perception. To aid clarity of interpretation, the scale (1 to 9$)$ for the following analyses were recoded, such that -4 indicated greater negative influence, 4 indicated greater positive influence, and 0 indicated no influence. First, a 3 (Control, Partisan, Correction) $\times 3$ (Weak partisan, Partisan, Strong partisan) between-subjects ANOVA was conducted to examine how much bias participants perceived in their quote evaluations. Results indicated main effects of both partisanship strength $\left(F(2,566)=9.13, p<.001, \eta_{p}{ }^{2}=0.03\right)$ and condition $(F(2,566)=$ $\left.21.10, p<.001, \eta_{p}{ }^{2}=0.07\right)$. These main effects were qualified by a significant interaction between these two variables $\left(F(4,566)=2.97, p<.001, \eta_{p}{ }^{2}=0.02\right)$. Simple effects tests indicated that this interaction was driven by no significant differences in bias perception based on partisanship for Control participants ( $p s<.93$ ), whereas there were significant effects involving partisanship in the other two conditions, with strong partisans perceiving the most bias. Within the Partisan condition, strong partisans $(M=-0.98)$ perceived more bias in their judgments than moderate partisans $(M=-0.46, p=.04)$ and weak partisans $(M=-0.22, p=.01)$; partisans did not perceive more bias than weak partisans $(p=.56)$. Within the Correction condition, strong partisans perceived more bias in their judgments $(M=-0.52)$ than weak partisans $(M=0.14, p$ 
$=.001)$; moderate partisans did not make significantly different judgments from either weak or strong partisans $(p s>.07)$.

Next, a similar between-subjects ANOVA was conducted on bias perception on judgments of guilt. Because Control participants were not exposed to political information for judgments of guilt (unlike quote judgments, in which they were presented with a control president), analyses for bias perception regarding judgments of guilt are only between the Partisan and Correction conditions. Results indicated that partisanship strength influenced perceived bias on judgments of guilt $\left(F(2,376)=3.03, p=.05, \eta_{p}{ }^{2}=0.02\right)$ as did condition $(F(2$, $376)=6.94, p=.01, \eta_{p}{ }^{2}=0.02$ ); Partisanship strength and condition also significantly interacted $\left(F(2,376)=4.49, p=.01, \eta_{p}{ }^{2}=0.02\right)$. Within the Partisan induction condition, strong partisans viewed their judgments as more biased than both moderate partisans $\left(M_{\text {diff }}=-.42, p=.027\right)$ and weak partisans $\left(M_{\text {diff }}=-.54, p=.017\right)$; moderate partisans did not view their judgments as more or less biased than weak partisans $\left(M_{\text {diff }}=-.12, p=.782\right)$. Conversely, the Correction condition bias perception was not influenced by partisanship strength ( $p s>.12)$. Reinforcing this, both moderate and strong partisans viewed their judgments as more biased in the Partisan induction condition than the Correction condition $\left(M_{\text {diff }}=-.26 p=.037 ; M_{\text {diff }}=-.61, p<.001\right.$, respectively). Weak partisans did not make different ratings between conditions, $p=.44$ (Figure 16).

Exposure to political information. Before being shown a second jury scenario and asked to indicate how certain they were that the defendant was guilty of assault and attempted murder (as in the first jury scenario), participants were given the option to either see the political views of the defendant or not. $28.5 \%$ of the sample $(n=109)$ chose to evaluate the jury scenario knowing the political views of the defendant, and this was not affected by their assignment to 
condition $\operatorname{Exp}(\beta)_{s}<.37, p>.73$ (Figure 17). This means that for correction participants, being asked to explicitly prevent the influence of political information on their prior judgments had no influence on whether they wished to see the political views on the defendant on a subsequent judgment. Similarly, a regression model including lay theories, dummy-coded condition variables, and interactions indicated that neither condition nor lay theories influenced whether people choose to view the irrelevant political information; there was no significant interaction between these variables $(p s>.13)$.

Regarding the actual judgments of guilt participants made in the second jury scenario, a regression analysis was conducted including lay theories, dummy-coded condition variables, informational choice (info. in vs. info. out), and interactions (2-way and 3-way). This model indicated that neither condition, lay theories, nor informational choice influenced judgments of assault (all ps $>.16)$.

When examining judgments of attempted murder with an analogous regression analysis, a nonsignificant main effect of lay theories $(t=1.84, \beta=.14, p=.07)$ was observed, though a significant interaction between lay theories and informational choice was observed, $t=-2.26, \beta=-.10, p$ $=.02$ (Figure 18). Those who anticipated a strong influence on their judgments who also chose the see the political views of the defendant judged him as guiltier than those who chose not to avoid the information (Figure 18), reinforcing the fact that viewing irrelevant political information has a profound influence on perceptions of guilt. All interactions (3-way and 2-way) with condition were non-significant in this model, $p s>0.44$. 


\section{Discussion}

Consistent with Pilot data, the present study identified that as partisanship strength increases, so does the expectation that partisan political information will influence one's judgments. Additionally, stronger lay theories and stronger partisanship were associated with believing that it is acceptable to incorporate partisan political information into judgments, despite that this information was irrelevant to the judgment at hand. Similar to lay theories, partisanship strength also predicted judgments of acceptability; strong partisans viewed it as more acceptable than weak partisans to incorporate such information into their judgments.

A straightforward takeaway is that people seem to possess a significant degree of awareness about their own propensity towards political bias, as well as awareness of bias in their judgments when it actually occurs. As predicted by the FCM (Wegener \& Petty 1995) participants engaged in theory-guided judgment correction, though only when evaluating the quotes. When explicitly asked to correct their judgments, participants who anticipated that their judgments would be influenced did so in line with their lay theories. Furthermore, participants with weak lay theories did not show evidence of being influenced in the first place, nor did they overcorrect their judgments. Although this judgment correction trended towards undercorrection, no significant difference was observed between Correction and Control participants, indicating that these participants had at least partially succeeded.

Regarding policy judgments, a lack of effect of condition, as well as non-significant interactions between condition and lay theories suggested that participants did not display bias when evaluating those proposals. However, for judgments of guilt, main effects of condition indicated that participants in the Partisan induction condition did view the defendant as guiltier 
than Control participants, though crucially not Correction participants, indicating that participants had corrected their judgments when asked to do so. Although there was no evidence that lay theories directly guided the apparent judgment correction for judgments of guilt, other factors such as motivation interacted with lay theories in such a way as to suggest that unmotivated individuals who anticipated being influenced by irrelevant political information were, indeed, influenced by this information. Moreover, analyses indicated that although lay theories did not guide judgment correction for judgments of guilt, views of acceptability did. Participants who viewed it as highly acceptable to incorporate partisan political information into their judgments nonetheless corrected their judgments when asked to do so. This highlight corroborates hypotheses that both lay theories and views of acceptability are crucial to the process of judgment correction, but highlights that these two factors may influence different types of judgments. Additionally, lay theories and views of acceptability do not appear to interact with each other, indicating that these two factors are not necessarily both required to be present in order for successful judgment correction to occur.

When participants were given the option to view or avoid viewing the political affiliation of the defendant on the second and final jury scenario about vehicular homicide, nearly one-third of participants chose to view irrelevant political information about the defendant when given the chance; prior assignment to condition and lay theories had no effect on peoples' desire to view this information. This choice had consequences for the perceived guilt of the defendant in that scenario: participants who anticipated a strong influence on their judgments who also chose to view this information viewed the defendant as guiltier of attempted murder relative to those who anticipated a strong influence on their judgments who chose not to know the defendant's political 
affiliation. Participants who anticipated no influence or a weak influence on their judgments were equally certain of the defendant's guilt, regardless of whether they viewed the information or not.

Wilson and Brekke (1994) identify that the most effective way to eliminate unwanted influences on judgments is to not allow oneself to see the irrelevant (or unwanted) information in the first place. Thus, it is consequential that, when given just such an opportunity, almost onethird of participants chose to view biasing information anyway. Given that many individuals predicted a strong influence on their judgments from irrelevant political information, many of those who elected to view this biasing information knew (or at least suspected) that this information would influence their judgments. This suggests that among a subset of participants, making judgment biased by irrelevant political information is intentional.

Moreover, judgments of bias perception indicated that the strongest partisans viewed their judgments as more biased than weak partisans, in conditions where they were exposed to political information. Indeed, these individuals' perceptions were correct: of all participants in the study, strong partisans produced judgments that were the most heavily influenced by the partisan information presented. Likewise, weak partisans accurately viewed themselves as making less biased judgments.

Although these data are insufficient to provide strong evidence towards addressing why strong partisans are willing to incorporate irrelevant partisan information into their judgments (both when the have the opportunity to choose to see this information, and when they are asked to not incorporate it), two pieces of information stand out. First, strong partisans also tended to indicate they were loyal to their preferred political party $(r=.33)$, indicating that support for 
one's political in-group is highly relevant when deciding what information to incorporate into one's judgment. Second, people (especially strong partisans) viewed the average member of their own political party as more able to prevent bias in their judgments than the average out-group political member (see Appendix). This suggests that although strong partisans view their own judgments as biased, they likely view political out-group members as significantly more biased, perhaps providing sufficient justification for one's own use of irrelevant information. 


\section{Overview}

\section{Study 2a}

Study 2a was designed to replicate and extend findings of Study 1 and addressed two main issues with the previous study. First, the design of Study 1 only presented participants with irrelevant political information of out-group members - democrats only judged Republicans and visa-versa. This resulted in political bias only being examined in a between-subjects manner. A stronger argument could be made if partisan political bias occurs in a within-subjects fashion as well — that is, if participants give higher approval ratings for quotes said by in-group vs. outgroup political figures. Thus, Study 2 a adapted the quote judgments from Study 1 and presented five from an in-group politician, and five from an out-group politician. Second, Study 2a examined a more age-diverse sample, because participants of Study 1 were University students predominantly between the ages of 18 and 22; this may have skewed perspectives of participants in a number of ways. Additionally, Study 2a measured lay theories immediately before the beginning of the study, as opposed to weeks in advance as in Study 1. Despite the potential concern that measuring lay theories immediately prior to a study may prompt spontaneous judgment correction, other recent work (Baker \& Scherer, in revision) has found that making lay theories highly accessible immediately prior to the study does not result in spontaneous judgment correction for those who anticipate being influenced. Finally, due to concerns over the length of the study in an online format, only quote evaluations were included as a dependent measure, and many individual difference measures from Study 1 were dropped.

\section{Methods}

Participants. A power analysis $(\alpha=.05,1-\beta=.2)$ based on the observed mean for the difference between Control and Partisan induction conditions for quote judgments in Study 1 
$\left(M_{\text {diff }}=.20\right)$ suggested that a minimum sample size of $n=109$. However, a minimum sample of $n$ $=125$ was sought to account for possible attrition. A final sample size of $N=379$ was acquired, providing sufficient statistical power for planned regression analyses.

Design/procedure. Study 2a was designed to be completed in approximately 10 minutes by online participants. After giving consent, participants were immediately asked to provide their lay theories about how they anticipated partisan information would influence their approval of a quote. Participants were then asked for their partisan leanings as in Study 1. Following this, participants were randomly assigned to either the Control, Partisan induction, or Correction conditions as in Study 1 before being presented with the main dependent variables: quote evaluations.

Participants were asked to evaluate five quotes ostensibly said by an in-group politician and five quotes by an out-group politician; the order of presentation for these quotes was counter-balanced. For Control participants, the Democratic politician was Woodrow Wilson, and the Republican politician was Warren Harding, as in Study 1. Unlike Study 1, no other dependent measures were presented following quote evaluations. Participants then answered a few brief individual difference measures before being asked demographic information. Participants were then debriefed and thanked.

Materials/measures. Nearly all materials and measures were taken directly from Study 1, though two new measures were presented. In addition to policy judgments and judgments of guilt being omitted, several individual difference measures were omitted as well. These included NFC, FI, views of rationality, and all measures of cognitive ability. These measures were omitted 
both to make the survey shorter, and because they were found to be unrelated to lay theories and the judgment correction process.

Three new measures were presented; the first of these assessed participants' general political knowledge with five items adapted from previous research (Carpini \& Keeter, 1993). Each item was presented as a True/False statement, with possible scores ranging from 0-5. Items included "Mike Pence is the sitting U.S. President" and "The U.S. Senate is currently run by the Democratic Party". Second, the 4-item scale measuring motivation was heavily altered, given the scale used in Study 1 had poor inter-reliability. Items were tailored to more closely assess motivation to make unbiased judgments of a political nature (e.g., When it comes to politics, making objective judgments, even if they go against my core beliefs, is the right thing to do). Finally, near the end of the study, participants were presented with an open-ended question as to their thoughts regarding how political information did (or did not) bias their judgments. This was included both to gain exploratory insight into how people consider their own propensity to make biased judgments, as well as a way to catch responses from bots in the online sample.

\section{Results}

Lay Theories. After collapsing the measure of lay theories from a 1(Would make my judgments much more negative), 5 (Would not influence my judgments), to 9 (Would make my judgments much more positive) scale into an absolute value scale ranging from 0 (No influence predicted) to 4 (Strong influence predicted), results indicated (18.4\%) of participants anticipated that their judgments of the quotes would not be influenced by the fact that they were said by either Trump or Obama. Approximately $15.0 \%$ of participants anticipated a weak influence, $27.1 \%$ a moderate influence, and $39.5 \%$ predicted a strong influence. An ANOVA comparing 
participants based on their partisanship strength identified that, as in Study 1, partisanship strength was a strong predictor of lay theories, $F(2,371)=39.29, \mathrm{p}<.001, \eta_{p}{ }^{2}=.18$. Strong partisans (i.e., Strong Democrats and Strong Republicans) anticipated a greater influence on their judgments than both moderate partisans (Democrats and Republicans) $\left(\mathrm{M}_{\mathrm{diff}}=0.69, p<.001\right)$ and weak partisans (independents leaning either towards Democrats or Republicans; $\mathrm{M}_{\mathrm{diff}}=1.25, p$ $<.001)$. Moderate partisans also anticipated greater influence compared to weak partisans $\left(\mathrm{M}_{\mathrm{diff}}=\right.$ $0.56, p=.001)$. Because partisanship was again found to be highly relevant to lay theories, this factor was included in regression models discussed below.

Judgments of Acceptability. A 3 (Control, Induction, Correction) $\times 3$ (Weak partisans, Partisans, Strong partisans) ANOVA was conducted to determine whether either condition or partisanship strength predicted judgments of acceptability. The main effect of condition as well as the interaction between condition and partisanship strength were non-significant in this model (ps > .43). However, partisanship strength was a significant predictor, $F(2,370)=6.79, p=.001$, $\eta_{p}{ }^{2}=.04$. As in Study 1, relative to weak partisans, strong partisans believed it was more acceptable to allow the identity of the speaker to influence one's quote ratings $\left(\mathrm{M}_{\mathrm{diff}}=0.49, p\right.$ $=.001)$.

Manipulation Check. A 3 (Control, Induction, Correction) $\times 2$ (Democratic vs. Republican participants) x 2 (In-group ratings vs. Out-group ratings) mixed-model ANOVA was conducted to examine if participants who had been asked to correct their judgments did so relative to participants in other conditions (i.e., "did you try to prevent the political information you were exposed to from influencing your judgments"). Democrats were compared to Republicans in this analysis because these two groups of participants evaluated the same quotes 
under the same of different politicians. Results indicated a main effect of condition $(F(2,373)=$ $37.53, p<.001)$ that was qualified by a significant 2 -way interaction between condition and political affiliation $(F(2,373)=3.78, p=.024)$, though other two-way interactions in the model were non-significant $(p s>.15)$. This 2-way interaction was, in turn, qualified by a significant 3way interaction between condition, political affiliation, and reported prevention of in-group vs. out-group quote ratings $(F(2,373)=4.36, p=.014)$.

Simple effects tests indicated that the 3-way interaction was driven primarily by differences between conditions, both when preventing influence for quotes of in-group presidents $\left(F(2,245)=39.70, p<.001, \eta_{p}{ }^{2}=.25\right)$ and out-group presidents $\left(F(2,245)=49.91, p<.001, \eta_{p}{ }^{2}\right.$ $=.29$ ). For both of these judgments, Correction participants tried harder to prevent an influence on their judgments than both Induction $\left(\mathrm{M}_{\text {diff }}=1.27, p<.001 ; \mathrm{M}_{\text {diff }}=1.23, p<.001\right.$, respectively $)$ and Control conditions $\left(\mathrm{M}_{\mathrm{diff}}=2.37, p<.001 ; \mathrm{M}_{\mathrm{diff}}=2.52, p<.001\right.$, respectively $)$. Induction participants also reported trying harder to correct their judgments than control participants $\left(\mathrm{M}_{\text {diff }}=1.10, p<.001 ; \mathrm{M}_{\text {diff }}=1.29, p<.001\right.$, respectively $)$, which is seemingly at odds with the fact that Induction participants displayed the most bias in their judgments and reported being aware of this relative to Correction and Control participants.

In addition, differences were pronounced between Democrats and Republicans, primarily in the correction condition. Democrats asked to correct their judgment reported doing so at higher rates than conservatives both for quotes of in-group presidents $\left(M_{\text {diff }}=0.65, p=.03\right)$ and out-group presidents $\left(M_{\text {diff }}=0.61, p=.03\right)$. However, Republican in the induction condition $\left(M_{\text {diff }}=0.59, p=.06\right)$ as well as the control condition $\left(M_{\text {diff }}=0.62, p=.08\right)$ reported trying somewhat harder to correct for the influence of their in-group president (i.e., Trump) compared 
to their democratic peers (i.e., Obama). These results indicate that correction participants tried harder to correct their judgments overall and that this effect was most pronounced in the correction condition (Figure 21).

Correlates with lay theories. Similar to Study 1 , partisanship strength $(r=.42, p<.001)$, political loyalty $(r=.25, p<.001)$, and political affiliation $(r=-.18, p<.001)$ were all significantly correlated with lay theories. Motivation (aggregate measure from revised 4-item measure) was similarly correlated motivation $(r=-.14, p<.001)$, though general political knowledge was uncorrelated with lay theories $(r=.08, p=.11)$.

Quote Judgments. A 3 (Condition: Control, Induction, Correction) $\times 2$ (Political affiliation: Democrats vs. Republican) x 2 (Target political affiliation: In-group ratings vs. Outgroup ratings) mixed-model repeated measures ANOVA was conducted to examine if participants' quote judgments were biased by the name of the speaker (i.e., higher approval ratings for in-group vs. out-group political quotes). Political affiliation was dichotomized in analyzes due to the fact that both Democrats and Democratic-leaning participants judged the same in-group/out-group presidents; these were always the opposite of Republican and Republican-leaning participants.

Results indicated that participants did indeed give more favorable ratings for quotes attributed to in-group politicians relative to out-group politicians $\left(M_{\text {diff }}=0.36 ; F(1,374)=57.96\right.$, $\left.p<.001, \eta_{p}{ }^{2}=.13\right)$. A significant main effect of political affiliation $(\mathrm{F}(1,374)=11.93, \mathrm{p}=.001$, $\left.\eta_{p}{ }^{2}=.03\right)$ indicated this difference was most pronounced for Democratic and democratic-leaning participants $\left(M_{\text {diff }}=0.49\right)$ compared with Republican and Republican-leaning participants, $M_{\text {diff }}=$ 0.22. A significant interaction between condition and target political affiliation $(F(1,374)=6.32$, 
$\left.p=.002, \eta_{p}{ }^{2}=.29\right)$ indicated that the aforementioned preference for in-group politicians over out-group politicians was observed in the Partisan induction $\left(M_{\text {diff }}=.55\right)$ and Correction $\left(M_{\text {diff }}=\right.$ $0.38)$ conditions, though not the Control condition $\left(M_{\text {diff }}=0.15\right)$.

As in Study 1, a regression model including lay theories, dummy-coded condition variables, and their interactions was conducted with the difference score between in-group and out-group quote ratings as the dependent variable. Results indicated a significant interaction between lay theories and Control vs. Partisan induction conditions $(t=3.10, \beta=.35, p=.002)$. This interaction indicated that Partisan participants with stronger lay theories displayed greater bias relative to participants with similar lay theories in the Control condition. Conversely, participants who anticipated a weak influence on their judgments in both the Partisan induction and Control conditions evaluated quotes said by in-group and out-group politicians equivalently; as can be seen in Figure 23, participants who anticipated a weak influence on their judgments in all three conditions made no distinction between ratings for quotes said by in-group and outgroup politicians. Crucially, the interaction between lay theories and Control vs. Correction conditions was non-significant $(t=0.63, \beta=.07, p=.53$ ), indicating that Control and Correction participants made approximately similar ratings, regardless of their lay theories. This provides the strongest evidence yet that those with stronger lay theories who are explicitly asked to correct their judgments do so in line with their lay theories, as predicted by the FCM.

To examine if judgments of acceptability influenced judgment correction for quote evaluations, a second model including lay theories, dummy-coded condition variables, judgments of acceptability, and interactions between these variables was conducted. Results indicated there were no significant effects of acceptability in the model (all $p s>.28$ ), and the key 
interaction between lay theories and Control vs. Partisan conditions remained significant $(t=$ $2.91, \beta=.35, p=.004)$, demonstrating that judgments of acceptability neither predicted quote ratings nor influenced the relationship between lay theories and correction instructions.

Individual differences: Alternative analyses. In an effort to identify if any other individual difference measures might plausibly account for the relationship between lay theories and instructions to correct one's judgments, exploratory regression analyses were conducted. Each model included lay theories, dummy-coded condition variables, and one of five variables (partisanship strength, political loyalty, motivation, and general political knowledge) in addition to all 2-way and 3-way interactions. First, the model including partisanship revealed a significant interaction between lay theories and Control vs. Partisan conditions $(t=2.90, \beta=.36, p=.004)$, though partisanship did not interact with either lay theories or condition at any level ( $p s>.09)$.

Next, the model examining political loyalty indicated that this did not interact with either lay theories or condition, nor was it predictive of quote judgments as a main effect $(p s>.14)$. Notably, in this model the key interaction between lay theories and Control vs. Partisan condition remained significant $(\mathrm{t}=2.98, \beta=.34, \mathrm{p}=.003)$. In the model examining motivation, a significant interaction between lay theories and Control vs. Partisan conditions was observed $(t=$ $-4.10, \beta=-.20, p<.001)$, thought motivation did not interact with condition ( $p s>.61)$, nor predicted quote ratings as a significant main effect $(p=.97)$. The key interaction between lay theories and Control vs. Partisan conditions remains significant in this model $(\mathrm{t}=2.73, \beta=.31, \mathrm{p}$ $=.007$ ) indicating that, although motivated individuals are more likely to display less bias overall, they are not necessarily more likely to correct their judgments. 
Finally, when examining general political knowledge, a significant 3-way interaction between lay theories, political knowledge, and control vs. induction conditions $(t=2.37, \beta=.15$, $p=.02)$ qualified the 2-way interaction between lay theories and control vs. induction condition $(t$ $=3.21, \beta=.37, p<.001)$. This interaction indicated that Partisan induction participants with stronger lay theories gave biased ratings regardless of their level of political knowledge, relative to Partisan participants who anticipated a weak influence on their judgments, who only gave biased ratings if they were lower in political knowledge. Conversely, Correction participants who predicted a strong influence on their judgments gave the most biased estimates if they were lower in political knowledge; those predicted a strong influence on their judgments who were also higher in political knowledge corrected their judgments, as instructed, and gave ratings similar to the peers in the Correction condition who anticipated a weak influence on their judgments from irrelevant political information.

Bias Perception. A 3 (Condition: Control, Induction, Correction) $\times 3$ (Partisanship strength: Weak Partisan, Partisan, Strong partisan) x 2 (Target speaker: Obama vs. Trump) mixed-model ANOVA was conducted to examine the extent to which condition and partisanship strength influenced bias perception. A main effect of target speaker indicated that participants viewed their judgments as more biased when the quotes were said by in-group president $(M=$ $0.61)$ relative to out-group presidents $(M=.08 ; F(1,371)=27.50, p<.001)$. Additionally, a main effect of partisanship $(F(2,371)=20.75, p<.001)$ indicated that strong partisans viewed their judgments as more biased than both partisans $\left(M_{\text {diff }}=.49, p<.001\right)$ and weak partisans $\left(M_{\text {diff }}\right.$ $=.78, p<.001)$. A significant 2 -way interaction between bias perception and condition $(F(2,371)$ $=12.15, p<.001)$ was driven primarily by participants in the Partisan induction and Correction 
conditions. Simple effects tests revealed that Partisan induction participants viewed their quote judgments from in-group presidents as significantly more biased than their judgments of outgroup presidents $\left(M_{d i f f}=1.17 ; p<.001\right)$, as did correction participants $\left(M_{d i f f}=0.43 ; t=3.19, p\right.$ $<.001)$.

Although revealing, an alternative model replacing political partisanship with participant political affiliation was conducted to examine if participants of a particular political party, and not their partisanship strength per se, was responsible for perceptions of bias in their own judgments. A 3 (Condition: Control, Partisan, Correction) $\times 2$ (Participant political affiliation: Democrat vs. Republican) x 2 (Target political affiliation: In-group vs. Out-group) mixed-model ANOVA indicated that political affiliation was the more potent predictor. Both political affiliation $(F(2,374)=15.27, p<.001)$ and in-group vs. out-group ratings $(F(2,374)=14.48, p$ $<.001)$ were significant main effects, though these were qualified by a significant 3-way interaction between condition, political affiliation, and target speaker $(F(2,374)=21.57, p$ $<.001)$, a significant 2-way interaction between condition and target speaker $(F(2,374)=5.59, p$ $=.004)$, and a significant 2 -way interaction between political affiliation and target speaker $(F(2$, $374)=35.69, p<.001)$.

Simple effects tests indicated that among control participants, Republicans viewed their judgments as more biased than Democrats, but only when estimating bias on judgments in which Woodrow Wilson was the speaker $\left(M_{\text {diff }}=0.50, p<.001\right)$, and not for judgments in which Warren Harding was the speaker $\left(M_{d i f f}=0.16, p=.48\right)$. For participants in the Partisan condition, Democrats perceived more bias than Republicans on judgments in which Obama was the speaker $\left(M_{\text {diff }}=0.67, p=.03\right)$, and Republicans perceived more bias in their judgments in which Trump 
was the speaker, $M_{\text {diff }}=1.97, p<.001$. Finally, Democrats and Republicans in the Correction condition viewed their judgments in which Obama was the speaker as equally biased ( $M_{\text {diff }}=$ $0.18, p=.44)$. However, Republicans viewed their judgments in which Trump was the speaker as more biased than Democrats $\left(M_{d i f f}=0.86, p=.001\right)$. These results indicate that both Democrats and Republicans displayed considerable self-awareness with regard to how their judgments had been influenced. Participants in the Partisan induction condition anticipated a positive influence when they were evaluating quotes said by their in-group president, and a less positive (or negative) influence when evaluating quotes said by their out-group president. Bias estimations were reduced for all participants in the correction condition, reflecting that participants in this condition were, indeed, less biased than their peers in the Partisan induction condition.

\section{Discussion}

Study 2a extended Study 1 in three key ways. First, by collecting a non-student sample, we were able to test hypotheses outside a context limited to very young adults at University. Second, Study 2a measured lay theories immediately before the beginning of the study, providing a stronger test of the FCM, allowing us to examine how lay theories influence judgment correction when they are highly available. Additionally, this approach allowed us to test assumptions made in previous research (DeSteno et al., 2000) that participants who anticipate that they will be influenced and are motivated to make unbiased judgments will spontaneously correct their judgments. Third, and most importantly, Study 2a assessed bias in a within-subjects fashion. This allowed for stronger claims about predictors of bias, because bias was assessed within individuals rather than inferred from group level differences. 
As in Study 1, results indicated that as partisanship strength increased, so did the magnitude of the predicted influence. Strong partisans anticipated that their judgments of a quote would be much more strongly influenced by the speaker (i.e., Trump or Obama) relative to moderate partisans and weak partisans. Similarly, strong participants also viewed allowing the name of the speaker to influence their evaluation of a quote as more acceptable than weak partisans.

As anticipated, participants exposed to relevant political figures (i.e., Trump and Obama) who "said" the quotes they were judging made more favorable ratings for quotes attributed to ingroup political figure than quotes said by their out-group political figure. In other words, participants made biased estimates - they were not merely evaluating the content of the quotes themselves but also the person who allegedly said the quote. However, participants were able to make unbiased judgments but only if they were explicitly asked to do so. As in Study 1, participants in the Correction condition who anticipated that their judgments would be strongly influenced by the name of the speaker corrected their judgments in line with their lay theories.

Contrary to findings from Study 1, views of acceptability did not influence judgment correction. This suggests that views of acceptability may be more pertinent information when lay theories are less accessible (i.e., measured weeks in advance). Thus, Study 2a provided further evidence for the FCM: participants used their lay theories as a guide for correcting their judgments, at least when lay theories are highly accessible and when they are explicitly asked to correct their judgments. Even for participants who a) anticipate that their judgments will be influenced, b) find it unacceptable to evaluate a quote based on the name of the speaker and c) are motivated to make unbiased judgments, no spontaneous judgment correction was observed. 
Judgment correction is only observed when participants are given explicit instructions to do so, indicating that whether or not participants correct their judgments is not so much a matter of if they can, but if they will. Moreover, this study provided the strongest evidence yet that some factors (e.g., motivation) may not be required per se for successful judgment correction to take place, counter to predictions made by the MCM (Wilson \& Brekke, 1994) and the FCM (Wegener \& Petty, 1997).

Finally, although partisanship did predict bias perception, political affiliation proved to be a much stronger predictor, almost certainly because partisans were presented with both in-group and out-group quote evaluations, setting the stage for predictable between-party differences in bias perception. Democratic and Democratic-leaning participants correctly identified that their judgments had been positively influenced by their in-group politician (i.e., Obama) and negatively influenced by a political they did not like (i.e., Trump). Although Republicans viewed their evaluations of Obama's statements as mildly positive, they viewed their judgments of Trump's statements as much more positive. These results indicate that both Democrats and Republicans have a considerable degree of awareness into whether (and to what extent) their own judgments had been biased by the name of the speaker. This is surprising, given the lack of evidence that people are aware of their cognitive biases, such as the halo effect (Geurin \& Innes, 1981; Wetzel, Wilson, \& Kort, 1981). 


\section{Overview}

\section{Study $2 b$}

First, Study $2 \mathrm{~b}$ endeavored to replicate findings after addressing flaws in the design of Study 1. First, a more appropriate measure of lay theories (i.e., directly measuring anticipated influence of irrelevant political information on judgments of guilt in a jury context) was employed. Second, Study $2 \mathrm{~b}$ examined judgments of guilt without also including quote evaluations. In Study 1, these dependent measures were always presented after quote evaluations, opening the possibility that order effects were responsible for the lack of clear theory-guided correction observed for judgments of guilt in Study 1. Thus, Study $2 b$ omitted other dependent measures. Finally, Study $2 \mathrm{~b}$ replicated the basic design of Study 1 in an online sample in order to address limitations arising from the use of a University sample.

\section{Methods}

Participants. 385 participants from Amazon's Mechanical Turk participated in this study in exchange for $\$ 1$. A power analysis conducted before the beginning of the study $(\alpha=.05,1-\beta$ $=.2$ ) based on the effects observed between control and induction conditions for judgments of assault in Study $1\left(M_{\text {diff }}=0.36, S D=.95\right)$ suggested that a minimum sample size of $n=109$. However, a higher minimum sample $(n=125)$ was sought to ensure adequate power in the event of attrition. Eight participants were removed for failing all attention check items, leaving a final sample size of $N=377$.

Design/procedure/materials. The design and materials were highly similar to both Study 1 and Study 2a, and details on materials can be revisited there. Participants first indicated their lay theories—or how they anticipated that their judgments of guilt in a jury scenario would be influenced by their knowledge of the defendant's political views. Participants were asked to 
imagine that they were judging an extreme right-wing conservative (left-wing liberal) accused of serious crimes, and how they thought their judgments would be influenced by the political information compared to not knowing their political views. Participants indicated their lay theories on a scale ranging from 1 (make me think they were much less guilty) to 5 (would not influence my judgment) to 9 (make me think they were much more guilty).

Participants were then asked to indicate their political affiliation before being randomly assigned to condition (Control, Partisan induction, Correction) and presented with the first jury scenario. As in Study 1, all participants were presented with a defendant on trial for assault and attempted murder whose political views disagreed with their own (based on their self-reported political affiliation). Participants were then offered a choice before seeing the second jury scenario: They could either see what the defendant's political views were or not; for those who chose to see the information, they were again presented with a defendant whose political affiliation disagreed with their won. After choosing, participants were presented with the scenario and asked to judge the likelihood that they were guilty of the crimes they were on trial for.

Following this, participants were asked the extent to which they perceived bias in their judgments, how hard they had tried to prevent their judgments from being biased, how acceptable it was to allow irrelevant political information to influence their judgments, and how internally motivated they were to make unbiased judgments. Three revised items were used to assess views of acceptability: participants were asked how acceptable it was for their judgments to be influenced by a defendant's liberal political views, a defendant's conservative political 
views, and finally a how acceptable it was in general to allow political information to influence how guilty they judged someone to be.

Participants were then given individual differences measures to assess their loyalty to their political party, general political knowledge, and tendency to respond in a socially desirable fashion as these were factors hypothesized to be relevant to the process of judgment correction, based on results from Study 1. Finally, participants answered the same demographic questions as in previous studies before being thanked and debriefed.

\section{Results}

Lay theories. After converting measures of lay theories to an absolute value scale ranging from 0 (no influence predicted) to 4 (strong influence predicted), results indicated $49.9 \%$ of participants anticipated that their judgments of guilt would not be influenced by the fact that the defendant was a member of an out-group political party. Approximately $20.9 \%$ of participants anticipated a weak influence from knowing the name of the speaker, $14.3 \%$ a moderate influence, and $14.8 \%$ predicted a strong influence. An ANOVA comparing participants based on their partisanship strength identified that, as in Study 1, partisanship strength was a strong predictor of lay theories, $F(2,367)=39.29, p<.001, \eta_{p}{ }^{2}=.18$. Strong partisans anticipated a greater influence on their judgments than both partisans $\left(M_{\text {diff }}=0.83, p<.001\right)$ and weak partisans $\left(M_{\text {diff }}=0.80, p<.001\right)$. Partisans did not, however, anticipate greater influence than weak partisans $\left(M_{\text {diff }}=0.03, p=.98\right)$. As in all previous studies, partisanship strength was thus highly relevant to lay theories; this factor was included in regression models discussed below. 
Correlates with lay theories. Of the individual difference measures included, judgments of acceptability were the most strongly correlated $(r=.66, p<.001$, with political loyalty $(r$ $=.43, p<.001)$ and partisanship strength $(r=.30, \mathrm{p}<.001)$ also being strongly associated. Similar to Study 1, although partisanship strength and political loyalty were themselves highly associated $(r=.41, \mathrm{p}<.001)$, they appeared to be distinct constructs. Both political knowledge $(r$ $=-.25, p<.001)$ and internal motivation $(r=-.26, p<.001)$ were negatively correlated, indicating that those who anticipated a strong influence on their judgments were also less likely to be motivated to make unbiased judgments or possess basic political knowledge. Political orientation was only weakly correlated with lay theories $(r=.14, p=.01)$.

Judgments of Acceptability. A 3 (Condition: Control, Induction, Correction) $\times 3$ (Partisanship strength: Weak partisans, Partisans, Strong partisans) ANOVA was conducted to see if either condition or partisanship strength predicted judgments of acceptability. Both the interaction between condition and partisanship strength and the main effect of condition were non-significant in this model ( $p s>.08)$. However, partisanship strength was a significant predictor, $F(2,370)=21.46, p<.001, \eta_{p}{ }^{2}=.11$. Strong partisans viewed allowing the identity of the speaker to influence one's quote ratings as more acceptable relative to both partisans $\left(\mathrm{M}_{\mathrm{diff}}=\right.$ $1.00, p<.001)$ and weak partisans $\left(\mathrm{M}_{\mathrm{diff}}=0.89, p<.001\right)$; partisans and weak partisans gave roughly equivalent ratings of acceptability $\left(\mathrm{M}_{\mathrm{diff}}=0.10, p=.84\right)$.

Manipulation Check. A 3 (Condition: Control, Induction, Correction) $\times 3$ (Partisanship strength: Weak partisan, Moderate partisan, Strong partisan) ANOVA indicated that, when participants were asked if they had tried to prevent political information from influencing their judgments, Condition influenced how hard people tried, as anticipated $(F(2,373)=9.69, p$ 
$\left.<.001, \eta_{p}{ }^{2}=.05\right)$. However, partisanship strength $\operatorname{did} \operatorname{not}(F(2,366)=0.68, p=.509)$, nor did partisanship and Condition interact in this model $(p=.83)$. Similarly, a 3 (Condition: Control, Induction, Correction) $\times 2$ (Partisan Political affiliation: Democrats vs. Republican) ANOVA indicated a main effect of condition $\left(F(2,373)=9.69, p<.001, \eta_{p}{ }^{2}=.05\right)$, such that Correction participants gave higher ratings than both Partisan induction $\left(M_{\text {diff }}=0.89, p<.001\right)$ and Control participants $\left.M_{\text {diff }}=0.89, p=.01\right)$. There was no influence from political affiliation; Democrats and Republicans gave roughly equivalent ratings, and political affiliation did not interact with condition $(p s>.61)$.

Judgments of guilt. An analysis of inter-reliability indicated that judgments of assault and attempted murder were sufficiently (if weakly) associated $(\mathrm{a}=.72)$, and were combined into an aggregate measure of guilt. A 3 (Condition: Control, Induction, Correction) $\times 3$ (Partisanship strength: Weak partisans, Partisans, Strong partisans) ANOVA indicated that a significant main effect of condition $\left(F(2,367)=8.92, p<.001, \eta_{p}{ }^{2}=.05\right)$ as well as a significant main effect of partisanship was observed, $F(2,367)=16.14, p<.001, \eta_{p}{ }^{2}=.08$ (Figure 29). However, condition and partisanship did not interact $(p=.838)$. Strong partisans judged the defendant as guiltier than both partisans $\left(M_{\text {diff }}=0.473, p<.001\right)$ and weak partisans $\left(M_{\text {diff }}=0.46, p=.002\right)$; partisans did not judge the defendant as guiltier than weak partisans $\left(M_{\text {diff }}=-0.27, p=.13\right)$.

A regression analysis included lay theories and dummy-coded condition variables indicated a main effect of lay theories $(t=4.02, \beta=.32, p<.001)$ as well as a non-significant interaction between lay theories and Control vs. Correction conditions, $t=1.87, \beta=.12, p=.06$. Although non-significant, it is important to point out that the trend is in the opposite predicted direction; participants asked to correct their judgments who also anticipated a strong influence on 
their judgments were more influenced by the irrelevant political information, relative to Control participants with similar lay theories.

In line with predictions regarding acceptability, an alternative model was constructed including judgments of lay theories, acceptability, and dummy-coded condition variables. Results indicated a significant effect of acceptability $(t=6.35, \beta=.48, p<.001)$, such that those who viewed incorporating irrelevant partisan information into their judgment as acceptable were more certain that the defendant was guilty. Additionally, lay theories and views of acceptability significant interacted; participants who viewed incorporating irrelevant partisan information into their judgments as highly acceptable, and who had stronger lay theories, were more certain of the defendant's guilt compared with participants with weak lay theories and lower views of acceptability. However, neither of these variables interacted with condition, indicating that neither was predictive of judgment correction $(p s>0.065)$.

Individual differences: Alternative analyses. As in Study 2a, exploratory regression analyses were conducted to examine if other variables (i.e., partisanship strength, political loyalty, political knowledge, motivation) could account for the reported judgment correction. First, the model including partisanship strength found a significant interaction between partisanship and lay theories $(t=-2.63, \beta=.40, p=.01)$, as well as a significant interaction between lay theories and Control. vs. Correction conditions $(t=2.11, \beta=.14, p=.04)$. There were no other significant effects in the model ( $p s>.14)$.

Next, the model examining political loyalty, lay theories, dummy-coded condition variables, and their interactions indicated a main effect of Control vs. Induction conditions $(t=$ $4.34, \beta=.24, p<.001)$ and political loyalty $(t=2.00, \beta=.16, p=.05)$. The higher the loyalty to 
one's political party, the guiltier the defendant was judged to be. This main effect was qualified by significant interactions between loyalty and Control vs. Induction conditions $(t=2.17, \beta$ $=.14, p=.03)$ and loyalty and Control vs. Correction conditions $(t=2.67, \beta=.17, p=.008)$. More loyal participants, in both the Induction and Correction conditions, found the defendant guiltier than their loyal peers in the control condition. Conversely, less loyal participants in the correction condition judged the defendant as less guilty than Control participants with similar levels of loyalty, suggesting that less loyal participants asked to correct their judgments may have driven the observed judgment correction discussed above (Figure 31).

A model including lay theories, political knowledge, dummy-coded condition variables, and all interactions (2-way and 3-way) was conducted. Political knowledge was not a significant predictor for any of the models ( $p s>.82$ ), indicating that the extent to which participants were familiar with basic political facts had little bearing on certain they were of the defendant's guilt. Lay theories remained a significant main effect in this model $(t=3.75, \beta=.30, p<.001)$, though lay theories did not interact with condition ( $p s>.14$ ), indicating that political knowledge may attenuate the relationship between lay theories and condition.

Finally, a model including lay theories, motivation, dummy-coded condition variables, and interactions indicated that motivation was non-significant at all levels $(p s>.08)$. As in previous models, lay theories were significant as a main effect $(t=3.50, \beta=.28, p=.001)$, and the interaction between lay theories and Control vs. Correction condition was significant ( $t=$ $2.15, \beta=.15, p=.03$ ), indicating that motivation did not account for the relationship between lay theories and instructions to correct judgments. 
Exposure to political information. As in Study 1, nearly one-third (32.1\%) of

participants chose to view the political views of the defendant, despite being explicitly reminded that the crimes of which the defendant is accused have nothing to do with politics. Furthermore, the binary logistic regression analyses indicate that the condition participants had been assigned to had no bearing on whether or not they wished to see the irrelevant political information, $\operatorname{Exp}(\beta)_{s}<0.85$ (Figure 32).

A 3 (Condition: Control, Induction, Correction) $\times 3$ (Partisanship strength: Weak partisan, Partisan, Strong partisan) x 2 (Choice: Political info. In vs. Political info. Out) between-subjects ANOVA indicated main effects of both informational choice $\left(F(1,358)=23.18, p<.001, \eta_{p}^{2}\right.$ $=.06)$ and partisanship strength $\left(F(2,367)=3.78, p=.02, \eta_{p}{ }^{2}=.02\right)$, though the interaction between these two factors was not significant $\left(F(2,358)=2.52, p=.08, \eta_{p}{ }^{2}=.01\right)$. Strong partisans judged the defendant as guiltier than both partisan $\left(M_{\text {diff }}=0.60, p=.001\right)$ and weak partisans $\left(M_{\text {diff }}=0.50, p=.01\right)$; partisans did not, however, judge the defendant as guiltier than weak partisans $\left(M_{\text {diff }}=-0.09, p=.86\right)$. Those who saw the irrelevant political information judged the defendant as guiltier than those who chose not to see this information $\left(M_{\text {diff }}=0.77, p<.001\right)$. Condition and all other interactions between these three variables were non-significant ( $p s$ $>.14)$.

A regression analysis including lay theories, dummy-coded condition variables, choice (i.e., Political info. In vs. Political info. Out), and their interactions revealed no significant interactions in the model (2-way or 3-way; $p s>.17)$. When all interaction terms were removed from the model, main effects of both lay theories $(t=3.81, \beta=.21, p<.001)$ and choice $(t=$ $4.15, \beta<-.22, p<.001)$ were evident. Participants with who anticipated a strong influence on 
their judgments, as well as those exposed to irrelevant political information, judged the defendant in the second scenario as guiltier. Alternative models replacing lay theories with acceptability and political loyalty likewise revealed no significant interactions ( $p s>.07)$, though both acceptability $(t=3.81, \beta=.21, p<.001)$ and political loyalty $(t=4.01, \beta=.21, p<.001)$ were significant main effects in their respective models. Similarly, political affiliation, political knowledge, and motivation were not significant predictors of how guilty the defendant was perceived to be, $p s>.09$ (Figure 33).

Bias perception. A 3 (Condition: Control, Induction, Correction) $\times 3$ (Partisanship strength: Weak partisans, Partisans, Strong partisans) ANOVA indicated a main effect of partisanship $\left(F(2,367)=13.97, p<.001, \eta_{p}{ }^{2}=.07\right)$, though both condition $(F(2,367)=2.13, p$ $\left.=.12, \eta_{p}{ }^{2}=.01\right)$ and their interaction $\left(F(4,370)=0.24, p=.92, \eta_{p}{ }^{2}=.00\right)$ were non-significant. Strong partisans perceived more bias in their judgments than both partisans $\left(M_{\text {diff }}=0.68, p\right.$ $<.001)$ and weak partisans $\left(M_{\text {diff }}=0.68, p<.001\right)$; partisans did not perceive more bias than weak partisans $\left(M_{\text {diff }}=0.01, p=.99\right)$, indicating that strong participants (who did display more bias) were also aware that their judgments were biased (Figure 34).

\section{Discussion}

Study $2 \mathrm{~b}$ largely replicated the results of Study 1 and extended it in two key ways. First, an issue with the measurement of lay theories from Study 1 was addressed, and lay theories specifically inquiring about anticipated influence on judgments of guilt in the context of jury deliberations were used. Second, Study $2 \mathrm{~b}$ utilized an online sample outside of University students, who display diverse political views but severely restricted in age. 
Approximately half of participants anticipated that their judgments of guilt would not be influenced by irrelevant political information. As in previous studies, participants who did not anticipate an influence were predominantly weak partisans, with strong partisans anticipating the strongest influence from irrelevant political information. Similarly, strong participants also viewed such influences are more acceptable than their less peers, indicating that not only did they know that irrelevant political information would influence their judgments but that they welcomed such an influence. Unsurprisingly, such individuals were also associated with being less internally motivated to make unbiased judgments $(r=-.26)$. The relationships between these variables are important to note, as the FCM predicts that unmotivated individuals are less likely to correct their judgments (Wegener \& Petty, 1995) presumably even if they also anticipate that their judgments will be influenced.

Study $2 \mathrm{~b}$ replicated the judgment correction at the level of condition observed in Study 1 . Participants explicitly asked to correct their judgments judged defendants about as guilty as those who weren't exposed to political information in the first place. Induction participants, who were not asked to correct their judgments, found the defendant guiltier. Furthermore, strong partisans gave the highest ratings of guilt across all conditions.

Differing from Study 1 , Study $2 \mathrm{~b}$ found a tentative interaction between lay theories and condition for judgments of guilt, but in the opposite direction predicted. Participants asked to correct their judgments who also anticipated a strong influence from irrelevant political information judged the defendant as significantly guiltier than Control participants with similar lay theories. However, Correction participants who did not anticipate being influenced gave lower ratings than control participants, largely accounting for the observed judgment correction 
at the level of condition. In other words, people who did not anticipate being influenced appeared to have overcompensated, rendering lower ratings than control participants, while those who anticipate a strong influence failed to correct their judgments at all.

Moreover, exploratory analyses indicated that those who were the most strongly influenced by the irrelevant political information also tended to be very loyal to their political party. Taken together, loyal individuals who anticipate that their judgments will be influenced are less likely to correct their judgments. This, in combination with the finding that strong partisans (and politically loyal) participants perceived much more bias in their judgments than other participants suggest that people possess a striking amount of awareness as to what will and will not influence their judgments. Participants who knew they would be influenced by irrelevant political information were also likely to correctly identify that they had been influenced, and to say that such influences were acceptable.

When participants were given the option to either view or not view irrelevant political information for the second jury scenario, approximately one-third of participants chose to see this information, regardless of condition. And viewing this irrelevant information did have consequences - those who viewed it gave higher ratings of guilt, regardless of condition, lay theories, views of acceptability, or political loyalty. As in the first jury scenario, strong partisans gave higher ratings of guilt than either partisans or weak partisans, though there was insufficient evidence to conclude that this occurred more strongly for those who viewed the irrelevant information. Given that these judgments (were they non-hypothetical) have objectively correct answers (i.e., guilty or not guilty) with serious consequences for both the individual in question 
and society at large, the willingness of some individuals to willfully incorporate irrelevant information into their judgments is both profound and disturbing. 


\section{General Discussion}

The present studies were conducted in order to expand knowledge on how people anticipate their judgments will (or will not) be influenced by irrelevant political information, whether they believe it is acceptable for that information to influence them, and whether people do (or do not) adjust their judgments for the influence of irrelevant political information after they have been exposed. Despite research documenting that people are unduly influenced by irrelevant political information (Entman, 2007; Iyengar, 1990; Redlawsk et al., 2002), prior to these studies there was little direct evidence as to a) how people thought their judgments would (or would not) be influenced (i.e., lay theories) b) how acceptable it was to allow one's judgments to be influenced by irrelevant political information, and c) whether or not lay theories were as crucial to the process of judgment correction as predicted by models of judgment correction (Wegener \& Petty, 1995).

These studies also took an initial look at the downstream consequences of explicit instructions to correct judgments. That is, after being explicitly asked (or not) correct one's judgments for the influence of irrelevant political information, Studies 1 and $2 \mathrm{~b}$ examined whether people would avoid exposing themselves to overtly irrelevant political information on subsequent judgments after previously being asked to prevent such information from influencing their judgments. The present studies also examined the extent to which people were aware of bias in their judgments, as previous literature on bias awareness suggests that people often have profound limitations in awareness about what information is (or is not) influencing their judgments (Hansen et al., 2014; Pronin et al., 2002). Finally, the present studies also provided initial evidence as to which individual difference factors are associated with lay theories, 
providing insight for future research aimed at understanding why some people anticipate that their judgments will be influenced, and others view their judgments as immune to undue influences.

With regard to lay theories, pilot studies established that people have expectations for how their judgments will (or will not) be influenced by political information that is irrelevant to the judgments at hand. For example, participants (typically strong partisans) often believed that knowing the speaker of a given quote (i.e., President Donald Trump) would influence their evaluation of that quote — negatively for their out-group president and positively for the president they agree with. Pilot Study 1 indicted that people held such expectations for a variety of disparate judgments, such as considering how their evaluations of a quote might be influenced to how trustworthy and likable they may find a neighbor to be. Additionally, pilot studies directly asked people how acceptable it was for their judgments to be influenced by irrelevant political information - a direct and consequential measurement hitherto unexamined in literatures on political bias, bias perception, and judgment correction. Pilot Study 2 identified that views of acceptability can be influenced by the order in which they are presented, but only for quote evaluations. Participants (primarily liberals) viewed it as far less acceptable to allow Donald Trump to influence their quote evaluations after they had previously admitted that knowing Donald Trump said a given quote would influence their judgments. However, the order of presentation did not influence views of acceptability for judgments of guilt. Across all present studies, ratings of acceptability were strongly associated with lay theories, partisanship strength, and partisan loyalty, indicating that those who viewed allowing irrelevant political information to influence their judgments as acceptable were also more likely to possess traits that decreased the 
likelihood that they would correct their judgments, even if explicitly asked to do so.

As expected, the relationship between peoples' lay theories and their views of acceptability are relevant for understanding one of the core goals of the present research: whether people correct their judgments for the influence of irrelevant political information when asked to do so. Studies 1 and 2 presented people with judgments in which participants were exposed (or not) to biasing political information-in Studies 1 and $2 b$, the political information presented to them was always highly disagreeable, and portrayed people and political affiliations participants personally disagreed with; Study 2a presented participants with both agreeable (i.e., in-group president) and disagreeable (i.e., out-group president) political information in order to create a within-subjects measure of judgmental bias. Influences of irrelevant political information were examined for both quote evaluation (less serious, more subjective judgments) and judging the guilt of a defendant in trial for assault and attempted murder (more serious, less subjective judgments). Results indicated that for both types of judgments, participants presented with irrelevant political information and not given any further instructions were influenced by this information; people liked quotes less when uttered by a disliked out-group president and were certain about the guilt of a defendant whose political views disagreed with their own.

Study 1 provided initial evidence that lay theories played a crucial role in the judgment correction process for subjective quote evaluations: The stronger the influence one expected on their judgments, the greater extent to which they corrected their judgments when asked to do so. Although results trended in the same direction for judgments of guilt, correction instructions themselves were sufficient to engender judgment correction; lay theories predicted judgments of guilt but, at best, exerted an indirect effect of judgment correction. That is, participants who 
anticipated a strong influence from irrelevant political information and were also highly internally motivated to correct their judgments were more likely to adjust how guilty they thought the defendant was when asked to do so, relative to their less motivated peers. Although these findings are partially in line with the FCM and MCM, both of which assert that people must be sufficiently motivated to successfully correct their judgments, the significant three-way interactions between lay theories, motivation, and condition observed in Study 1 may be driven by outliers who were especially unmotivated. Whether or not such findings will replicate in subsequent studies remains to be seen.

Not predicted by the FCM or the MCM was that judgments of acceptability were predictive of judgment correction for judgments of guilt. Despite the fact that it ran counter to their values, participants who thought that it was highly acceptable to incorporate irrelevant political information into their judgments of guilt nevertheless corrected their judgments for this influence when instructed to do so. Thus, both lay theories and views of acceptability are important for the process of judgment correction, although Study 1 did not find evidence that these two factors were both needed to engage in successful judgment correction. Moreover, predicting whether lay theories or views of acceptability are more important for judgment correction appears to vary on the judgment context (i.e., evaluating quotes vs. assessing a defendant's guilt).

Finally, Study 1 also found no evidence that measures of cognitive ability were predictive of judgment correction, corroborating the literature finding evidence that the presentation of bias is relatively independent of cognitive ability (Stanovich \& West, 2013). Moreover, identityrelevant measures (e.g., political loyalty, motivation) proved much more relevant to judgment 
correction, further suggesting that bias and bias correction has little to do with cognitive ability.

Study 2a replicated these findings with a different (online) sample. When participants were asked to correct their quote evaluations for the influence of the speaker (Trump or Obama), participants did so in line with their lay theories. Those who anticipated a strong influence of the speaker on their judgments corrected their judgments to a greater extent that those who anticipated only a weak influence. Those who did not anticipate any influence at all were neither influenced by the name of the speaker, nor (over)corrected their judgments.

Crucially, Study 2a expanded on Study 1 by providing evidence that political biasgreater preference for quotes said by an in-group president vs. an out-group president—existed in a within-subjects fashion. That is, Democrats (Republicans) rated quotes by Obama (Trump) higher than they rated quotes by Trump (Obama). This not only verifies that the bias inferred in Study 1 exists in a more tangible sense, but also that people do not appear to adjust their judgments to spontaneously correct for their bias, despite how transparent the study design was; it would have taken little reflection for people to realize that the questions they were being asked might reveal their political bias. This is crucial, as previous literatures has been concerned with participants becoming aware that they may be displaying bias and so seek to avoid displaying it (DeSteno et al., 2000) by spontaneously correcting their judgments. The fact that this did not occur indicates that, at least in the context of politics, participants are unconcerned with appearing biased. This interpretation of the data can be asserted over the suggestion that participants were not aware of their political bias because, when asked directly if they were aware that their judgments were biased, participants indicated that, yes, they had been. Moreover, participants who were the most biased also indicated that a greater amount of bias in 
their judgments relative to their less biased peers. Thus, participants displayed a high level of awareness as to how their judgments were being influenced by the name of the speaker and even to what extent their judgments had been influenced.

Similarly, Study $2 \mathrm{~b}$ largely replicated findings from Study 1 with respect to judgments of guilt in a jury context. Participants asked to correct their judgments did so relative to participants exposed to irrelevant political information who were not asked to correct their judgments. Although evidence that lay theories were responsible for guiding judgment correction was nuanced and largely indirect in study 1 , Study $2 \mathrm{~b}$ found no evidence that lay theories guided judgment correction when assessing the guilt of defendants on trial. Strong partisans were more certain in the guilt of the defendant than their less partisan peers, though this occurred across conditions; Lay theories did interact with condition, but not in the manner predicted by the FCM. Correction participants who anticipated a strong influence on their judgments were just as likely as Partisan induction participants with similar beliefs to be highly certain that the defendant was guilty. However, it appears that the irrelevant political information produced a bias such that those in the Partisan induction condition who did not anticipate that they would be influenced were, in fact, influenced in the defendant's political views. As a result, the main effect of condition which indicated that participants in the Correction condition, overall, succeeded in adjusting their judgments for the influence of the defendant's political views appeared to be driven by those with weak lay theories. This was the only point in the present research in which those with weak lay theories were observed correcting their judgments.

A similar pattern was found in exploratory analyses examining political loyalty. The more loyal participants were, the stronger the political information influenced their judgments; this 
was true for loyal participants in both the Induction and Correction conditions. However, relatively disloyal participants who were asked to correct their judgments gave lower ratings of guilt than similarly disloyal Control participants.

These findings highlight the fact that lay theories and partisan loyalty are entwined factors that jointly influence judgment correction. Given that these results are contrary to the FCM, it is unclear whether this is due to the fact that the jury scenarios were seen as serious in nature, or the fact that the underlying judgment in a jury context reflects an objective response (i.e., the defendant must be either guilty or not guilty). Future research should probe this question to identify what judgments contexts are responsible for lay theories being predictive (or not) of judgment correction. To further highly the surprising findings of Study $2 b$, counter to predictions made prior to these studies, judgment acceptability and internal motivation to make unbiased judgments influenced guilt ratings overall, though there is no evidence that either of these factors influenced the judgment correction process itself.

\section{Judgment Correction: An Updated View}

These results provide new insight into how and why people do (and do not) correct their judgments for the influence of compelling but irrelevant political information. Perhaps most importantly, these results offer at least a partial explanation for why some previous research has concluded that explicit calls to make unbiased judgments are often ineffective, even in serious situations such as a court of law (Daftary-Kapur, Dumas \& Penrod, 2010; Steblay et al., 2006). Namely, none of the previous research measured how people expected to be influenced (i.e., their lay theories) or how acceptable they viewed a given piece of biasing information to be. As a result, previous research examining judgment correction may have missed that a subset of people 
could have, in fact, corrected their judgments when instructed to do so- but without measuring lay theories, it was not possible to observe this nuance. Additionally, recent research has identified that people often have to be persuaded to adjust their judgments for an inappropriate influence (Dietvorst \& Simonsohn, 2018). These findings dovetail with the present findings, which suggests that people do not correct their judgments unless explicitly asked to do so-and even then, only for quote evaluations. Thus, the correction instructions in the present studies may have been sufficient to persuade people to correct their judgments, but previous studies relying on subtler cues to correct their judgments may have been insufficient (DeSteno et al., 2000; Isbell \& Wyer, 1999; Wegener \& Petty, 1993).

Relatedly, previous studies (DeSteno et al., 2000; Isbell \& Wyer, 1999; Stapel et al.,1998) have assumed that judgment correction may occur spontaneously; simply making participants aware that their judgments might be influenced by a given piece of irrelevant information has been assumed to be sufficient to engender judgment correction, at least in some cases. However, in Studies 1 and 2, participants who were not asked to correct their judgments were given reasonably obvious cues that they were being presented with irrelevant, politically charged information; many of these participants were influenced by this information anyway, regardless of their lay theories or internal motivation to make unbiased judgments, indicating that spontaneous judgment correction did not occur.

Moreover, participants in Studies $2 \mathrm{a}$ and $2 \mathrm{~b}$ were asked their lay theories immediately before beginning the study - explicitly cueing them to think about how their judgments will or will not be influenced by political information. Yet even here, participants were influenced by the irrelevant political information unless explicitly asked to prevent this influence. This strongly 
supports the conclusion that adjusting one's judgment is something people choose to do, and likely need to be persuaded to do (Dietvorst \& Simonsohn, 2018). Although I grant that spontaneous judgment correction is possible for judgment contexts not tested in the present studies (e.g., racial information, unappealing personality traits), these results nonetheless challenge the idea that judgment correction occurs spontaneously; future research should take care to test any and all assumptions about how participants may (or may not) correct their judgments for a given context.

Another revealing implication these findings highlight concerns the nature of the judgments themselves. Namely, the process of judgment correction appears to operate differently for evaluation of quotes and evaluation of criminal guilt. One possibility is that the nature of the judgment itself - the perceived subjectivity or objectivity of a response - influences the way in which participants engage in judgment correction. Another possibility is that the perceived seriousness of a judgment motivates (or demotivates) participants to engage in judgment correction.

A third explanation comes from examining the data from Study $2 b$ with regard to political loyalty. As previously discussed, participants who were disloyal to their identified political party were less certain of the guilt of the defendant on trial than their disloyal peers in the control condition. This suggests that politically disloyal participants are willing to correct their judgments for the influence of a defendant's political views, whereas more loyal individuals intentionally ignore calls to correct their judgments. Politically loyal individuals may thus intentionally render biased judgments if they view the punishment of out-group political members are acceptable, which is possible given recent findings that partisan views out-group 
political actors as failed moral agents (Bruchmann, Koopman-Holm, \& Scherer, 2018).

\section{Correction Instructions Do Not Influence Information Seeking}

Perhaps the most surprising finding from the present research concerned the information seeking behavior of participants. When presented with a second jury scenario in which they were told they would need to identify the guilt (or innocence) of the defendant for assault and attempted murder, participants were given the choice to either opt in and view the political attitudes of the defendant, or opt-out and avoid seeing them. Despite the heavy-handed disclaimer that the crimes the defendant was on trial for had nothing to do with politics, nearly one-third of participants elected to view the irrelevant political views of the defendant, in both Study 1 and Study $2 \mathrm{~b}$. What is most striking about this is the fact that prior correction instructions had no influence on information seeking, as was predicted. Those who had previously been asked to correct their judgments — many successfully — were just as likely as other participants to choose to see the political views of the defendant.

Moreover, participants who anticipated a strong influence on their judgments from who chose to see the irrelevant political information were, in fact, influenced by it, as they had expected to be. These participants then indicated that the judgments they made in the jury scenarios had been influenced by the political information they observed, making it unlikely that these participants errantly thought they could (or did) prevent the influence of the political information. This strongly suggests that people have a non-trivial degree of awareness into their own judgment-making process, at least in the context of partisan politics. People who are influenced by irrelevant information know they will be influenced, choose to see biasing information, and know that it has influenced them after exposure. 


\section{Updating Models of Judgment Correction}

Collectively, these results provide insights into how models of judgment correction could be updated to make more accurate predictions of when and to what extent people will correct (or fail to correct) their judgments for a given influence. First, models such as the MCM and FCM should include acceptability of influence as a separate factor into updated models. The present data suggests that perception of acceptability is a separate construct from both lay theories and motivation to prevent bias and may predict judgment correction in some instances, as Study 1 indicated. Additionally, because at least some judgment contexts require people to be persuaded to correct their judgments (Dietvorst \& Simonsohn, 2018), knowing whether or not an individual perceives a given influence as acceptable information to incorporate into a judgment is likely to be highly predictive as to whether or not a given individual will succeed (or fail) to correct their judgments for a given influence.

Additionally, a person's general internal motivation to make unbiased judgments may not predict, in specific instances, how willing someone is to actually correct their judgments. People who believe that they ought to make unbiased judgments may nevertheless need to be presented with compelling evidence to actually do so. Future research should identify the contexts in which persuasion is required (e.g., possibly identity-relevant factors) and those in which it is not (e.g., estimating the number of dots on a screen; Wegener \& Petty, 1993).

With regard to both the FCM and MCM, a shift away from speaking of factors relevant to judgment correction (e.g., lay theories, motivation, sufficient cognitive resources, etc.) as necessary for judgment correction should instead be spoken of in terms of being sufficient for judgment correction. These results not only demonstrated that participants could fail to correct 
their judgments even when they fully anticipated an influence from irrelevant political information, but Study $2 \mathrm{~b}$ also provided evidence that people who did not anticipate being influenced were nevertheless able to adjust their judgments when instructed, a finding directly counter to predictions made by the FCM.

Collectively, these results suggest that the process of judgment correction is much more nuanced than previously conceived. Although measuring a person's lay theories, partisan loyalty, views of acceptability, and internal motivation may help predict how likely a person will be to correct their judgments, it would not be appropriate to say a person lacking prior awareness to their own susceptibility to a given influence (e.g., name of a disliked politician) means they will be unable to correct their judgments when asked. Lay theories, despite being highly predictive, do not appear to be required for judgment correction to occur, per se. Nor do factors such as lay theories and motivation necessarily operate in an ordered, step-wise fashion as is implied by a key figure from the seminal article on mental contamination, which imagines judgment correction as a series of criteria that must be met in a logical order; if any one of these steps fails to manifest, judgments become "contaminated" (Wilson \& Brekke, 1994). Factors that predict successful (and unsuccessful) judgment correction are interrelated, and likely influence each other in a dynamic, iterative mental process; lacking any one of these factors (e.g., motivation) does not mean that a person is doomed to make a biased judgment, and possessing them all does not mean that an unbiased judgment will occur.

Finally, accessibility of lay theories appears to play an important factor in the judgment correction process, though it has received little attention in prior research, and only received a small amount of attention in these studies. Strikingly, Study 1 revealed that lay theories guide the 
correction process (at least for quote evaluations) despite the fact that participant's lay theories were measured weeks in advance. This supports predictions made by the FCM that lay theories are stored and retrieved when needed in order to correct one's judgment (Wegener \& Petty, 1995; 1997). Study 2, however, demonstrated that lay theories guide judgment correction much more strongly (again, for quote evaluations) when lay theories are measured immediately before the beginning of the study. This suggests that lay theories are far more effective predictors of judgment correction when highly accessible — such as recalling them close in time to making a judgment.

One might convincingly argue that noting the importance of accessibility in the judgment-making process is an obvious prediction made by more basic social and cognitive research (see Houston \& Fazio, 1989; MacLeod \& Campbell, 1992; Schimmack \& Oishi, 2005). However, this finding is important with respect to the judgment correction literature, as it illustrates the need to factor the accessibility of one's lay theory into the model of judgment correction. Asking people to consider relevant and irrelevant information immediately prior to making a judgment is likely to be more effective than inserting a given amount of time (e.g., minutes, hours, days, months) between considering one's lay theories and making a judgment. Perhaps the most salient question to emerge from this observation is how much time is needed between measuring lay theories and making a judgment before lay theories are no longer useful predictors of judgment correction. Deliberately manipulating the amount of time between measuring lay theories and presenting participants with a key judgment that needs to be unbiased would provide researchers with the ability to make more specific predictions about when and to what extent people are able and willing to correct their judgments. This could have both 
theoretical implications for updating the FCM, as well as practical implications, such as when and how often a judge in a court of law should order (or remind) members of a jury to discount a given piece of information.

\section{Limitations}

Several limitations associated with these studies should be taken into consideration when interpreting these findings. Perhaps the most salient issue concerns that nature of bias. At the outset of this manuscript, it was argued that influences such as the name of a politician (e.g., Donald Trump) when evaluating a quote attributed to them constituted political bias. This argument was made because the name of a speaker shouldn't exert an influence on the degree to which you agree or disagree with the words themselves, at least when you are explicitly asked to only evaluate the words themselves.

More strongly still, the jury scenarios provided a context in which allowing the political views of a defendant to influence one's judgments of their guilt is objectively and legally irrelevant information. Therefore, judging a defendant as more or less guilty based on their political views would constitute bias. However, one could argue that this is an insufficient definition of bias, namely because it is appropriate to allow political information to influence one's judgments. Given that "bias" is often used in a pejorative fashion, especially when it comes to politics, it is well taken that use of this term may engender disagreement. For anyone adopting the perspective that it is acceptable to incorporate irrelevant political information into judgments, the burden of proof may present an issue. If one wishes to argue that political information is relevant for a given judgment, the burden lies with that individual to defend why that information is, in fact, relevant. In some contexts, such an argument would be strong (e.g., considering the 
political views of a defendant when judging their guilt for a politically-motivated assault) but not for others (e.g., considering political views when judging guilt for a non-politically-motivated assault).

A second, related limitation in these studies lies with the specific jury scenarios that were selected. For both scenarios, serious violent crimes were invoked (i.e., attempted murder); participants may have made assumptions that the political views of the defendant were a relevant source of information because they may view out-group political members are more inherently violent (e.g., white nationalist conservatives are prone to acts of violence). Although we attempted to address this by including a disclaimer that the defendant had no prior history of violence, it is acknowledged that this may not have been enough to ameliorate underlying preconceptions that participants had about violent out-group political actors. Thus, a follow-up study will be conducted in which jury scenarios involve equally serious non-violent crimes that are also unrelated to politics.

A methodological limitation with the measurement of lay theories also prevented stronger conclusions from being drawn for Study 1 . Specifically, no lay theory items dealt directly with judgment of guilt in a jury context due to a shift in which dependent measures would be used after lay theory items had been determined and submitted. Lay theory items only pertained to quote and policy evaluation. This limitation may be why lay theories were not found to predict judgment correction for judgments of guilt in Study 1, although lay theories also did not predict judgment correction in Study 2b, when lay theories were properly measured. It is notable that in Study 1 lay theories still predicted judgments of guilt overall, despite the mismatch between the context in which the lay theory was measured (e.g., quotes) and the actual judgments made 
(judgments of guilt).

\section{Conclusion}

Explicitly instructing people to correct their judgments is sufficiently effective for successful judgment correction, though this form of explicit motivation is limited to the type of judgment being asked. When it comes to making a judgment that has been contaminated by irrelevant, persuasive political information—often, information about those whom people disagree with politically — the most appropriate frame with which to approach the topic is not whether someone can or cannot correct their judgments, but whether someone will or will not correct their judgments. Models of judgment correction should be updated to account for peoples' surprising self-awareness about bias in their own judgments, as well as why people choose not to correct their judgments even when they could do so. 


\section{References}

Amodio, D., Mendoza. S. Implicit intergroup bias: Cognitive, affective, and motivational underpinnings B. Gawronski, B.K. Payne (Eds.), Handbook of implicit social cognition, Guilford, New York (2010), pp. 353-374.

Anderson, C. A., Lepper, M. R., \& Ross, L. (1980). Perseverance of social theories: The role of explanation in the persistence of discredited information. Journal of personality and social psychology, 39(6), 1037.

Baron, J., \& Jost, J. T. (2018). False equivalence: Are liberals and conservatives in the US equally “biased?”. Perspectives on Psychological Science.

Beer, A., \& Watson, D. (2009). The individual and group loyalty scales (IGLS): Construction and preliminary validation. Journal of personality assessment, 91(3), 277-287.

Berkowitz, L., Jaffee, S., Jo, E., \& Troccoli, B. T. (2000). On the correction of feeling-induced judgmental biases. In J. P. Forgas (Ed.), Studies in emotion and social interaction, second series. Feeling and thinking: The role of affect in social cognition (pp. 131-152). New York, NY, US: Cambridge University Press.

Berinsky, A. J. (2017). Rumors and health care reform: Experiments in political misinformation. British Journal of Political Science, 47(2), 241-262.

Birch, S. A., \& Bloom, P. (2007). The curse of knowledge in reasoning about false beliefs. Psychological Science, 18(5), 382-386.

Blanken, I., van de Ven, N., \& Zeelenberg, M. (2015). A meta-analytic review of moral licensing. Personality and Social Psychology Bulletin, 41(4), 540-558.

Bless, H., \& Schwarz, N. (2010). Mental construal and the emergence of assimilation and 
contrast effects: The inclusion/exclusion model. In Advances in experimental social psychology (Vol. 42, pp. 319-373). Academic Press.

Brewer, M. B. (1999). The psychology of prejudice: Ingroup love and outgroup hate? Journal of social issues, 55(3), 429-444.

Bruchmann, K., Koopmann-Holm, B., \& Scherer, A. (2018). Seeing beyond political affiliations: The mediating role of perceived moral foundations on the partisan similarity-liking effect. PloS one, 13(8).

Camerer, C., Loewenstein, G., \& Weber, M. (1989). The curse of knowledge in economic settings: An experimental analysis. Journal of political Economy, 97(5), 1232-1254.

Chan, M. P. S., Jones, C. R., Hall Jamieson, K., \& Albarracin, D. (2017). Debunking: A metaanalysis of the psychological efficacy of messages countering misinformation. Psychological science, 28(11), 1531-1546.

Carpini, M. X., \& Keeter, S. (1993). Measuring political knowledge: Putting first things first. American Journal of Political Science, 37(4), 1179.

Crocker, J. Schwartz, I. (1985). Prejudice and ingroup favoritism in a minimal intergroup situation: Effects of self-esteem. Personality and Social Psychology Bulletin, 11, 379386.

DeSteno, D., Petty, R. E., Wegener, D. T., \& Rucker, D. D. (2000). Beyond valence in the perception of likelihood: The role of emotion specificity. Journal of personality and social psychology, 78(3), 397.

De Neys, W., Cromheeke, S., \& Osman, M. (2011). Biased but in doubt: Conflict and decision confidence. PloS one, 6(1). 
Ditto, P. H., Clark, C. J., Liu, B. S., Wojcik, S. P., Chen, E. E., Grady, R. H., ... \& Zinger, J. F. (2019). Partisan bias and its discontents. Perspectives on Psychological Science, 14(2), 304-316.

Doherty, C., Kiley, J., \& Johnson, B. (2017). “The Partisan Divide on Political Values Grows Even Wider.” Pew Research Center, Washington, D.C. https://www.peoplepress.org/2017/10/05/the-partisan-divide-on-political-values-grows-even-wider/.

Doherty, C., Kiley, J., \& Johnson, B. (2018) “The public’s Voting Values.” Pew Research Center, Washington, D.C. https://www.people-press.org/2018/10/29/the-publics-voting-values/.

Doherty, C., Kiley, J., \& Johnson, B. (2019) 'Little Public Support for Reductions in Federal Spending.” Pew Research Center, Washington, D.C.) https://www.peoplepress.org/2019/04/11/little-public-support-for-reductions-in-federal-spending/.

Dovidio, J., Gaertner, S. (2000). Aversive racism and selection decisions: 1989 and 1999. Psychological science, 11(4), 315-319.

Ecker, U. K., Lewandowsky, S., \& Tang, D. T. (2010). Explicit warnings reduce but do not eliminate the continued influence of misinformation. Memory \& cognition, 38(8), $1087-$ 1100.

Ecker, U. K., Lewandowsky, S., Swire, B., \& Chang, D. (2011). Correcting false information in memory: Manipulating the strength of misinformation encoding and its retraction. Psychonomic Bulletin \& Review, 18(3), 570-578.

Entman, R. M. (2007). Framing bias: Media in the distribution of power. Journal of communication, 57(1), 163-173.

Epstein, S., Pacini, R., Denes-Raj, V., \& Heier, H. (1996). Individual differences in intuitive- 
experiential and analytical-rational thinking styles. Journal of personality and social psychology, 71(2), 390

Fein, S., McCloskey, A. L., \& Tomlinson, T. M. (1997). Can the jury disregard that information? The use of suspicion to reduce the prejudicial effects of pretrial publicity and inadmissible testimony. Personality and Social Psychology Bulletin, 23(11), 1215-1226.

Fischoff, B. (1981). Debiasing. Kahneman, Slovic, \& Tversky (Eds.), Judgment under uncertainty: Heuristics and biases. (pp. 33-57).

Fleming, M. A., Wegener, D. T., \& Petty, R. E. (1999). Procedural and legal motivations to correct for perceived judicial biases. Journal of Experimental Social Psychology, 35(2), 186-203.

Funk, C. \& Caiazza, T. (2018) "Majority of Americans Believe It Is Essential That the U.S. Remain a Global Leader in Space.” Pew Research Center, Washington, D.C. https://www.pewresearch.org/science/2018/06/06/majority-of-americans-believe-it-isessential-that-the-u-s-remain-a-global-leader-in-space/.

Heider, F. (1958). The Psychology of Interpersonal Relations. New York: John Wiley \& Sons. Holroyd, J. (2015). Implicit bias, awareness and imperfect cognitions. Consciousness and cognition, 33, 511-523.

Guerin, B., \& Innes, J. M. (1981). Awareness of cognitive processes: Replications and revisions. The Journal of General Psychology, 104(2), 173-189.

James, O., \& Van Ryzin, G. G. (2016). Motivated reasoning about public performance: An experimental study of how citizens judge the affordable care act. Journal of Public Administration Research and Theory, 27(1), 197-209. 
Haglin, K. (2017). The limitations of the backfire effect. Research \& Politics, 4(3), 2053168017716547.

Heath, C., \& Heath, D. (2006). The curse of knowledge. Harvard Business Review, 84(12), 2023.

Houston, D. A., \& Fazio, R. H. (1989). Biased processing as a function of attitude accessibility: Making objective judgments subjectively. Social cognition, 7(1), 51-66.

Isbell, L. M., Ottati, V. C., \& Burns, K. C. (2006). Affect and politics: Effects on judgment, processing, and information seeking. In Feeling politics (pp. 57-86). Palgrave Macmillan, New York.

Isbell, L. M., \& Wyer Jr, R. S. (1999). Correcting for mood-induced bias in the evaluation of political candidates: The roles of intrinsic and extrinsic motivation. Personality and Social Psychology Bulletin, 25(2), 237-249.

Iyengar, S. (1990). Framing responsibility for political issues: The case of poverty. Political behavior, 12(1), 19-40.

Johnson, H. M., \& Seifert, C. M. (1998). Updating accounts following a correction of misinformation. Journal of Experimental Psychology: Learning, Memory, and Cognition, 24(6), 1483.

Jussim, L. (1991). Social perception and social reality: A reflection-construction model. Psychological review, 98(1), 54.

Kahan, D. M., Peters, E., Wittlin, M., Slovic, P., Ouellette, L. L., Braman, D., \& Mandel, G. (2012). The polarizing impact of science literacy and numeracy on perceived climate change risks. Nature climate change, 2(10), 732. 
Kahan, D. M., Peters, E., Dawson, E. C., \& Slovic, P. (2017). Motivated numeracy and enlightened self-government. Behavioural Public Policy, 1(1), 54-86.

Kahneman, D., Slovic, S. P., Slovic, P., \& Tversky, A. (Eds.). (1982). Judgment under uncertainty: Heuristics and biases. Cambridge university press.

Kuklinski, J. H., Quirk, P. J., Jerit, J., Schwieder, D., \& Rich, R. F. (2000). Misinformation and the currency of democratic citizenship. The Journal of Politics, 62(3), 790-816.

Kassin, S. M., \& Sommers, S. R. (1997). Inadmissible testimony, instructions to disregard, and the jury: Substantive versus procedural considerations. Personality and Social Psychology Bulletin, 23(10), 1046-1054.

Larrick, R. P., Morgan, J. N., \& Nisbett, R. E. (1990). Teaching the use of cost-benefit reasoning in everyday life. Psychological Science, 1(6), 362-370.

Larrick, R. (2004). Debiasing. Derek \& Harvey (Eds.), Blackwell Handbook of Judgment \& Decision Making. (pp. 316-337).

Lewandowsky, S., Ecker, U. K., Seifert, C. M., Schwarz, N., \& Cook, J. (2012). Misinformation and its correction: Continued influence and successful debiasing. Psychological Science in the Public Interest, 13(3), 106-131.

London, K., \& Nunez, N. (2000). The effect of jury deliberations on jurors' propensity to disregard inadmissible evidence. Journal of Applied Psychology, 85(6), 932.

Lord, C. G., Ross, L., \& Lepper, M. R. (1979). Biased assimilation and attitude polarization: The effects of prior theories on subsequently considered evidence. Journal of personality and social psychology, 37(11), 2098.

MacLeod, C., \& Campbell, L. (1992). Memory accessibility and probability judgments: An 
experimental evaluation of the availability heuristic. Journal of personality and social psychology, 63(6), 890.

Martin, L. L., Seta, J. J., \& Crelia, R. A. (1990). Assimilation and contrast as a function of people's willingness and ability to expend effort in forming an impression. Journal of Personality and Social Psychology, 59(1), 27.

Mason, L., \& Wronski, J. (2018). One tribe to bind them all: How our social group attachments strengthen partisanship. Political Psychology, 39, 257-277.

McCaslin, M. J., Petty, R. E., \& Wegener, D. T. (2010). Self-enhancement and theory-based correction processes. Journal of Experimental Social Psychology, 46(5), 830-835.

McFarland, C., White, K., \& Newth, S. (2003). Mood acknowledgment and correction for the mood-congruency bias in social judgment. Journal of Experimental Social Psychology, 39(5), 483-491.

Miron, A. M., \& Brehm, J. W. (2006). Reactance theory-40 years later. Zeitschrift für Sozialpsychologie, 37(1), 9-18.

Nam, H. H., Jost, J. T., \& Van Bavel, J. J. (2013). "Not for all the tea in China!” Political ideology and the avoidance of dissonance-arousing situations. PloS one, 8(4), e59837.

Nisbett, R. E., \& Wilson, T. D. (1977). Telling more than we can know: Verbal reports on mental processes. Psychological review, 84(3), 231.

Nyhan, B., \& Reifler, J. (2010). When corrections fail: The persistence of political misperceptions. Political Behavior, 32(2), 303-330.

Paluck, E. L. (2009). Reducing intergroup prejudice and conflict using the media: a field experiment in Rwanda. Journal of personality and social psychology, 96(3), 574. 
Petty, R. E., \& Wegener, D. T. (1993). Flexible correction processes in social judgment: Correcting for context-induced contrast. Journal of Experimental Social Psychology, 29(2), 137-165.

Petty, R. E., Wegener, D. T., \& White, P. H. (1998). Flexible correction processes in social judgment: Implications for persuasion. Social cognition, 16(1), 93-113.

Petty, R. E., Briñol, P., Tormala, Z. L., \& Wegener, D. T. (2007). The role of meta-cognition in social judgment. Social psychology: Handbook of basic principles, 2, 254-284.

Patel, N., Baker, S. G., \& Scherer, L. D. (2019). Evaluating the cognitive reflection test as a measure of intuition/reflection, numeracy, and insight problem solving, and the implications for understanding real-world judgments and beliefs. Journal of experimental psychology. General.

Plessner, H., Betsch, C., \& Betsch, T. (Eds.). (2011). Intuition in judgment and decision making. Psychology Press.

Pronin, E., Lin, D. Y., \& Ross, L. (2002). The bias blind spot: Perceptions of bias in self versus others. Personality and Social Psychology Bulletin, 28(3), 369-381.

Pronin, E., Gilovich, T., \& Ross, L. (2004). Objectivity in the eye of the beholder: divergent perceptions of bias in self versus others. Psychological review, 111(3), 781.

Pronin, E., \& Kugler, M. B. (2007). Valuing thoughts, ignoring behavior: The introspection illusion as a source of the bias blind spot. Journal of experimental social psychology, 43(4), 565-578.

Pronin, E. (2009). The introspection illusion. Advances in experimental social psychology, 41, 167. 
Redlawsk, D. P. (2002). Hot cognition or cool consideration? Testing the effects of motivated reasoning on political decision making. The Journal of Politics, 64(4), 1021-1044.

Reynolds, W. M. (1982). Development of reliable and valid short forms of the Marlowe-Crowne Social Desirability Scale. Journal of clinical psychology, 38(1), 119-125.

Schimmack, U., \& Oishi, S. (2005). The influence of chronically and temporarily accessible information on life satisfaction judgments. Journal of personality and social psychology, 89(3), 395.

Sears, D. O. (1994). Ideological bias in political psychology: The view from scientific hell. Political Psychology, 547-556.

Seifert, C. M. (2002). The continued influence of misinformation in memory: What makes a correction effective? In Psychology of learning and motivation (Vol. 41, pp. 265-292). Academic Press.

Sherif, M., Harvey, O. J., White, B. J., Hood, W. R., \& Sherif, C. W. (1988). The robbers cave experiment. Intergroup conflict and cooperation.

Ståhl, T., Zaal, M. P., \& Skitka, L. J. (2016). Moralized rationality: Relying on logic and evidence in the formation and evaluation of belief can be seen as a moral issue. PloS one, 11(11), e0166332.

Stanovich, K. E., West, R. F., \& Toplak, M. E. (2013). Myside bias, rational thinking, and intelligence. Current Directions in Psychological Science, 22(4), 259-264.

Stanovich, K. E., \& West, R. F. (2007). Natural myside bias is independent of cognitive ability. Thinking \& Reasoning, 13(3), 225-247.

Stapel, D. A., Martin, L. L., \& Schwarz, N. (1998). The smell of bias: What instigates correction 
processes in social judgments? Personality and Social Psychology Bulletin, 24(8), 797806.

Steblay, N., Hosch, H. M., Culhane, S.E., \& McWethy, A. (2006). The impact on juror verdicts of judicial instruction to disregard inadmissible evidence: A meta-analysis. Law and Human Behavior, 30(4), 469-492.

Stroud, N. J. (2010). Polarization and partisan selective exposure. Journal of communication, 60(3), 556-576.

Taber, C. S., \& Lodge, M. (2006). Motivated skepticism in the evaluation of political beliefs. American Journal of Political Science, 50(3), 755-769.

Tetlock, P. E. (1991). An alternative metaphor in the study of judgment and choice: People as politicians. Theory \& Psychology, 1(4), 451-475.

Tetlock, P. E. (2002). Social functionalist frameworks for judgment and choice: intuitive politicians, theologians, and prosecutors. Psychological review, 109(3), 451.

Petty, R. E., \& Wegener, D. T. (1993). Flexible correction processes in social judgment: Correcting for context-induced contrast. Journal of Experimental Social Psychology, 29(2), 137-165.

Wegener, D. T., \& Petty, R. E. (1995). Flexible correction processes in social judgment: The role of naive theories in corrections for perceived bias. Journal of personality and social psychology, 68(1), 36.

Wegener, D. T., \& Petty, R. E. (1997). The flexible correction model: The role of naive theories of bias in bias correction. In Advances in experimental social psychology (Vol. 29, pp. 141-208). Academic Press. 
Wegener, D. T., Kerr, N. L., Fleming, M. A., \& Petty, R. E. (2000). Flexible corrections of juror judgments: Implications for jury instructions. Psychology, Public Policy, and Law, 6(3), 629.

West, R. F., Meserve, R. J., \& Stanovich, K. E. (2012). Cognitive sophistication does not attenuate the bias blind spot. Journal of personality and social psychology, 103(3), 506.

Wetzel, C. G., Wilson, T. D., \& Kort, J. (1981). The halo effect revisited: Forewarned is not forearmed. Journal of Experimental Social Psychology, 17(4), 427-439.

Wilson, T. D., \& Brekke, N. (1994). Mental contamination and mental correction: unwanted influences on judgments and evaluations. Psychological bulletin, 116(1), 117.

Wistrich, A. J., Guthrie, C., \& Rachlinski, J. J. (2004). Can Judges Ignore Inadmissible Information-The Difficulty of Deliberately Disregarding. U. Pa. L. Rev., 153, 1251.

Wood, T., \& Porter, E. (2016). The elusive backfire effect: mass attitudes' steadfast factual adherence. Political Behavior, 1-29. 
Table 1. Means, SDs, and bivariate correlations among key variables and individual difference measures from Study 1.

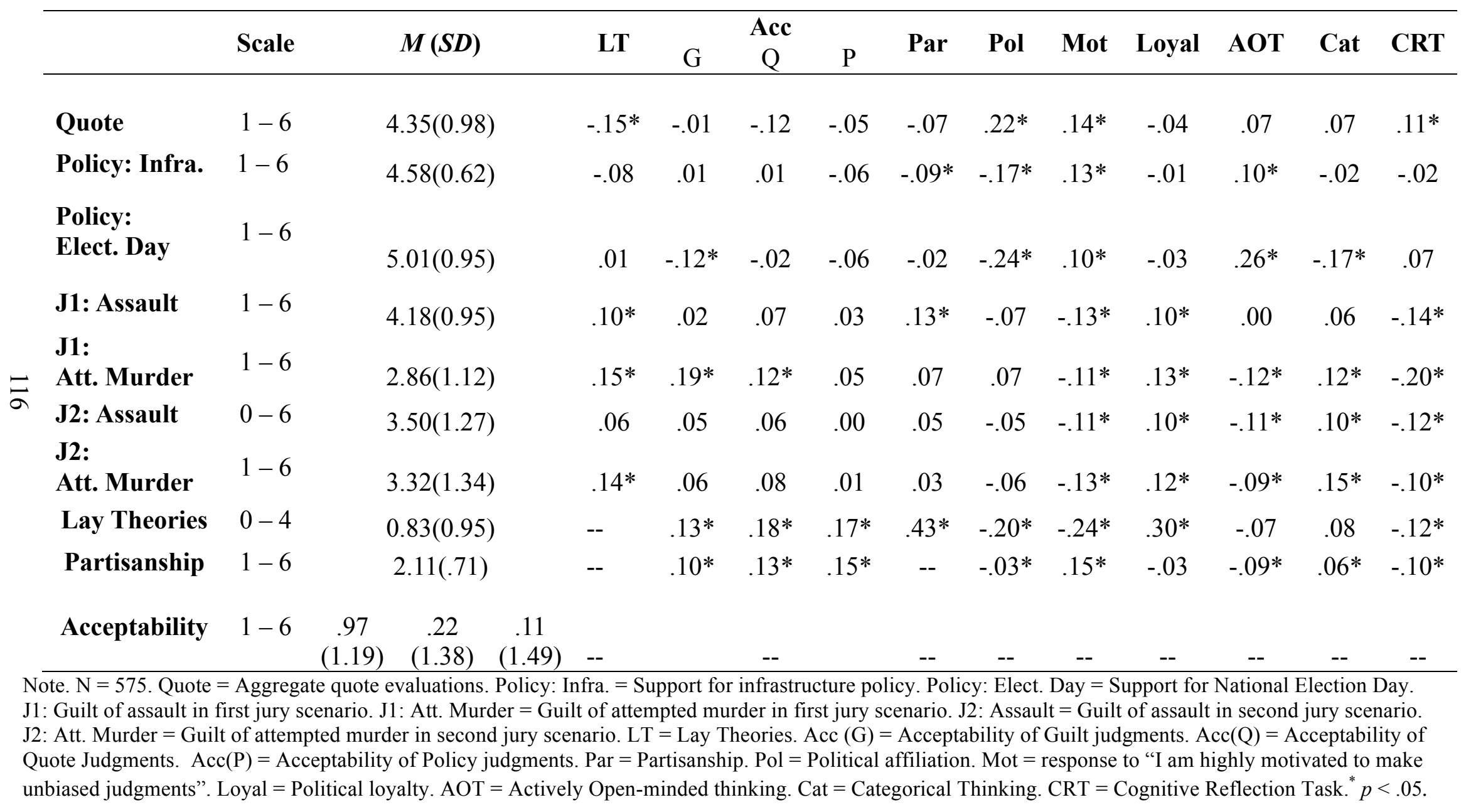




\section{THE LOG IN MY EYE}

Table 2. Means, SDs, and bivariate correlations among key variables and individual difference measures for Study $2 b$.

\begin{tabular}{llllllllll}
\hline & Scale & $\boldsymbol{M}(\boldsymbol{S D})$ & $\mathbf{L T}$ & Acc & Par & Pol & Mot & Know & Loyal \\
\hline Quote: In-group & $1-6$ & $4.62(0.69)$ & $.17^{*}$ & $.14^{*}$ & .20 & .02 & $16^{*}$ & .02 & $.30^{*}$ \\
Quote: Out-group & $1-6$ & $4.22(0.83)$ & $-.11^{*}$ & .04 & .03 & .22 & $26^{*}$ & -.02 & $20^{*}$ \\
Lay Theories & $0-4$ & $1.86(1.23)$ & -- & $.31^{*}$ & $.42^{*}$ & $.18^{*}$ & $.14^{*}$ & 08 & $25^{*}$ \\
Partisanship & $1-6$ & $2.13(0.83)$ & -- & -- & - & $.12^{*}$ & .04 & .08 & $29^{*}$ \\
Acceptability & $1-6$ & $4.05(1.08)$ & -- & -- & $.19^{*}$ & .09 & .19 & -.10 & $19^{*}$ \\
\hline
\end{tabular}

Note. $N=380$. Quote: In-group = Aggregate measure of quotes said by in-group president. Quote: Out-group = Aggregate measure of quotes said by out-group president. LT = Lay Theories. Acc $=$ Acceptability of Guilt judgments. Par $=$ Partisanship. Pol = Political affiliation. Mot $=$ aggregate motivation measure. Know $=$ score of general political knowledge (0-5). Loyal $=$ aggregate political loyalty measure. ${ }^{*} p<.05$. 
Table 3. Means, SDs, and bivariate correlations among key variables and individual difference measures for Study $2 b$.

\begin{tabular}{lclllllllll}
\hline & Scale & $M(S D)$ & LT & Acc & Par & Pol & Mot & Know & Loyal \\
\hline J1: Guilt & $1-6$ & $3.71(1.12)$ & $.42^{*}$ & $.55^{*}$ & $.19^{*}$ & .06 & $-.15^{*}$ & $-.23^{*}$ & $.33^{*}$ \\
J2: Guilt & $1-6$ & $3.57(1.37)$ & $.32^{*}$ & $.46^{*}$ & $.16^{*}$ & .06 & -.09 & $-.25^{*}$ & $.31^{*}$ \\
Lay Theories & $0-4$ & $0.90(1.17)$ & -- & $.66^{*}$ & $.30^{*}$ & $.14^{*}$ & $-.26^{*}$ & $-.25^{*}$ & $.43^{*}$ \\
Partisanship & $1-6$ & $2.12(0.82)$ & -- & -- & - & -.05 & -.07 & $-.16^{*}$ & $.41^{*}$ \\
Acceptability & $1-6$ & $2.60(1.47)$ & -- & -- & $.27^{*}$ & $.14^{*}$ & $-.33^{*}$ & $-.43^{*}$ & $.47^{*}$
\end{tabular}

Note. $N=380$. Quote: In-group = Aggregate measure of quotes said by in-group president.

Quote: Out-group = Aggregate measure of quotes said by out-group president. LT = Lay Theories. Acc $=$ Acceptability of Guilt judgments. Par $=$ Partisanship. Pol = Political affiliation. Mot $=$ aggregate motivation measure. Know $=$ score of general political knowledge (0-5). Loyal $=$ aggregate political loyalty measure. ${ }^{*} p<.05$. 
Figure 1. Lay theories (absolute value measure) by political affiliation.

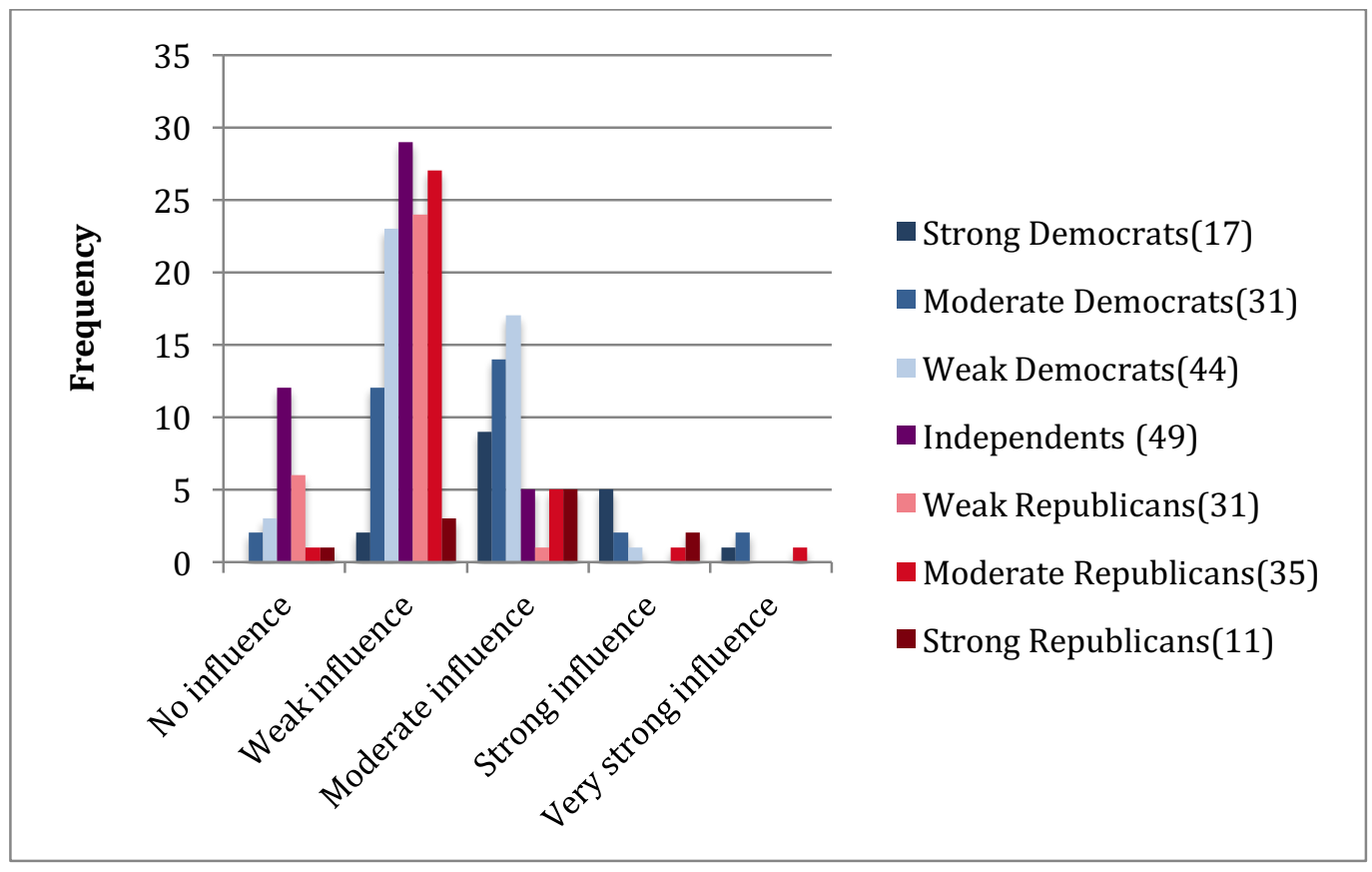


Figure 2. Lay theories of quotes between in-group and out-group president, and presentation order.

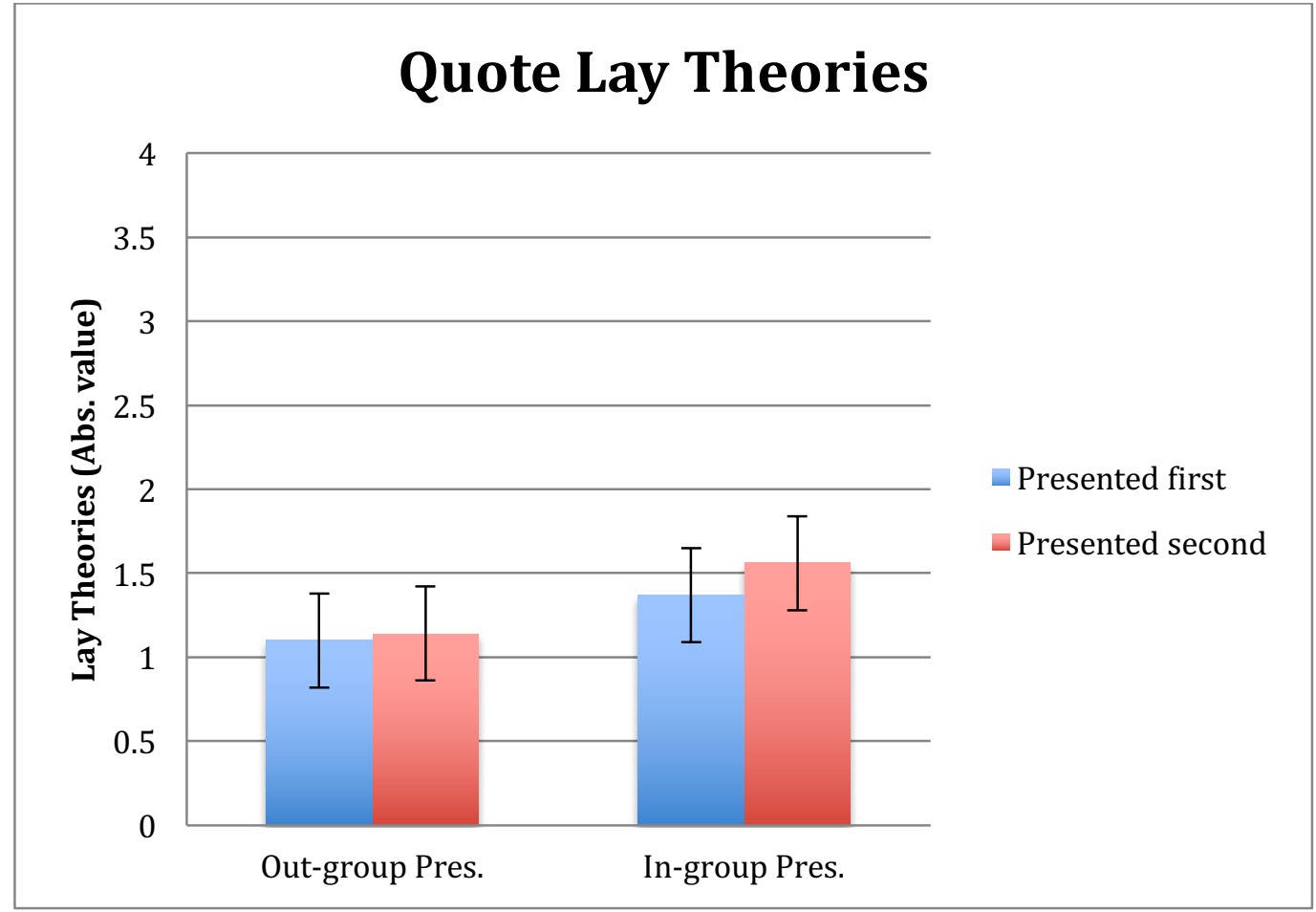


Figure 3. Lay theories of guilt judgments between in-group and out-group defendant, and presentation order

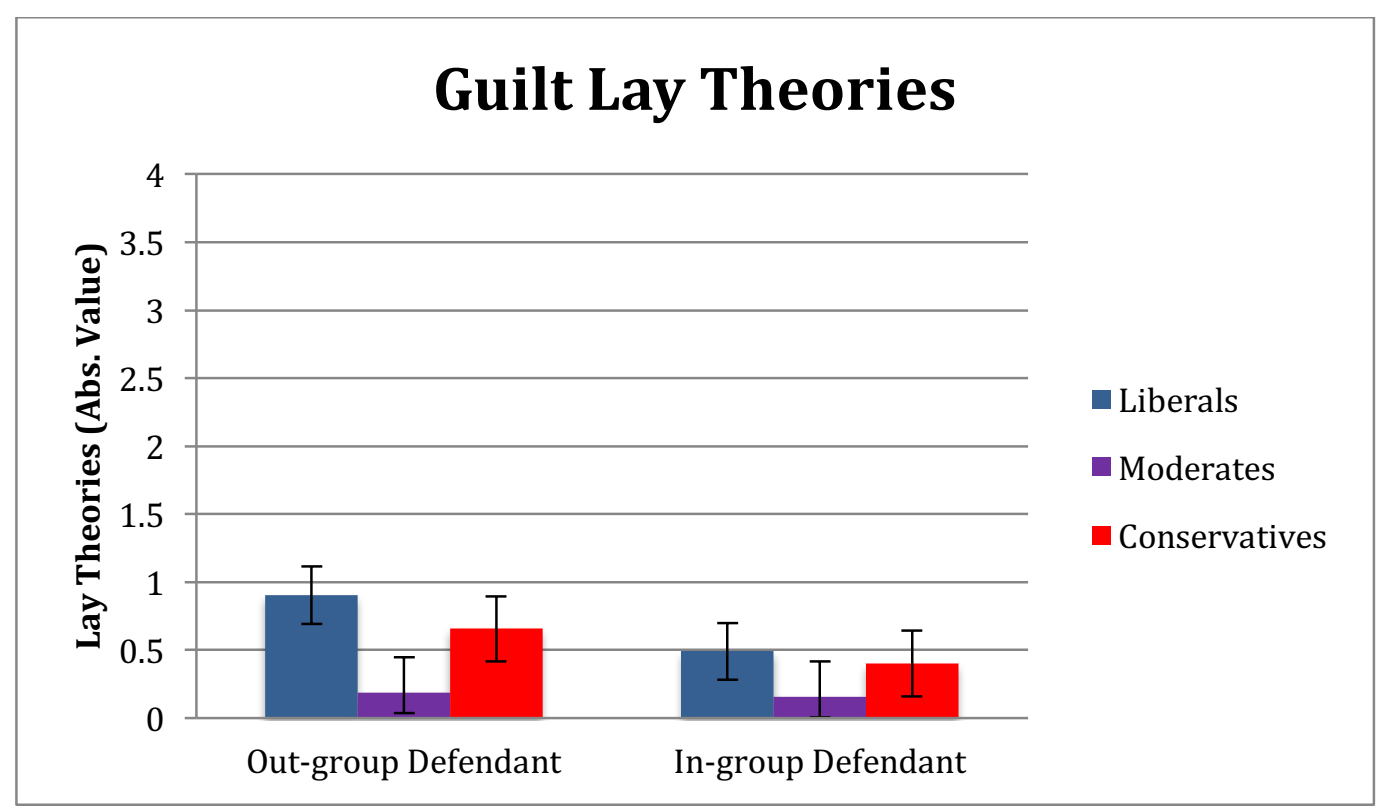


Figure 4. Acceptability (quotes) between in-group and out-group president, and presentation order.

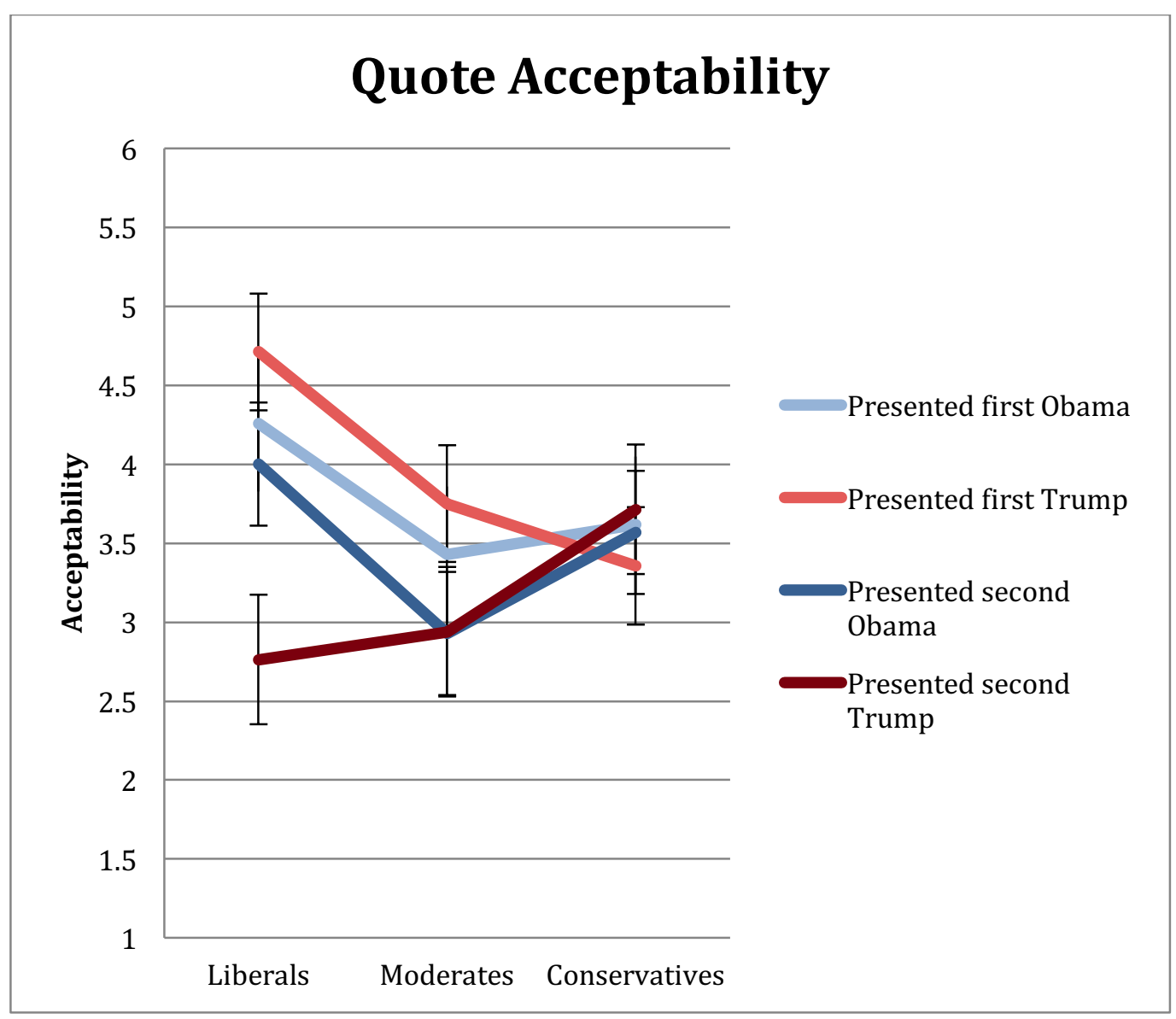


Figure 5. Acceptability (guilt) between in-group and out-group defendant, and presentation order.

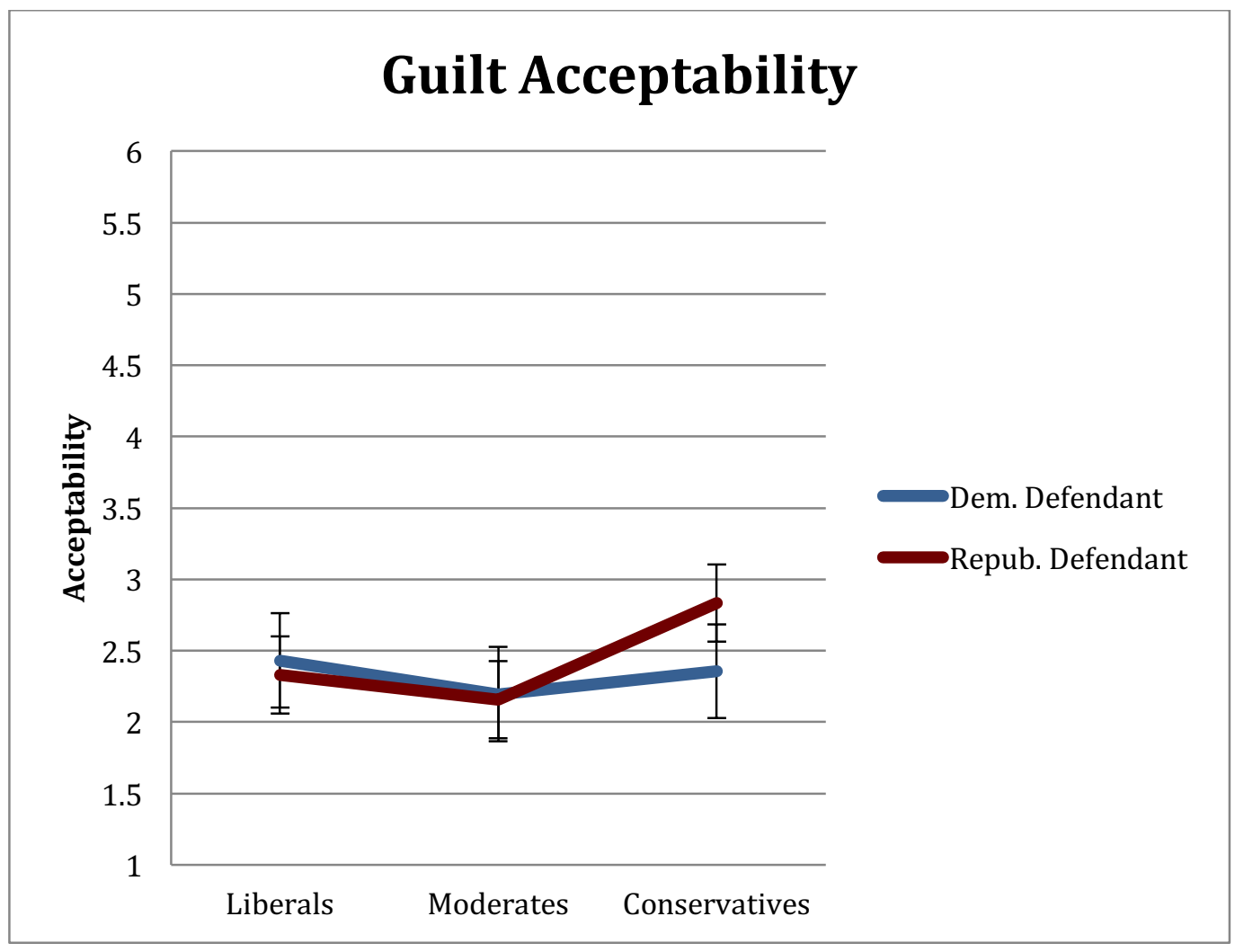


Figure 6a. Study 1: Lay theories (absolute value measure) by partisanship strength.

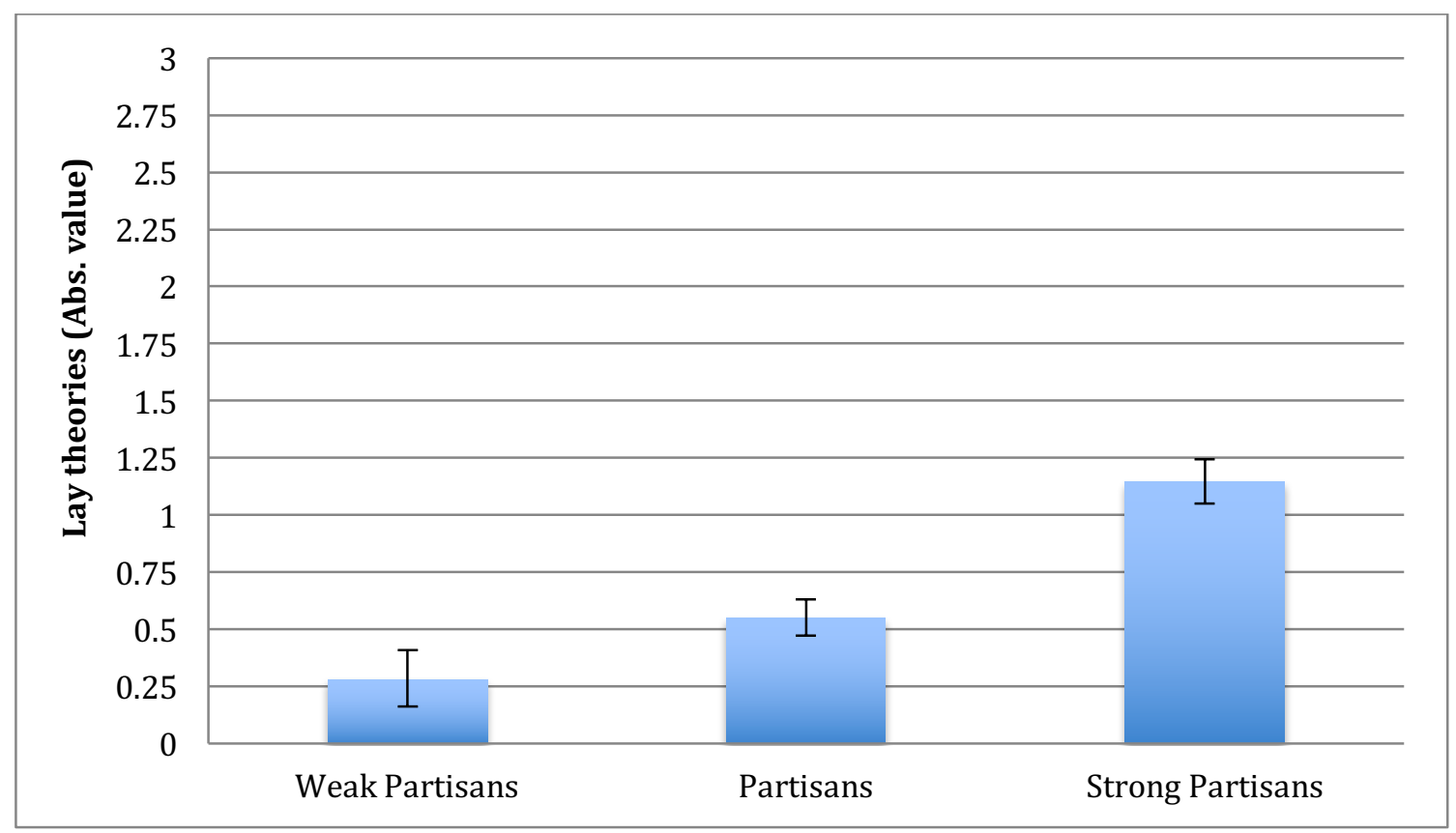


Figure 6b. Study 1: Lay theories by political affiliation. Y-axis represents frequency.

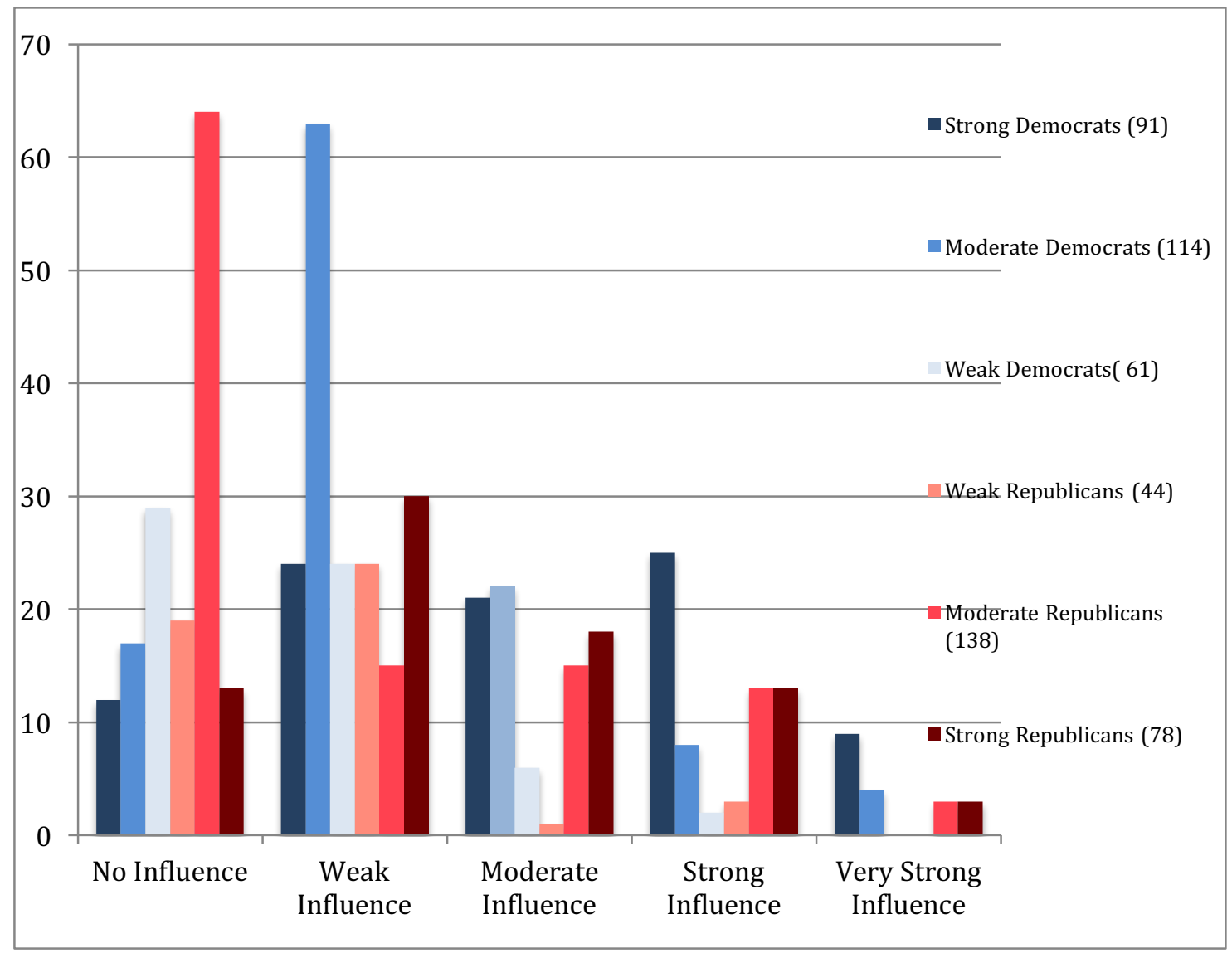


Figure 7. Study 1: Judgments of acceptability between conditions, partisanship strength, and judgment type.

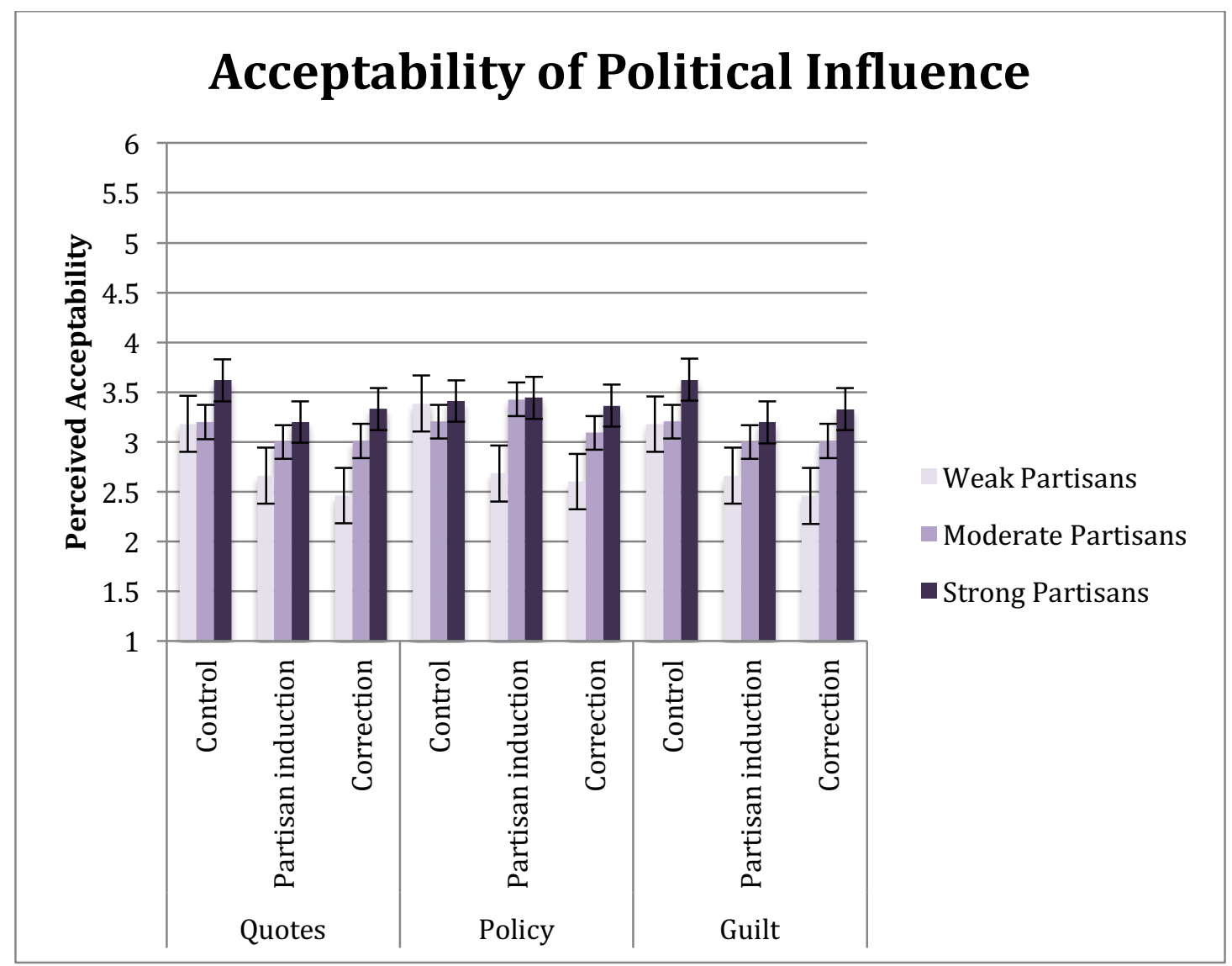


Figure 8a. Study 1: Evaluation of quotes between conditions. X-axis: Lay theories (absolute value measure).

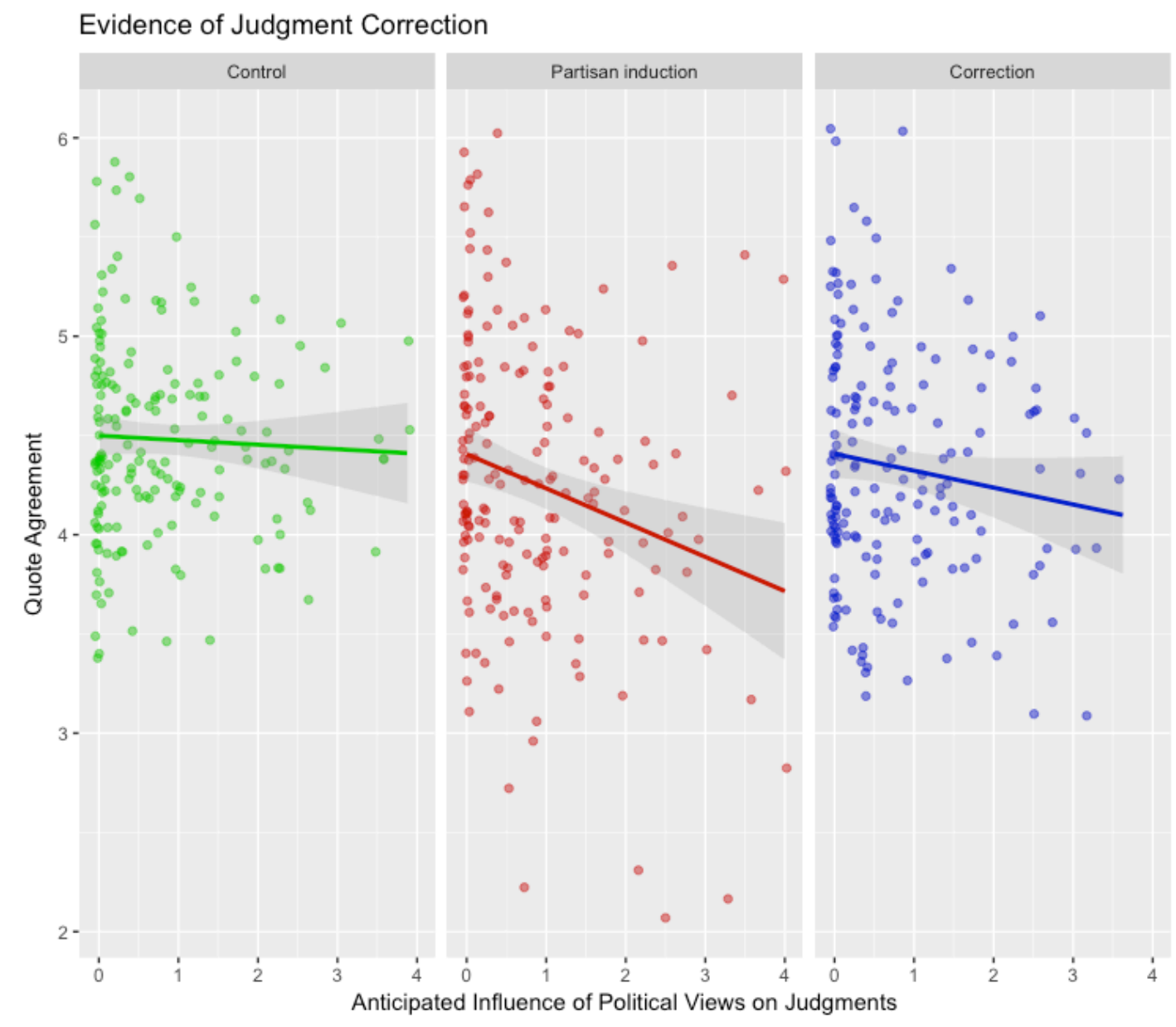


Figure 8b. Study 1: Evaluation of quote evaluations between conditions. X-axis: Judgments of acceptability.

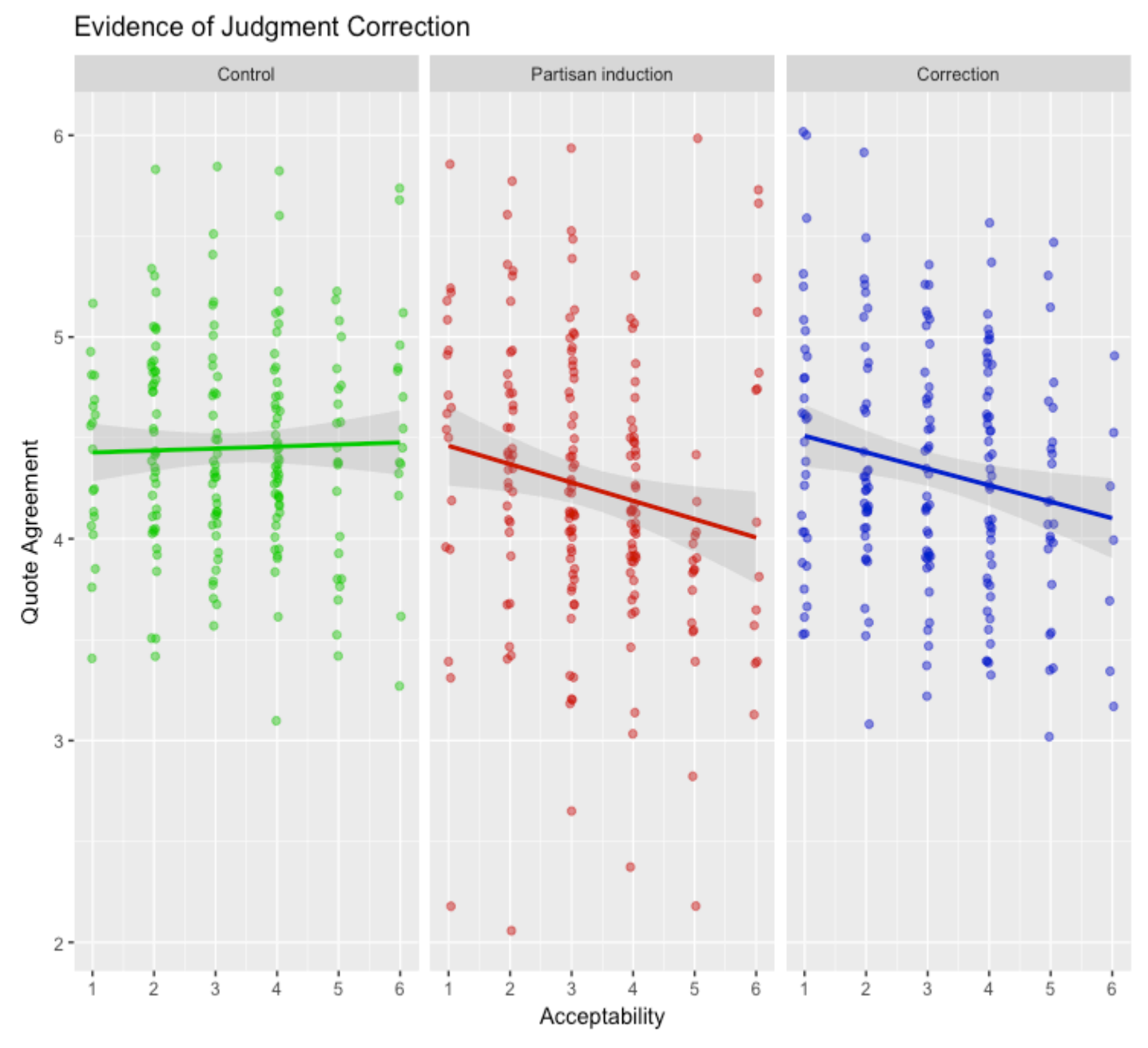


Figure 9. Study 1: Evaluation of quote evaluations across lay theories, between partisanship strength and condition. X-axis: Lay theories (absolute value measure).

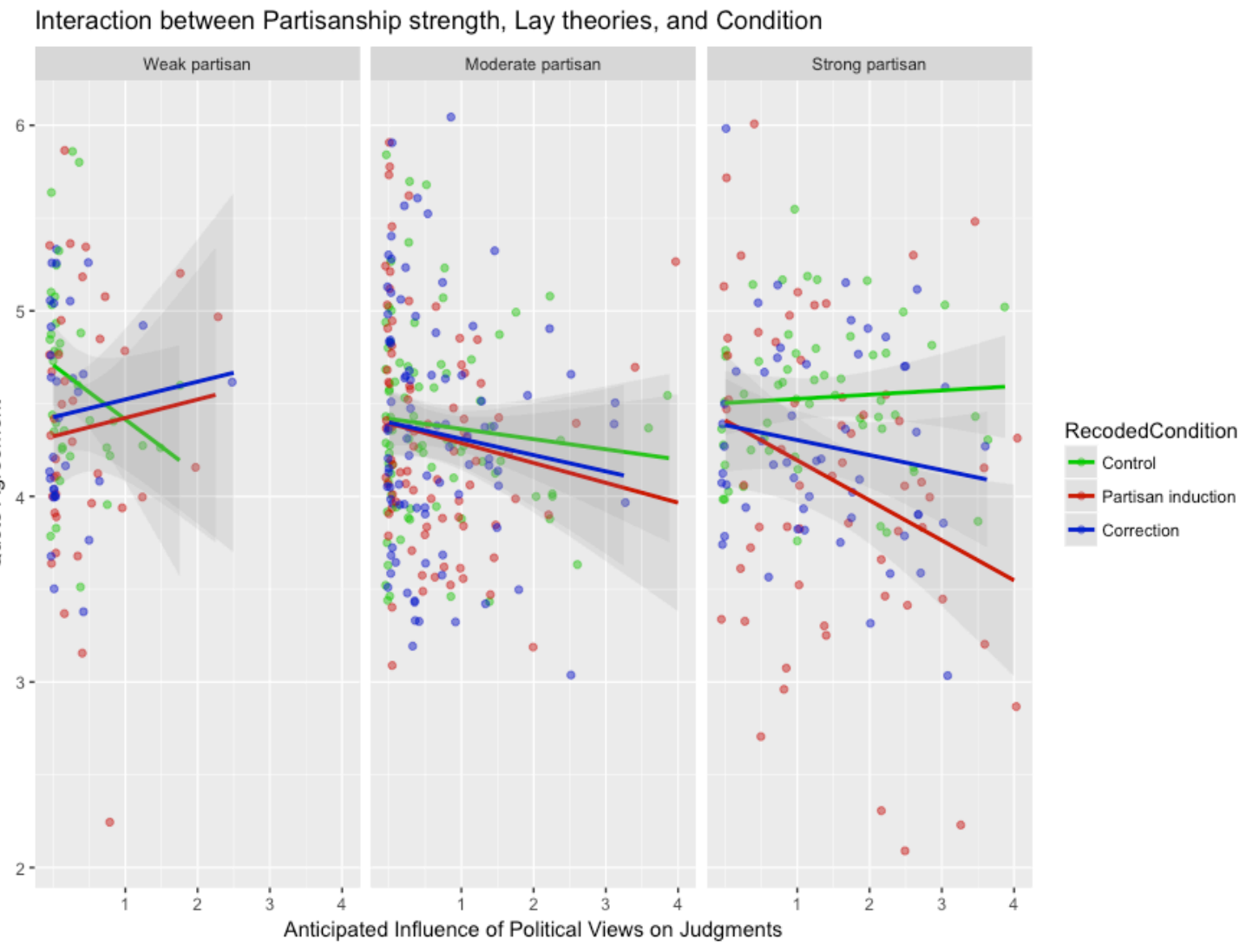


Figure 10. Study 1: Quote ratings across motivation, between condition and categorized level of lay theories. Lay theories "no influence": Lowest quartile of lay theories. "Strong influence": Highest quartile of lay theories.

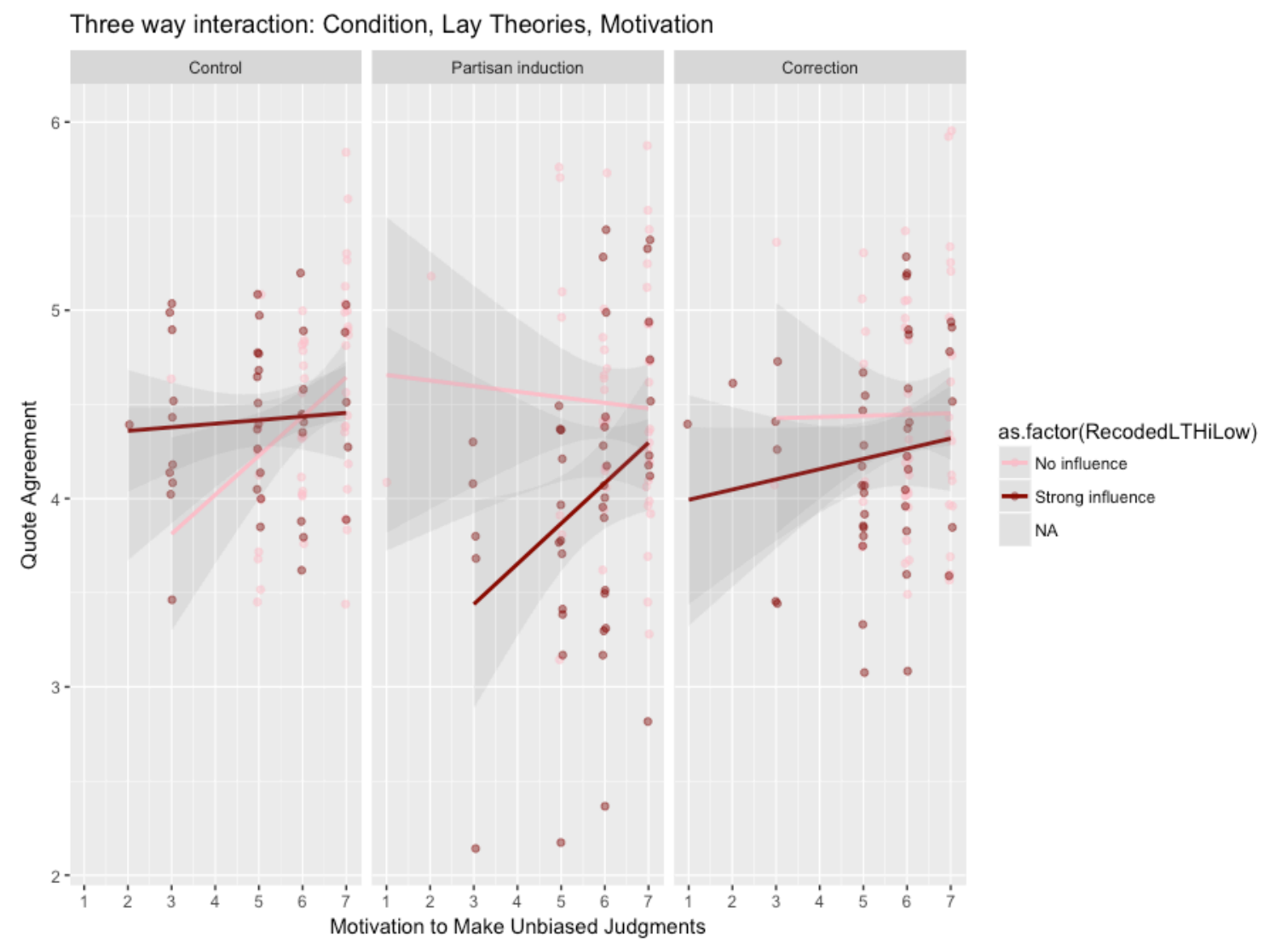


Figure 11. Study 1: Judgments of assault by condition and partisanship strength.

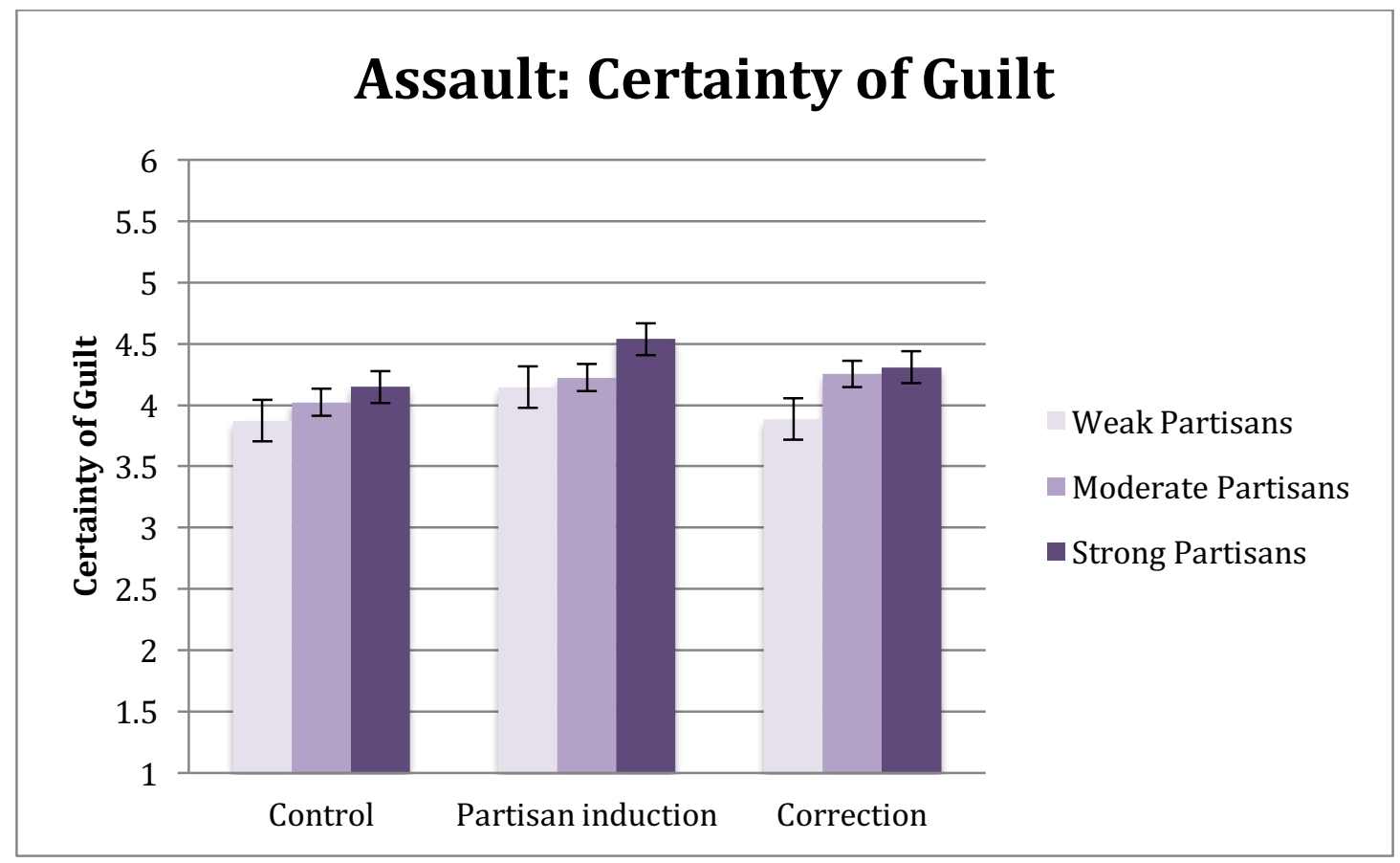


Figure 12. Study 1: Perceived guilt: Assault across views of acceptability and between conditions.

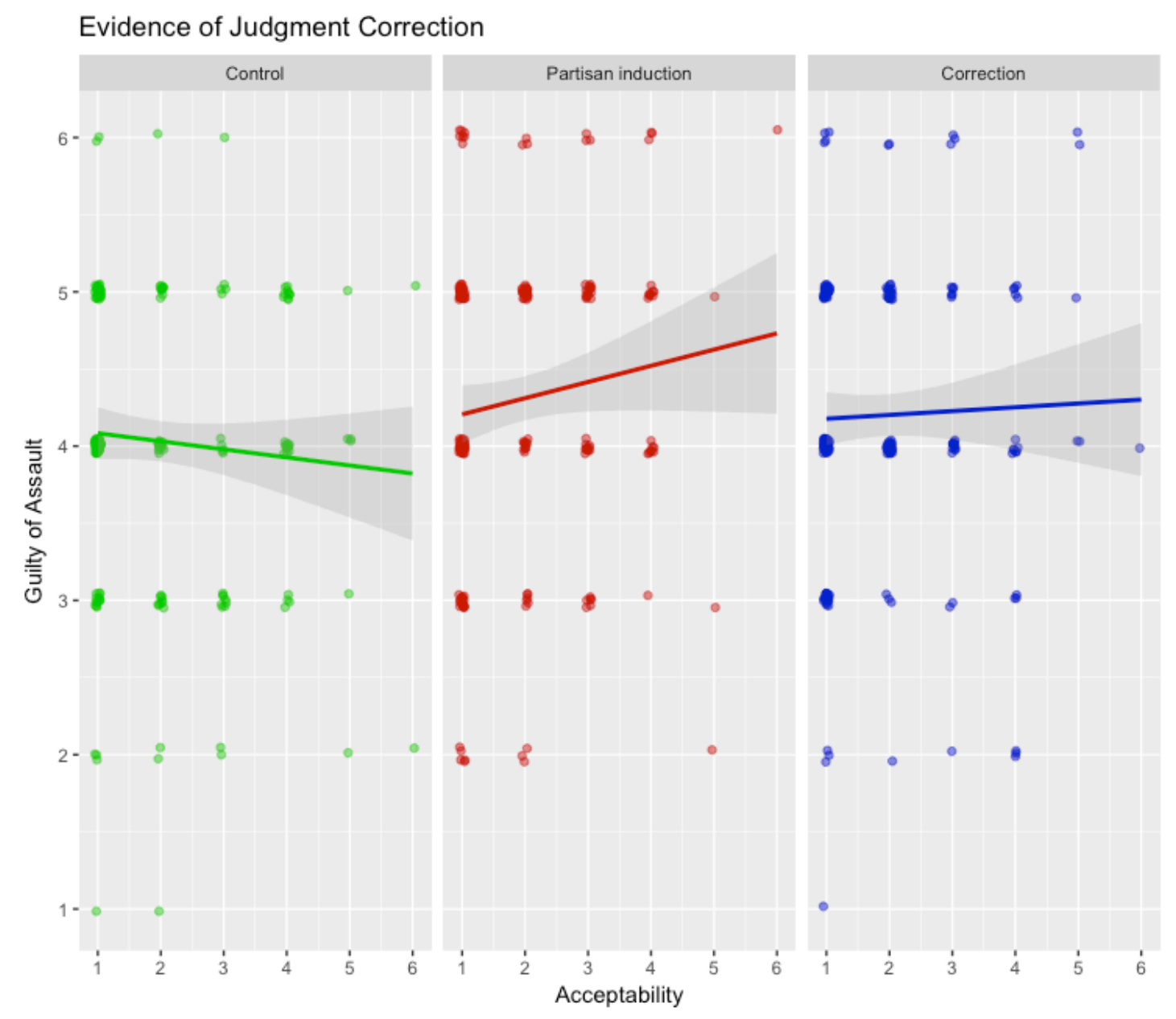


Figure 13. Study 1: Judgments of assault across motivation, between condition and grouped lay theories.

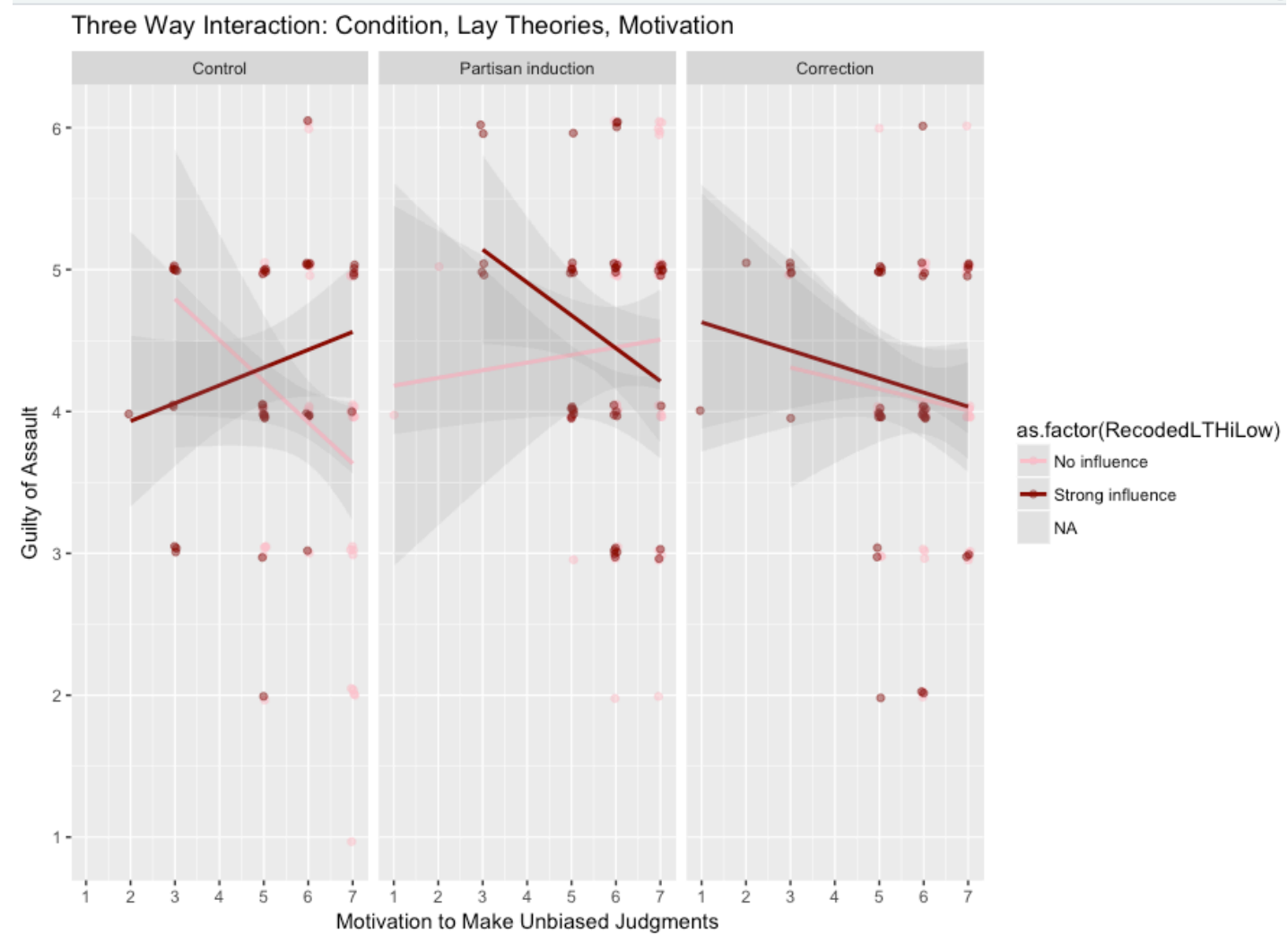


Figure 14. Study 1: Perceived guilt of attempted murder across views of acceptability and between conditions.

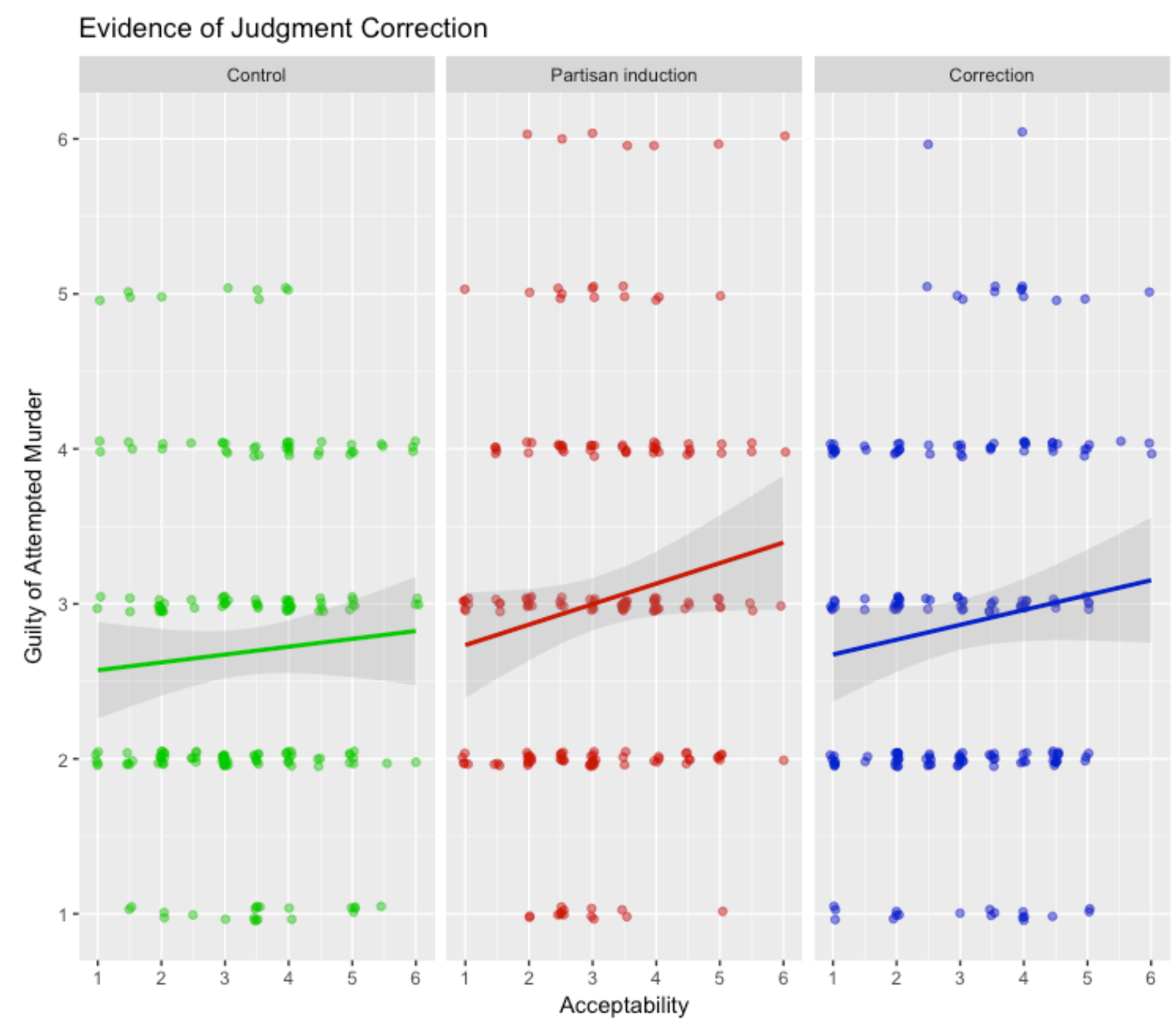


Figure 15. Study 1: Judgments of attempted murder across motivation, between conditions and grouped lay theories.

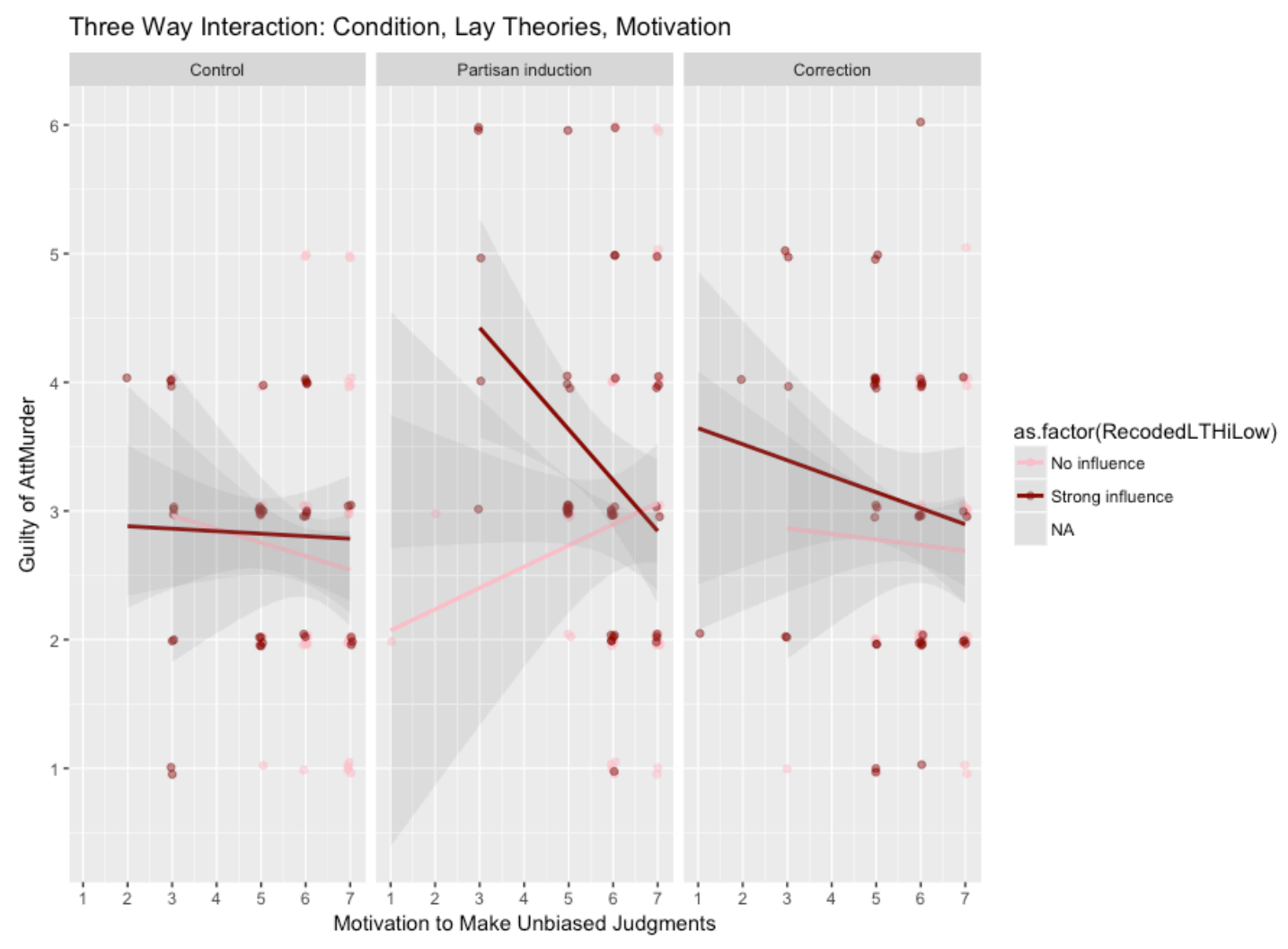


Figure 16. Study 1: Bias perception on quote judgments, between condition and partisanship strength.

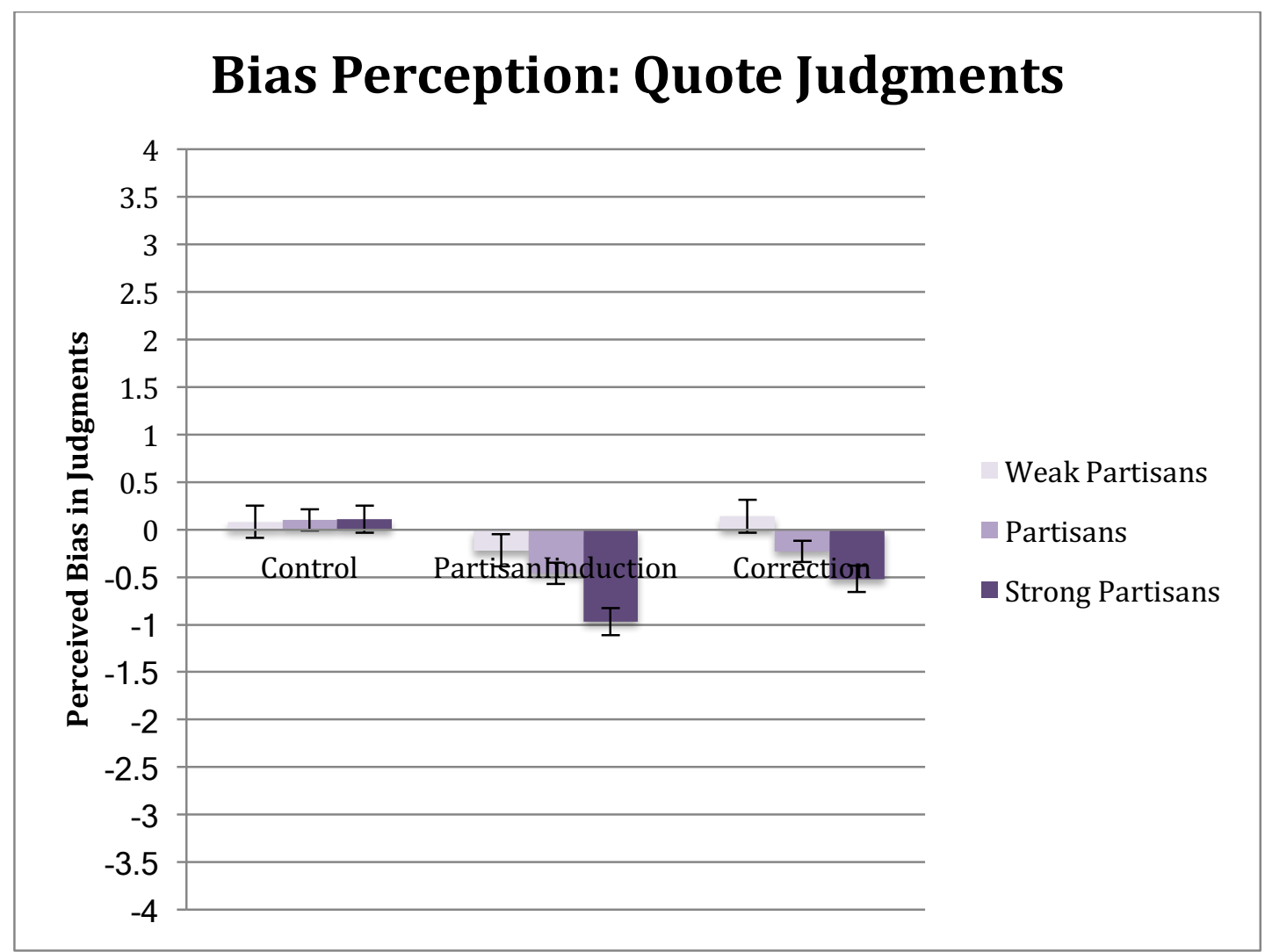


Figure 17. Study 1: Percentage of participants electing to view irrelevant political information about defendant between conditions.

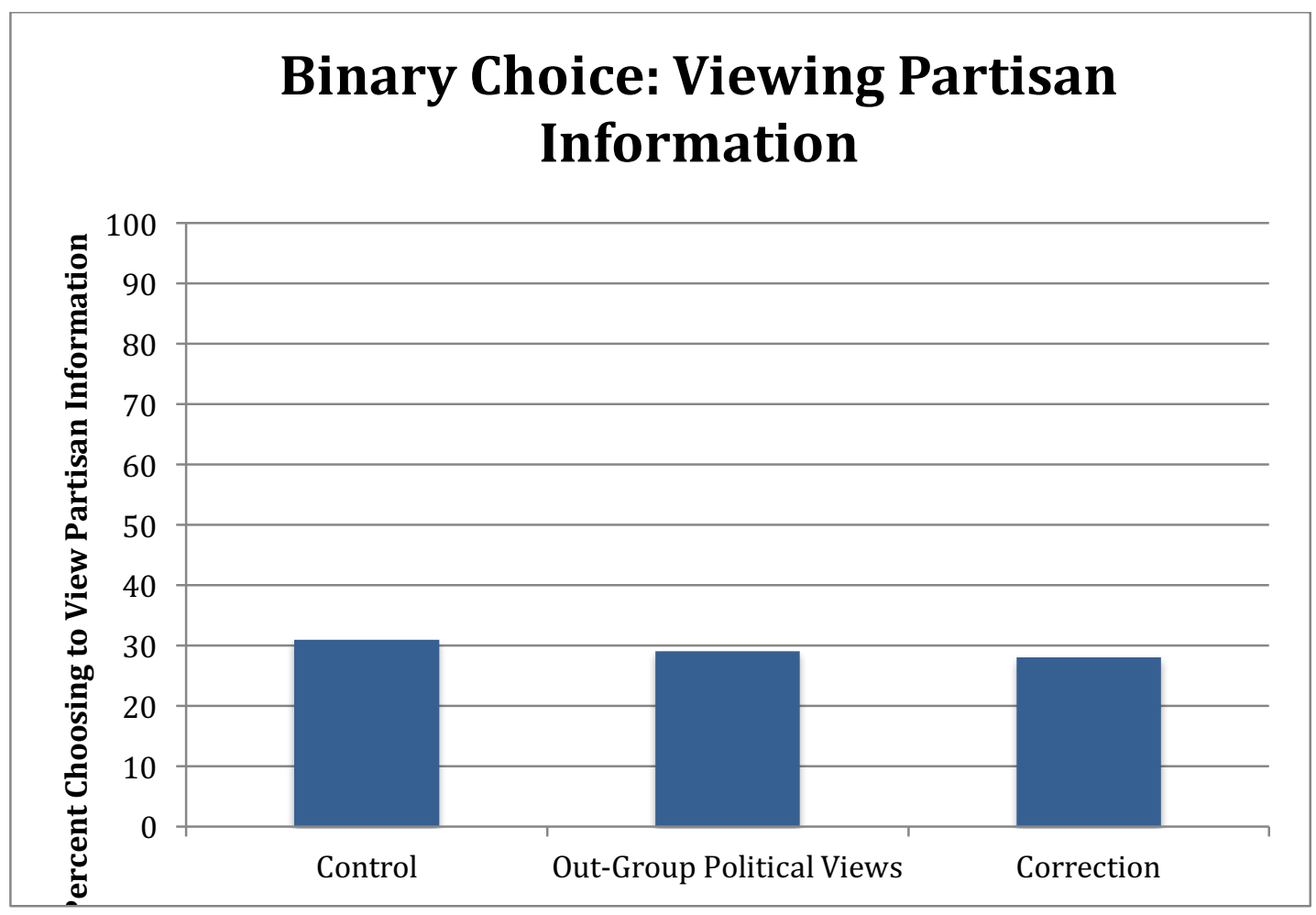


Figure 18. Study 1: Judgments of guilt in second jury scenario, across lay theories and between those who chose to view irrelevant partisan information and those who chose to avoid it.

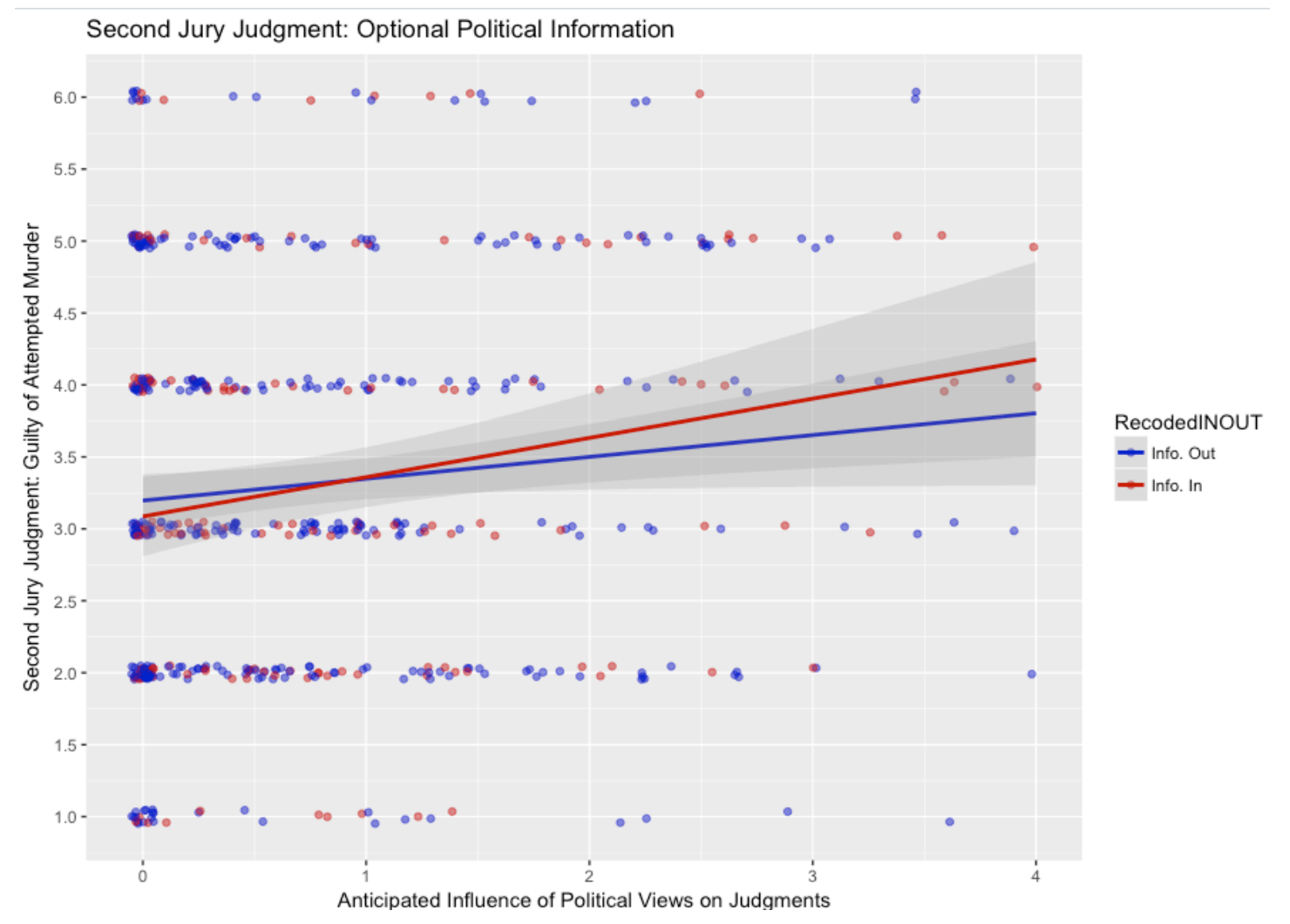


Figure 19a. Study 2a: Lay theories between levels of partisanship strength.

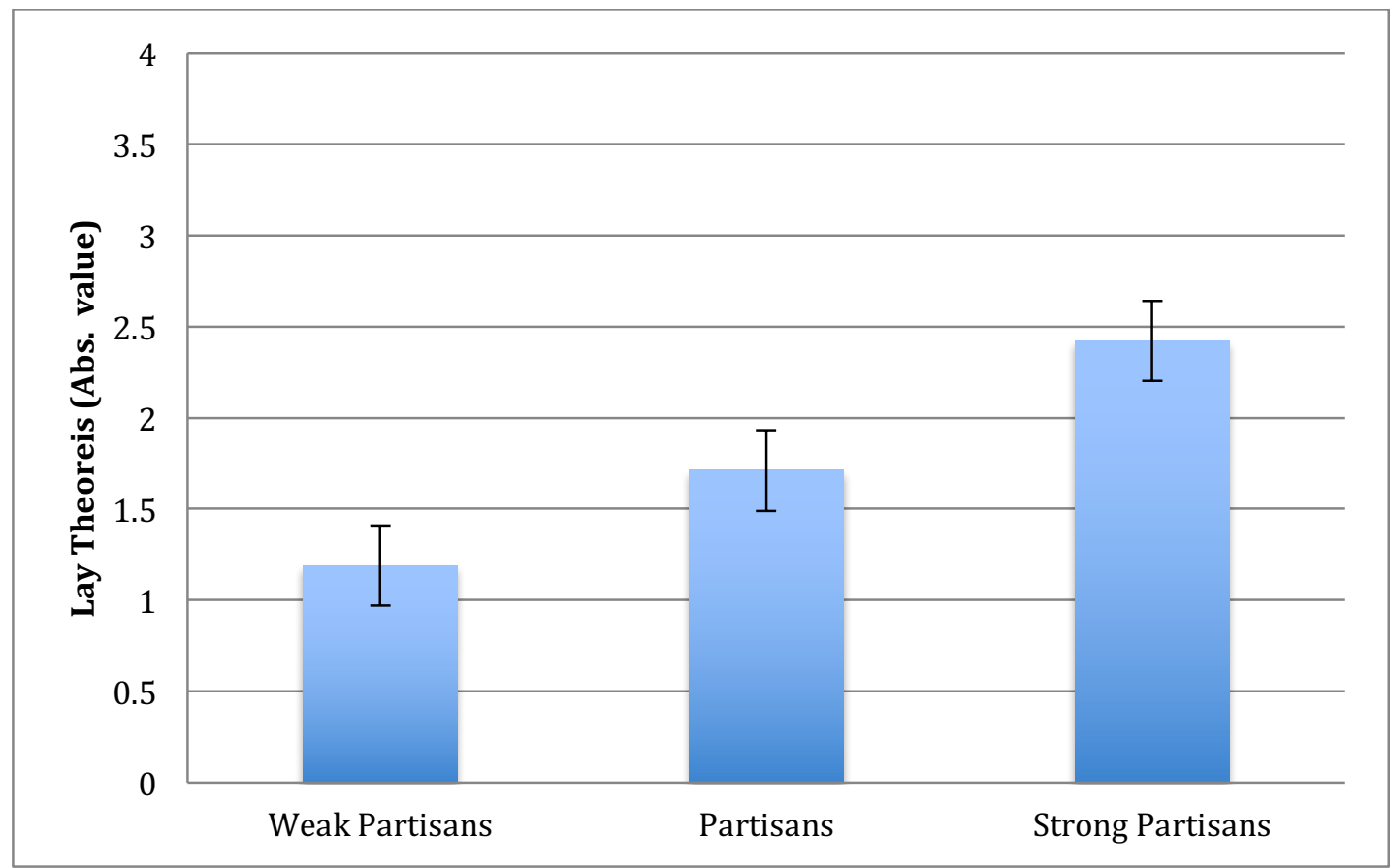


Figure 19b. Study 2a: Lay theories across political affiliation.

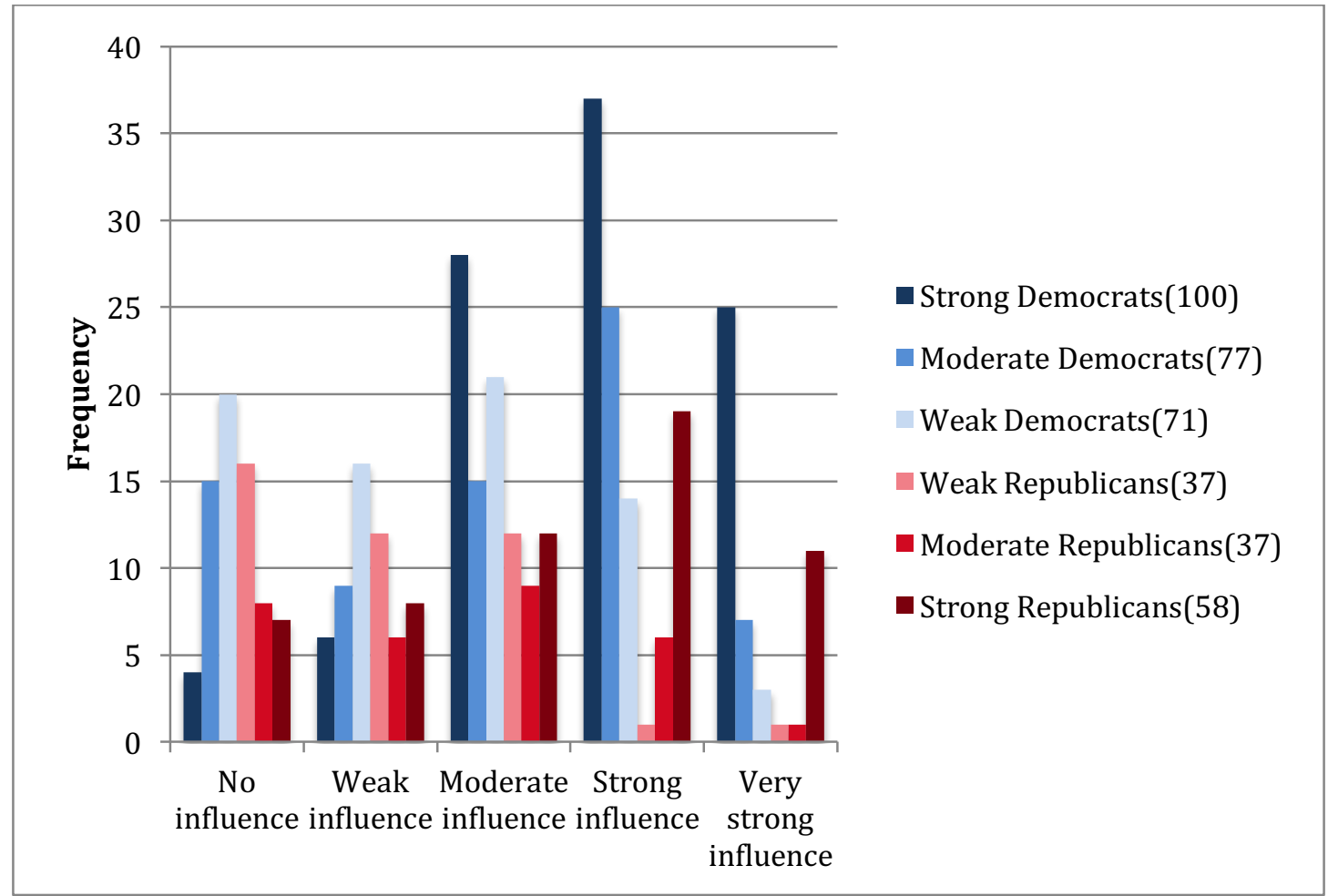


Figure 20. Study 2a: Acceptability by partisanship strength.

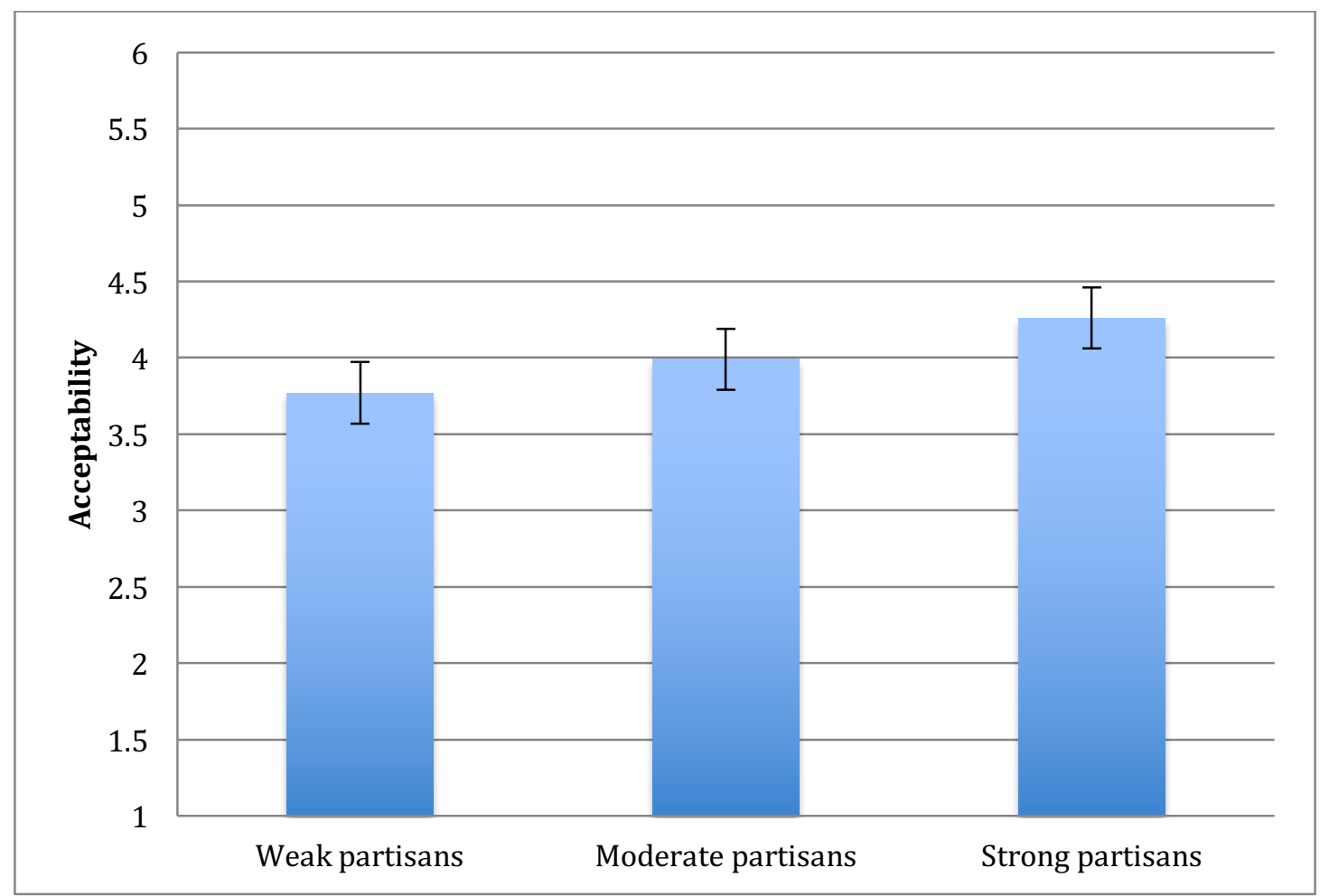


Figure 21. Study 2a: Bias prevention measures between conditions and political affiliation.

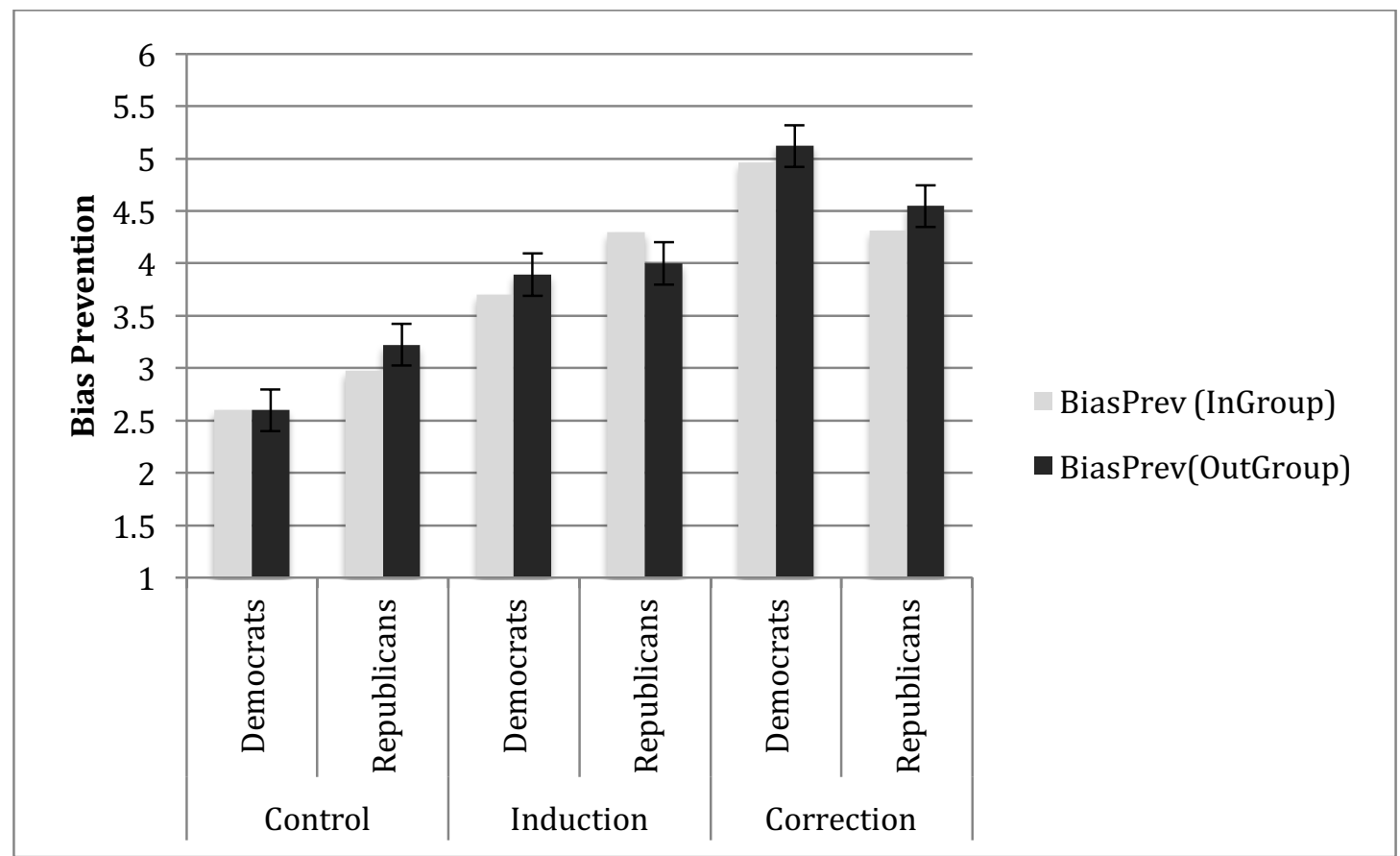


Figure 22. Study 2a: Quote ratings (In-group vs. Out-group) between condition and political affiliation.

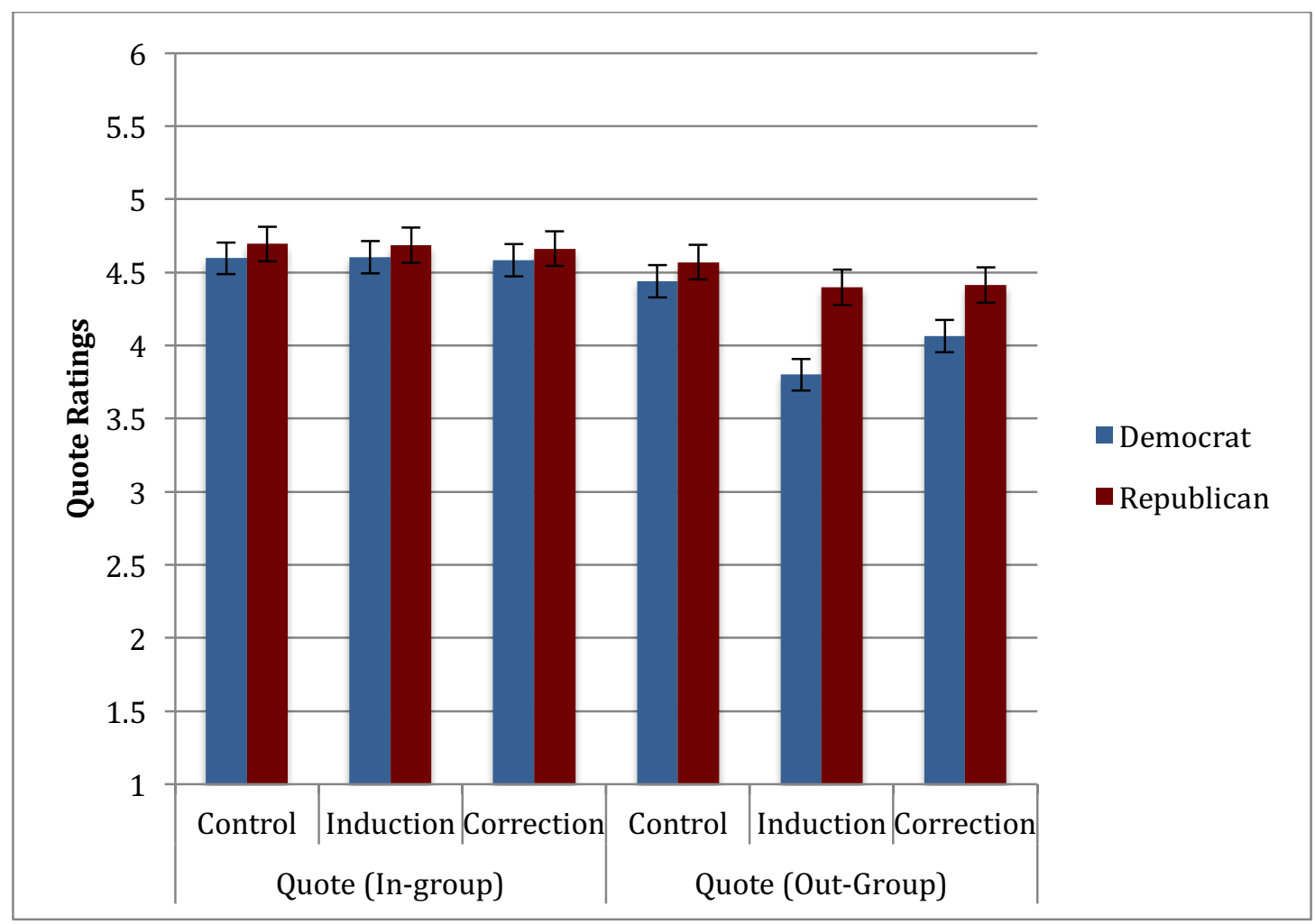


Figure 23. Study 2a: Quote judgments (difference score) across lay theories and between condition.

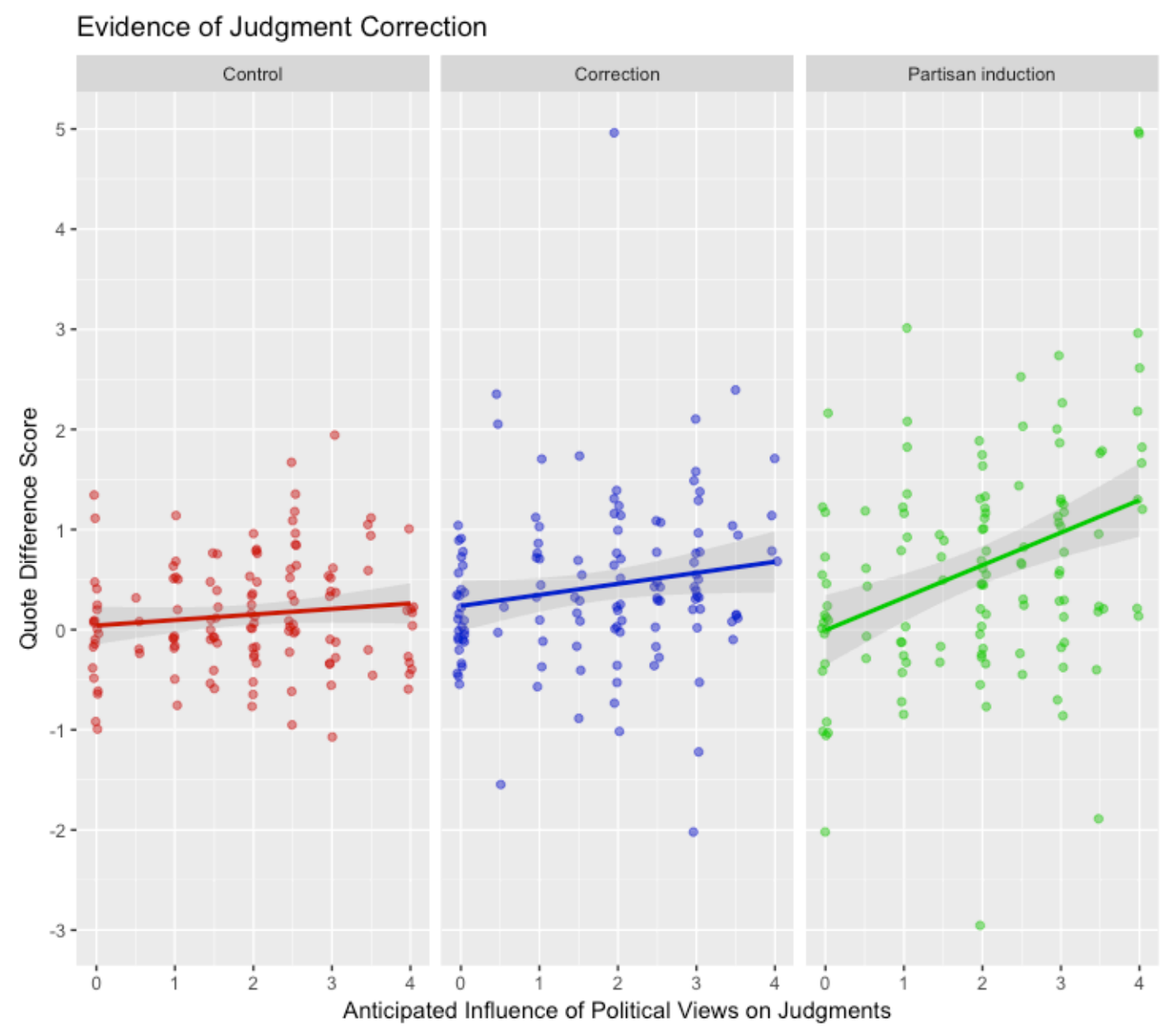


Figure 24. Study 2a: Quote judgments (difference score) across political knowledge, between conditions and grouped lay theories.

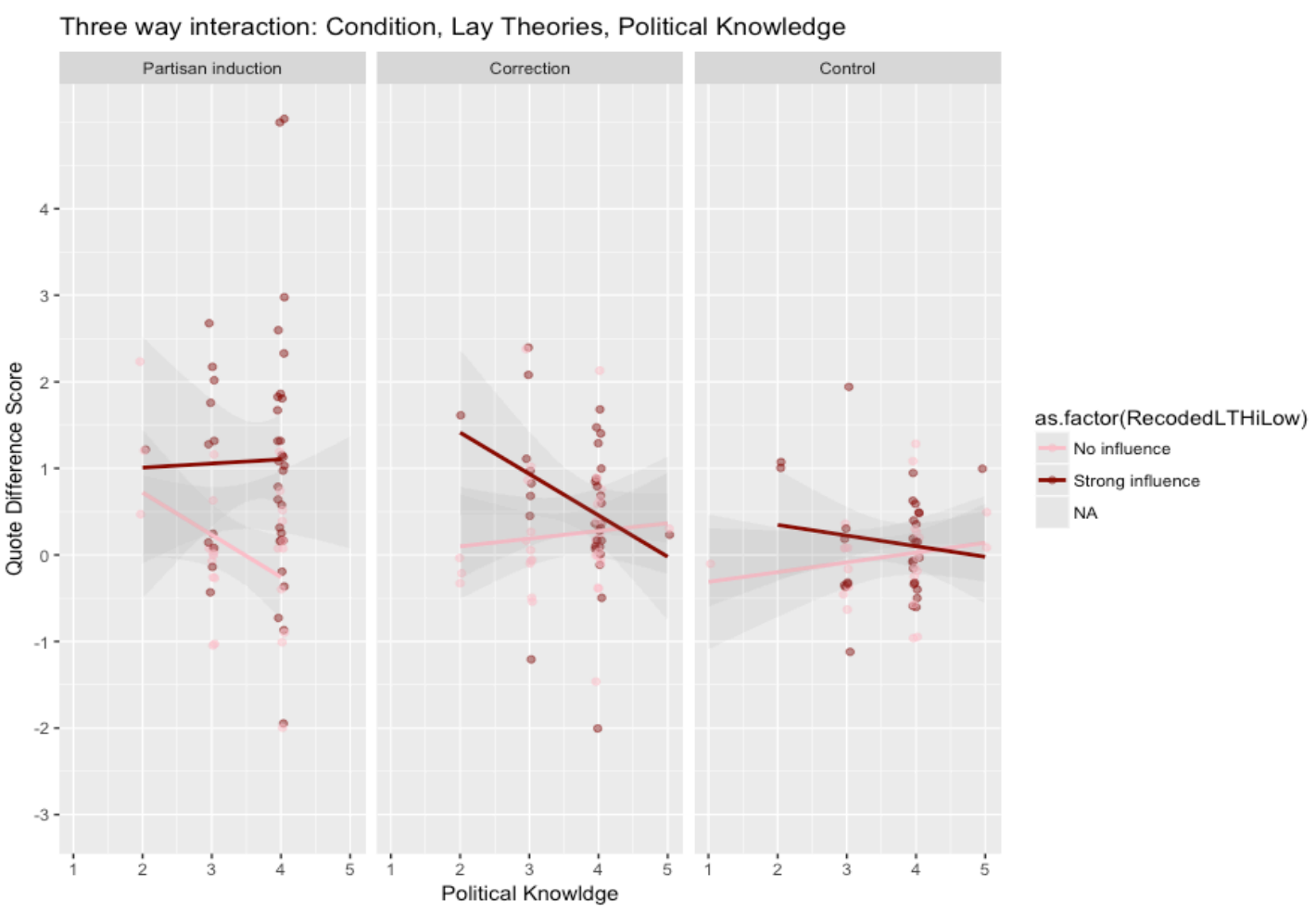


Figure 25. Study 2a: Bias perception (In-group vs. Out-group) between conditions.

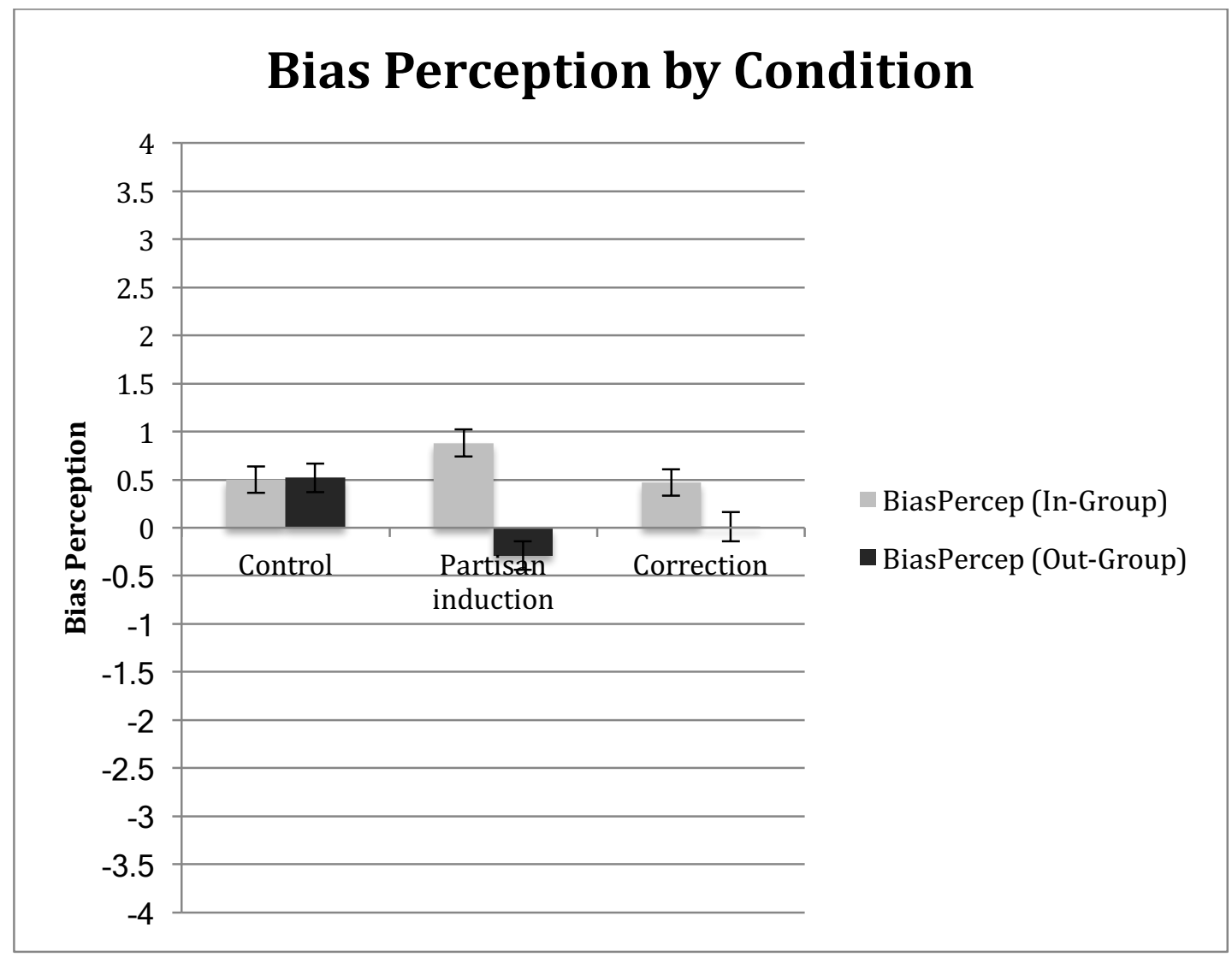


Figure 26. Study 2a: Bias perception (In-group vs. Out-group) between conditions and political

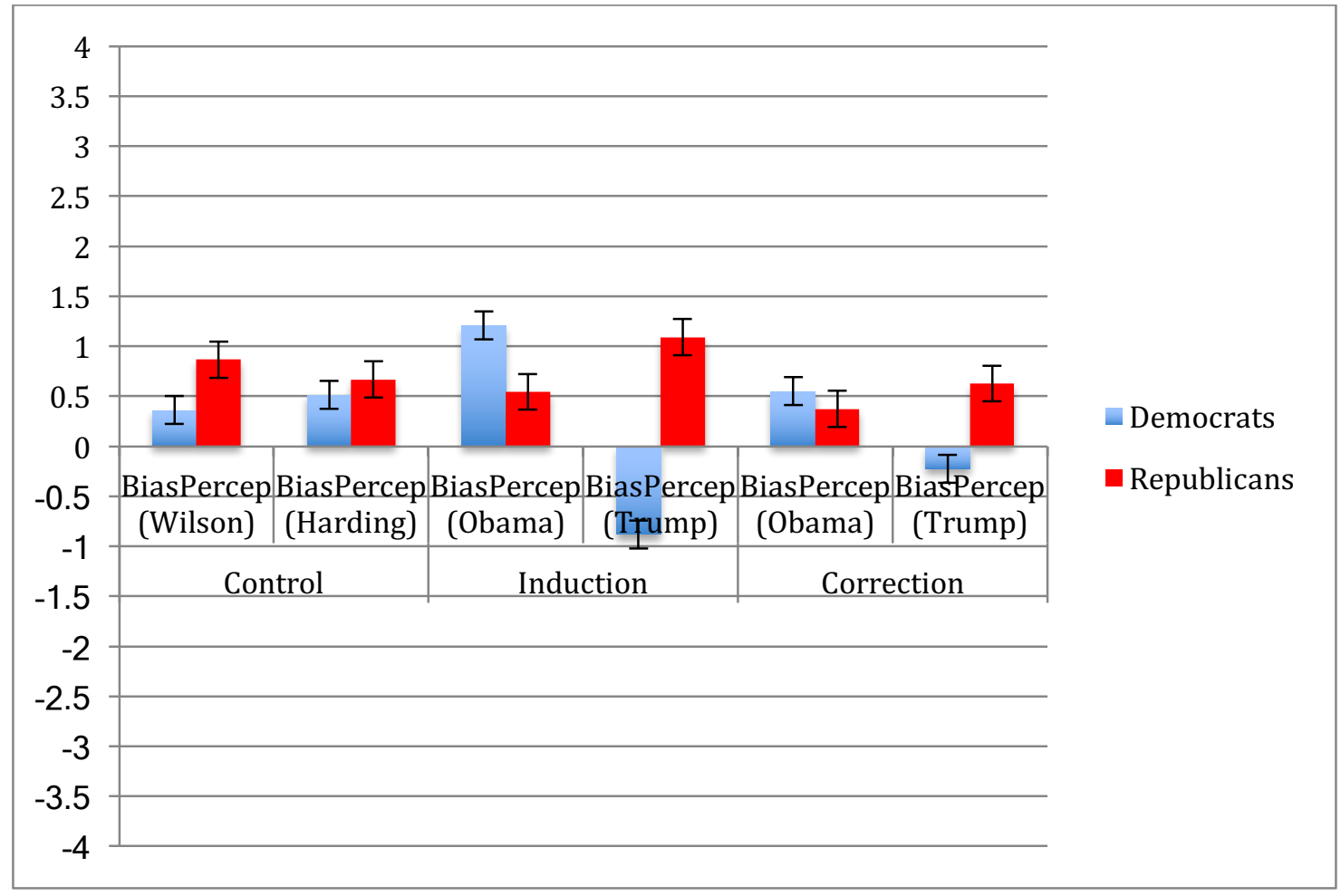


Figure 27a. Study 2b: Lay Theories by partisanship strength

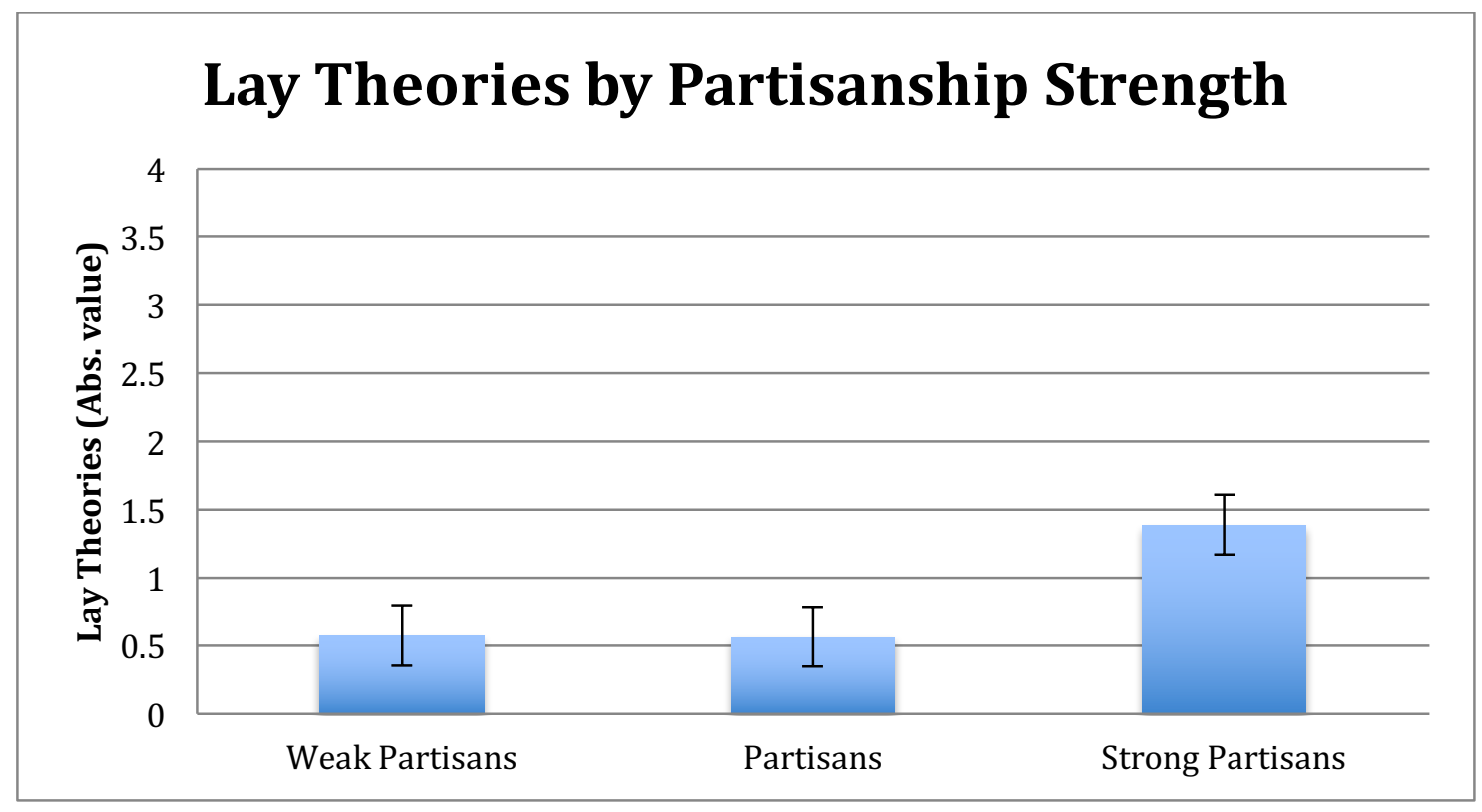


Figure 27b. Study 2b: Lay theories across political affiliation.

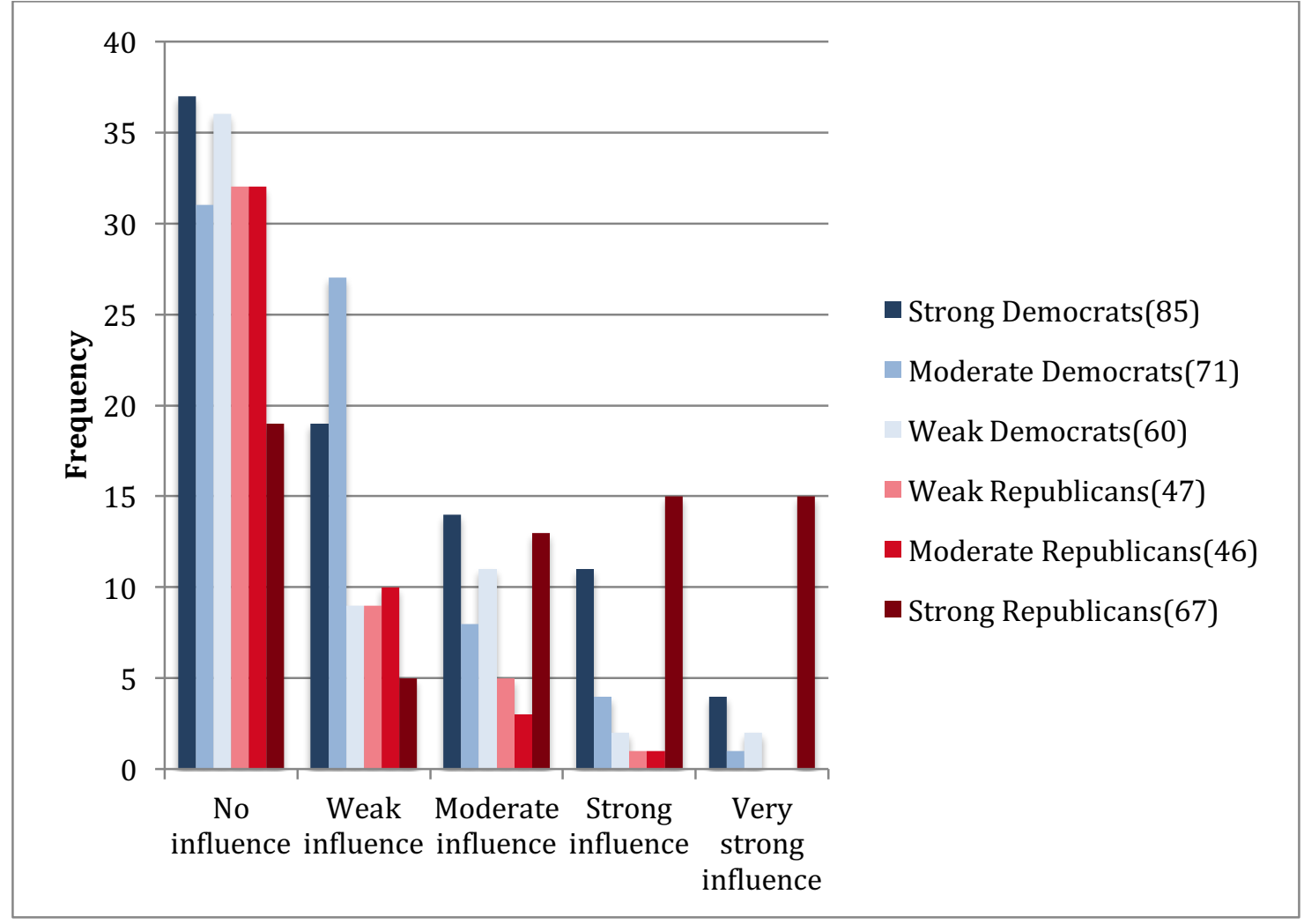


Figure 28. Study 2b: Ratings of acceptability between condition and partisanship strength.

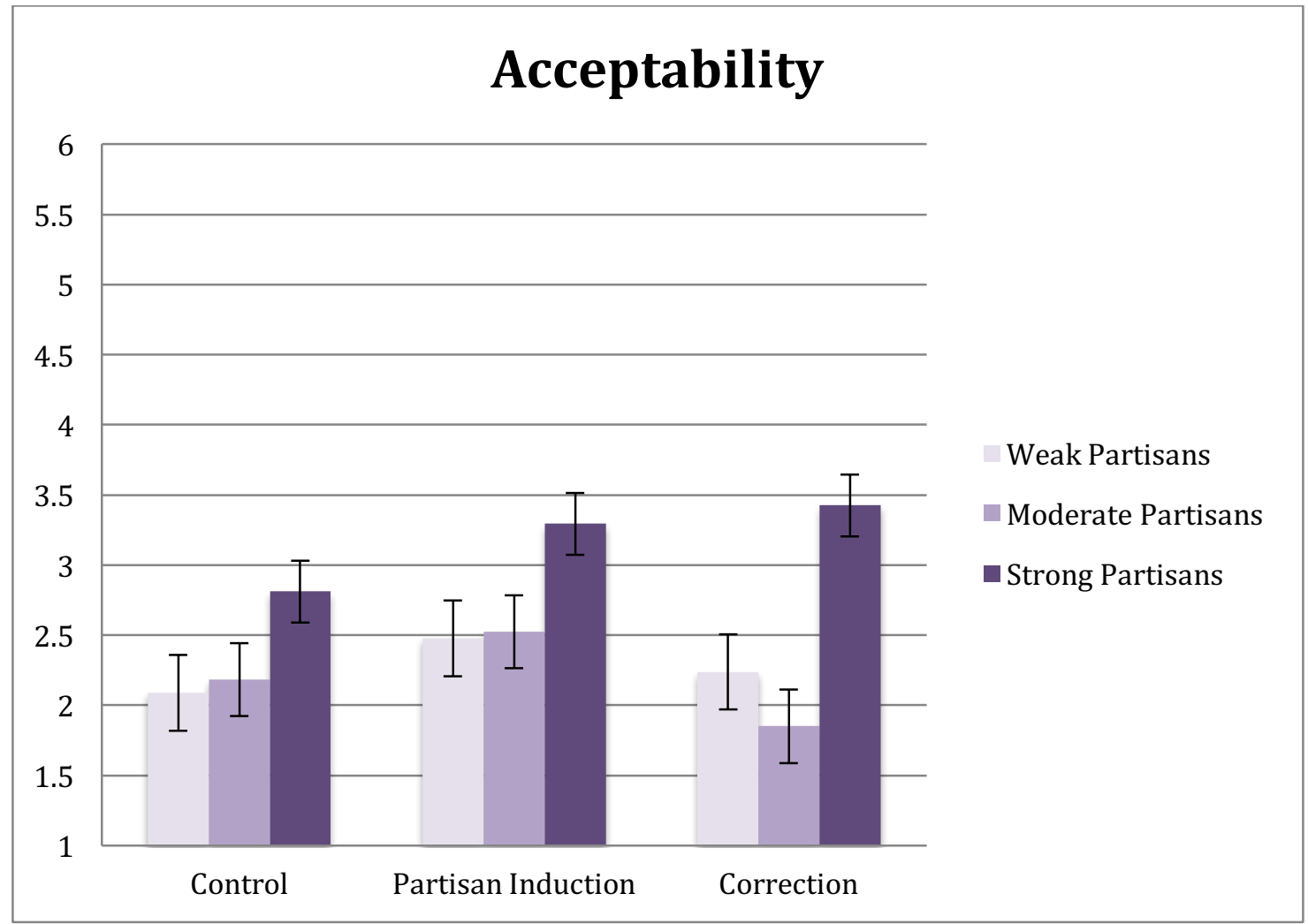


Figure 29. Study 2b: Judgments of guilt between condition and level of partisanship.

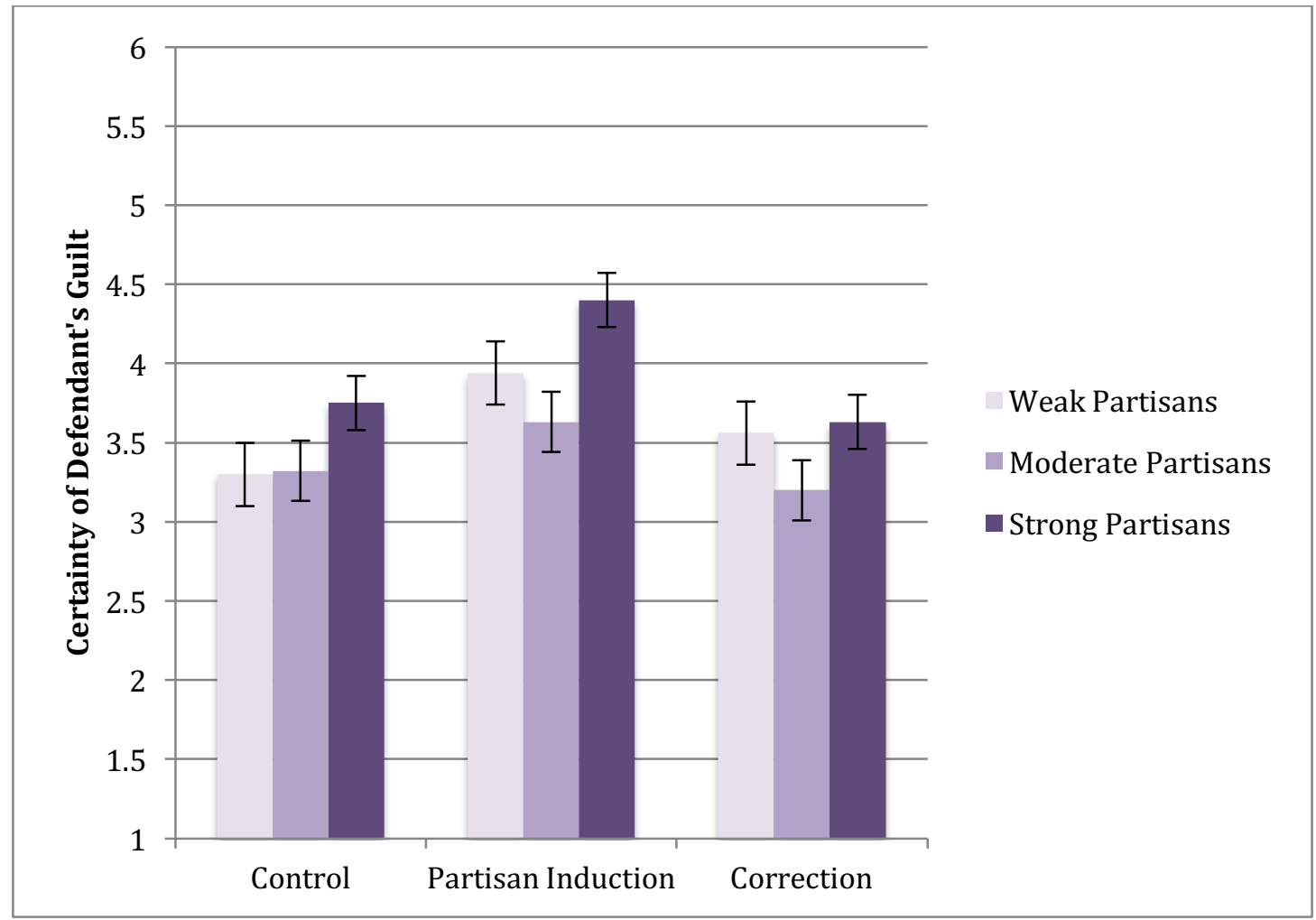


Figure 30. Study 2b: Judgments of guilt across lay theories and between condition.

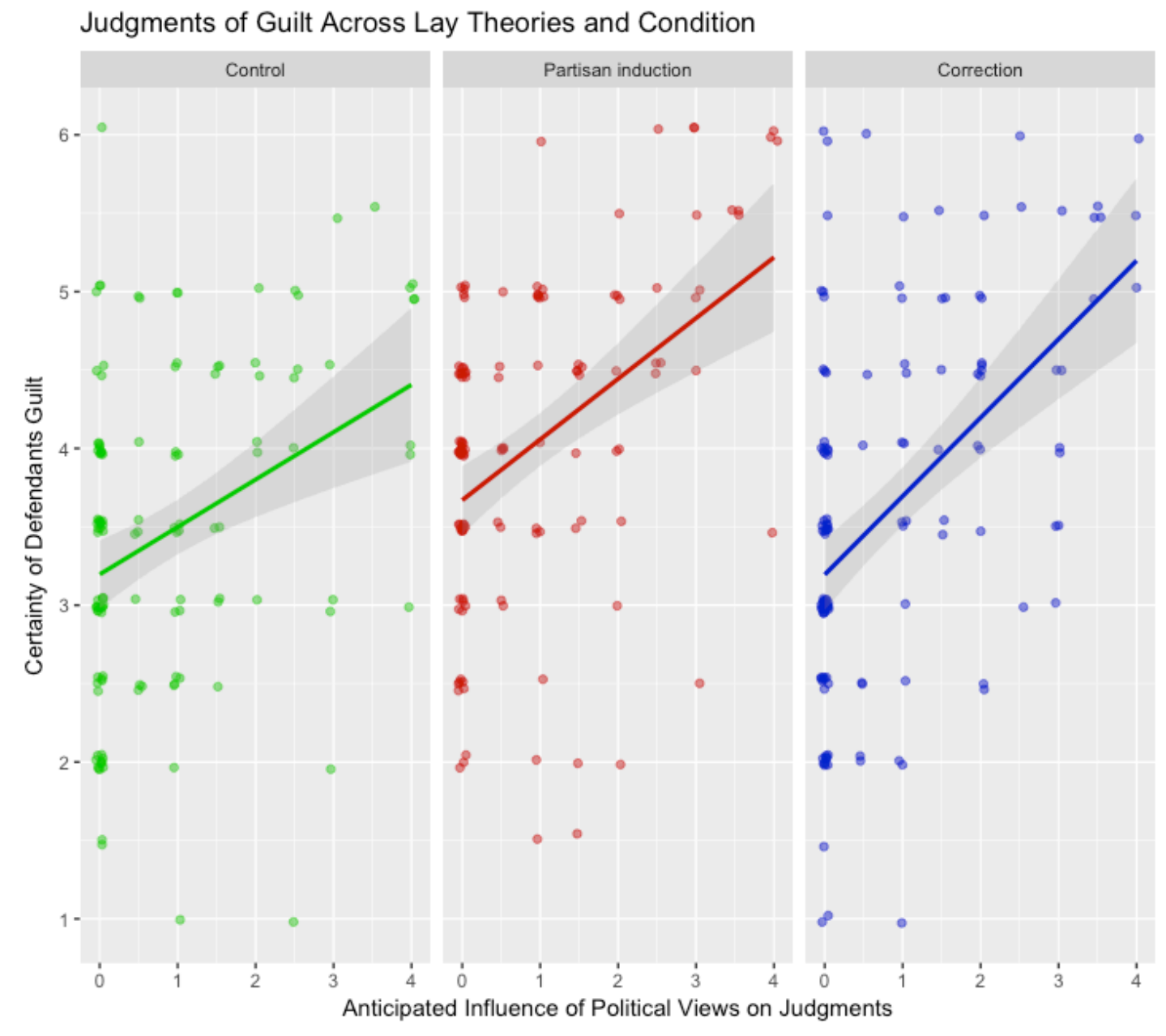


Figure 31. Study 2b: Judgments of guilt across political loyalty and between condition.

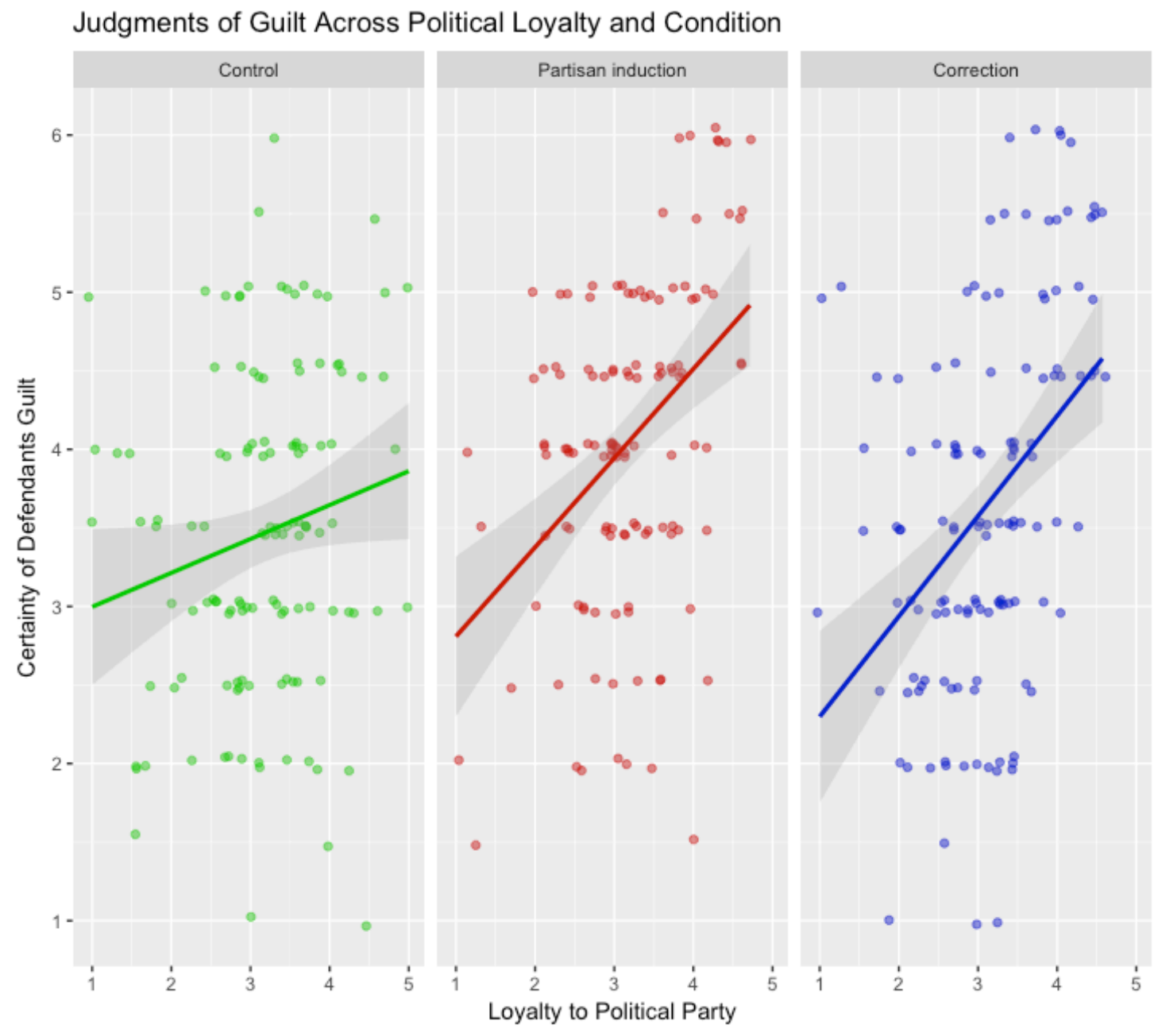


Figure 32. Study 2b: Selection of irrelevant political information between condition. Y-axis represents percentage of sample within each condition.

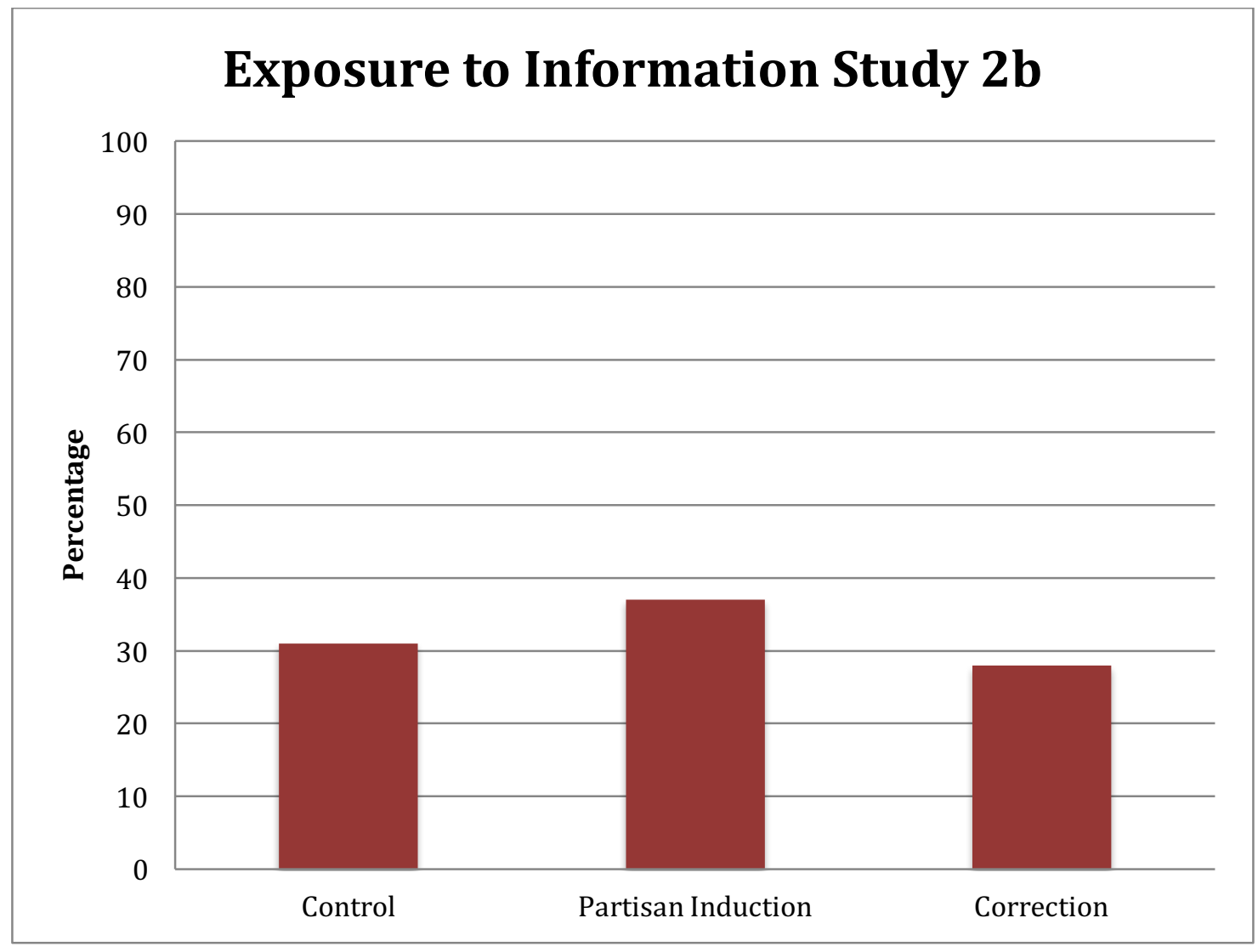


Figure 33. Study 2b: Guilt ratings across lay theories and between informational choice.

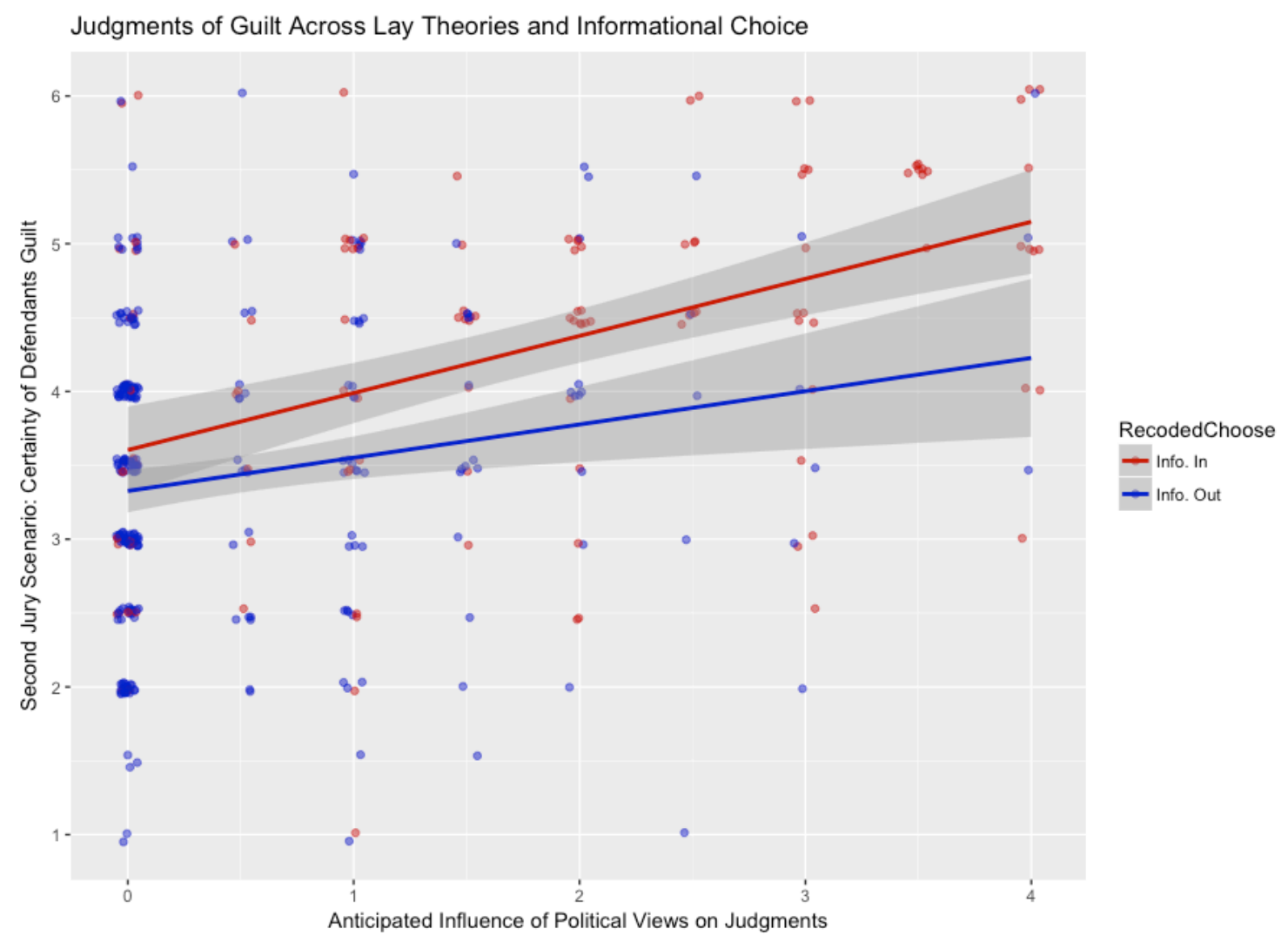


Figure 34. Study 2b: Bias perception between condition and level of partisanship strength.

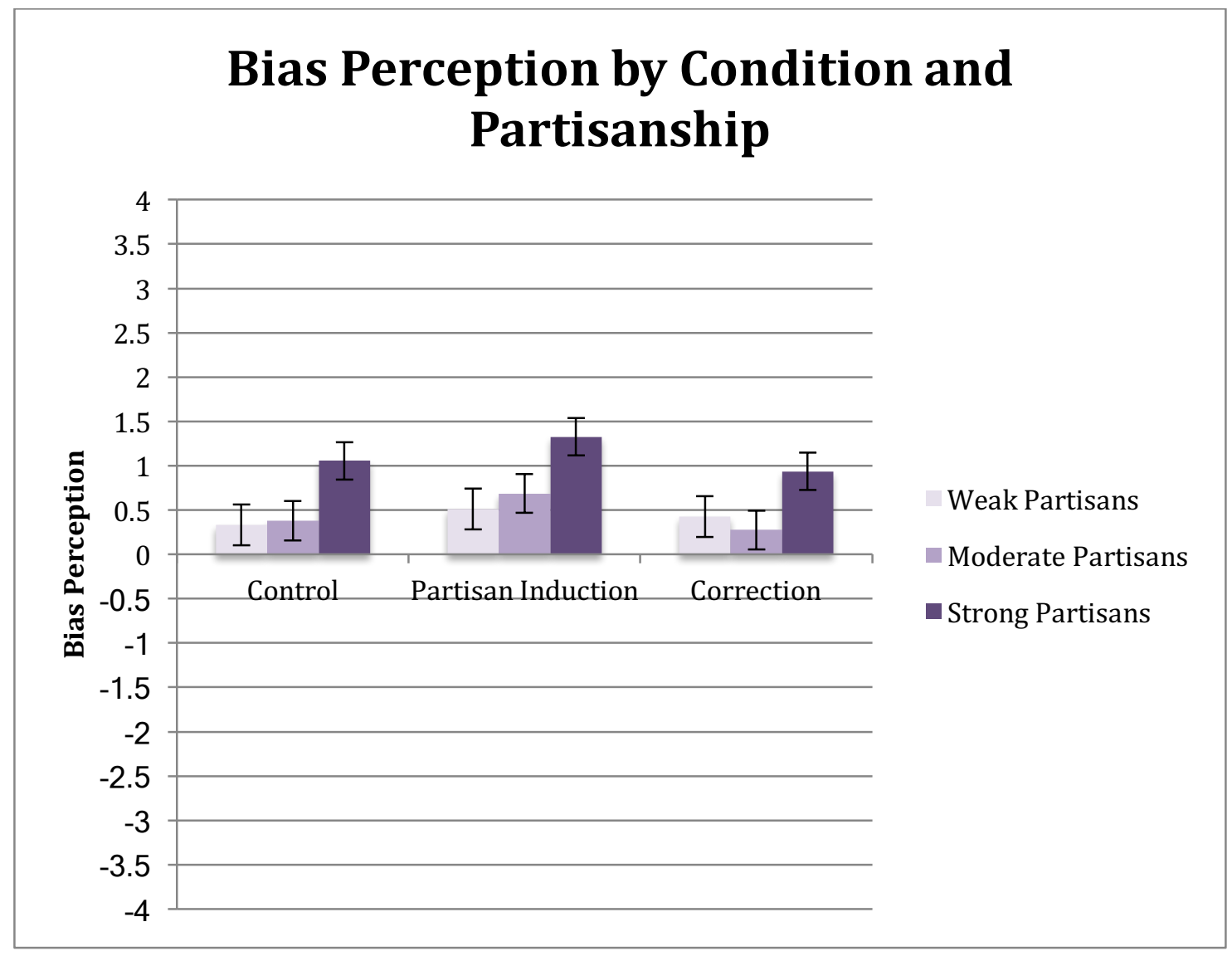




\section{Appendix}

\section{Table of Contents}

Pilot Study 1 Procedure..................................................... 159

Pilot Study 1 Materials........................................................ 161

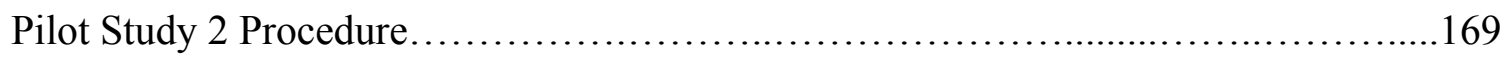

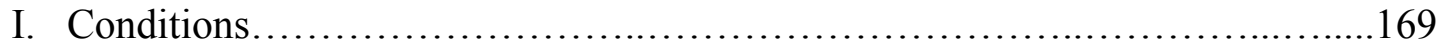

II. Survey Flow..................................................... 170

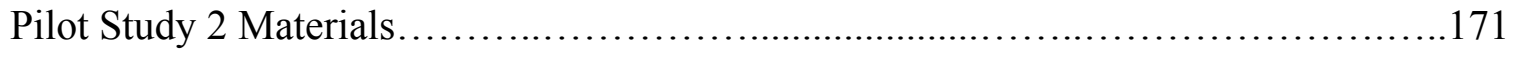

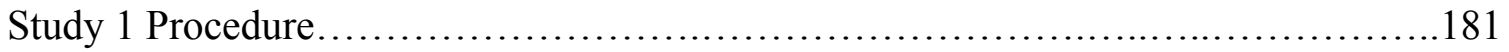

I. Conditions.......................................................... 181

II. Survey Flow......................................................... 182

Study 1 Materials......................................................... 184

Study 1 Supplemental analyses.............................................. 216

I. Perceived bias prevention ability .....................................2 216

II. Within-subjects acceptability analyses................................2218

III. Perceived seriousness of crimes in jury scenario..........................220

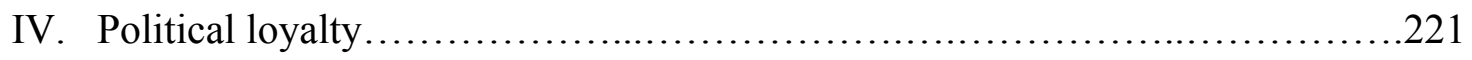

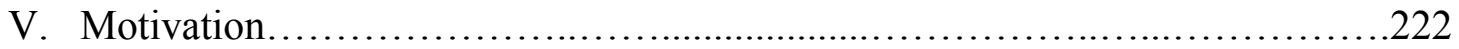

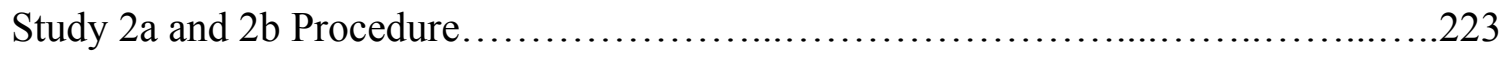

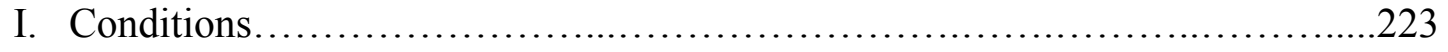

II. Survey Flow.......................................................224

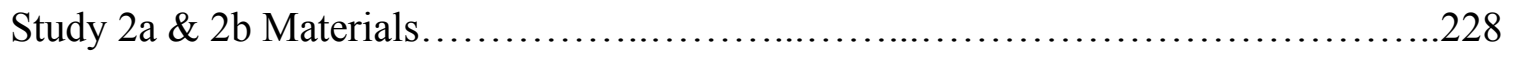




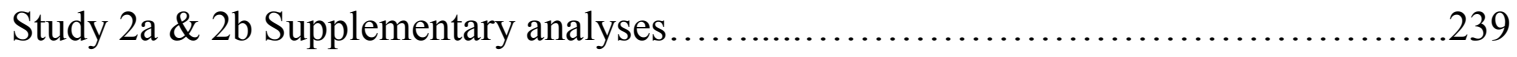

I. Study 2a: Political Loyalty...............................................229

II. Study 2b: Political Loyalty .........................................240

III. Study 2a: Political Knowledge..............................................241

IV. Study 2b: Political Knowledge............................................242 


\section{Pilot Study 1 Procedure}

\section{Congressional bills}

a. Lay theories and acceptability (items randomized between political party and bill)

i. Republican Senator: Healthcare Bill

ii. Republican Senator: Tax Reform Bill

iii. Democratic Senator: Healthcare Bill

iv. Democratic Senator: Tax Reform Bill

\section{Crowd size estimation}

a. Lay Theories and acceptability (presented in random order)

i. Trump Crowd estimation

ii. Obama Crowd estimation

\section{Evaluating politicians}

a. Lay theories and acceptability (presented in random order)

i. Evaluating Republican Politician

ii. Evaluating Democratic Politician

\section{Evaluating new neighbors}

a. Lay theories and acceptability (presented in random order)

i. New Republican neighbor

ii. New Democratic neighbor

\section{Evaluating presidents' likableness}

a. Lay theories and acceptability (presented in random order)

i. Trump

ii. Obama

\section{Evaluating Presidential quotes}

a. Lay theories and acceptability (presented in random order)

i. Quotes attributed to Trump

ii. Quotes attributed to Obama

\section{Individual Difference Measures}
a. General ability to prevent political influences on judgments
b. Actively open-minded thinking (7-items)
c. Categorical thinking (3-items)
d. Two-dimensional Cultural Worldview-Scale 
i. Views on individualism (6-items)

ii. Views on hierarchy (6-items)

e. Science Literacy (8-items)

f. Wason Card Selection Task (1-item)

g. Rasch Numeracy (8-items)

\section{Demographic information}

a. Political affiliation (3-items)

i. Political orientation

1. (Scale: 1(Extremely liberal) to 7(Extremely conservative))

ii. Voting pattern (Scale: 1-7)

1. (Scale: 1(Exclusively Democratic) to 7(Exclusively Republican))

iii. Partisan support

1. (Scale: 1(Exclusively Democratic) to 7(Exclusively Republican)) 


\section{Pilot Study 1 Materials}

\section{Congressional Bills}

Republican (Democratic) Healthcare Bill. Imagine that you are evaluating a new healthcare bill from Congress. Your goal is to evaluate only the policy contents of the bill itself. You also know that the bill was written by a well-known Republican Senator. It's possible that your feelings toward Republicans might influence how you evaluate the bill. That is, knowing that it was written by a Republican might cause you to evaluate the bill more positively or negatively, relative to how you would have elevated it if you did not know who wrote it.

To what extent do you think that your feelings toward Republican (either positive or negative) would influence your evaluation of the policies that are presented in the healthcare bill?

1) My knowledge of the author's political party...

a. 1 (Would make my evaluation much more negative), 5 (Would not influence my evaluation), 9 (Would make my evaluation much more positive).

2) To what extent is it acceptable for your political views to influence this judgment?

a. 1 (Strongly unacceptable), 5 (Neither acceptable, nor unacceptable), 9 (Strongly acceptable) 
Republican (Democratic) Tax Reform Bill. Imagine that you are evaluating a new tax reform bill from Congress. Your goal is to evaluate only the policy contents of the bill itself. You also know that the bill was written by a well-known Republican Senator. It's possible that your feelings toward Republicans might influence how you evaluate the bill. That is, knowing that it was written by a Republican might cause you to evaluate the bill more positively or negatively, relative to how you would have elevated it if you did not know who wrote it.

To what extent do you think that your feelings toward Republican (either positive or negative) would influence your evaluation of the policies that are presented in the tax reform bill?

1) My knowledge of the author's political party...

a. 1 (Would make my evaluation much more negative), 5 (Would not influence my evaluation), 9 (Would make my evaluation much more positive).

2) To what extent is it acceptable for your political views to influence this judgment?

a. 1 (Strongly unacceptable), 5 (Neither acceptable, nor unacceptable), 9 (Strongly acceptable) 


\section{Crowd Estimation}

Imagine that you are being asked to estimate the size of the crowd in a picture of President Donald Trump's (former President Barack Obama’s) inauguration. Your goal is the estimate the size of the crowd as accurately as possible. It's possible that your feelings towards Donald Trump might influence your estimation. That is, knowing that it is a picture of Trump's inauguration might cause you to say there are more or fewer people in the picture, relative to what you would have said if you did not know that it was Trump's inauguration.

To what extent do you think that your feelings toward Donald Trump (Barack Obama) (either positive or negative) would influence your estimate of the size of the crowd in the picture?

1) My feelings towards Donald Trump (Barack Obama)...

a. 1 (Would greatly decrease my estimation), 5 (Would not influence my estimation), 9 (Would greatly increase my estimation)

2) To what extent is it acceptable for your political views to influence this judgment?

a. 1 (Strongly unacceptable), 5 (Neither acceptable, nor unacceptable), 9 (Strongly acceptable) 


\section{Evaluating Politicians}

Imagine you are evaluating a new political candidate who is running for President of the United States. This person is running on a platform promising healthcare for all Americans, and is a member of the Republican (Democratic) Party. It is possible that your feelings toward Republicans (positive or negative) might influence your evaluation of this policy promising healthcare for all Americans. That is, knowing that this candidate is a Republican might cause you to evaluate their political agenda more positively or negatively, relative to how you would have evaluated it if you did not know their party affiliation.

To what extent do you think that your feelings toward Republicans (Democrats) (either positive or negative) would influence your evaluation of healthcare for all Americans?

1) My feelings toward Republicans (Democrats)...

a. 1 (Would make me much LESS willing to support healthcare for all) 5 (Would not influence my support for healthcare for all), 9 (Would make me Much MORE likely to support healthcare for all)

2) To what extent is it acceptable for your political views to influence this judgment?

a. 1 (Strongly unacceptable), 5 (Neither acceptable, nor unacceptable), 9 (Strongly acceptable) 


\section{Evaluating New Neighbors}

Imagine you are evaluating a new political candidate who is running for President of the United States. This person is running on a platform promising healthcare for all Americans, and is a member of the Democratic (Republican) Party. It is possible that your feelings toward Democrats (positive or negative) might influence your evaluation of this policy promising healthcare for all Americans. That is, knowing that this candidate is a Democrat might cause you to evaluate their political agenda more positively or negatively, relative to how you would have evaluated it if you did not know their party affiliation.

To what extent do you think that your feelings toward Democrats (Republicans) (either positive or negative) would influence your evaluation of healthcare for all Americans?

1) My political views...

a. 1 (Would make me think neighbor is much less responsible), 5(Would not influence my judgment of neighbor's responsible), 9 (Would make me think neighbor is much more responsible)

2) To what extent is it acceptable for your political views to influence this judgment?

a. 1 (Would make me much LESS willing to support healthcare for all) 5 (Would not influence my support for healthcare for all), 9 (Would make me Much MORE likely to support healthcare for all)

3) Next, imagine that you are asked to judge how likable your Republican (Democratic) neighbor is. My political views... 
a. 1 (Would make me think neighbor is much less likable), 5(Would not influence my judgment of neighbor's likable), 9 (Would make me think neighbor is much more likable)

4) To what extent is it acceptable for your political views to influence this judgment?

a. 1 (Would make me much less willing to support healthcare for all) 5 (Would not influence my support for healthcare for all), 9 (Would make me much more likely to support healthcare for all)

5) Next, imagine that you are asked to judge how athletic your Republican (Democratic) neighbor is.

My political views...

a. 1 (Would make me think neighbor is much less likable), 5(Would not influence my judgment of neighbor's likable), 9 (Would make me think neighbor is much more likable)

6) To what extent is it acceptable for your political views to influence this judgment?

a. 1 (Would make me much less willing to support healthcare for all) 5 (Would not influence my support for healthcare for all), 9 (Would make me much more likely to support healthcare for all) 


\section{Evaluating Presidents' Likableness}

Next, we will ask you to consider how your political attitudes will influence your judgments of President Donald Trump.

Imagine you are asked to judge how kind President Donald Trump (Barack Obama) is. My political views...

1) 1 (Would make me judge Trump (Obama) as much less kind), 5 (Would not influence my judgment of Trump's (Obama's) kindness), 9 (Would make me judge Trump's (Obama's) as much more kind)

2) To what extent is it acceptable for your political views to influence this judgment?

a. 1 (Would make me much less willing to support healthcare for all) 5 (Would not influence my support for healthcare for all), 9 (Would make me much more likely to support healthcare for all)

3) Next, imagine you are asked to judge how athletic President Donald Trump is. My political views...

a. 1 (Would make me judge Trump (Obama) as much less athletic), 5 (Would not influence my judgment of Trump's (Obama’s) athletic ability), 9 (Would make me judge Trump (Obama) as much more athletic)

4) To what extent is it acceptable for your political views to influence this judgment?

a. 1 (Would make me much less willing to support healthcare for all) 5 (Would not influence my support for healthcare for all), 9 (Would make me much more likely to support healthcare for all)

\section{Evaluating Presidential Quotes}


Imagine that you came across a quote from a politician regarding American values. As you are reading, you find out that the quote was said by President Donald Trump (Barack Obama). It is possible that your feelings toward Trump (positive or negative) might cause you to be more likely to agree or disagree with the quote, relative to how you would have felt about it if you did not know who had said it.

To what extent do you think your feelings toward Donald Trump (Barack Obama) (either positive or negative) would influence your agreement or disagreement with the quote?

1) My feelings toward Trump...

a. 1 (would make me much more likely to agree with the quote), 5 (would NOT influence my agreement with the quote), 9 (would make me much more likely to agree with the quote).

2) To what extent is it acceptable for your political views to influence this judgment?

a. 1 (Would make me much less willing to support healthcare for all) 5 (Would not influence my support for healthcare for all), 9 (Would make me much more likely to support healthcare for all) 


\section{Political affiliation (3-items)}

a. Political orientation (Scale: 1-7)

b. Voting pattern (Scale: 1-7)

c. Partisan support (Scale: 1-7)

2a. Between-subjects manipulation: Quote judgments or Jury judgments

Condition 1: Lay theories/Acceptability regarding influence of Presidents (i.e., Trump/Obama) on evaluation of quotes.

Condition 2: Lay theories/Acceptability regarding influence of defendant's political views on judgments of guilt.

2b. Between-subjects manipulation: Lay theories or bias acceptability first

Counterbalance 1: Lay theories $\rightarrow$ Bias acceptability

Counterbalance 2: Bias acceptability $\rightarrow$ Lay theories

3. Condition 1: Quote evaluations. Anticipated influence of political views on:

a. Five Quotes by President Donald Trump

i. Would knowing Trump said it influence the degree to which you feel positively or negatively towards the quote?

b. Five Quotes by former President Barack Obama

i. Would knowing Obama said it influence the degree to which you feel positively or negatively towards the quote?

4. Condition 2: Judgments of Guilt

a. First Jury Scenario: Defendant on trial for assault and attempted murder from a bar fight

b. Second Jury Scenario: Defendant on trial for assault and attempted murder from an attempted vehicular homicide

i. Participants able to choose to see (or not see) political views of defendant before reading the scenario.

For both scenarios, defendant is an extreme conservative for liberal participants, and an extreme liberal for conservative participants.

\section{Bias perception judgments}

a. Bias denial (3-items)

i. This measure operates as a manipulation check to examine whether participants truly understood that knowing the author of the bill would constitute a biasing influence.

b. Would knowing the author of the bill influence your evaluations? (1 item) 
c. How acceptable would it be for your evaluations to be influenced by the affiliation of the author? (multiple items)

d. How motivated are you to ensure that your judgments are not influenced by the author? (5-items)

e. Did you try to prevent the party affiliation of the bill's author from influencing you? (1-item)

f. In general, how hard do most Republicans try to prevent their political views (when it is not appropriate to consider them) from influencing their political judgments? (1item)

g. In general, how hard do most Democrats (Republicans) try to prevent their political views (when it is not appropriate to consider them) from influencing their political judgments? (2-items) 


\section{Pilot Study 2 Materials}

\section{First 5 Quotes: Out-group President (Trump or Obama)}

On the next page are several quotes. We would like you to imagine that these quotes were originally said by $\$\{$ e://Field/President $\}$.

Consider: would knowing that $\$\{\mathbf{e}: / /$ Field/President $\}$ said this change how positively or negatively you feel about the quote itself?

Click to continue (page break)

1) Consider the following quote:

Without passion, you have no energy. Without energy, you have nothing"

My knowledge that Trump (Obama) said this would cause me to evaluate the quote...

a. 1(Much more negatively), 5 (Would not influence my judgment), 9 (Much more positively)

2) Consider the following quote:

"Right reason is stronger than force"

My knowledge that Trump (Obama) said this would cause me to evaluate the quote...

a. 1(Much more negatively), 5 (Would not influence my judgment), 9 (Much more positively)

3) Consider the following quote:

Effort and courage aren't enough without purpose and direction"

My knowledge that Trump (Obama) said this would cause me to evaluate the quote...

a. 1(Much more negatively), 5 (Would not influence my judgment), 9 (Much more positively)

4) Consider the following quote:

"It is easier to do a job right than to explain why you didn't"

My knowledge that Trump (Obama) said this would cause me to evaluate the quote... 
a. 1(Much more negatively), 5 (Would not influence my judgment), 9 (Much more positively)

5) Consider the following quote:

Men aren't prisoners of fate, only their own minds"

My knowledge that Trump (Obama) said this would cause me to evaluate the quote...

a. 1(Much more negatively), 5 (Would not influence my judgment), 9 (Much more positively) 


\section{Condition 1: Lay theories and Acceptability for Quote Evaluations}

\section{Second 5 quotes: In-group President (Trump or Obama)}

1) Consider the following quote:

We can't get yesterday back, but tomorrow is ours to win or lose"

My knowledge that Trump (Obama) said this would cause me to evaluate the quote...

a. 1(Much more negatively), 5 (Would not influence my judgment), 9 (Much more positively)

2) Consider the following quote:

"If you always support the correct principles then you will never get the wrong results"

My knowledge that Trump (Obama) said this would cause me to evaluate the quote...

a. 1(Much more negatively), 5 (Would not influence my judgment), 9 (Much more positively)

3) Consider the following quote:

"If you always support the correct principles then you will never get the wrong results"

My knowledge that Trump (Obama) said this would cause me to evaluate the quote...

a. 1(Much more negatively), 5 (Would not influence my judgment), 9 (Much more positively)

4) Consider the following quote:

"I can never consent to being dictated to"

My knowledge that Trump (Obama) said this would cause me to evaluate the quote...

a. 1(Much more negatively), 5 (Would not influence my judgment), 9 (Much more positively)

5) Consider the following quote:

"Any man worth his salt will stick up for what he believes is right"

My knowledge that Trump (Obama) said this would cause me to evaluate the quote...

a. 1(Much more negatively), 5 (Would not influence my judgment), 9 (Much more positively)

\section{Acceptability}




\section{Instructions (If randomly assigned to see acceptability first)}

In a minute, we are going to show you a series of quotes and ask you to evaluate them (tell us know much you agree or disagree with the quotes). You will be told who said each quote, and will know that it is a famous president.

You goal is to evaluate the quote itself (how much you agree or disagree with it), but not to evaluate the person who said the quote. The quotes themselves do not concern any political issues.

Would it be acceptable for your evaluation of the quote to by influenced by the person who said it?

For example, imagine that the quote was something that you would ordinarily agree with, but you learn that it was said by a president who you really dislike. We would like you to consider if it would be acceptable or unacceptable for your evaluation of the quote to be influenced by knowing the person who said it.

Click to continue

1) Imagine that you are evaluating a quote and learn that it was said by U.S. President Barack Obama.

How acceptable is it for your evaluation (how positively or negatively you feel towards the quote) to be influenced by your knowledge that it was said by Barack Obama?

b. 1 (Completely unacceptable), 6 (Completely acceptable)

2) Imagine that you are evaluating a quote and learn that it was said by U.S. President Donald Trump.

How acceptable is it for your evaluation (how positively or negatively you feel towards the quote) to be influenced by your knowledge that it was said by Donald Trump? 
a. 1 (Completely unacceptable), 6 (Completely acceptable)

Condition 2: Lay theories and Acceptability for Judgments of Guilt 


\section{First jury scenario: Defendant political out-group member}

Next, we will ask you to read and evaluate two scenarios in which you are to imagine that you are a jury member who must decide whether or not each defendant is guilty of the crimes they have been charged with.

Click to continue

As a jury member, you are instructed to ensure that you ONLY consider the evidence of this case to determine, to the best of your knowledge, whether the defendant is innocent or guilty. You are instructed NOT to allow yourself to be influenced by incidental information, including personal information about the defendant.

\section{Imagine that you are a jury member on a trial.}

The defendant is on trial for assault and attempted murder.

The defendant is a 40 year-old white man with no known history of violence. He is an extreme right-wing conservative and a known member of the American Freedom Party, an extremist right-wing authoritarian organization. (He is an extreme left-wing liberal and a known member of ANTIFA, an extremist left-wing socialist organization.)

Following a heated shouting match involving multiple people, a fistfight broke out in an alleyway next to a bar between two of the individuals who had been engaged in the shouting match. The plaintiff (a 35 year-old white man) was severely injured, suffering seven broken bones, the loss of most of his teeth, and extensive internal bleeding. 
The defendant claims that he was not the one who attacked the plaintiff, and that he went home after initially yelling at the plaintiff and his friends. Several witnesses place him at the bar during the shouting match, but no eyewitnesses saw him enter or leave the alleyway.

The DNA (taken from hairs) at the crime scene match the defendant. The defendant claims that he spent a lot of time in and around the bar, so his hair could have ended up there on another occasion. There is only blurry video evidence of the attack taken on a security camera. The faces of the attacker and defender are not visible in the video.

1) To what extent do you believe that this defendant's political views would influence your judgment of their guilt, compared to NOT knowing their political views?

If I was actually judging their guilt, knowing the political views of this defendant would cause me to think the defendant...

a. 1 (Was much less likely to be guilty), 5 (This would not influence my judgment), 9 (Was much more likely to be guilty) 


\section{Second Jury Scenario: Defendant political in-group member}

As a jury member, you are instructed to ensure that you ONLY consider the evidence of this case to determine, to the best of your knowledge, whether the defendant is innocent or guilty. You are instructed NOT to allow yourself to be influenced by incidental information, including personal information about the defendant.

\section{Imagine that you are a jury member on a trial.}

The defendant is on trial for assault and attempted murder.

The defendant is a 32 year-old white man with no history of violence.

The defendant and the plaintiff had been close friends for 10 years before an affair developed between the defendant's wife and the plaintiff one month ago. $\$\{$ e://Field/Values 2$\}$

The plaintiff (a 28 year-old white man) was severely injured after a large SUV slammed into his driver's door in a T-bone collision at approximately $50 \mathrm{MPH}$. He suffered the amputation of his left hand due to massive blunt force trauma, the loss of his right eye, and he spent one week in an intense care unit in a medically induced coma.

The SUV was later found abandoned in a ditch, and was registered as belonging to the defendant's wife. Two eyewitnesses accurately described the SUV that hit the plaintiff's car before fleeing the scene.

The defendant's wife claims that her husband stole her car and intentionally rammed it into the plaintiff's car due to the fact he suspected the two of them to be having an affair. The defendant claims that he was framed, and that he had been drinking alcohol at a friend's house with many people for the entire evening; four of these friends testified that the defendant was at the party. He claims that his wife hit the plaintiff with her car due to a lover's quarrel. 
1) To what extent do you believe that this defendant's political views would influence your judgment of their guilt, compared to NOT knowing their political views?

If I was actually judging their guilt, knowing the political views of this defendant would cause me to think the defendant...

a. 1 (Was much less likely to be guilty), 5 (This would not influence my judgment), 9 (Was much more likely to be guilty) 


\section{Acceptability}

\section{Instructions (If randomly assigned to see acceptability first)}

In a minute, we are going to show you a hypothetical jury scenario and ask you to imagine being a member of the jury who has to decide whether or not the defendant is guilty. Will be be given many details about the defendant, including their political views.

You goal is to evaluate the evidence at hand that is relevant for deciding whether or not the defendant is guilty, but not to evaluate the defendant as a person. The trial itself is not about politics in any way.

Please consider: if you were a member of this jury, do you think would it

be acceptable for your evaluation of the quote to by influenced by the political views of the defendant?

Click to continue 


\section{Study 1 Procedure}

\section{Experimental Conditions}

\begin{tabular}{|c|c|c|}
\hline Control & Partisan Induction & Correction condition \\
\hline $\begin{array}{l}\text { Condition } \\
\begin{array}{l}\text { 1. No instructions } \\
\text { to correct } \\
\text { judgments for } \\
\text { influence of } \\
\text { partisan } \\
\text { information } \\
\text { 2. No exposure to } \\
\text { partisan } \\
\text { information }\end{array}\end{array}$ & $\begin{array}{l}\text { condition } \\
\text { 1. No instructions to correct } \\
\text { judgments for influence of } \\
\text { irrelevant partisan } \\
\text { information } \\
\text { 2. Exposure to partisan } \\
\text { information } \\
\text { a. Name of President } \\
\text { who "said" a given } \\
\text { quote } \\
\text { b. Name of President } \\
\text { who sponsored } \\
\text { political policy } \\
\text { c. Political views of } \\
\text { defendant on trial }\end{array}$ & $\begin{array}{l}\text { 1. Explicit instructions to } \\
\text { correct judgments for the } \\
\text { influence of irrelevant } \\
\text { partisan information } \\
\text { 2. Exposure to partisan } \\
\text { information } \\
\text { a. Name of } \\
\text { President who } \\
\text { "said" a given } \\
\text { quote } \\
\text { b. Name of } \\
\text { President who } \\
\text { sponsored } \\
\text { political policy } \\
\text { c. Political views of } \\
\text { defendant on trial }\end{array}$ \\
\hline
\end{tabular}




\section{Study 1 Procedure}

\section{Pre-measured items (Mass pretest)}

a. Lay theories (8-items)

b. Bias acceptability (4-items)

b. Note: acceptability measures only available for quotes and policy positions

c. Perceived bias acceptability of others (for quotes, policy positions)

\section{Political views}

a. Political affiliation: Democrat, or Republican, or independent?

b. if Dem (Repub.): do you consider yourself a strong or not so strong Dem (Repub.)?

i. If Independent, which way do you lean (Dem/Repub.)?

c. Did you vote in the 2016 presidential election?

d. If so, who did you vote for (Donald Trump, Hillary Clinton, other).

\section{Manipulation: Correction instructions}

Condition 1: Control (no biasing information presented for any questions).

Condition 2: Exposure to biasing information (no correction instructions).

Condition 3: Exposure to biasing information (explicit correction instructions)

\section{Presidential quotes (10)}

a. Five quotes presented.

b. Each quote said by a U.S. President, though none were said by Trump or Obama

c. Quotes presented in random order

d. Control participants told the quotes were from President Warren Harding. 


\section{Policy proposals (2)}

a. Participants told that out-group president (Obama/Trump) made proposal

i. Proposal: Spend 1.5 trillion on public infrastructure

ii. Proposal: Create Election Day, a new national holiday

\section{Judgments of Guilt (20}

a. First Jury Scenario: Defendant on trial for assault and attempted murder from a bar fight

b. Second Jury Scenario: Defendant on trial for assault and attempted murder from an attempted vehicular homicide

i. Participants able to choose to see (or not see) political views of defendant before reading the scenario.

For both scenarios, defendant is an extreme conservative for liberal participants, and an extreme liberal for conservative participants.

\section{Bias perception judgments}

a. Did you try to prevent the party affiliation from influencing you? ( 3 items)

b. Perception of bias control (1 item)

c. Most Democrats (Republicans) can prevent irrelevant information from influencing (2-items).

d. Acceptability (3-items). One for each type of judgment (quotes, jury, policy)

e. General motivation to make unbiased judgments (4-items).

\section{Individual difference measures}

a. Perspective taking (3-items)

b. Group loyalty (8-items)

a. Political party loyalty (7-items)

c. Insight Problems (4-items)

a. And CRT

d. Actively Open-Minded Thinking (7-items)

a. Categorical Thinking (3 items)

e. Moralizing Rationality (15-item; Stahl, Zaal, \& Skitka, 2016)

f. Social Desirable Responding (11-items; Reynolds, 1982)

g. Bias denial (3-items) - holding that political views are always relevant to a given judgment 


\section{Study 1 Materials}

\section{Lay Theories (Mass-pretest Fall 2018)}

Instructions: Imagine that you are working for a non-partisan think tank, and it is your job to evaluate Congressional bills and their impact on Americans.

1) You are currently evaluating a voting reform bill that, among other things, would create a national holiday for voting. You learn that a Republican wrote the bill.

To what extent would knowing that a Republican wrote this bill influence your evaluation of the bill, compared to evaluating this bill and not knowing the party affiliation of the author?

Scale (1-9): 1 (It would make my evaluation much more negative)...5 (it would not influence me...9 (it would make my evaluation much more positive)

2) You are currently evaluating an infrastructure renewal bill. This bill aims to fix crumbling public infrastructure across the nation using tax payer dollars. You learn that a Republican wrote the bill.

To what extent would knowing that a Republican wrote this bill influence your evaluation of the bill, compared to evaluating this bill and not knowing the party affiliation of the author?

Scale (1-9): 1 (It would make my evaluation much more negative)...5 (it would not influence me...9 (it would make my evaluation much more positive)

3) You are currently evaluating a gerrymandering reform bill. Gerrymandering is when a political party in power systematically creates voting districts that will help their own party get reelected. You learn that a Republican wrote the bill. 
To what extent would knowing that a Republican wrote this bill influence your evaluation of the bill, compared to evaluating this bill and not knowing the party affiliation of the author?

Scale (1-9): 1 (It would make my evaluation much more negative)...5 (it would not influence me...9 (it would make my evaluation much more positive)

4) Imagine that you are reading a quote and evaluating the extent to which you agree or disagree with the statement. You learn that the quote you are reading was said by President

\section{Donald Trump.}

To what extent would knowing that Donald Trump said this quote influence the extent to which you feel positively or negatively towards the quote, relative to not knowing who the quote was from?

Scale (1-9): 1 (It would cause me to feel much more negative about this quote)...5 (it would not influence me...9 (it would cause me to feel much more positively about this quote)

Instructions: Now we would like to consider how your judgments might be influenced if the bills were written by members of the other major political party.

Imagine that you are working for a non-partisan think tank, and it is your job to evaluate Congressional bills and their impact on Americans.

5) You are currently evaluating a voting reform bill that, among other things, would create a national holiday for voting. You learn that a Democrat wrote the bill.

To what extent would knowing that a Democrat wrote this bill influence your evaluation of the bill, compared to evaluating this bill and not knowing the party affiliation of the author?

Scale (1-9): 1 (It would make my evaluation much more negative)...5 (it would not influence me...9 (it would make my evaluation much more positive) 
6) You are currently evaluating an infrastructure renewal bill. This bill aims to fix crumbling public infrastructure across the nation using tax payer dollars. You learn that a Democrat wrote the bill.

To what extent would knowing that a Democrat wrote this bill influence your evaluation of the bill, compared to evaluating this bill and not knowing the party affiliation of the author?

Scale (1-9): 1 (It would make my evaluation much more negative)...5 (it would not influence me...9 (it would make my evaluation much more positive)

7) You are currently evaluating a gerrymandering reform bill. Gerrymandering is when a political party in power systematically creates voting districts that will help their own party get reelected. You learn that a Democrat wrote the bill.

To what extent would knowing that a Democrat wrote this bill influence your evaluation of the bill, compared to evaluating this bill and not knowing the party affiliation of the author?

Scale (1-9): 1 (It would make my evaluation much more negative)...5 (it would not influence me...9 (it would make my evaluation much more positive)

8) Imagine that you are reading a quote and evaluating the extent to which you agree or disagree with the statement. You learn that the quote you are reading was said by former President Barack Obama. 
To what extent would knowing that Barack Obama said this quote influence the extent to which you feel positively or negatively towards the quote, relative to not knowing who the quote was from?

Scale (1-9): 1 (It would cause me to feel much more negative about this quote)...5 (it would not influence me...9 (it would cause me to feel much more positively about this quote). 


\section{Correction Instructions}

For the first section of this study, we will be asking you to make several judgments that could be influenced by the political views and attitudes of the people you are evaluating.

For the purposes of this study, it is very important that you do NOT allow your judgments and evaluations to be influenced by the political views or identities that you are presented with.

For each judgments you are asked to make in the first part of this study, the political views and/or identities you read about are irrelevant to the judgment or evaluation at hand.

\section{Click to continue}

Your job is to evaluate the available information and make judgments using only the relevant information, and not allow the irrelevant political information you are given to influence your judgments.

In this study, we are testing whether or not people are able to disregard irrelevant information when making judgments and evaluations. This is important because sometimes in the real world you will be required to make judgments that are not influenced by irrelevant political information, even if that political information feels very persuasive.

Click to continue

Again, your goal is to evaluate only the relevant information at hand, and disregard the political information that is presented. Any political information you see is not really relevant to your evaluations, since your job is to evaluate the core information at hand and not to evaluate the person or their beliefs.

To be sure that you understand, please endorse the following statement:

-I will not allow the judgments and evaluations I make in this study to be influenced by any political views, beliefs, or identities I am presented with

\section{Control and Partisan induction instructions}


Please read and evaluate the following quotes, each of which was said by U.S.

President Warren Harding (Trump; Obama) during a state of the union speech

Click to continue 


\section{Quote Judgments}

On the next page are several quotes. We would like you to imagine that these quotes was originally said by President Trump (Obama).

Consider: would knowing that President Trump (Obama)said this change how positively or negatively you feel about the quote itself?

Click to continue

(page break)

1) Consider the following quote:

Without passion, you have no energy. Without energy, you have nothing"

How positively or negatively do you feel towards this quote?

a. 1(Very negatively) ...6 (Very positively)

To what extent do you personally agree with this quote?

b. 1(Strongly agree) ...6 (Strongly disagree)

2) Consider the following quote:

\section{"Right reason is stronger than force"}

How positively or negatively do you feel towards this quote?

a. 1(Very negatively) ...6 (Very positively)

To what extent do you personally agree with this quote? 
b. 1(Strongly agree) ...6 (Strongly disagree)

3) Consider the following quote:

\section{Effort and courage aren't enough without purpose and direction"}

How positively or negatively do you feel towards this quote?

a. 1(Very negatively) ...6 (Very positively)

To what extent do you personally agree with this quote?

b. 1(Strongly agree) ...6 (Strongly disagree)

"It is easier to do a job right than to explain why you didn't"

How positively or negatively do you feel towards this quote?

a. 1(Very negatively) ...6 (Very positively)

To what extent do you personally agree with this quote?

b. 1(Strongly agree) ...6 (Strongly disagree)

\section{Men aren't prisoners of fate, only their own minds"}

a. How positively or negatively do you feel towards this quote? 1(Very negatively) ...6 (Very positively)

d. To what extent do you personally agree with this quote?

a. 1(Strongly agree) ...6 (Strongly disagree)

b.

6) Consider the following quote:

We can't get yesterday back, but tomorrow is ours to win or lose"

How positively or negatively do you feel towards this quote? 
a. 1(Very negatively) ...6 (Very positively)

To what extent do you personally agree with this quote?

b. 1(Strongly agree) ...6 (Strongly disagree)

7) Consider the following quote: "If you always support the correct principles then you will never get the wrong results"

How positively or negatively do you feel towards this quote?

a. 1(Very negatively) ...6 (Very positively)

To what extent do you personally agree with this quote?

b. 1(Strongly agree) ...6 (Strongly disagree)

8) Consider the following quote:

"If you always support the correct principles then you will never get the wrong results"

How positively or negatively do you feel towards this quote?

a. 1(Very negatively) ...6 (Very positively)

To what extent do you personally agree with this quote?

b. 1(Strongly agree) ...6 (Strongly disagree)

9) Consider the following quote:

"I can never consent to being dictated to"

How positively or negatively do you feel towards this quote?

a. 1(Very negatively) ...6 (Very positively)

To what extent do you personally agree with this quote?

b. 1(Strongly agree) ...6 (Strongly disagree)

10) Consider the following quote: 
"Any man worth his salt will stick up for what he believes is right"

How positively or negatively do you feel towards this quote?

a. 1 (Very negatively) ...6 (Very positively)

To what extent do you personally agree with this quote?

b. 1(Strongly agree) ...6 (Strongly disagree) 


\section{Policy Judgments}

\section{Instructions (for Correction participants)}

Remember: You have been instructed to ensure that the political views of the person who proposed this policy do NOT influence your judgment.

\section{Infrastructure}

A proposal to spend 1.5 trillion dollars to fix existing roads, bridges, and other public infrastructure in danger of catastrophic failure is being debated in Congress. $\$\{$ e://Field/Proposal $\}$

The primary purpose spending money to improve and maintain public infrastructure is to keep citizens safe from crumbling bridges and roads that endanger lives, as well as improve the economy by fixing bad roads that slow down travel time.

1. To what extent do you support this proposal?

a. 1 (Do not support at all) ...6 (Strongly support)

2. To what extent do you trust that this proposal will be good for the American people?

a. 1 (Do not trust at all) ...6 (Strongly trust) 


\section{National Election Day}

A proposal to create a new national holiday: Election Day is being debated in Congress. $\$\{$ e://Field/Proposal $\}$

Election Day would always occur on the second Tuesday in November. The primary purpose for this holiday would be to make it easier for all citizens to vote, and extend the operating times for all polling locations to 24 hours. It is predicted that creating a national holiday for voting would increase voter turnout by an average of $15 \%$ at all elections.

1. To what extent do you support this proposal?

a. 1 (Do not support at all) ...6 (Strongly support)

2. To what extent do you trust that this proposal will be good for the American people?

a. 1 (Do not trust at all) ...6 (Strongly trust) 


\section{Judgments of Guilt}

\section{Instructions (for Correction participants):}

Remember: As a jury member, you are instructed to ensure that the political views of the defendant do NOT influence your judgment as you consider the evidence, and decide if the defendant is guilty or innocent of the following crimes.

\section{Imagine that you are a jury member on a trial.}

The defendant is on trial for assault and attempted murder.

The defendant is a 40 year-old white man with no known history of violence. He is an extreme right-wing conservative and a known member of the American Freedom Party, an extremist right-wing white nationalist organization (He is an extreme left-wing liberal and a known member of ANTIFA, an extremist left-wing socialist organization.)

Following a heated shouting match involving multiple people, a fistfight broke out in an alleyway next to a bar between two of the individuals who had been engaged in the shouting match. The plaintiff (a 35 year-old white man) was severely injured, suffering seven broken bones, the loss of most of his teeth, and extensive internal bleeding.

The defendant claims that he was not the one who attacked the plaintiff, and that he went home after initially yelling at the plaintiff and his friends. Several witnesses place him at the bar during the shouting match, but no eyewitnesses saw him enter or leave the alleyway. 
The DNA (taken from hairs) at the crime scene match the defendant. The defendant claims that he spent a lot of time in and around the bar, so his hair could have ended up there on another occasion. There is only blurry video evidence of the attack taken on a security camera. The faces of the attacker and defender are not visible in the video.

1) To what extent do you believe that the defendant is likely to be guilty of assault? 1 (Very certain that he is not guilty)...6 (Very certain that he is guilty)

2) To what extent do you believe that the defendant is likely to be guilty of assault? 1 (Very certain that he is not guilty)...6 (Very certain that he is guilty)

3) How serious are the crimes that the defendant is accused of? 1 (Not at all serious)...6 (Very serious) 


\section{Instructions (for Correction participants):}

Remember: As a jury member, you are instructed to ensure that the political views of the defendant do NOT influence your judgment as you consider the evidence, and decide if the defendant is guilty or innocent of the following crimes.

\section{Imagine that you are a jury member on a trial.}

The defendant is on trial for assault and attempted murder.

The defendant is a 32 year-old white man with no known history of violence. He loves guns and staunchly defends the 2nd amendment. He believes that the government should never regulate the buying and selling of all guns and ammunition. (He strongly dislikes guns and staunchly opposes the 2 nd amendment. He believes that the government should strongly regulate the buying and selling of guns and ammunition.

The defendant and the plaintiff had been close friends for 10 years before an affair developed between the defendant's wife and the plaintiff one month ago.

The plaintiff (a 28 year-old white man) was severely injured after a large SUV slammed into his driver's door in a T-bone collision at approximately $50 \mathrm{MPH}$. He suffered the amputation of his left hand due to massive blunt force trauma, the loss of his right eye, and spent one week in an intense care unit in a medically induced coma.

The SUV was later found abandoned in a ditch, and was registered as belonging to the defendant's wife. Two eyewitnesses accurately described the SUV that hit the plaintiff's car before fleeing the scene. 
The defendant's wife claims that her husband stole her car and intentionally rammed it into the plaintiff's car due to the fact he suspected the two of them to be having an affair. The defendant claims that he was framed, and that he had been drinking alcohol at a friend's house with many people for the entire evening; four of these friends testified that the defendant was at the party. He claims that his wife hit the plaintiff with her car due to a lover's quarrel.

1) To what extent do you believe that the defendant is likely to be guilty of assault? 1 (Very certain that he is not guilty)...6 (Very certain that he is guilty)

2) To what extent do you believe that the defendant is likely to be guilty of assault? 1 (Very certain that he is not guilty)...6 (Very certain that he is guilty)

3) How serious are the crimes that the defendant is accused of? 1 (Not at all serious)...6 (Very serious) 


\section{Acceptability of incorporating irrelevant political information into judgments}

How acceptable is it for political information (such as the political views of others) to influence your...

1) Judgments about jury trials.

2) Evaluation of presidential quotes.

3) Evaluation of policy proposals (e.g., Election Day).

1(Completely unacceptable)...6 (Completely acceptable) 


\section{Bias Perception Judgments (8-items)}

1) Earlier, you were presented with political information before making judgments, such as the name of the president who said a particular quote, or proposed a particular policy.

To what degree were your evaluations of the presidential quotes influenced by the president who said them?

Knowing the president who said the quotes caused me to judge them...

1 (Much more negatively) ...5 (Did not influence my judgments) ...9 (Much more

positively)

2) To what degree were your evaluations of the policy positions (e.g., Election day, Infrastructure spending) influenced by the president who proposed them?

Knowing the president who made the proposal caused me to judge the policy positions...

1 (Much more negatively) ...5 (Did not influence my judgments) ...9 (Much more

positively)

3) To what degree were your judgments about the jury trials influenced by the political information that you were exposed to?

The political views of the defendant made me think they were...

1 (Much less likely to be guilty) ...5 (Did not influence my judgments) ...9 (Much more likely to be guilty) 


\section{Bias Refusal}

Scale for all items: 1(No, not at all) to 7 (yes, definitely)

Let's return to the Congressional bills that we asked you about at the start of your survey.

1) If you worked for an independent think tank that was trying to produce objective evaluations of Congressional bills, do you think that your personal political attitudes should be considered as a part of that evaluation?

2) Do you believe that is it always relevant to know the political beliefs and values of the person who has written a Congressional bill? 


\section{Motivation}

Scale: 1 (strongly disagree) to 7 (strongly agree)

1) I believe it is very important to make unbiased political judgments.

2) I am highly motivated to make unbiased political judgments.

3) Making objective political judgments, even if they go against my core beliefs, is the right thing to do.

4) I am highly motivated to identify biasing information that could influence thinking before I make a judgment. 


\section{Bias Prevention}

1) When making judgments about a defendant in a jury trial, did you prevent political information that you were exposed to from influencing your judgment?

2) When evaluating presidential quotes, did you prevent political information that you were exposed to from influencing your judgment?

3) When evaluating policy proposals (e.g., Election Day), did you prevent political information that you were exposed to from influencing your judgment?

Scale for all: 1 (No, not at all) ...6 (Yes, definitely)

\section{Supplemental bias prevention items}

1) To what extent to you agree or disagree with the following statement?

In general, I can easily prevent political information that is irrelevant from influencing my judgments and decision if I want to.

1(Strongly disagree) ...6(Strongly agree)

2) To what extent to you agree or disagree with the following statements?

a. Most Republicans can easily prevent political information that is irrelevant from influencing their judgments and decision if they want to.

b. Most Democrats can easily prevent political information that is irrelevant from influencing their judgments and decision if they want to.

1(Strongly disagree) ...6(Strongly agree) 
Perspective Taking (3-items). All items in this scale were created for the purposes of this study.

Scale: 1(strongly disagree to 7 (strongly agree)

1) When I confront an argument, I like to do a mental exercise where I look at the issue from both sides.

2) Before making an important judgment, it is very important that I take other peoples' perspectives.

3) I am skilled at perspective-taking. 
Group Loyalty (8-items; Beer \& Watson, 2009)

Scale: 1 (strongly disagree) to 5 (strong agree)

In general, I...

1) Admire school spirit

2) Do not criticize our country

3) Admire patriotism

4) Am a team player

5) Am loyal to our country

6) Respect the flag

7) Am loyal to my school

8) Do not bad mouth my country

Political Loyalty (7-items; inspired by Beer \& Watson, 2009, items created for these studies)

Scale: 1 (strongly disagree) to 5 (strong agree)

In general, I...

1) Believe those who share my political views should be protected

2) Do not criticize members of my own political party

3) Admire those who protect members of their own political party

4) Will protect those who share my political views

5) Am loyal to my political party

6) Respect members of my political party

7) I am loyal to those who share my political views 
Science Literacy (8-items; Braman et. Al, 2012; National Science Board, 2010)

Scale for first six items: Yes/No

1) The center of the Earth is very hot

2) All radioactivity is man-made

3) Lasers work by focusing sound waves

4) Electrons are smaller than atoms

5) It is the father's genes that decides whether the baby is a boy or a girl

6) Antibiotics kill viruses as well as bacteria

7) Does the Earth go around the Sun, or the Sun go around the Earth?

a) Sun goes around the Earth

b) Earth goes around the sun

8) How long does it take for the Earth to go around the Sun?
a) 1 Day
b) 1 Month
c) 1 Year
d) The Earth does not go around the Sun 
Rasch numeracy (8-items; Weller et al., 2013)

Next please answer the following math questions. Please do not use a calculator.

1) Imagine that we roll a fair, six-sided die 1,000 times. Out of 1,000 rolls, how many times do you think the die would come up as an even number?

2) Next please answer the following math questions. Please do not use a calculator. Imagine that we roll a fair, six-sided die 1,000 times. Out of 1,000 rolls, how many times do you think the die would come up as an even number?

3) In the ACME PUBLISHING SWEEPSTAKES, the chance of winning a car is 1 in 1,000. What percent of tickets of ACME PUBLISHING SWEEPSTAKES win a car?

4) If the chance of getting a disease is $10 \%$, how many people would be expected to get the disease out of 1000 people?

5) If the chance of getting a disease is 20 out of 100 , this would be the same as having a $\%$ chance of getting the disease.

6) Suppose your friend just had a mammogram. The doctor knows from previous studies that, of 100 women like her, 10 have tumors and 90 do not. Of the 10 who do have tumors, the mammogram correctly finds 9 with tumors and incorrectly says that 1 does not have a tumor. Of the 90 women without tumors, the mammogram correctly finds 80 without tumors and incorrectly says that 10 have tumors. The table below summarizes this information. 


\begin{tabular}{|c|r|r|c|}
\hline & $\begin{array}{r}\text { Tested } \\
\text { Positive }\end{array}$ & Tested & Negative \\
\hline otals \\
\hline Actually has a tumor & 9 & 1 & 0 \\
\hline Does not have a \\
tumor
\end{tabular}

7) Imagine that your friend tests positive (as if she had a tumor), what is the likelihood that she actually has a tumor? State your answer as " out of

8) If John can drink one barrel of water in 6 days, and Mary can drink one barrel of water in 12 days, how long would it take them to drink one barrel of water together?

Number of days:

9) Jerry received both the $15^{\text {th }}$ highest and the $15^{\text {th }}$ lowest mark in the class. How many students are in the class?

Number of students

10) When solving these questions, did you use any of the following to help you calculate? Please be honest. There is no penalty for using any calculation device, but knowing will help us with our study. Please select all that apply. 
Actively Open-minded Thinking (8-items; Stanovich \& West, 1997)

Scale: 1 (completely disagree) ...4(neutral)...7(completely agree)

1) Allowing oneself to be convinced by an opposing argument is a sign of good character

2) One should disregard evidence that conflicts with one's established beliefs.

3) People should revise their beliefs in response to new information or evidence.

4) People should take into consideration evidence that goes against their beliefs.

5) It is important to persevere in your beliefs even when evidence is brought to bear against them.

6) Intuition is the best guide in making decisions.

7) Changing your mind is a sign of weakness.

Categorical Thinking (3-items; Stanovich \& West, 1997)

1) There are basically two kinds of people in this world, good and bad

2) I think there are many wrong ways, but only one right way, to almost anything

3) I tend to classify people as either for me or against me 
Moralizing Rationality (9-items; Stahl, Zaal, \& Skitka, 2016)

\section{Scale: 1 (Strongly disagree) to 7 (Strongly agree)}

1) Being skeptical about claims that are not backed up by evidence is a moral virtue.

2) Holding on to beliefs when there is substantial evidence against them is immoral.

3) It is morally wrong to trust your intuitions without rationally examining them.

4) It is morally wrong to rely on anything else other than logic and evidence when deciding what is true and what is not true.

5) It is a moral imperative that people can justify their beliefs using rational arguments and evidence.

6) It is immoral to hold irrational beliefs.

7) A person's moral authority depends on their rationality.

8) A person's morality is in no way determined by their rationality.

9) Whether a person can be convinced by reason and evidence is in no way indicative of their morality. 
Importance of Rationality (6-items; Stahl, Zaal, \& Skitka, 2016)

Scale: 1 (Strongly disagree) to 7 (Strongly agree)

1) It is important to me personally to be skeptical about claims that are not backed up by evidence.

2) It is important to me personally to remain rational and levelheaded even in heated arguments.

3) It is important to me personally to examine traditionally held beliefs using logic and evidence.

4) It is important to me personally that I can justify my beliefs using rational arguments and evidence.

5) It is important to me personally to critically examine my long-held beliefs.

6) It is important to me personally to be a rational person. 
Insight problems (Patel, Baker, \& Scherer, in press).

1) A man in a small town married 20 different women of the same town. All are still living and he never divorced. Polygamy is against the law (no exceptions), but he has broken no law. How can this be?

2) A human walked for 20 minutes on the surface of a lake without sinking, but without any form of floatation aid. How can this be?

3) A man is reading a book (not on any electronic device) when the lights go off in a room with no windows. Even though the room is pitch dark, the man goes on reading. How can this be?

4) Joe Fan has no psychic powers, but he can tell you the score of any football game before it starts. How can this be? 


\section{Demographics}

How do you identify?

Man

Woman

Transgender man

Transgender woman

Non-Binary

Other

What is your age?

Which of the following best describes your race? (select all that apply)
White/ Caucasian
Black/ African-American
Asian/ Asian-American
Native American or Native Alaskan

Pacific Islander or Native Hawaiian

Asian Indian

Other (please specify)

Are you Hispanic/Latino/a?

Yes

No

Are you of Middle Eastern origin?

Yes

No

How many semesters of college-level coursework have you completed?

\section{$\hat{\imath}$}




\section{Debriefing}

Thank you for participating in our study! We are examining how people believe that their political views will influence them on a variety of real-world political issues, such as healthcare and tax reform. We are also interested in how acceptable people believe making biased political judgments are. Furthermore, we would like to identify who is likely to believe that political biases are acceptable, versus those who believe that it is unacceptable. For example, it is possible that a variety of factors predict who will anticipate making biased political judgments and how acceptable they find this bias. Possible factors include general intelligence, categorical thinking, and perspective taking. This research is especially important now, given public discussions, debates, and accusations regarding political bias. Your participation will help us understand the nature of bias in judgments and decision-making, and we appreciate your time!

If you have any questions, comments, or concerns, you may reach out to the primary investigator of this study, Glenn Baker (sgb4h8@mail.missouri.edu) or the director of our research laboratory, Dr. Laura Scherer (schererl@mail.missouri.edu).

\section{Thanks again! Please click to finish the study and submit your responses.}




\section{Study 1 Supplemental Analyses}

\section{Perceived Bias Prevention Ability}

Participants were asked to indicate a) how well they thought they could prevent unwanted, irrelevant political information from influencing their judgments, and b) how well the thought the average Republican (and Democrat) could do the same. Notably, when comparing within-subject ratings between these measures, we find a self-other difference emblematic of the general "bias blind spot" phenomenon (Pronin, 2002). Republicans $(M=5.79)$, Democrats $(M=$ 5.55), and Moderates $(M=6.09)$ all viewed themselves as significantly better at preventing irrelevant political information from influencing their judgments than both the average Republican and the average Democrat.

Second, A 3 (Republican, Moderate, Democrat) x 2 (average Republican bias prevention, average Democrat bias prevention) repeated-measures ANOVA was conducted, revealing a main effect of partisanship $\left(F(2,569)=5.67, p=.004, \eta_{p}{ }^{2}=.02\right.$. Republicans gave higher average ratings of bias prevention $(M=4.57)$ than Democrats $(M=4.10)$, but not Moderates $(M=4.14)$ and. This main effect was qualified by a significant interaction between party and judgments of bias prevention $\left(F(2,569)=74.48, p<.001, \eta_{p}{ }^{2}=.21\right.$. Simple effects tests indicated that Republicans $(M=5.15, S D=2.04)$ viewed the average member of their own party was better at preventing bias than the average member of the Democratic party $(M=3.99, S D=2.09 ; t=8.91$, $p<0.001)$. Similarly, Democrats also believed that members of their own party $(M=4.39, S D=$ 1.98) were better at preventing bias than members of the Republican party $(M=3.62, S D=1.98$; $t=-7.01, p<.001)$. By contrast, Moderates viewed the bias prevention ability of Republicans and Democrats as roughly equivalent $(M=4.07, M=4.22$, respectively; $p=.17)$. Mostly strikingly, 
Republicans judged fellow Republicans as much more able to prevent bias than either Moderates $\left(M_{\text {diff }}=1.09, S E=.23, p<.001\right)$ Democrats $\left(M_{\text {diff }}=1.55, S E=1.98, p<.001\right)$. Surprisingly, however, Democrats did not judged the average Democrat as being better able to prevent bias than either Moderates $\left(M_{\text {diff }}=-.22, S E=.19, p=.10\right)$ or Democrats $\left(M_{\text {diff }}=-.39, \mathrm{SE}=.19, p\right.$ $=.10$ ). Thus, the interaction reported above is primarily driven by within-subject ratings of how good Republicans and Democrats are at preventing bias in their judgments, though betweensubjects ratings for Republicans were also pronounced.

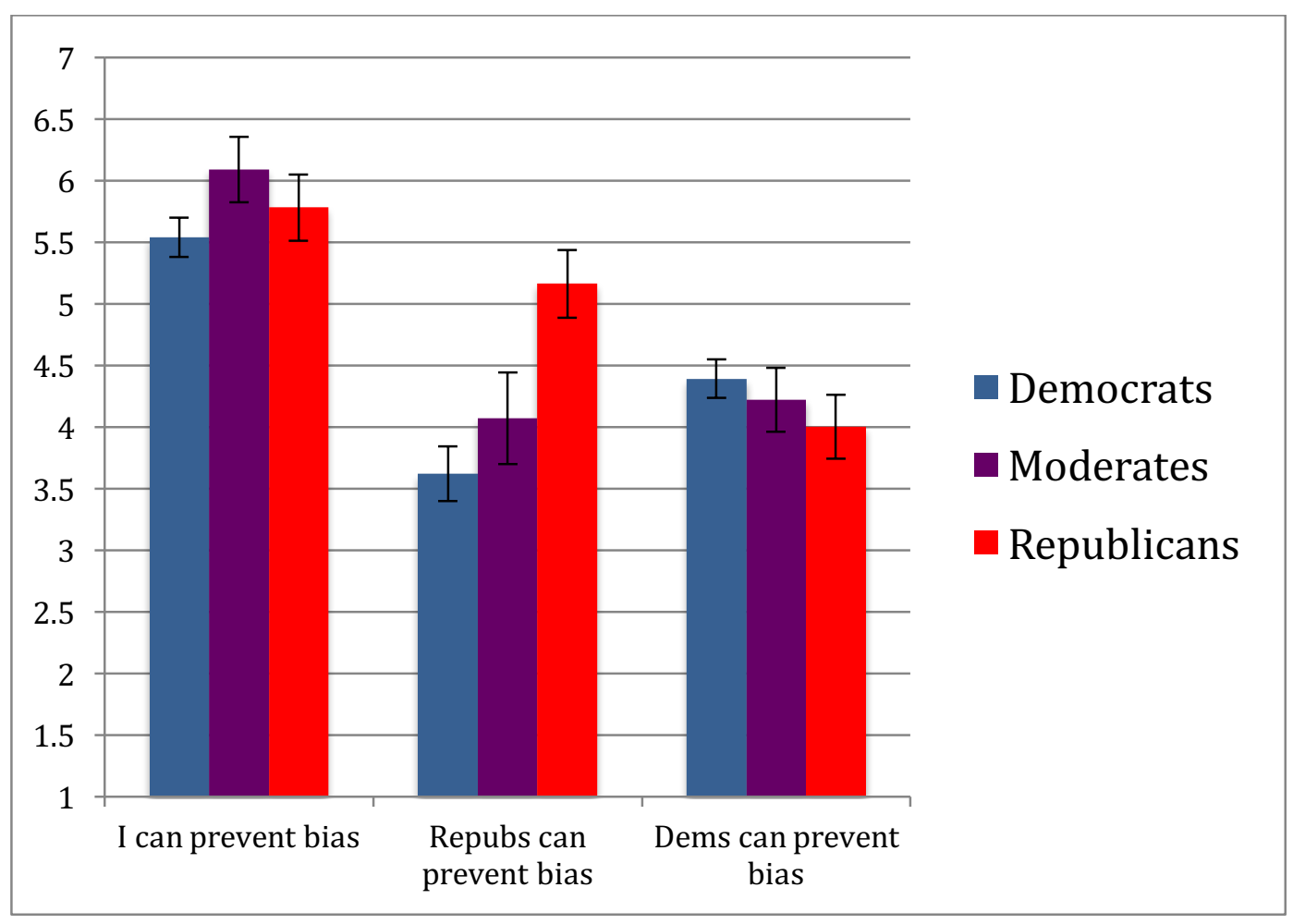




\section{Within-subjects Comparison of Acceptability Views}

Because participants were asked how acceptability it was to allow political information (e.g., partisanship of a target of judgment) to influence their judgments (e.g., quote evaluation, policy evaluation), a within-subjects comparison of acceptability views both before the study and immediately after the study was possible. Prior to the study, participants were also asked how acceptable they thought most others thought it was to incorporate partisan political information into their judgments. However, these ratings did not vary by partisanship $(p=.94)$ and is not discussed further.

A 3 (Weak partisan, Moderate partisan, Strong partisan) $\times 2$ (Acceptability judgment: pre-measure vs. post-measure) mixed model ANOVA indicated a main effect of partisanship strength $\left(F(2,572)=7.41, p=.001, \eta_{p}{ }^{2}=0.03\right)$, such that strong partisans $(M=3.42)$ viewed incorporating irrelevant political information into their judgment as more acceptable than moderate partisans $(M=3.20, S E=.09, p=.05)$ and weak partisans $(M=2.97, S E=.11 ; p$ $<.001)$; moderate partisans did not give higher ratings of acceptability than weak partisan ( $p$ $=.11)$. A small main effect of acceptability pre-post was also observed $(F(2,572)=5.97, p=.02$, $\left.\eta_{p}{ }^{2}=0.01\right)$, such that participants deemed it more acceptable to incorporate political information into their judgments prior to the study $(M=3.20, S E=.06)$ than after the study $(M=3.10, S E$ $=.06)$. Partisanship strength did not interact with the pre/post measure of acceptability $(p=.18)$. 


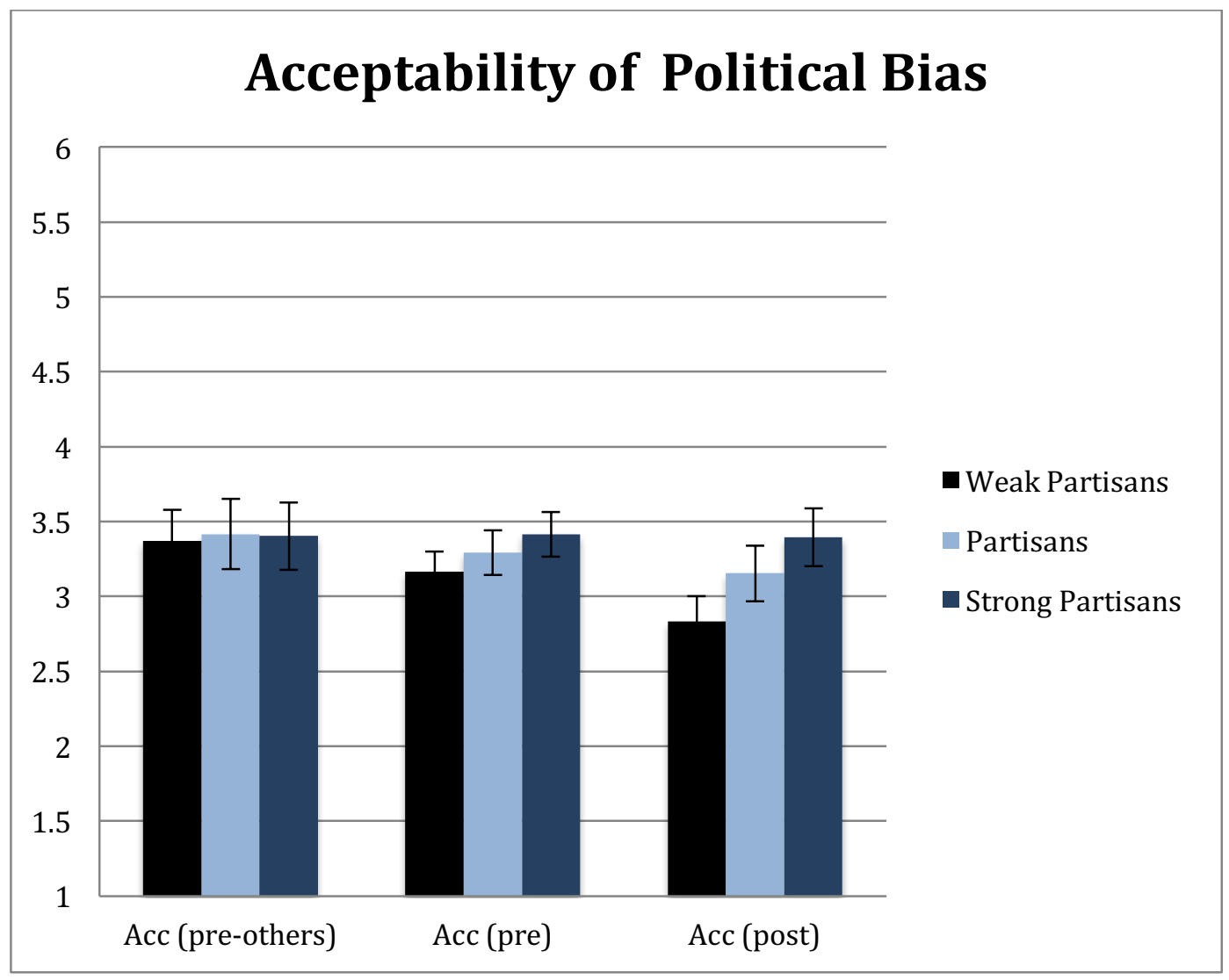




\section{Perceived Seriousness of Jury Scenarios}

Participants were asked to indicate how serious they viewed both of the jury scenarios in order to ascertain whether these two scenarios had successfully been balanced in terms of severity. A 3 (Control, Partisan, Correction) x 3 (Weak partisan, Moderate partisan, Strong partisan) x 2 (First jury scenario vs. Second jury scenario) mixed model ANOVA indicated that participants viewed the first jury scenario $(\mathrm{M}=5.08, \mathrm{SD}=0.82)$ as significant less serious than the second $(\mathrm{M}=5.40 \mathrm{SD}=0.71)$. Although ratings of seriousness were, overall, relatively high for both scenarios, this indicates that some additional balancing in severity needs to be made. There was no difference in perceived severity by condition $(p=.13)$, though there was based on partisanship $\left(F(2,570)=4.12, p=.02, \eta_{p}{ }^{2}=0.01\right)$. Strong partisans viewed both scenarios as more serious than moderate partisans $\left(M_{\text {diff }}=.17, p=.02\right)$, though not weak partisan $\left(M_{\text {diff }}=.04\right.$, $p=.87)$.

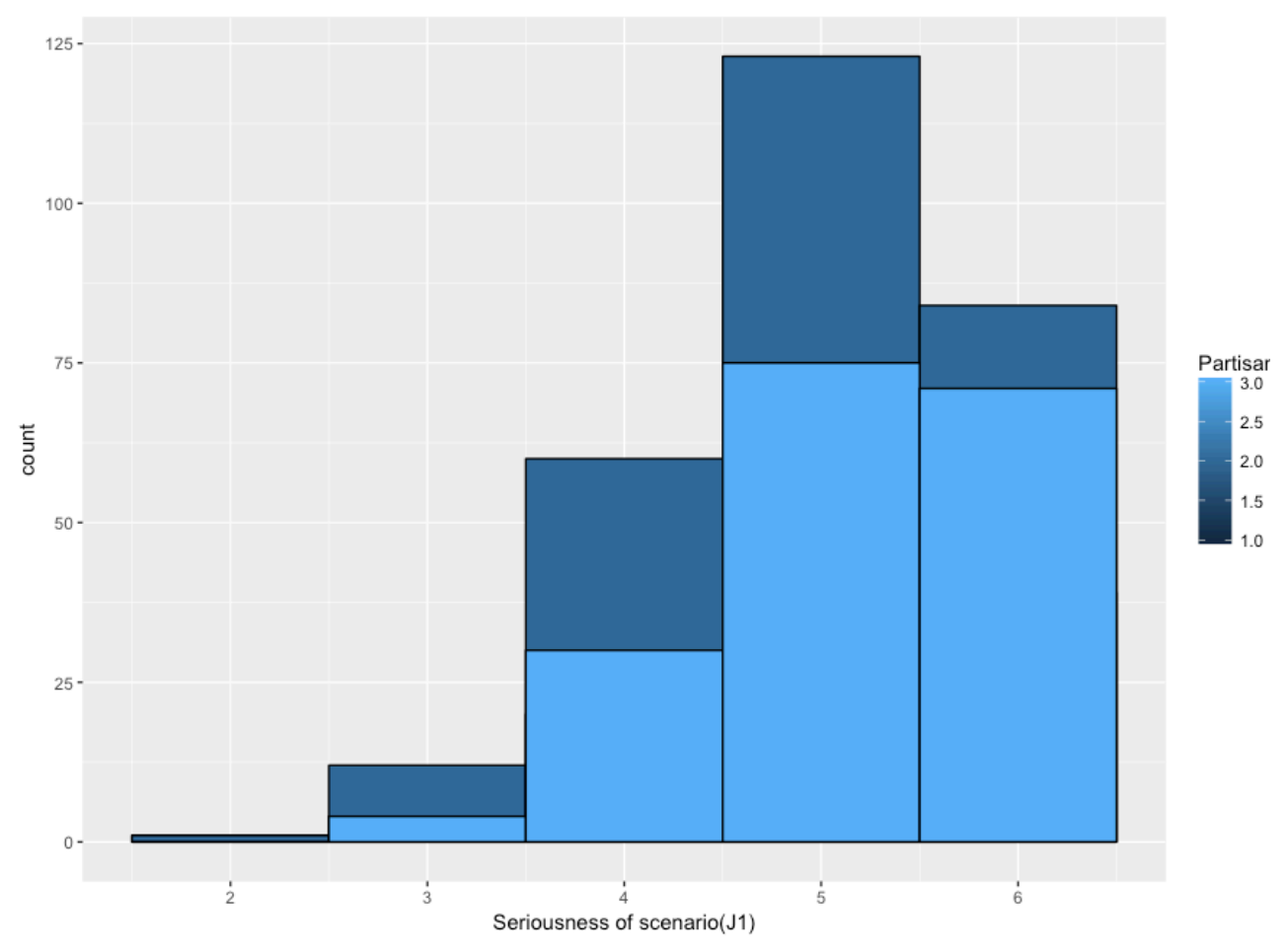




\section{THE LOG IN MY EYE}

\section{Political Loyalty}

The 7-item scale of political loyalty created for the purposes of this study was found to have high inter-reliability between items (Cronbach's alpha: .89). Reported political loyalty was higher than anticipated $(\mathrm{M}=3.39, \mathrm{SD}=.70)$. Political loyalty varied, perhaps predictably, by partisanship strength $(\mathrm{F}(2,574)=27.43, \mathrm{p}<.001)$. Weak participants were less loyal $(\mathrm{M}=3.13)$ than both moderate partisans $(\mathrm{M}=3.31, \mathrm{p}=.04)$ and strong partisans $(\mathrm{M}=3.68, \mathrm{p}<.001)$. Political loyalty was significantly correlated with political affiliation $(1=$ strong Democrat...6 $=$ strong Republican), albeit weakly $(\mathrm{r}=.12)$. More conservative participants were somewhat more loyal than more liberal participants.

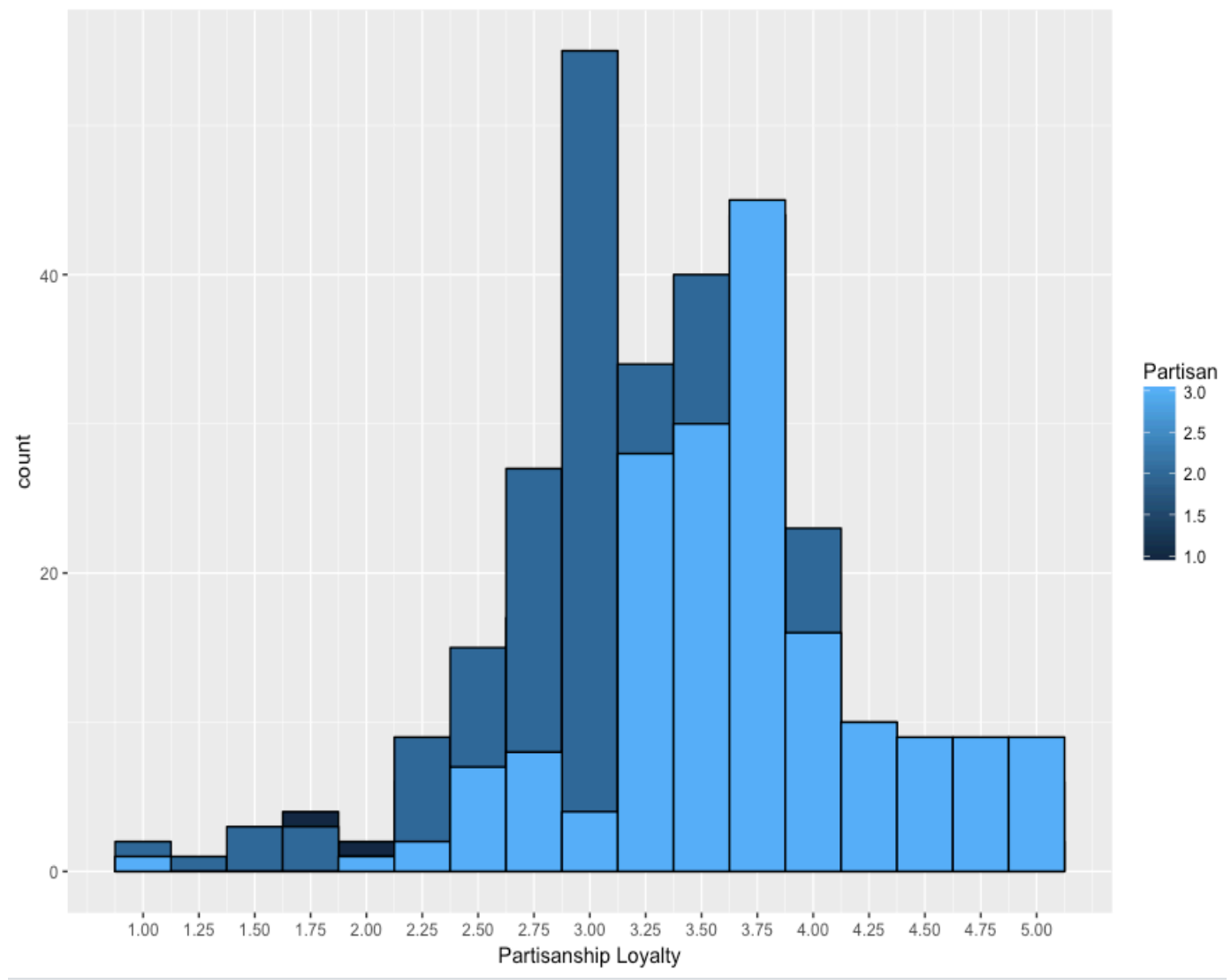

\section{Motivation}


Because the 4-item scale of motivation created for the purposes of this study was found to have low inter-reliability between items $(\alpha=.56)$, only the second item ("I am highly motivated to make unbiased judgments") was included in analyses. Reported political loyalty was higher than anticipated $(\mathrm{M}=3.39, \mathrm{SD}=.70)$. Motivated varied by partisanship strength $(F(2,570)=9.84, p<.001)$. Weak participants were more motivated to correct their judgments $(M=6.17)$ than both moderate partisans $(M=5.74, p=.003)$ and strong partisans $(M=5.56, p<$ .001). This motivation item was not correlated with political affiliation $(1=$ strong Democrat...6 $=$ strong Republican; $r=.00)$, though it was correlated with both lay theories $(r=-.24)$ and views of acceptability $(r=-.23)$. Perhaps the most important thing to not about motivation is that it is skewed (-1.40), such that most participants indicated they were highly motivated to make unbiased judgments.

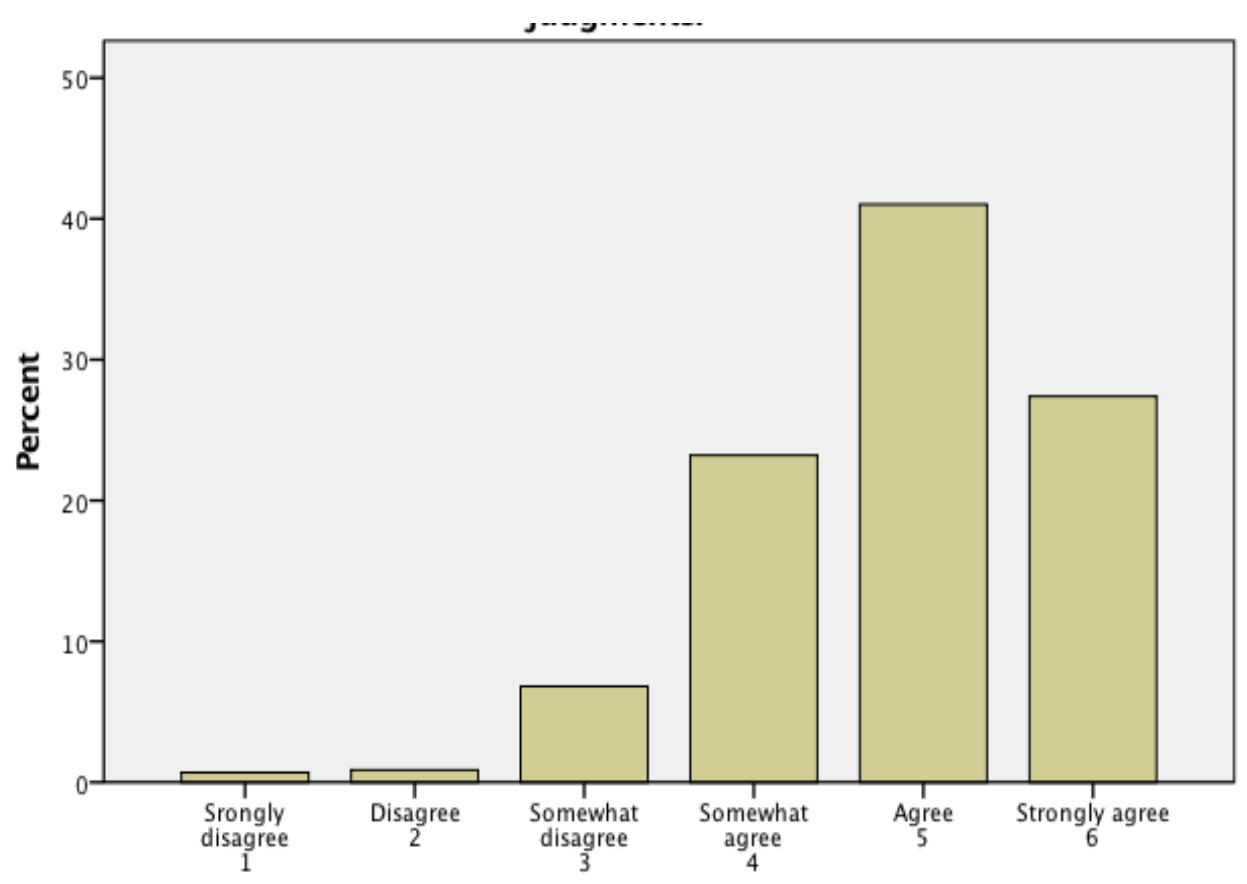


Study 2a \& 2b Procedure

\section{Experimental Conditions}

\begin{tabular}{|c|c|c|c|}
\hline Study $2 a$ & 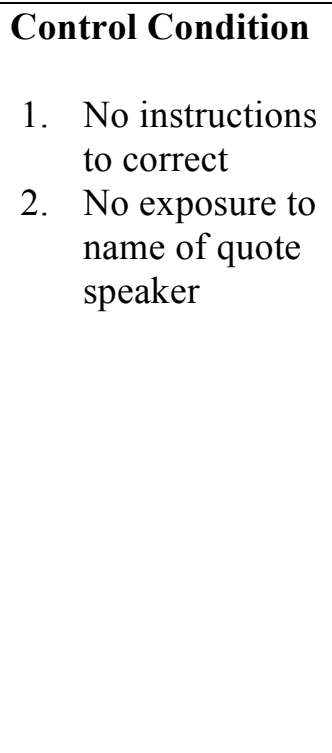 & $\begin{array}{l}\text { Partisan Induction } \\
\text { condition } \\
\text { 1. No instructions to } \\
\text { correct judgments } \\
\text { for the influence of } \\
\text { irrelevant partisan } \\
\text { information } \\
\text { Exposure to } \\
\text { partisan } \\
\text { information } \\
\text { a. Name of } \\
\text { President } \\
\text { who "said" } \\
\text { a given } \\
\text { quote }\end{array}$ & $\begin{array}{l}\text { Correction condition } \\
\begin{array}{l}\text { 1. Explicit instructions } \\
\text { to correct judgments } \\
\text { for the influence of } \\
\text { irrelevant partisan } \\
\text { information } \\
\text { 2. Exposure to partisan } \\
\text { information } \\
\text { a. Name of } \\
\text { President } \\
\text { who "said" } \\
\text { a given } \\
\text { quote }\end{array}\end{array}$ \\
\hline Study $2 b$ & $\begin{array}{l}\text { 1. No instructions } \\
\text { to correct } \\
\text { 2. No exposure to } \\
\text { defendant's political } \\
\text { views }\end{array}$ & $\begin{array}{l}\text { 1. Explicit } \\
\text { instructions to } \\
\text { correct judgments } \\
\text { for the influence of } \\
\text { irrelevant partisan } \\
\text { information } \\
\text { 2. Exposure to } \\
\text { partisan } \\
\text { information } \\
\text { a. Political } \\
\text { views of } \\
\text { defendant } \\
\text { on trial }\end{array}$ & $\begin{array}{l}\text { 1. Explicit instructions } \\
\text { to correct judgments } \\
\text { for the influence of } \\
\text { irrelevant partisan } \\
\text { information } \\
\text { 2. Exposure to partisan } \\
\text { information } \\
\text { a. Political } \\
\text { views of } \\
\text { defendant } \\
\text { on trial }\end{array}$ \\
\hline
\end{tabular}




\section{Study 2a: Procedure}

\section{Political views}

a. Political affiliation: Democrat, or Republican, or independent?

b. if Dem (Repub.): do you consider yourself a strong or not so strong Dem (Repub.)?

i. If Independent, which way do you lean (Dem/Repub.)?

c. Did you vote in the 2016 presidential election?

d. If so, who did you vote for (Donald Trump, Hillary Clinton, other).

2. Lay theories: Predicted influence from Trump and Obama (respectively)

\section{Manipulation: Correction instructions}

Condition 1: Control (no biasing information presented for any questions).

Condition 2: Exposure to biasing information (no correction instructions).

Condition 3: Exposure to biasing information (explicit correction instructions)

\section{Main DV: Presidential quotes}

a. Five quotes presented: randomly assigned to seeing 5 quotes from in-group president or 5 quotes from out-group president.

i. Each quote said by a U.S. President, though none were said by Trump or

Obama

1. Control participants told the quotes were from President Warren Harding or Woodrow Wilson.

ii. Quotes (within both groups of 5) presented in random order

b. Five quotes presented: Whichever set (in-group or out-group president) not already 
shown

\section{Bias perception judgments}

a. Did you try to prevent Trump/Obama from influencing you? (2-items)

c. Most Democrats (Republicans) can prevent irrelevant information from influencing (2-items).

6. View of acceptability

a. Is it acceptable to allow Trump/Obama to influence your evaluation? (2-items).

7. Motivation to make unbiased judgments (4-items).

\section{Individual difference measures}

a. Political party loyalty (7-items)

b. Social Desirable Responding (11-items; Reynolds, 1982)

c. Bias denial (3-items) - holding that political views are always relevant to a given judgment 


\section{Study 2b: Procedure}

\section{Political views}

a. Political affiliation: Democrat, or Republican, or independent?

b. if Dem (Repub.): do you consider yourself a strong or not so strong Dem

(Repub.)?

i. If Independent, which way do you lean (Dem/Repub.)?

c. Did you vote in the 2016 presidential election?

d. If so, who did you vote for (Donald Trump, Hillary Clinton, other).

2. Lay theories: Predicted influence from Trump and Obama (respectively)

\section{Manipulation: Correction instructions}

Condition 1: Control (no biasing information presented for any questions).

Condition 2: Exposure to biasing information (no correction instructions).

$\underline{\text { Condition 3: Exposure to biasing information (explicit correction instructions) }}$

\section{Main DV: Judgments of Guilt}

a. First Jury Scenario: Defendant on trial for assault and attempted murder from a bar fight

b. Second Jury Scenario: Defendant on trial for assault and attempted murder from an attempted vehicular homicide

i. Participants able to choose to see (or not see) political views of defendant before reading the scenario.

c. For both scenarios, defendant is an extreme conservative for liberal participants, and an extreme liberal for conservative participants. 


\section{Bias perception judgments}

a. Did you try to prevent Trump/Obama from influencing you? (2-items)

c. Most Democrats (Republicans) can prevent irrelevant information from influencing (2-items).

6. View of acceptability

a. Is it acceptable to allow Trump/Obama to influence your evaluation? (2-items).

7. Motivation to make unbiased judgments (4-items).

\section{Individual difference measures}

d. Political party loyalty (7-items)

e. Social Desirable Responding (11-items; Reynolds, 1982)

Bias denial (3-items) - holding that political views are always relevant to a given judgment 


\section{Study 2a \& 2b Materials}

\section{Note: identical materials from earlier studies not re-listed here}

\section{Lay Theories}

Study $2 \mathrm{a}$

1) Imagine that you are reading a quote and evaluating the extent to which you agree or disagree with the statement. You learn that the quote you are reading was said by President Donald Trump.

To what extent would knowing that Donald Trump said this quote influence the degree to which you feel positively or negatively about it, relative to how you would evaluate it if you didn't know who said it?

Knowing Donald Trump said the quote would make me...

1(feel much more negatively about this quote), 5(Would not influence my judgment), 9 (feel much more positively about this quote)

2) Imagine that you are reading a quote and evaluating the extent to which you agree or disagree with the statement. You learn that the quote you are reading was said by former President Barack Obama.

To what extent would knowing that Barack Obama said this quote influence the degree to which you feel positively or negatively about it, relative to how you would evaluate it if you didn't know who said it?

Knowing Barack Obama said the quote would make me... 
1(feel much more negatively about this quote), 5(Would not influence my judgment), 9 (feel much more positively about this quote)

Study $2 b$

1) Imagine that you are reading about a jury trial, and it is your job to judge how likely a person is guilty of serious, non-political crimes. You learn that the person you are judging is an extreme right-wing conservative.

To what extent would knowing that the person you are judging is a conservative influence the extent to which you believe they are guilty, relative to how you would judge them if you didn't know their political views?

Knowing the person I'm judging is a conservative would make me think that they are... 1(Much less likely to be guilty), 5(Would not influence my evaluation), 9 (Much more likely to be guilty)

2) Imagine that you are reading about a jury trial, and it is your job to judge how likely a person is guilty of serious, non-political crimes. You learn that the person you are judging is an extreme left-wing liberal.

To what extent would knowing that the person you are judging is a liberal influence the extent to which you believe they are guilty, relative to how you would judge them if you didn't know their political views?

Knowing the person I'm judging is a liberal would make me think that they are... 
1(Much less likely to be guilty), 5(Would not influence my evaluation), 9 (Much more likely to be guilty) 


\section{Bias Perception}

\section{Study $2 \mathrm{a}$}

1) Earlier, you were presented with political information before making judgments, such as the name of the president who said a particular quote.

To what degree were your evaluations of the quotes by Trump (Obama) influenced by your knowledge of who said them?

Knowing that Trump (Obama) said the quotes caused me to judge them...

1 (Much more negatively), 5 (did not influence my judgments), 9 (Much more positively).

2) identical question: opposite president (Trump/Obama) inserted.

3) To what extent to you agree or disagree with the following statement?

In general, I can easily prevent political information that is irrelevant from influencing my judgments and decision if I want to.

$\underline{\text { Study } 2 \mathrm{~b}}$

1) Presented to Democratic control participants who opted OUT of seeing partisan information in the second jury scenario.

Imagine that you were told the political views of defendants on trial before judging how guilty you thought they were.

Imagine that you were told the defendants were extreme conservatives. How would this have influenced your judgments? 
Knowing that the defendants were extreme conservatives would have caused me to judge them as...

1 (Much less likely to be guilty), 5 (Would not influence my judgment), 9 (Much more likely to be guilty)

2) Presented to Republican control participants who opted OUT of seeing partisan information in the second jury scenario.

Imagine that you were told the political views of defendants on trial before judging how guilty you thought they were.

Imagine that you were told the defendants were extreme liberals. How would this influence your judgments?

Knowing that the defendants were extreme liberals would have caused me to judge them as...

1 (Much less likely to be guilty), 5 (Would not influence my judgment), 9 (Much more likely to be guilty)

\section{3) Presented to Democratic control participants who opted IN of seeing partisan information in the second jury scenario.}

On the second jury scenario you were presented, you chose to see the political views of the defendant.

When you were told that the defendant was an extreme conservative, how did it influence your judgments? 
Knowing that the defendant was an extreme conservative caused me to judge them as...

1 (Much less likely to be guilty), 5 (Would not influence my judgment), 9 (Much more likely to be guilty)

\section{4) Presented to Republican control participants who opted IN of seeing partisan} information in the second jury scenario.

On the second jury scenario you were presented, you chose to see the political views of the defendant.

When you were told that the defendant was an extreme liberal, how did it influence your judgments?

Knowing that the defendant was an extreme liberal caused me to judge them as...

1 (Much less likely to be guilty), 5 (Would not influence my judgment), 9 (Much more likely to be guilty)

\section{5) Presented to Democrats in the Partisan induction and Correction conditions.}

Earlier, you were told the political views of defendants on trial before judging how guilty you thought they were.

When you were told that the defendants were extreme conservatives, how did it influence your judgments?

Knowing that the defendants were extreme conservatives caused me to judge them as... 
1 (Much less likely to be guilty), 5 (Would not influence my judgment), 9 (Much more likely to be guilty)

6)Presented to Republicans in the Partisan induction and Correction conditions.

Earlier, you were told the political views of defendants on trial before judging how guilty you thought they were.

When you were told that the defendants were extreme liberals, how did it influence your judgments?

Knowing that the defendants were extreme liberals caused me to judge them as...

1 (Much less likely to be guilty), 5 (Would not influence my judgment), 9 (Much more likely to be guilty) 


\section{Bias Prevention}

Presented in both studies $2 \mathrm{a}$ and $2 \mathrm{~b}$

1) When making judgments about a defendant in a jury trial, did you prevent political

information that you were exposed to from influencing your judgment?

1 (No, not at all) ...6(Yes, definitely)

\section{Exploratory Bias prevention items}

2) To what extent to you agree or disagree with the following statement?

In general, I can easily prevent political information that is irrelevant from influencing my judgments and decision if I want to.

1 (Strongly disagree) ...6(Strongly agree)

3) To what extent to you agree or disagree with the following statements?

a. Most Republicans can easily prevent political information that is irrelevant from influencing their judgments and decision if they want to.

b. Most Democrats can easily prevent political information that is irrelevant from influencing their judgments and decision if they want to.

1 (Strongly disagree) ...6(Strongly agree) 


\section{Acceptability}

Study $2 \mathrm{a}$

1) (In-group president inserted)

How acceptable is it for your knowledge that Trump (Obama) said a quote to influence your evaluation of that quote?

1 (Completely unacceptable) ...6(Completely acceptable)

2) (Out-group president inserted)

How acceptable is it for your knowledge that Trump (Obama) said a quote to influence your evaluation of that quote?

1 (Completely unacceptable) ...6(Completely acceptable)

3) In general, how acceptable is it for political information (such as the name of the President who said a quote) to influence your evaluation of that quote?

1 (Completely unacceptable) ...6(Completely acceptable)

\section{Study $2 b$}

1) How acceptable is it for your knowledge about a defendant's conservative political views to influence your judgments about that defendant in a jury trial?

1 (Completely unacceptable) ...6(Completely acceptable)

2) How acceptable is it for your knowledge about a defendant's liberal political views to influence your judgments about that defendant in a jury trial?

1 (Completely unacceptable) ...6(Completely acceptable) 
3) In general, how acceptable is it for political information (such as the political views of others) to influence your judgments about defendants in jury trials?

1 (Completely unacceptable) ...6(Completely acceptable) 


\section{Motivation}

Presented in both Study $2 \mathrm{a}$ and Study $2 \mathrm{~b}$

Response scale: 1(Strongly disagree) ...6(Strongly agree)

1) I believe it is very important to make unbiased judgments when it comes to politics

2) I am highly motivated to make unbiased political judgments.

3) When it comes to politics, making objective judgments, even if they go against my core beliefs, is the right thing to do.

4) I am highly motivated to identify irrelevant information that could influence my thinking before I make a political judgment.

Political Knowledge (Adapted from Carpini \& Keeter, 1993)

Presented in both Studies $2 \mathrm{a} \& 2 \mathrm{~b}$

Binary response scale: True/False

1) The Democrats are the current majority party in the U.S. Senate

2) Mike Pence is the current U.S. Vice President

3) The U.S. Supreme Court has the power of judicial review

4) A 2/3 supermajority is required in BOTH chambers of Congress in order to overturn a presidential veto.

5) The Democratic Party is more conservative than the Republican party

\section{Open Response}

Presented in both Studies 2a \& $2 \mathrm{~b}$

We would like to hear your thoughts about political bias.

How do you think political information influences (or does not influence) your judgments in situations in which that political information is irrelevant? Please be as specific as possible. 


\section{Study 2a \& 2b Supplemental Tables and Analyses}

\section{Study 2a: Political Loyalty}

The 7-item scale of political loyalty created for the purposes of this study was found to have high inter-reliability between items $(\alpha=.88)$. Political loyalty was approximately normally distributed (Skewness $=-.31 ; M=3.25, S D=.76)$. Political loyalty varied by partisanship strength $(F(2,378)=18.09, \mathrm{p}<.001)$. Weak participants were less loyal $(M=2.98)$ than and strong partisans $(M=3.50, p<.001)$, but not moderate partisans $(M=3.15, p=.18)$. Strong partisans were also more loyal than moderate partisans $\left(M_{\text {diff }}=0.35, \mathrm{p}<.001\right)$.

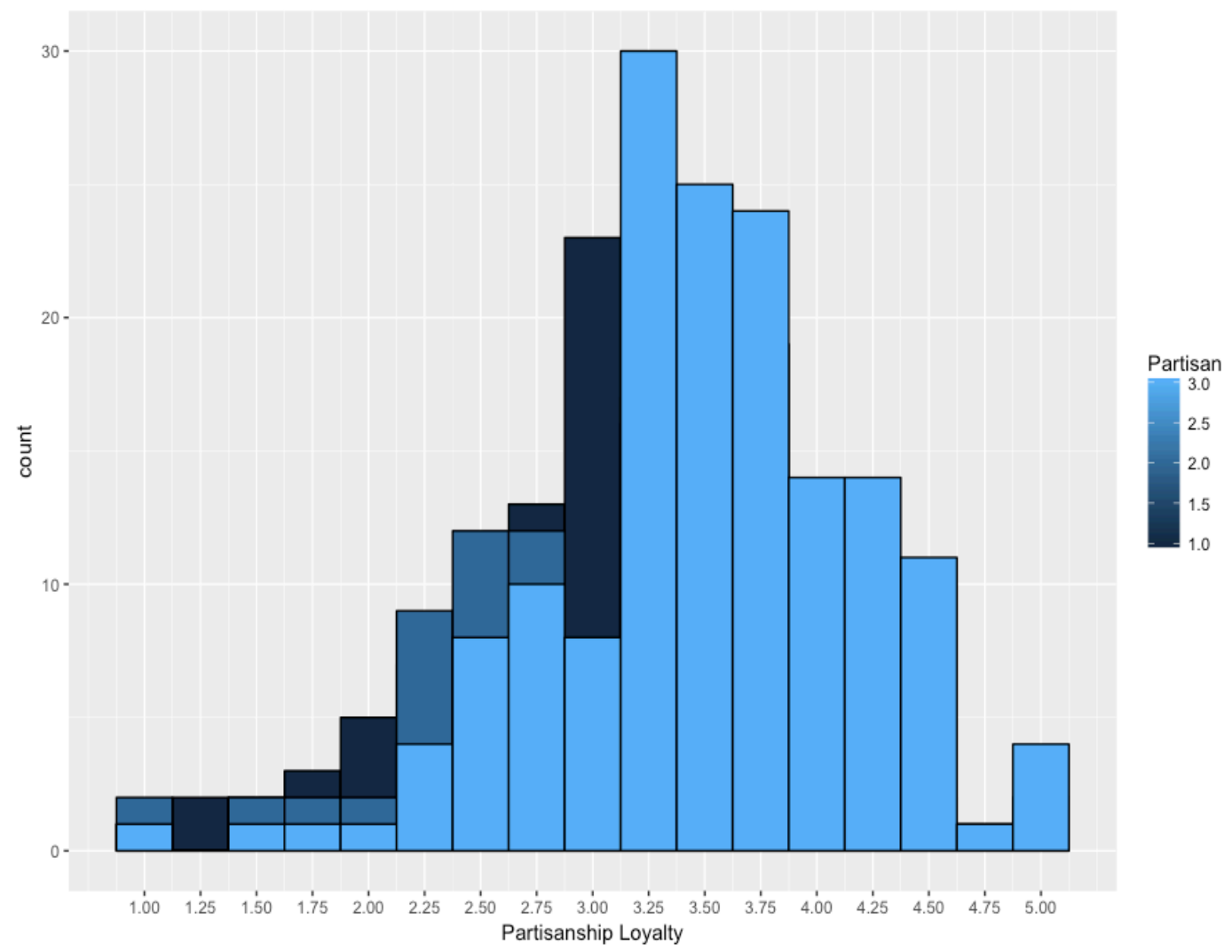




\section{Study 2b: Political Loyalty}

The 7-item scale of political loyalty created for the purposes of this study was found to have high inter-reliability between items $(\alpha=.88)$. Political loyalty was approximately normally distributed (Skewness $=-.32 ; M=3.14, S D=.80)$. Political loyalty varied by partisanship strength $(F(2,372)=41.70, \mathrm{p}<.001)$. Weak participants were less loyal $(M=2.76)$ than and strong partisans $(M=3.54, p<.001)$, but not moderate partisans $(M=2.96, p=.09)$. Strong partisans were also more loyal than moderate partisans $\left(M_{\text {diff }}=0.58, \mathrm{p}<.001\right)$.

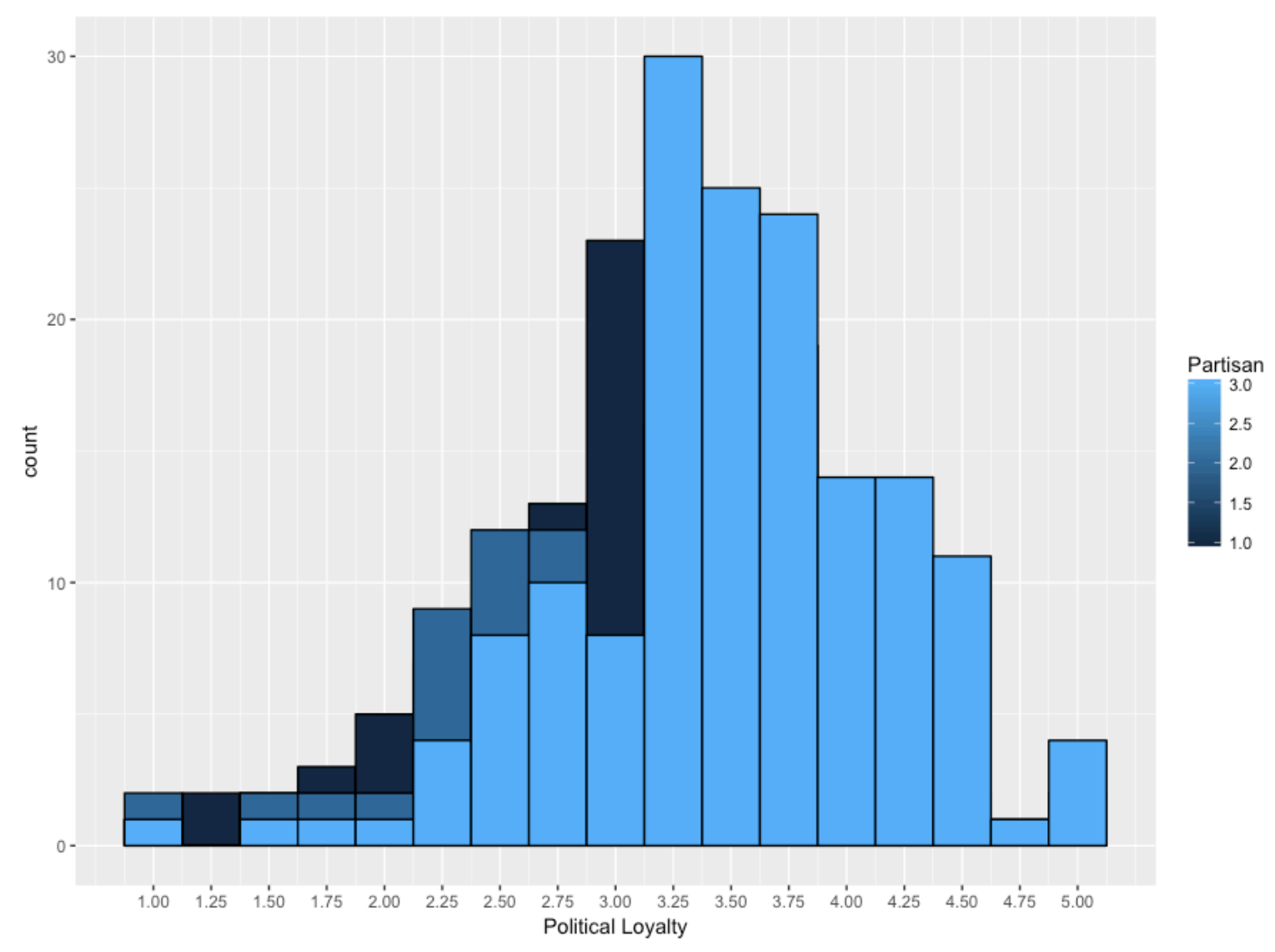




\section{Study 2a: Political Knowledge}

Political knowledge was found to be high, on average, with a skewed distribution $($ Skewness $=-.83 ; M=3.53$, Median $=4, S D=.71)$. Political knowledge did not vary by partisanship strength $(p=.28)$.

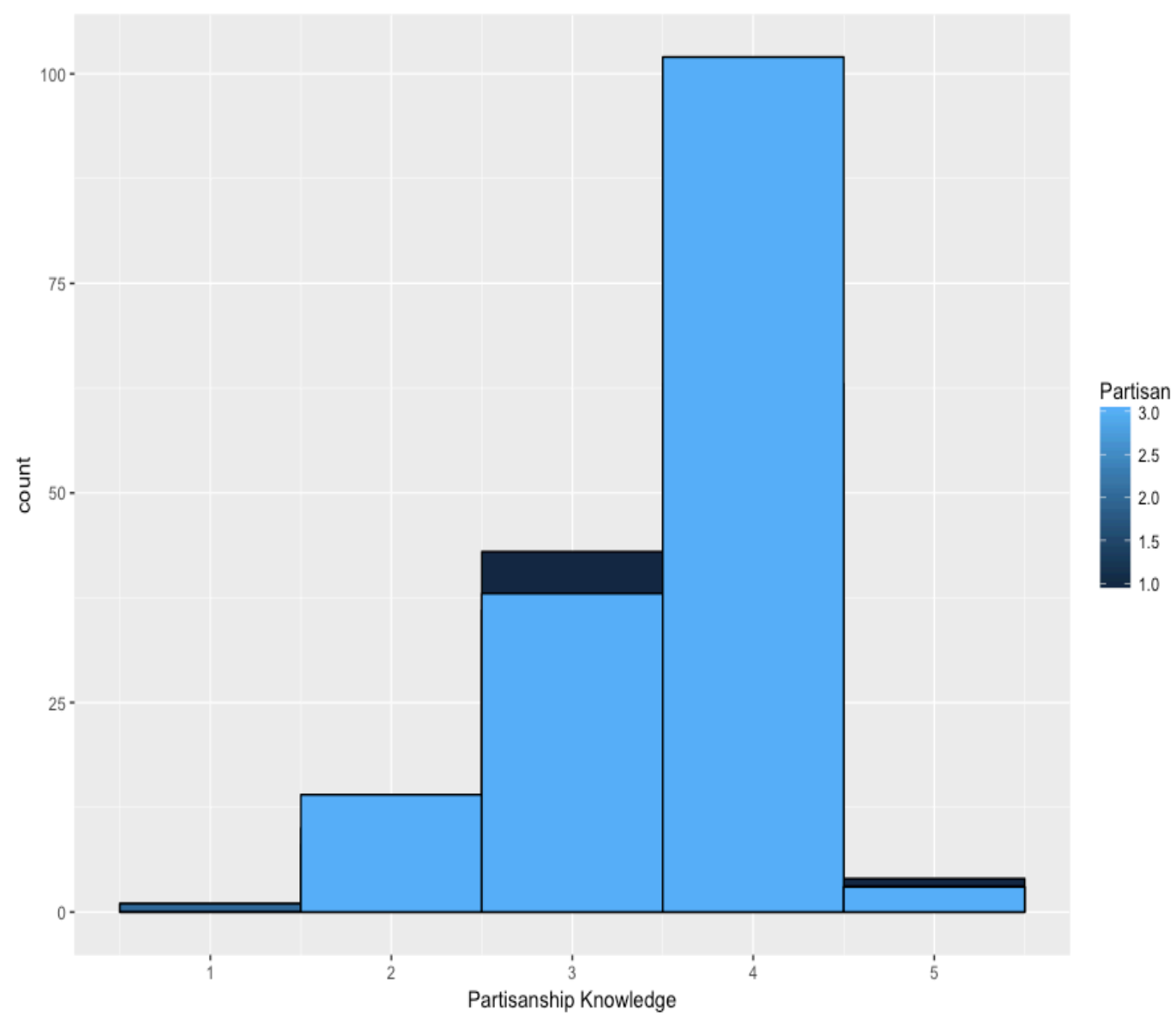




\section{Study 2b: Political Knowledge}

Political knowledge was found to be high, on average, with a skewed distribution $($ Skewness $=-1.30 ; M=4.26$, Median $=4, S D=.90)$. Political knowledge varied by political partisanship $(F(2,372)=5.06, \mathrm{p}=.007)$. Weak participants were more knowledgeable $(M=$ 4.49) than and strong partisans $(M=4.13, p<.001)$, but not moderate partisans $(M=4.22, p=$ .08). Strong partisans were not more knowledgeable than moderate partisans $\left(M_{\text {diff }}=-0.09, \mathrm{p}=\right.$ $.68)$.

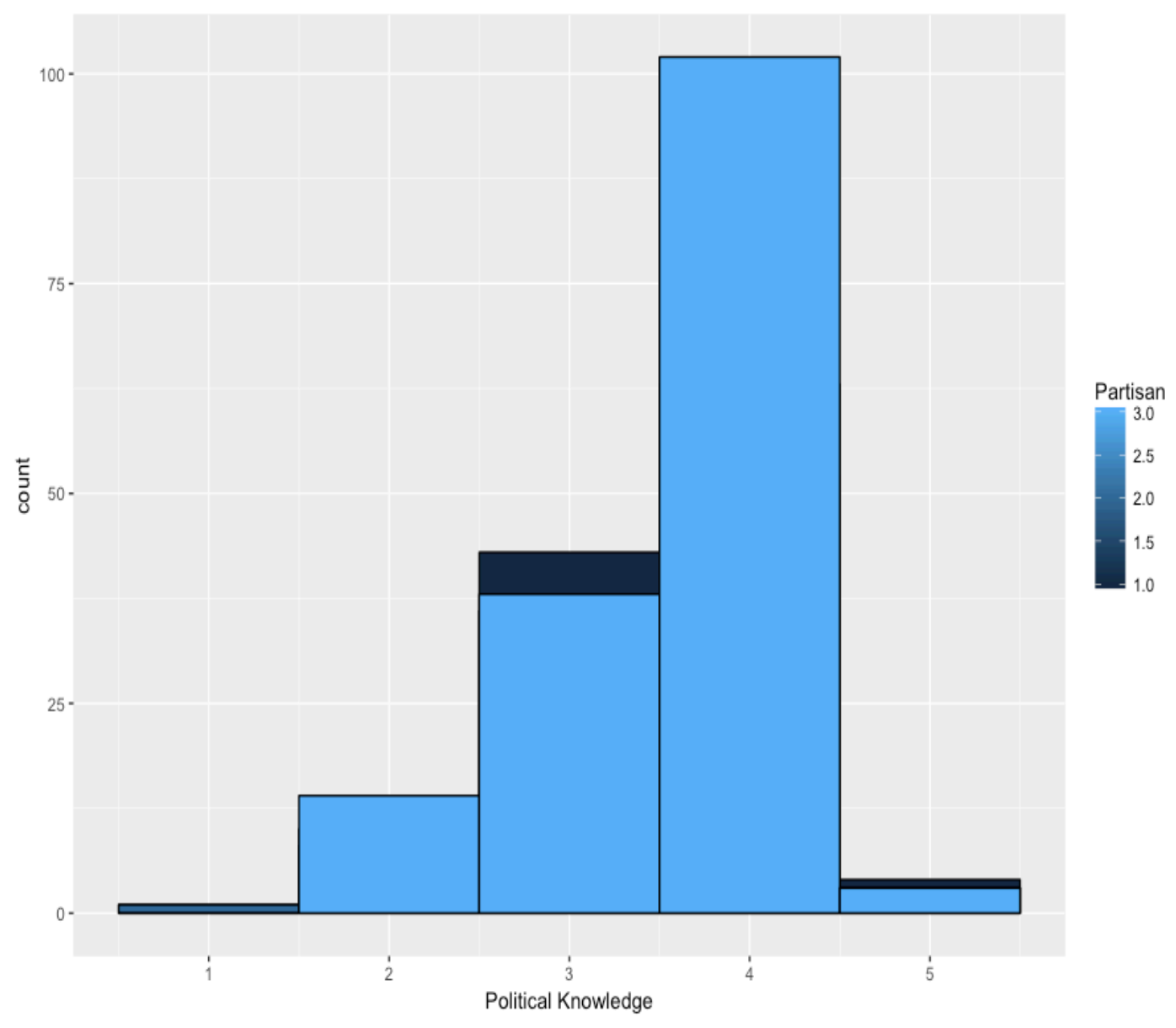




\section{VITA}

Samuel Glenn Baker was born in Muscatine, IA where he was raised and attended school. Glenn earned his bachelor's degrees in Psychology and Philosophy from The University of Iowa in May of 2013. During his undergraduate program, Glenn began working as a research assistant in the Judgment, Decision, and Social Comparison Lab with Dr. Paul Windschitl, as well as the Attitudes and Social Cognition Lab with Dr. Jason Clark. Glenn accepted an offer to join the department of Psychological Sciences at the University of Missouri in the fall of 2013 working under the supervision of Dr. Laura D. Scherer. Glenn has primarily studied how people's emotional states and beliefs influence consequential every day decisions, such as political and health decisions. Additionally, Glenn has been very interested in how (un)aware people are of their own biases, and the consequences of being blind to one's own biases.

Outside of work, Glenn engages in a robust array of hobbies to stave off existential dread. Glenn is a lifelong drummer and has continued to play as a local jazz musician after moving to Columbia, and enjoys meeting and playing with new musicians. He also enjoys cycling, gaming, and writing fiction in his spare time. Glenn wishes to communicate to the readers of this document that he is terrified that this relatively shallow, two-paragraph summary of his most basic academic facts and hobbies will someday be all that is left of him. He felt insincere the entire time writing this vita, and as a result did not enjoy it at all. Glenn hopes that anyone determined enough to read this far into his dissertation will endeavor to discover more about him than these two paragraphs, even if the man the reader discovers from those readings is found wanting. To be viewed complexly is a gift most precious. 